\title{
REFLECTION ON PRACTICE: A STUDY OF FIVE CHORAL EDUCATORS' REFLECTIVE JOURNEYS
}

\section{DISSERTATION}

\author{
Presented in Partial Fulfillment of the Requirements for \\ The Degree Doctor of Philosophy in the Graduate \\ School of The Ohio State University
}

By

Marla Ann Butke, B. M. E., M. M. E.

$* * * * *$

The Ohio State University

2003

Doctoral Committee:

Professor R. J. David Frego, Adviser

Approved by

Professor Timothy A. Gerber

Professor Jan H. McCrary

Adviser

School of Music 
Copyright by Marla Ann Butke 2003 


\begin{abstract}
The enormity of scope involved in a teaching life creates the need for an educator to seek continual growth in mind and spirit. It is through reflection that a teacher can find new ways to understand the challenges that are faced both inside and outside the classroom. The purpose of this study was to examine how choral music teachers would engage in a reflective process for the purpose of understanding and enacting change within their practice.
\end{abstract}

This qualitative research involved five choral teachers from both the middle and high school levels. For a nine-week period the educators used a variety of reflective tools for the purpose of engaging in a reflective process. Bi-weekly observations were made, constructive dialogues occurred, and reflections in diverse formats were employed. The data are presented in the form of five narrative stories that combined the events of the choral rehearsals, reflections of the teachers, student reflections, and the reflective thoughts of the researcher as they occurred in time.

These teachers created unique reflective paths during the course of this study. Five significant points of interest emerged from this research: constructive dialogues serve as valuable and successful means for reflection; reflection is influenced by the attribute of perfectionism; there are time issues related to the successful implementation 
of a reflective process; the feelings of pleasure and pain are associated with reflection; and reflection is an instrument for tangible change as well as the processing of personal and educational philosophies.

A Cyclical Model of Reflection was developed as a proposed theoretical model based on the analysis of the teachers' reflective journeys. The model incorporates Schon's two dimensions of reflection and appends a third dimension, reflection-foreaction. Thinking, writing, and conversing designate the three modes of reflection, which are executed through six methodologies. This study identified the interrelated nature of the three dimensions and analyzed each of the modes and methodologies.

This study represents the first investigation of practicing choral educators engaged in a reflective process. As a result of the reflective process, these teachers experienced change in practice and the assessment of current educational and personal philosophies. 
Dedicated with love and gratitude to my family, Sarah, Ryan, and Lee, who always believed in me, encouraged me, and shared their love with me. 


\section{ACKNOWLEDGMENTS}

There are many people who graciously helped me to complete this document. Words cannot fully express my sentiments and gratitude for the time and support each of you has given me.

David Frego, your encouragement and critical eye assisted me in achieving my best. You exemplify excellence as a music educator and serve as a great role model for all of your students. Thank you for your integrity, professionalism, and warm heart. I will always be grateful.

Tim Gerber, your optimism, support, and passion for teaching music were points of inspiration throughout my doctoral journey. You embrace a philosophy of music education that I truly admire and will hold steadfast in my continued teaching.

Jan McCrary, you helped me to see the world differently and encouraged me to continue the path forward. You represent our profession with wisdom and grace. It has been a privilege to know you.

The five choral teachers, you gave so much of your time and shared your lives so freely with me. You taught me so much about our profession and gave me encouragement for the future of our world. Your students and I have been very fortunate to have learned from you. 
Judy Petrou, Susan Kleinline, and Diana Erchick you each lent personal assistance for this dissertation. Your professional expertise and supportive spirit were so appreciated.

My friends and family, you cared enough to listen to me talk about my "other life" as a doctoral student. I have been blessed with wonderful people surrounding me.

Sarah, you were always proud of me and encouraged me when I needed it the most. You continue to strengthen my belief that by staying positive, great things can be accomplished.

Ryan, you shared my intellectual journey with me and listened with a genuine sense of caring and respect. You challenged me not to be ordinary or trite but instead, to be a creative and scholarly thinker.

Lee, you have been by my side every step of the way and never let me become discouraged. Your passion about work and play has served as a constant source of inspiration to me. Thank you from the bottom of my heart for everything that you have done. 
VITA

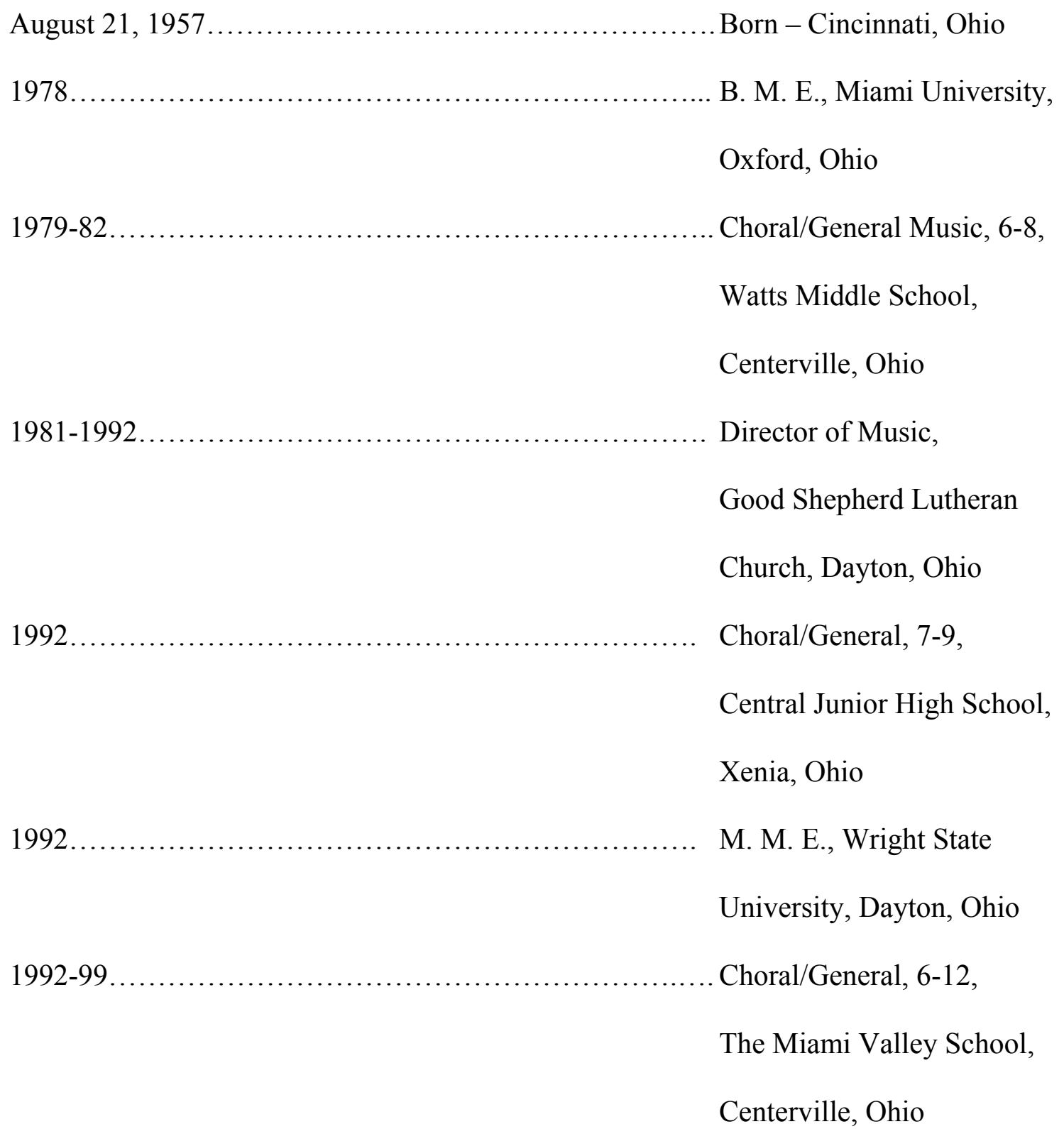


1999-2001, 2002-2003

Graduate Teaching

Associate, Music Education

Department, The Ohio State

University

$2000-$

Adult Choir Director

Prince of Peace Lutheran

Church, Dublin, Ohio

$2001-2002$

Music Education Instructor,

Ohio Wesleyan University,

Delaware, Ohio

\section{PUBLICATIONS}

1. Butke, M. (2002). Teaching for an aesthetic response. TRIAD, 69(6), $64-65$

2. Butke, M. (2002). Choral education. In K. H. Burns (Ed.), Women

and music in America Since 1900: An Encyclopedia (pp.92-95).

Westport, CT: Greenwood Press.

3. Butke, M. (2002). Music Education Organizations. In K. H. Burns (Ed.), Women and music in America Since 1900: An encyclopedia (pp. 483-487). Westport, CT: Greenwood Press.

\section{FIELDS OF STUDY}

Major Field: Music Education 


\section{TABLE OF CONTENTS}

\section{$\underline{\text { Page }}$}

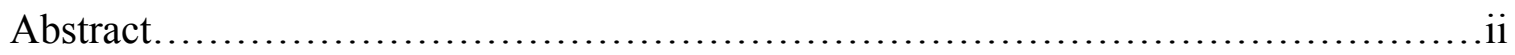

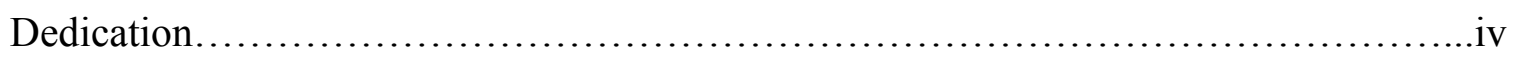

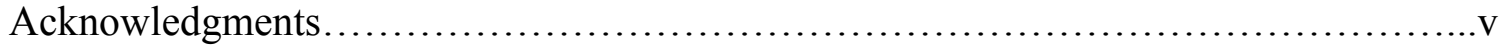

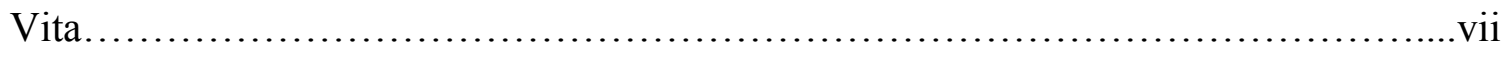

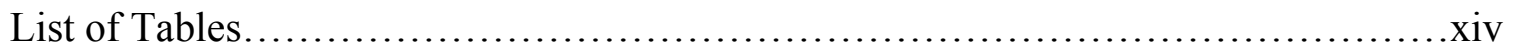

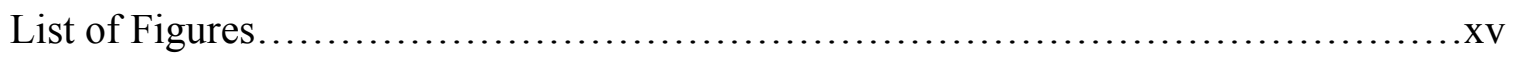

\section{Chapters:}

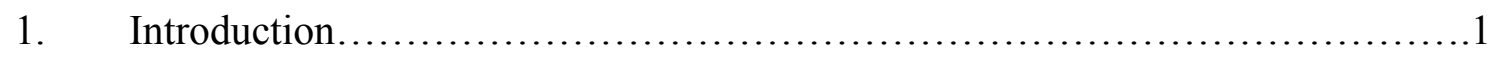

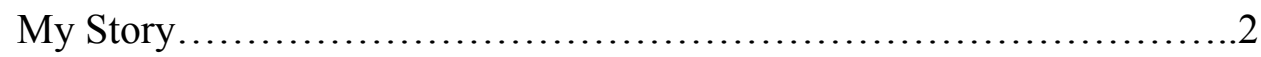

Purpose of the Study ..............................................

Reflection Defined................................................

Statement of the Problem............................................. 6

Reflexive Teaching.......................................6

The Discovery of Conscious, Authentic Teaching Through a Reflective Process...............................8

The Canon of Teaching Choral Music - Definitions and Challenges....................................... 9

The Delineation of the Reflective Process............................ 14

Categories of Reflection and the Lenses Used to Define a Choral Teacher's Practice........................14

The Process of Reflection.....................................17

Limitations of Study ............................................. 18

Significance of Study ............................................. 19

Reflection Encourages Growth in Teaching and

Change in Practice...................................20

Self-Awareness and Life Experiences Inform Practice............20

ix 
Reflection is Based on the Problematic.......................21

Summary

Reflection Clarifies and Directs Change in Practice...............22

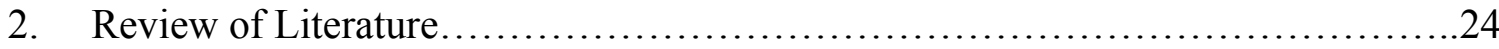

Reflective Teaching - Historical Foundations........................24

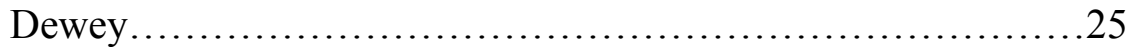

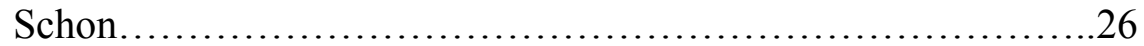

Research Studies in Education Based on Reflection....................29

Related Studies of Teacher Education Programs..................30

Related Studies of Practicing Classroom Teachers................34

Related Research Studies in Music Education............................36

Categories of Reflection...........................................42

Pedagogical Reflection...................................42

Curricular Reflection.....................................44

Personal/Professional Reflection...........................45

Critical Reflection...........................................48

Benefits of Reflection.............................................53

Gaining Professional and Personal Knowledge.................53

Changed/Improved Practice..................................55

Barriers to Reflection..............................................56

Cultural Barriers.............................................57

Time Barrier...............................................58

Personal Risk Barrier......................................59

Motivation Barrier.........................................60

Conclusion.......................................................61

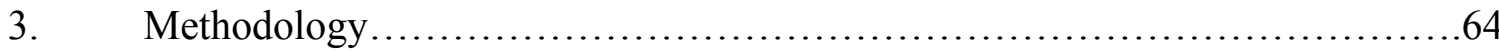

Theoretical Framework............................................64

Qualitative Inquiry.....................................64

Interpretative Paradigm....................................64

Constructivist's Perspective................................65

Qualitative Case Studies.....................................66

Phenomenology.........................................67

Ethnological Approach......................................66

Research Design................................................68

Overview..................................................68

Research Questions........................................69

Participants............................................. 70

Data Gathering Techniques.................................76

Data Analysis................................................... 83

Narrating the Data................................................ 86

Methodological Issues............................................88 


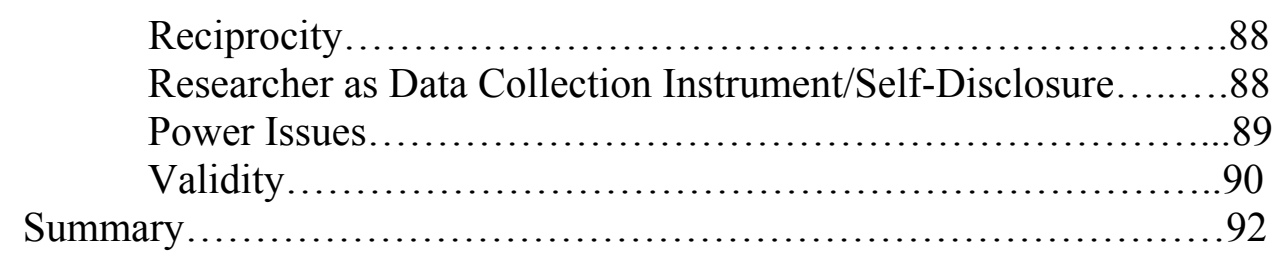

4. The Five Choral Teachers' Reflective Journeys.................................93

Introduction................................................... 93

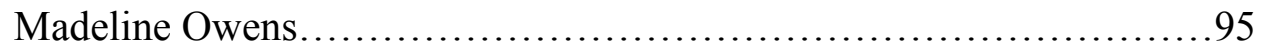

Jacob Hamilton..................................................... 117

Jacqueline O'Keefe..............................................145

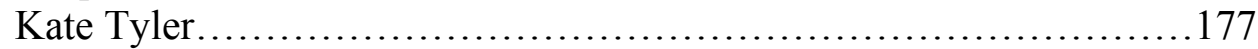

Ashley Brooks.....................................................203

Summary of Each Teacher's Journey ...............................233

Madeline Owens...............................................233

Jacob Hamilton..........................................237

Jacqueline O'Keefe.........................................241

Kate Tyler.............................................245

Ashley Brooks..........................................248

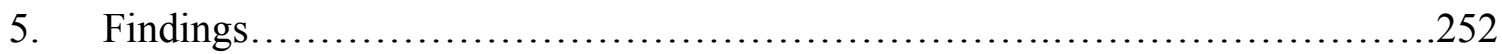

Cross-Case Analysis............................................253

Four Categories of Reflection................................253

Research Questions...........................................260

The Cyclical Model of Reflection....................................269

The Three Dimensions of Reflection.............................269

The Three Models of Reflection..............................270

The Six Methodologies of Reflection.........................270

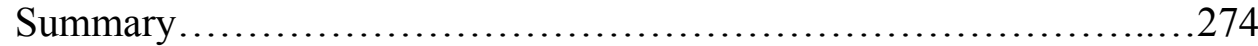

Noteworthy Findings.....................................274

The Value of Engaging in a Reflective Process.................277

The Usefulness of the Qualitative Paradigm....................278

Implications for Music Teacher Education and Professional

Development.............................................279

Music Teacher Education.......................................2279

Professional Development..................................281

Recommendations for Further Research...........................282

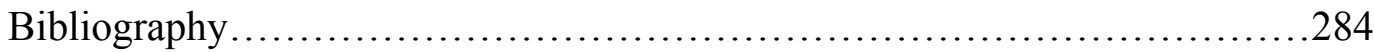


Appendices

A. Letter for Obtaining Participants................................299

B. Consent for Participation in Social and Behavioral Research.......301

C. Solicitation Letter for Parents/Students..........................303

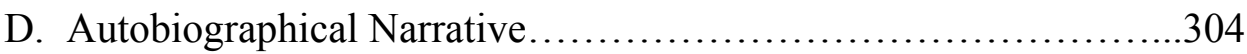

E. Reflective Narrative Exercises.................................305

F. Verbal Script for Informing Students about Study..................306

G. Support Form - Principal..................................307

H. Student Journal Reflection Questions For Research Study...........308 


\section{LIST OF TABLES}

$\underline{\text { Table }} \quad \underline{\text { Page }}$

1. Data Gathering Schedule................................................ 75 


\section{LIST OF FIGURES}

Figure $\quad$ Page

1. The Cycle of Reflection............................................ 272 


\section{CHAPTER 1}

\section{INTRODUCTION}

It is the first day of school and the outside temperature is a warm 84 degrees. You can feel both excitement and apprehension in the air as 60 middle school students enter the choral classroom in various groupings at intermittent times. A petite, blonde-haired girl with glasses slowly walks to her place on the risers with a somber look on her face. Two tall and lanky boys talk loudly as they push their way through the door hoping to get attention from their peers. Another boy with messy hair and baggy pants is talking to himself as he proceeds to the bulletin board to find his position on the risers. A group of three girls brush each other's hair while they are sitting on the risers, gossiping about a girl who was just dumped by her boyfriend. Five students are excitedly sharing summer vacation stories, with each one interrupting the other in rapid succession. Every student entering this classroom brings a unique personal and educational story for the teacher to unravel. The most anxious person in the room is indeed, the choral teacher. What road will she choose to meet her goal of giving these ever-changing adolescents a meaningful choral experience during this new school year?

The enormity of scope involved in a teaching life creates the need for an educator to seek continual growth in mind and spirit. It is through reflection that a teacher can find new ways to understand the challenges that are faced both inside and outside the 
classroom. My own reflective journey created new opportunities for me to examine my pedagogical approaches and philosophical underpinnings, and helped me to begin to develop an "authentic" teaching practice.

\section{My Story}

When I began my first teaching position as a choral music teacher at the middleschool level, I found myself frighteningly unprepared to develop a meaningful curriculum for my students. My undergraduate general music methods course consisted of unsituated, random musical experiences that seemed inapplicable to this teaching position. My two student-teaching situations were at polar opposites: one cooperating teacher handed over all of the general music classes to me on the first day with no guidance; the second cooperating teacher allowed me to teach only three times, and in those three instances, told me exactly how and what to teach. The cooperating teacher at the middle school did not want to relinquish his choirs to a student-teacher so he asked me to serve as the accompanist. With no direct choral experiences in the studentteaching term, I was left with a strong sense of being unprepared.

My first autonomous position as a choral educator was filled with mixed emotions. On one hand I felt awkward and strange. I believed that I was ill equipped in both training and experience. However, my youthful enthusiasm and positive approach pushed me to get the job done. Without any real contemplation or reflection, I simply started my teaching journey on automatic pilot. I began teaching the way I had been taught by former choral teachers. My choral program represented a culmination of my prior experiences. Although my student-teaching had been a disappointing experience, my choral background involved positive attributes such as musically talented directors, 
superior ratings at competitions, excellent concert performances of pieces from within the choral canon, and recognition that I was a capable choral student. These experiences, which gave me confidence, were the same opportunities I wanted my students to acquire. The structure of my teaching practice proceeded in a forward, linear motion.

My rehearsals followed the typical routine of my past choral directors. I used vocal warm-up exercises that had been learned from my high school and college directors. The purposes those warm-ups served had already been established by past directors, thus in my mind eliminating the need for me to understand the pedagogical reasoning for their specific use. I chose previously sung repertoire because of the familiarity and comfortableness with those pieces of music. I assured myself that since my highly respected former directors had made these selections, they must be worthwhile repertoire for my own students to learn. By incorporating the vocal techniques and repertoire selected by my mentors, teaching quickly became more routine.

As my teaching career progressed, I grew into a confident choral educator. Issues of classroom management, school politics, and parental interactions became less stressful. My choral program eventually included authentic assessment of student learning, a sight-reading program, and a slightly expanded repertoire incorporating music from other cultures. Rehearsal planning was routine and concert programs were predictable. My choirs received superior ratings at adjudicated events. I had reached an adequate level of success and was a respected member of both the school and professional communities. This was made evident by positive administrative evaluations as well as through complimentary feedback provided by parents and choral colleagues. I had conformed into a role that had been externally determined by colleagues, parents and 
administrators. However, I was not aware of how my past had influenced my practice, or what the ramifications of my routine pedagogical and curricular implementations were on my practice or my students' lives. I had not engaged in a reflection process.

When I left the teaching profession after nine years to pursue graduate studies, I was introduced to the concept of reflection. While assisting in an undergraduate choral methods course, the professor asked the students to reflect about their practicum teaching experiences. Although the term reflection was not new to me, I had never had the experience of writing about my own teaching experiences. It sparked my interest and I began to read about the subject as well as talk with students about how the process influenced their thoughts about teaching. Reflective thoughts began to surface following my teaching experiences. I began to keep a reflective journal about my classes/rehearsals concerning what went well and what needed improvement. These reflective journals were rooted in feelingful reactions and slowly progressed to critical inquiry pertaining to why I taught what I did. When I began undergraduate college teaching, I included a reflective process for my student-teachers and discussed with them how reflection could possibly affect their teaching. What resulted from that process were pre-service teachers who genuinely wanted to understand their practice and find new ways to grow.

The current study grew out of my own reflections concerning my past teaching practice that revealed areas where my teaching was not authentic. This meant that my practice had not been created for my own students who were indeed a different group of people living in a different place and existing in a different time than I. The motivation for this study was the consideration of the possibility that other teachers may be having the same experiences: teaching as they were taught without questioning the 
pedagogical/curricular appropriateness within different contexts. I wanted to explore what new discoveries teachers could make when they are engaged in a reflective process.

\section{Purpose of the Study}

The purpose of this study is to understand how a reflective process affects teaching in the choral classroom. The following elements will be examined: how choral teachers use the reflection process to understand and shape their practice; the ways that they reflect; and when they reflect. The format of the study involves two dimensions, descriptive and generative. As a descriptive study, the intention is to describe the ways in which teachers engage and use a reflective process. Through the voices of self, peer, and student, the teacher may be able to encapture a plethora of understandings that are related to a teaching practice. As a generative study, the goal is to bring to the surface issues that arise in defining a teaching practice, new ideas for pedagogy and curriculum, and new approaches of reflection.

\section{Reflection Defined}

For teachers, reflection involves the cognizant act of looking at the technical aspects of a teacher's practice and analyzing the assumptions about and the effectiveness of a prescribed pedagogy and curriculum. The word reflection is derived from the Latin word, reflectere, which means "to bend back." Similarly, a reflective person is one who thinks back on what is seen or heard, thus becoming a deliberate thinker. The term can further be defined as a conscious, thoughtful, purpose-related process (Baird, 1992). Ross (1990) understands reflective thinking as careful, contemplative thinking, which can occur alone or with others, and requires time as well as structural and personal support. Greene (1986) presents that the ideal of reflection is to reflect in the course of situated 
teaching by consciously attending to what is happening with those who are present with the teacher in a shared moment of life. By deliberating among competing views of teaching, an educator must look at the context of each situation and, therefore, understand the relativistic quality of knowledge. Reflection enables the teacher to reconstruct experience, to make sense of this knowledge, and to transform practice.

Statement of the Problem

\section{Reflexive Teaching}

The scenario of a grocery store clerk checking out a customer's groceries helps to flesh out the perception of a reflexive act. The clerk mindlessly scans each item over the IPC reader while paying little attention to the item or its price. It is possible that an item may be scanned incorrectly, scanned twice, or not scanned at all. The clerk goes through a routine act without paying attention to the possible complexities of the act, and with little regard as to the impact of an incorrect scan on the customer. A second beep from the scanner indicating a problem might also cause the clerk to react in a reflexive manner, therefore repeating the scan and ignoring the problem. This automatic mode of operation removes any conscious thought, sensation, or feeling of awareness during the scanning of the items. The premise of this study is that many choral teachers may be progressing through their day and perhaps drifting through their career in an automatic mode as they settle into a routine of acquired skills and behaviors. Reflexive teachers are those who practice without conscious thought. Reflexive teaching is not to be confused with reflexivity, another definition commonly found within the qualitative paradigm, specifically, a type of self-inspection or critical inspection (Schwandt, 1997). 
Reflexive teaching involves a predetermined, consistent reaction to a behavior or event, and is related to terms such as routine and habit. The relationship between reflexivity and reflection is noted in Dewey's belief (1933) that reflection was in direct opposition to routine thought. According to Dewey, routine thought is transferred through outside forces and is guided by tradition, authority, and perimeters set by a social reality. Mindlessly conforming to tradition and authority are in opposition to being a reflective thinker.

Routine, reflexive teaching is supported by and individual's recognition that the act of teaching what is familiar eliminates negative feelings of tension or uncertainty. It is human nature to avoid feelings of dissonance and discomfort. Problem-solving is averted because there is no awareness of any conflicts. Reflexive teaching avoids the complexities of the classroom by placing the teacher's pedagogy in a repetitive and linear motion. At the end of the day, a reflexive teacher might not be able to articulate the rich nuances of the students' actions or the musical experiences that occurred. The teacher is essentially on "automatic pilot."

Negative connotations can be associated with the reflexive choral teacher. However, it is inappropriate to assume that the reflexive teacher is unmotivated or even ineffective. For the purposes of this study, reflexivity is specifically related to the lack of awareness of a teaching moment and/or the lack of developing a philosophy that can speak to the needed fluidity of a teacher's practice. Integrity and hard work ethics are not issues here. Most choral teachers are busy people; they actively participate during entire rehearsal periods, frequently teaching large numbers of students while continuously 
preparing for performances. The issue of how a reflective process can be implemented amidst the demanding schedule of a choral teacher's life will be addressed in this study. The Discovery of Conscious, Authentic Teaching Through a Reflective Process

The metaphor, "waking up," is used as a meaningful expression of a teacher's experience of discovering new ways of being in the world as illuminated by a reflective process. Dewey believed that a fundamental purpose of education is to help people acquire habits of reflection so they can engage in intelligent action. He referred to the "awakening" metaphor in his statement that education "consists in the formation of wideawake, careful, thorough habits of thinking" (1933, p. 78). Henderson (2001) also utilizes the awakening image in his view that self-awareness will enable teachers to see their beliefs, therefore promoting teaching that is steeped in discovery, inventiveness, and experimentation while grounded in deeply held beliefs and values. Through the initiation of a reflective practice, teachers may be woken up as they become more conscious about what they do and will therefore be ready to implement appropriate changes in their practice, thus infusing authenticity. The awareness of the influences of past experiences and external forces, which compose the choral discourse, is an important step in moving from reflexivity to a practice rooted in meaningful reflection.

Choral teachers may choose to improve their practice when they understand what the benefits of reflection could extend to their students, the community, and themselves in both a professional and personal sense. This process involves a willingness to take risks and be open to new ways of learning. Through the initial decision to examine a teaching practice and its evolution by using a reflective process, a choral teacher can then begin to move from reflexive teaching to a deliberate, empowered way of teaching. 
It is through conscious teaching that a teacher's practice becomes more authentic. Authenticity infers genuiness, and implies sincerity of intention and being exactly what is claimed. Trustworthiness and credibility are characteristics of authenticity. Authentic elements also include capturing the essence and spirit of a teacher. Authenticity can be found when there is a direct connection between a teacher's philosophy and the actual teaching practice. Choral teachers imitating past teachers and colleagues represent teaching that is less authentic.

\section{The Canon of Teaching Choral Music -- Definitions and Challenges}

As a complex montage of philosophical goals, repertoire, and teaching pedagogy, the canon of choral music can be perpetuated by undergraduate training and by memories of past choral experiences. If the choral teacher continues this canon without seeking relevant and contextual ways of making music and relating to the students, then the teacher may be operating in a reflexive mode. Specifically, the repertoire performed and the "product-oriented" nature of a choral program may perpetuate the existence of a reflexive choral teacher. These three areas, undergraduate training and experiences, repertoire selection, and emphasis on product versus process will be addressed as key components of the canon of choral music education.

The experiences at the college level that are directly related to preparing future choral teachers include: conducting techniques, choral methods classes, and choral ensembles. Standard conducting texts include Rudolf's Grammar of Conducting (1950), which focuses on gesture, Jordan's Evoking Sound (1996), which emphasizes the understanding of the body and its' relationship to sound, Green's The Modern Conductor (1997), which devotes a significant amount of time to score study, and Phillips' Basic 
Techniques of Conducting (1997), which establishes a course of study on skill-building. Whereas these four texts utilize different approaches to making conducting decisions, they all employ a prescriptive methodology concerning the process of conducting.

The training of choral music education students has had consistent theoretical foundations. Choral music teaching and learning has been heavily influenced by Ralph Tyler (1950). Tylerian thinking is clearly evident in the rehearsal-planning component of many choral method textbooks (Collins, 1993; Hylton, 1995; Brinson, 1996). In a Tylerian approach, the choral teacher selects a musical objective or concept within a piece, devises an exercise to teach the objective, and evaluates whether the objective was met. Rehearsal plans are presented in a linear fashion, which suggests that learning in a choral context is sequential. However, the habitual exercising of an objectives-based approach may lead the teacher-in-training down a path of reductionistic thinking that ultimately discourages reflective thinking (Snow, 1998). Lesson planning must allow for the numerous possibilities of learning opportunities that can spontaneously arise during a choral rehearsal.

The choral performing experiences of the college student form frames of reference in terms of repertoire and the role of the conductor. The traditional role of the choral conductor has been deconstructed by O’Toole (1994). According to O'Toole, hegemonic power relations have so defined notions of conductor/student as to become "normalized" and are accepted conventions of choral pedagogy. Unexamined power relations may contribute to a patriarchal discourse that discourages choral students from 
taking ownership over musical decision-making (Snow, 1998). An awareness of the power structure within the choral classroom is a necessary step in deconstructing the effectiveness of a teacher's practice.

The selection of repertoire, which is the primary textbook in the choral classroom, is based upon the knowledge stemming from the choral teacher's undergraduate classes, past choral experiences, collegial sharing, and professional conferences. In a reflexive mode, a choral director may repeatedly choose repertoire that has been promoted within the profession. This canonized music is drawn from the dominant Western culture. Many choral concerts are programmed with a chronological display of music from the Western culture, ending with a short selection of contemporary literature or repertoire from various cultures. The 1995-1996 Fifty All-State Repertoire List for High School Mixed Choir reveals that out of 299 pieces, $83 \%$ were written by Western composers (this excludes the Western composers who arranged pieces representative of cultures outside of the United states), of which $42 \%$ were composed by the masters from the Western discourse (Reames, 1997). This piece of data demonstrates the perpetuation of the dominant choral discourse.

Women composed four percent of the Western selections found in the All-State Repertoire List. Two scenarios can explain this statistic: there are only a few works written by women composers that are being accepted as valid repertoire, or there are only a few choral composers who are women. In either scenario, the philosophy of a critical pedagogy is not aligned with the current status of the choral profession in terms of the creation of repertoire. Issues of critical pedagogy include the values and politics of the educational system as well as the hegemonic assumptions that influence the instruction of 
students. Music composed by marginalized voices, which includes women, and people from cultures, ethnicities, and religions outside of the United States, accounts for a small portion of the choral repertoire.

Moral/ethical consciousness issues arise when selecting repertoire that encompasses a diversity of styles and cultures composed by musicians from a variety of ethnicities, religions, and genders. In addition, the music that choral teachers do not choose sends a message concerning the value system of the field of choral music. This "hidden curriculum" by default conveys to students that certain types of music have less value and therefore perpetuates a dominant musical tradition. The scenario of recycling the same pieces of repertoire is in direct correlation with reflexive teaching as these musical choices replicate comfortable, familiar arenas of the teacher's own choral experiences and education without regard for a critical pedagogy. While there is certainly strong argument for the teaching and performing value of the profession's "musical chestnuts," it is in the arena of having the freedom, appropriate motivation, and knowledge to choose other pieces as well that is part of a reflective teacher's challenge.

Choral music educators are part of the "deskilled" discourse. Apple (1989) proposes his theory of the deskilling of teachers in the way that curriculum, pedagogy, and evaluation are standardized or prepackaged. Teachers become isolated executors of someone else's plans, procedures, and evaluative methods. Control of the classroom is taken out of the hands of teachers by allowing them only to execute the prescribed curriculum as opposed to developing it. Specifically in the choral arena, school traditions, competitions, and show choirs are possible mandated components of a choral program. A teacher may feel constricted in the ability to control and develop a choral 
program that best suits the educational goals within the critical paradigm as well as the individual needs of the students. A prescribed choral agenda can override the creative programming that teachers should be empowered to design. Another deterrent of a teacher's practice rooted in a critical pedagogy involves constituencies outside of the choral classroom often dictating the number of concerts that must be performed each year. Often, those concerts become caricatures of the dominant culture with unspoken demands of repertoire that will please the majority. For example, a choral teacher may feel obligated to continue the tradition of a Christmas concert even though that teacher may feel that a program with multiple themes may be a more appropriate educational goal for the students. Resistance to unfamiliar styles and genres of music can cause the choral teacher to give in to the demands of the larger community. As these choral teachers are considered fringe benefits in many school districts, they may feel the overshadowing anxiety of possible elimination. A reflective teacher may address the challenges of blending internal and external philosophies in order to place into perspective the educational needs of the students along with the expectations of the school community.

The nature of choral music education is more product-oriented than processoriented. A process-oriented choral curriculum would represent a comprehensive musicianship format where students would be studying theory, history, and culture as related to the choral repertoire. This comprehensive approach to learning choral repertoire is often time-consuming, and therefore, could limit the amount of literature that could be learned or the number of performances that could occur. Again, reflective teachers must consider issues of balance within their educational philosophy. 
The effects of a product-based agenda in a choral curriculum can be understood through the writings of Small. Small (1998) claims that music has become equated with "works of music" in the Western tradition, and what is valued is the created art object itself rather than the action of art, the act of creating, or the perceiving of and responding to the work. Small posits that if musical meaning resides in music objects, then musical performance plays no part in the creative process. Performance is only the medium through which the isolated, self-contained work has to pass in order to reach its goal -the listener. The choral singers, then, are not creators of musical meaning. A choral ensemble can clarify or obscure a work, while presenting it adequately or not, but they have nothing to contribute to it (Small, 1998). Students who are participating in a product-oriented curriculum may not have the ability to fully understand the craftsmanship nor the context of the choral music performed. Reflective teachers must grapple with these conflicting agendas and choose a curriculum that will best suit the needs of the students.

The Delineation of the Reflective Process Categories of Reflection and the Lenses Used to Define a Choral Teacher's Practice Theorists in the past three decades have assembled working models to define and explain the reflective process (Van Manen, 1977; Grimmett, Erickson, MacKinnon, \& Riecken 1990; Tabachnick \& Gitlin, 1991; Valli, 1992; Wellington \& Austin, 1996; and Taggert \& Wilson, 1998). Each of the models breaks down the process of reflection into categories that center on distinct lineages of thought associated with a teaching practice. 
The four categories used in this study, pedagogical, curricular, personal/professional, and critical, arose out of the theorists' terms used in the various delineations of the reflective process.

The term, technical, was used in all the working models of those named theorists as the first category of reflection. Technical reflection focuses on instructional methodologies involved in a teaching practice. Pedagogical was chosen as a categorical heading for this study due to its common usage in the educational discourse and to separate out issues of curriculum, which was blended with the technical category in some of the models. Pedagogical reflection involves introspection on the practical matters of the choral rehearsal. Areas such as classroom management, rehearsal procedures, choir formations, and learning sequences are examples of pedagogical issues on which a teacher might reflect.

Curriculum was a category of reflection presented in Valli's model (1992) and serves the same function in this research as well. Specifically, curricular reflection concentrates on the concepts that the choral director is teaching. The choral repertoire functions as the vehicle for learning the specific objectives of the curriculum, which may include vocal technique, music theory, music history, sight-reading, and ear-training.

The terms, personalistic (Valli, 1992) and transpersonal (Wellington \& Austin, 1996), served as the forerunners of the label, personal, employed in this study. Valli (1992) explained the personalistic category as a focus on a teacher's own personal growth and personal relationships with students. Wellington and Austin's (1996) transpersonal orientation centers on self-development and personal responsibility as it relates to self and others. In this research, personal reflection centers on those attributes of a teacher's 
personality and life situations outside of the classroom that influence practice. Connected to the personal category are those reflections on professional aspects of a teacher's life that are linked to the teaching environment. These points of professional reflection include interactions with colleagues and administrators, as well as opportunities for extended learning throughout the teacher's career. The two areas of personal and professional reflection are combined into one category as they both relate to interactions and events that take place outside of the classroom.

The fourth category of critical reflection was used in the models of Van Manen (1977), Tabachnick and Zeichner (1991), Bullough and Gitlin (1991), and Valli (1992). This study also uses the label of critical reflection to understand the transformation of a teacher's practice to reflect the contextual reality of the teacher and students, and requires the evaluation of the goals of schooling in light of social, moral, and political dimensions. A critically reflective process will affect teaching in a number of ways: teachers will be able to realize the ideological basis to teaching; teachers will see themselves as being in continual formation; and teachers will try to create classrooms that are more democratic (Brookfield, 1995). Whereas many teachers strive to instruct students using effective pedagogy and an established curriculum, other teachers see curriculum as transformative, going beyond subject matter as the main focus of their goals for education. In this democratic classroom, an educator's job is teaching a way of living. Teachers are to help students realize their capacities to live as free and responsible adults. Justice and compassion are democratic ideals for which educators must strive (Liston \& Zeichner, 1987; Purpel, 1989; Henderson, 2001). The nature of large group dynamics commonly found in a choral ensemble lends itself to the teaching of democratic and responsible 
ways of living in the world. For example, the implementation of multicultural music education can initiate conversations among students to explore social and political ideologies. A reflective process can enable the choral teacher to consider acknowledging the opportunity to utilize a critical pedagogy in the classroom.

The four categories can be further delineated into two different lenses that serve to explain a teacher's practice and through which the teachers in this study might reflect upon their practice. The first lens involves the technical, pragmatic aspects of what the teacher is doing pedagogically, of what the curriculum is comprised, and how the personal and professional aspects of a teacher's life affect practice. The "whats" and "how-tos" of each teacher's practice will be reflected upon in this area of the study. The second lens involves the ideological, critical issues that relate to a teacher's practice. Teachers will be addressing the issue of "why do I do what I do?" and looking towards "what do I need to be doing?" This lens addresses pedagogical, curricular, and personal/professional issues in a critical way by examining their foundations and functions.

\section{The Process of Reflection}

Systematic reflection is a learned activity. Wildman, Niles, Magliaro, and McLaughlin (1990) found in their study that any effort to promote reflective practice will benefit from a carefully designed set of tasks that help teachers develop: 1) a sensitivity to their ways of looking at and talking about teaching; 2) a positive attitude toward inquiry; and 3) a self-analytic approach to teaching. This study will include specific formats designed to encourage reflective thinking. Teachers will use two vehicles to 
engage in reflective practice: the written and the spoken word. Through autobiographical narratives, narratives concerning their teaching practice, and reflective journals (both directed and non-directed), these teachers will realize the process of reflection.

Collaboration has been shown to be a common denominator for teachers being able to grow and change in their practice (Cruickshank, 1985; Clemson, 1987; Gore, 1987; Thies-Sprinthall, 1987; Pugach \& Johnson, 1990; Richardson, 1990b; Doyle, 1992; Hay, 1995; Strong-Cvetich, 1995; Stegman, 1996; Bogan, 1997; Kruse, 1997; Powers, 1999; Humphreys \& Suzak, 2000; Neelly, 2000; McDonald, 2001). Stegman's study (1996) found that reflection through dialogue provided student teachers the opportunity to describe and analyze their practice. The collaborative reflection sessions served as external motivation for reflection. In Neelly's case study (2000) of an early childhood music teacher's collaboration with the classroom teacher, a new understanding of music as an enculturation process for young children and adults was achieved through dialogue. Constructive dialogue with peers and the researcher can contribute to the reflective process and give further insights into practice and philosophy.

\section{Limitations of Study}

The ability to develop a reflective practice fully will take more time than the nine weeks of this study. A teacher's personality and life history will determine the rate of adaptation of pedagogical and philosophical changes that can occur in a practice. The small number of participants (five) makes the data gathered ungeneralizable. Within the qualitative paradigm, individuals must be studied from multiple perspectives through the implementation of various methodologies, which therefore justifies the inclusion of this number of participants. 
The stories of these five choral teachers and the reflective practice each one adapts will be the essence of the study. Each story is as unique as each teacher. The writings and dialogues of each teacher, the researcher's observations, and the students' abilities to be articulate and honest, determine the insight into each teacher's life and practice.

\section{Significance of the Study}

The importance of this research rests in its unique connection of reflective practice to teaching, specifically in the choral field. Typically, educators who are committed to excellent teaching continually seek growth and improvement, as the art of teaching is never a finished product. A changing community of learners requires teachers to be in constant formation and to be able to justify their pedagogy and educational philosophies. The rationale for this study stems from the premise that choral educators need to find a vehicle for growth and improvement. While effective teachers often think about their practice, the purposes, goals, and methodologies involved in a reflective process may work together to create a new world of educational imperatives for choral teachers and students. The unique factors of a choral teacher's isolation, the productoriented nature of a choral program, and the perpetuation of the choral discourse add to the justification of adapting a reflective process for the purpose of strengthening a teacher's professional and personal life. The development of a reflective process can serve as an important tool in increasing self-knowledge and seeking new ways of educating students. 
There are four assumptions about improving education that merge in this study and that serve as a driving force in realizing the impact of the bodies of knowledge that could evolve from this study. They are: 1) reflection encourages growth in teaching and change in practice; 2) self-awareness and life experiences inform practice; 3) reflection is based on the problematic; and 4) articulating reflection clarifies and directs change in practice.

Reflection Encourages Growth in Teaching and Change in Practice

Teachers increase the capacity to grow when they reflect upon their own teaching practice. These reflections, therefore, lead to empowerment and the ability to improve classroom practice (Zeichner, 1987). MacKinnon (1987) states that teachers who engage in a process of cyclical reflection and goal setting are more likely to consider new curricular approaches or practices. When teachers are encouraged to reflect on both technical and critical aspects of practice, such reflection can lead to action-research in teaching, which involves the need for teachers to think, redefine, and make changes (Gore \& Zeichner, 1991). To be continually evolving is part of the nature of the critical reflection process. Teachers should never consider the possibilities for learning and change to be fully closed (Brookfield, 1995). The teachers in this study must therefore, be open to the possibilities of a transformed practice. Self-Awareness and Life Experiences Inform Practice

The recognition of the need for teachers to have self-knowledge is a starting point in the process of becoming critically reflective. Significant learning experiences and the people associated with them all influence teaching practice. Teachers, coaches, music directors, counselors, relatives, neighbors, friends, religious leaders, and co-workers are 
people who can affect the practice of an educator (Posner, 1996). The degree of influence on a practice has infinite possibilities. The challenge for each teacher is to be able to remember, define, and see the relevance of these significant people and events to their teaching practices.

Continuous growth is enhanced by gaining distance from practice and exploring different dimensions of experience from different points of view (Holly, 1989). The teachers in this study have examined their practice through the lenses of themselves, their peers, and their students. Self-reflection methods, reflective writings by the researcher, collegial discussions, and student journals are all triangulated to facilitate the development and of each teacher's reflective process.

All teachers impose value-laden frames on their teaching practices. There are preconceptions about the nature of what is being taught, preconceptions about learning and how it takes place, preconceptions about students that place limits upon what is thought to be useful or possible, beliefs about priorities and constraints inherent in the professional and institutional context, and the nature of a teacher's overall commitment to teaching (Barnes, 1992). Teachers must be aware of their beliefs in order to understand the degree of influence on a teaching practice.

\section{Reflection is based on the Problematic}

The process of making the teaching situation problematic is central to inquiry. Smyth (1984) posits that when teachers adopt a reflective attitude toward their teaching by actually questioning their own practices, they then engage in a process of rendering problematic or questionable those aspects of teaching generally taken for granted. Tom (1985) reports that inquiry-oriented teachers differ substantially concerning what aspects 
of the teaching situation ought to be made problematic. Arenas of the problematic, which are arranged by degrees of comprehensiveness, include the teacher-learning process, subject-matter knowledge, political/ethical principles underlying teaching, and issues involving society. These problematic schema fit within the framework of this study. Reflection Clarifies and Directs Change in Practice

Reflection articulated through a written medium can be a powerful tool for change. Written reflections may take many forms, including personal reflective journals, dialogue journals, and narrative stories of experience. Through this methodology, teachers can make notes of daily events, spontaneous ideas, emotional responses, and deliberative thought and analysis related to practice (Holly, 1989). The purpose of these written reflections can also be to stimulate greater awareness of personal values and implicit theories of teaching (Ross, 1990). Reflective writing is the capturing of the human experience. Once that experience is consciously remembered, a cyclical process can begin. Reflection can stimulate change and change will in turn, be cause for reflection.

Reflection, which involves an oral process, can also direct change in practice. Barnes (1976) revealed that: 1) oral dialogue can promote exploration and extension of teacher knowledge to generate knowledge about teaching; 2) oral dialogue may be preferable and equally effective for some teachers to the often time-consuming and individual activity of journal writing; and 3) compassionate peer critique can provoke reflection where introspection cannot. Dialogue will heighten sensitivity and increase the understanding of inconsistencies in one's teaching practice (Henderson, 2001). Oral 
reflection, like written reflection, can be seen as a cyclical reflection process whereas a teacher can share thoughts and then be responded to by a colleague who can then reflect upon that same issue. The initiating teacher will then have a new perspective on which to reflect. Reflective dialogue among several teachers can stretch each teacher beyond their individual points of reflection to address a myriad of issues that impact other teachers in the same field of choral music education.

\section{Summary}

This study is expected to provide a rich description of five choral teachers' engaged in a reflective process. It is not intended to serve as a broad generalization on how to reflect, but rather, it is hoped to serve as a single strand in the research field on reflective thinking in the music education profession. The remainder of the document is presented as follows: Chapter 2 outlines the significant contributors and theories to the discourse on reflection; the methodology used in the study is the focus of Chapter 3; Chapters 4 describes each of the teacher's reflective journeys in the form of individual narratives and concludes with a summation of the five educators; and Chapter 5 includes a cross-case analysis of the teachers, summarizes the study by presenting significant findings, and reveals implications for future research. 


\section{CHAPTER 2}

\section{REVIEW OF LITERATURE}

The review of related literature begins with the historical and philosophical foundations of reflective teaching by Dewey and Schon. This historical perspective will lead to a discussion of other related studies in the fields of general education and music education. The four categories of reflection used for this study, pedagogical, curricular, personal/professional, and critical, will be examined through the related writings and performed studies. The critical category blurs into the pedagogical and curricular areas, but will be discussed individually due to its treatment in the literature. The literature discussing both the benefits and the barriers to reflection will be examined at the end of this chapter.

\section{Reflective Teaching -- Historical Foundations}

The term "reflective teaching" has become part of the teacher education discourse in the last thirty years (Liston \& Zeichner, 1987; Grimmett \& Erickson, 1988; Valli, 1992). Different interpretations of the concept have evolved throughout time and within various disciplines, therefore making a clear definition of the phrase complicated (Richardson, 1990b; Sparks-Langer, 1992; Zeichner, 1992; Zeichner \& Liston, 1996). Calderhead (1989) expresses the diversity in ideas of what being a reflective teacher is:

Reflective teaching has been justified on grounds ranging from moral responsibility to technical effectiveness, and reflection has been incorporated into teacher education courses as divergent as those employing a behavioral skills approach, in which reflection is viewed as 
a means to the achievement of certain prescribed practices, to those committed to a critical science approach in which reflection is seen as a means toward emancipation and professional autonomy. (p. 43)

The evolution of the theoretical underpinnings of the concept of reflection can help to shed light on the philosophical and practical manifestations of its implementation.

Dewey

John Dewey is generally acknowledged to have set the foundation for reflection in teaching (Goodman, 1984; Ross \& Hannay, 1986; Gore, 1987; Smyth, 1992; Kruse, 1997; Valli, 1997). In How We Think (1933) Dewey described attributes of the ideal teacher. According to Dewey, teachers should acquire a habit of on-going thoughtfulness and examination of the beliefs and theories they use to inform their instruction of students. This process of reflection helps teachers develop specific orientations, such as open-mindedness, responsibility, and wholeheartedness. Dewey characterizes reflection as a specialized form of thinking as it serves the purpose of transforming a perplexing situation into a settled one by providing a tentative resolution to the initial problem. Reflection can, therefore, lead into acting in a "deliberate and intentional fashion" (1933, p. 78), which promotes purposeful teaching. Dewey was mostly preoccupied with the cognitive, systematic aspects of reflection rather than with issues of intuition (Valli, 1997). Reflection based on intuition stem from hunches and feelings and are not activated by conscious reasoning. Dewey believed that sequence and consequence are at the heart of reflective thinking. This structured approach can be seen in his reflection theory. Dewey's problem-solving theory $(1933$, p. 102) contains five phases: 
1) feeling or sensing a problem; 2) defining the problem; 3) hypothesizing for a solution; 4) reasoning about methods for solution; and 5) testing the hypothesis. These five steps indicate that reflection is a process that streams in a logical progression.

In addition to the procedural approach of his reflective theory, Dewey proposes that teachers need to be reflective about "the moral, technical and political issues, as well as the instrumental issues that are embedded in their everyday thinking and practice" (Zeichner, 1983, p. 6). For Dewey, the moral teacher is a person who is reflective. This moral individual, whose pedagogy is rooted in a value-related system, would treat professional actions as experimental and reflect upon the actions and their consequences. Schon

Donald Schon draws from the writings of Dewey in The Reflective Practitioner (1983). Schon views teaching as an activity filled with uncertainty. According to Schon, teaching is so complicated that teachers cannot merely apply what they have learned in an inflexible manner. Schon describes two types of reflection: reflection-on-action and reflection-in-action. Reflection-on-action involves the systematic and deliberate thinking about a teaching episode after it has occurred (Schon, 1983). This type of reflection has no direct connection to present action (Schon, 1987). It takes place after a dilemma or experience has been resolved. This concept of reflection is the one most commonly referred to in the educational discourse. Typical reflection-on-action methodologies used in the teaching profession include journaling, reflective questionnaires, autobiographies, portfolios, and reflective discussions on relevant educational issues with colleagues or supervisors (Holly, 1989; Pugach \& Johnson, 1990; Brookfield, 1995; Powers, 1999). 
Reflection-in-action refers to what happens when the practitioner suddenly comes upon a problematic situation and must resolve it. During this procedure the teacher consciously interacts with a problematic situation, converses, and experiments with it. Reflection-in-action is a four-step process. The first step is problem-setting where the teacher defines the problem, the ends to be achieved, and the means that may be chosen (Schon, 1983). The teacher must first be aware of a dilemma to initiate the problemsetting mode. The second stage of the process is called reframing. Schon uses this term to describe what happens when the practitioner looks at a problem in a different way and is then able to solve the puzzle because of the new insight. This reframing of a problem situation enables practitioners to make use of their existing repertoire of examples, images, understandings, and actions (Schon, 1987). Intervening involves the development and testing of a hypothesis to successfully resolve the dilemma. The fourth step in the process is an evaluation of the effectiveness of the intervention. If the teacher judges the intervention ineffective in solving the problem, the teacher may either try another intervention or reframe the problem again.

Schon's concept of "knowledge-in-action" is the information called upon in the second stage of the process of reflection-in-action. This type of knowledge does not rely on a series of conscious steps in a decision-making process, rather, it is based on the past experiences of the teacher interacting with a particular situation (Richardson, 1990a). Each problematic situation an educator may encounter calls on a type of tacit knowledge that an individual does not consciously articulate at the time. This tacit knowledge includes a repertoire of values, knowledge, theories, and practices. 
Reflection-in-action is little understood as it is problematic to describe and observe (Russell \& Munby, 1991). Smith's (1999) research involving two beginning and two experienced elementary teachers highlighted four difficulties found in studying reflection-in-action: 1) it is hard to see teachers thinking on their feet in the classroom setting; 2) it must be studied in its immediate context; 3 ) it is idiosyncratic and improvisational; and 4) teachers know more than they show and can talk of easily. Smith concluded that although it is difficult and challenging to document, reflection-in-action offers a way to further understand professional learning.

Improvisation is used as a metaphor in Elliott's (1995) interpretation of reflectionin-action. Improvisation as a spontaneous action in the teaching moment is an essential skill in the difficult gap between inert teaching knowledge and actual teaching practice (Smith, 1999). The connection between improvising jazz music and improvising in a teaching practice is understood through Elliott's rendering of jazz great John Coltrane's ability to compose in real time at mind-boggling speed, noting in preparation that Coltrane spent years studying the improvisations of great musicians before him as well as having an extraordinary understanding of the harmonic language of the bebop jazz tradition (Elliott, 1995). Improvisation is, therefore, dependent on the performer's knowledge of the domain so that action may be taken in the musical moment. In music teaching, an action based on reflection in the moment will follow from the situated understandings of musical content knowledge, pedagogical content knowledge, general pedagogical knowledge and contextual knowledge (Smith, 1999). The teacher is making split-minute decisions based upon an understanding of the domain and a lifetime of personal experiences. 
Schon (1988) encourages educators to tell stories about experiences that hold elements of surprise, positive or negative. Stories can be understood as products of reflection, which need to be recorded so teachers can look at them again for the purpose of understanding the meanings that have been built into them. Schon (1988) suggests that teachers need to pay attention to the assumptions and ways of framing experiences built into those stories. Old stories bring meaning to current problematic encounters, thereby creating new stories. Schon sees teachers as builders of repertoire rather than accumulators of procedures and methods for the purpose of reframing problematic situations.

Schon's emphasis on uncertainty, intuition, and value judgments differs from Dewey's more Western emphasis on sequential logic and rationality in reflective thought (Valli, 1997). An alternate view states that Schon has confirmed the thinking of Dewey rather than advancing it (Kilbourn, 1992). The common thread between the two theorists rests in the idea of inquiry and experiment in practice as the basis for the development of professional knowledge.

Research Studies in Education Based on Reflection Reflection as a part of teacher preparation and teacher development has received considerable attention in the field of general education (Clift, Houston, \& Pugach, 1990; Tabachnick \& Zeichner, 1991). Primarily, the focus in the research has been on teacher education programs (Carter, 1992; Smith, 1999). Studies pertaining to issues of reflection can be viewed as relating to one of two scholarly lineages with a variety of gradation in between (Stegman, 1996). Reflecting on a practice through a critical lens is 
typically related to Dewey’s (1933) approach, whereas Schon's (1983) reflection-inaction is based on the notion of the intelligent knowing-in-action that teachers do as they act and interact within the immediacy of problematic situations.

\section{Related Studies of Teacher Education Programs}

Goodman (1984) conducted a study that assessed an implemented teacher education program. The seminar course, with a practicum component, was founded as a humanistic alternative. The importance of the individual's feelings, attitudes, perceptions, and ideas was emphasized. The students were presented with the concept that skills are a means for implementing a person's beliefs and educational purposes, and are not an end in themselves. The concept that "there is no one right way to teach" was presented to the pre-service teachers as the pedagogical philosophy. Results showed that the seminars helped students to reflect upon their own educational values. However, when faced with the realities of the practicum, reflection meant thinking about which techniques seemed best in any given situation.

The study's results pose the question, does reflection-in-action concerning more probing questions only occur with teachers who are experienced, confident, or risktakers? The reflective quality of openmindedness requires a teacher to give full attention to alternative possibilities (Dewey, 1933). Goodman proposes that there must be a desire and ability to synthesize diverse ideas, to make sense out of nonsense, and to apply information in an aspired direction. Teachers need to go beyond questions of immediate utility. The attitude of wholeheartedness (Dewey, 1933) gives educators the internal strength necessary for reflection. However, Goodman found that pre-service teachers were too insecure or fearful to be reflective. 
Russell and Munby (1991) performed research based on Schon's theoretical foundations. Their work focused on shedding light on the elusive nature of reflection-inaction. Specifically, they concentrated on the study of the reframing component of Schon's reflective process. Russell and Munby assert that reframing involves "seeing" or "hearing" differently, whereby perception is a unified process in which observation is interpretive. This observation is then reflected in language, specifically, in changes in metaphors. In a five-year series of studies, Russell, Munby, Spafford, and Johnston (1988) and Russell and Munby (1991) investigated how teachers used metaphors to describe the reframing of certain classroom experiences. The first study examined reflection from the narrated stories of teachers. The follow-up study in 1991 explored metaphor as an interpretive description of situations and roles. It was found that pedagogical change in practice may take up to several months to occur.

Richert's study (1992) of student teachers' reflective content examined the roles of reflective partners and portfolios in helping to foster reflection. The data came primarily from journal narratives written by the student-teachers. Richert found that student-teachers reflect differently in different conditions. Their primary focus was on the technical aspects of learning to teach as well as the emotional effects of classroom struggles. Richert states in the conclusion:

To facilitate reflection in beginning teachers, teacher educators may wish to create programs that offer opportunities for students to learn the knowledge and skills of reflective practice. Understanding the conditions that promote reflection in beginning teachers is fundamental to creating such programs. (p. 188)

Richert's conclusion calls for understanding the factors that contribute to, or hinder reflective teaching. 
Doyle's study (1992) describes how two elementary pre-service teachers thought about their field experiences as they analyzed classroom situations. Specifically, the study looked at what situations these teachers found to be problematic, how they thought about problematic situations, what resources or knowledge they used to thing about problematic situations, and how their background knowledge and attitudes about teaching and learning influenced their thinking during the field experience. The pre-service teachers used knowledge from teacher education courses, experience, and intuition to think about and generate possible solutions to problematic classroom situations. Doyle found that the pre-service teachers' backgrounds, and beliefs and attitudes about teaching and learning influenced their reflective thinking processes as they analyzed problematic classroom situations throughout the field experience. The use of peer collaboration and journal writing proved to be effective in stimulating and examining these teachers' thinking.

The categories of reflection performed by student-teachers were the focus of West's study (1994). West found the following four categories of reflection occurring among the student-teachers: task; self-adequacy; impact; and survival. Tasks were the most common areas of reflection. Structured feedback to journal entries of the studentteachers appeared to elicit more comments in the critical discourse categories, thus supporting the concept of the engagement of collaboration in promoting the examination of critical issues.

Smits (1994) and Dinkelman (1997) conducted action research with the purpose of promoting reflective teaching. Smits' study was part of an action research project prompted by the University Of Alberta's Faculty of Education. What the meaning of 
reflection is in the experiences of learning to become a teacher was the question asked in this study. The student-teachers' stories were learned from unstructured interviews conducted throughout the term. The challenges of student- teachers, including classroom management, pacing, and lesson planning, point to the problems of practicing reflection in absence of self-understanding and lack of support for formation of identity in terms of broader and more ethical views of teaching. Reflection among student-teachers is easily provoked by moment of crisis that can offer opportunities for self-understanding. Reflection can be seen as a narrative experience, which involved linking personal concerns, histories, and ideologies, with a creative and critical appropriation of the experiences of becoming a teacher.

Dinkelman sought out evidence of critical reflection and critically reflective teaching in multiple settings, including: interviews conducted with case study participants at the start, midpoint, and conclusion of each of the two semesters of the study; observations of the participants' practice and the field notes these observations generated; and assignments and other written work collected from the participants. All three of the participants displayed critical reflection throughout the two semesters of the study. The results of the study suggest that teacher educators can influence pre-service teachers to become more critically reflective. However, influencing the quality and content of critical reflection appears to be a greater challenge.

Two studies (Galvez, 1995; Williams, 1995) focused on the examination of reflective teaching as a clinical laboratory-based instruction strategy designed to help preservice teachers examine their teaching behaviors. The philosophical underpinnings of 
Dewey serve as the rationale for these two studies. Galvez concluded that the reflective teaching model results in increased reflection among pre-service teachers than for those who participated in content-neutral reflective teaching lessons.

Hight (1998) investigated two undergraduate teacher education courses in the Midwest. The question studied was, "Does the model based on deconstruction promote reflection?" The model emphasizes the recognition of unintended contradictions within a text. Hight points out that the model for reflective teaching must include the provisions of tools, time and legitimation for reflection by creating an atmosphere conducive for reflection while resisting the urge to dictate its ends. The conclusions point out that this model of deconstruction promoted reflection but other unintended currents resulted as well.

\section{Related Studies of Practicing Classroom Teachers}

Many writers in the field of educational research are calling for studies following the reflective practices of professional teachers (Clark \& Lampert, 1986; Zeichner \& Liston, 1987; Houston \& Clift, 1990; Carter, 1992). Kilgore, Ross, and Zbikowski (1989) investigated how the reflective attitudes of first year teachers demonstrated what they had learned in their teacher education program concerning reflective teaching. One of their findings indicated that reflective dispositions among teachers are maintained in a supportive school atmosphere. External support coupled with the internal reflective dispositions of teachers propels them to act in certain ways.

Four beginning elementary teachers were the focus of a study by Hamrick (1995). The major influences, found through reflection that impacted instruction, were the life experiences of the teachers, teacher education courses, student-teaching experiences, 
observed practices of cooperating teachers, and public school colleagues. Hamrick concluded that opportunities to reflect on beliefs during the first year of teaching were beneficial. Implications for teacher education programs include the implementation of student-teaching experiences that incorporate reflection and consistent support for those pre-service teachers.

The purpose of Deutsch's research (1996) was to determine if teachers who had been trained to identify reflective practice perceived that there were factors that enhanced or impeded reflective practice within the school context. These factors identified by the teachers in order of importance were: internal resources and strengths; intrinsic and extrinsic motivation; organizational climate; administrative authority; and career and organizational commitment. Deutsch found that the teachers used a reflective practice as a valuable tool to refine their ability to analyze positive and negative factors that influenced their performance within the school context. Deutsch recommends training teachers to be reflective with the purpose of educational change to increase effectiveness.

Bogan (1997) posited that long-term dialogue on educational philosophy is a process to engage teachers in intellectual discourse and to reflect on their beliefs and practices. A three-year dialogue program between high school teachers and the superintendent was set up for the purposes of this study. Although individual teachers attested to professional and personal growth through the dialogue, there was minimal transfer of that knowledge to improve their teaching. It was found that the structure of the dialogue resembled more of a hierarchical teacher-student relationship than a collegial conversation among peers, which created a culture of deep distrust. 
The purpose of Powers' study (1999) was to examine the day-to-day practice of three reflective teachers in order to better understand reflective practice and the reflective process, both individually and collaboratively. There was a focus on exploring the role of dialogue in reflection, especially on the connection between the conversations with others and the mental conversations with self. Powers concluded that the teachers had a deep commitment to student learning which prompted continual reflection about student and school issues. Both the inner and outer conversations of the teachers served to problem-solve, evaluate, and create options. The implications from this study are to encourage study groups and other activities that promote reflective thinking.

Smith's study (1999) examined how four practicing classroom teachers, two beginning teachers and two experienced, processed reflection-in-action. Specifically, Smith posed the questions: 1) Do teachers reflect?; 2) What is the content of the reflection?; 3) How does proximity to an event affect reflection?; and 4) What factors influence teachers' reflective content and processes? Smith's study revealed that the teachers spoke more of controlling and reducing dilemmas than of resolving them. Smith concluded that more studies on reflection-in-action are warranted as they can reveal nuances in a teacher's practice when reflections are captured and articulated.

\section{Related Research Studies in Music Education}

Music teacher education and music teacher development are areas identified as needing increased attention in the research field (Boardman, 1990; Verrastro \& Leglar, 1992; Stegman, 1996). Research in these two areas has provided the profession with fragmented information and limited recommendations. Although reflective teaching has received considerable attention in general education, the field of music education has 
been slow in attracting researchers who will investigate this topic. Music teaching in the twenty-first century will likely require the ability to address instructional issues involving diverse and complicated factors (Stegman, 1996). Olson (1988) points out that the music teacher of the future must be prepared to think critically, plan, evaluate, and continuously increase effectiveness as an independent teacher. The accountability issues of today's schools calls for the music teachers of tomorrow to be immersed in undergraduate and professional development training that promotes reflective thinking in order to improve practice.

A review of research revealed a limited number of studies that were related to music education and the reflective process. Four studies were found that contained a reflective component within them (Whitaker, 1989; Zimmerman-Brown, 1992; Parr, 1996; Whitaker, 1996). Eleven studies have been conducted which are situated in the reflective discourse and will be discussed in detail.

In 1993, Nightingale examined the practices of three elementary music teachers in their evaluation of students. With the goal of gaining a holistic view of the evaluation process, teachers used a reflective process to record their thought processes, feelings, and Conscious Decisions that they made while teaching. Through this reflective process the teachers were able to evaluate current and future planning, and student learning.

Dolloff (1994) used the reflection process as the catalyst for the development of expertise in choral music teachers. The powerful tool of modeling was employed to improve the practice of these pre-service teachers. Written reflective exercises were part of the methodology used to raise the level of expertise in each teacher. Dolloff concluded 
that teacher capabilities and self-esteem improved when teachers participated in reflective activities. This study represents the first substantive qualitative inquiry into music teacher expertise with emphasis on the reflection process.

Choral music teacher education was the focus of the study performed by Stegman (1996). The purpose of the study was to investigate six choral music student-teachers' perceptions of successes and problems as they reflected on their music teaching. Guided questioning was used to stimulate reflection. One of Stegman's assumptions was that in the process of becoming a teacher, systematic reflection and analysis of practice can assist in the development of effective and reflective teachers. Dialogue was an important tool for reflection in this study. Stegman defined verbal interaction as "meaningful communication between parties based on shared interest and respect for each others' views." Dialogue sessions provided a means for the teachers to describe and analyze their practice. Engaging in mutual reflection also served as an external motivator. The emphasis of dialogue with an experienced teacher was considered a critical ingredient to facilitating reflection.

Schon's theory of reflection was the basis for the studies of Hamlin (1995) and Snow (1998). Hamlin examined the development of a young music teacher's practical knowledge during the process of reflection-in-action. In this case study, the teacher was able to reframe a situation when students would not respond and allow new levels of understanding to emerge through the reflective process. Snow's study used reflection as a component of the development of expertise in choral music educators. Written reflections on teaching and planning processes as well as self and peer reflections were incorporated. The student-teachers were divided into two categories based on their 
critical thinking skills: linear thinkers and spiral thinkers. Linear thinkers controlled their teaching acts in direct ways. They adhered closely to lesson plans and had a more difficult time linking teaching strategies with personal decision-making as they approached the choral repertoire. Spiral thinkers could improvise more easily in the teaching act and were more comfortable using brainstorming as a preparatory process for teaching. According to Snow, this ability to brainstorm extensively is representative of reflection-on-action. The essence of reflection-in-action could also be found in the spiral thinker in that those teachers were able to think on their feet and adjust their teaching as needed. This dual approach of reflection-on-action and reflection-in-action represents the theoretical foundations based upon Schon's (1983) concept of successful teaching. Snow concluded that this combination of reflection-on-action and reflection-in-action found in the spiral thinkers fostered the expansion of novice conductor/teacher thinking in the preparation for teaching.

The use of a reflective process during the music student-teaching experience was also investigated by Coleman (1999), Bailey (2000), and Burrack (2001). Coleman incorporated Van Manen's levels of reflection as a means to frame and interpret study data. Guided reflection was the vehicle employed to explore teaching objectives and behaviors. Coleman concluded that because the student-teachers were in the survival stage, this new process of reflection was not an effective means of changing behaviors. Coleman recommended that reflection be taught and modeled in the undergraduate curriculum to assist in the transfer for student-teaching. Bailey (2000) used videotaping and written narratives as tools for reflection. The primary themes for reflection were classroom management, student learning, and the goals of the music education 
curriculum. The thinking of these student-teachers indicated there were different levels of reflection based on the individual. Burrack's (2001) study examined the development of instrumental music student-teachers' instructional thought. The investigator sought to explore how implicit theories and beliefs affected instructional decisions that occurred in the interactive environment of a music classroom and the changes that occurred in the music teacher's instructional thought processes. Through the use of reflective journals and video self-confrontation, the student-teachers learned to know how and why they made instructional choices and came to understand the relevance of past experience and education.

Neelly (2000) conducted a case study of a preschool music teacher on collaborative reflective practice. This study found through a collaborative reflection model that the music teacher and early childhood teachers gained an understanding of music as an enculturation process for young children and adults. Neelly concluded that collaboration can aid in the focus on skills, adult learning processes, roles, and strategic positioning.

Eight general music teachers examined issues of classroom discipline through the use of a reflective process in McDonald's study (2001). McDonald's premise was that time is not allotted for critical reflection with peers on discipline concerns specific to music teaching. This qualitative study used the process of guided critical reflection to investigate discipline issues. The study concluded that participants were able to engage effectively in critical reflection and peer problem-solving. There were positive changes 
in the participants' classroom discipline, continued reflective practice, increased dialogue with peers, emergence of peer leadership, and improved communication with others at school and district locations over time.

Raiber's (2001) quantitative study of instrumental teachers is the most current examination of the reflective process in the field of music education. The goal of this study was to determine the extent to which instrumental music teachers' aptitude for reflection and/or self-reported engagement in a reflective practice could predict their instructional effectiveness. Raiber's findings included the significance of knowledge of students' reflective aptitude at the initial stages of music teacher education, and the recognition that school environments that are conducive to reflective teaching may allow more experienced music teachers to continue their reflective abilities to improve instruction.

These studies mark the beginnings of the music education field's awareness and acceptance of the importance of reflective teaching. All 11 pieces of research found benefits for teachers' development of a reflective practice. It is important to note that none of these studies involved practicing choral music teachers utilizing a reflective process, therefore, revealing an opening in the research discourse. This study could serve as the first step in the investigation of the reflective process by practicing choral music teachers. 


\section{Categories of Reflection}

Four categories of reflection, which were outlined in chapter 1, are utilized in this study for the purpose of organizing the content of the choral teachers' reflections. These delineated categories include pedagogical, curricular, personal/professional, and critical. How these categories are addressed in the literature will be discussed.

\section{Pedagogical Reflection}

Teaching involves knowledge about techniques, strategies, and methods.

Pedagogical reflection is concerned with the technical aspects of how to teach. Teachers who are reflecting in this mode are developing their craft. Henderson (2001) refers to the term "craft reflection" as a teacher's thinking about instructional study. A teacher who is focusing solely on the nuts and bolts of the classroom process is experiencing pedagogical reflection (Brookfield, 1995). According to Van Manen (1977), the effective application of skills and technical knowledge in the classroom are a part of this mode. This category of reflection facilitates conformity to a predetermined, external standard (Grimmett, 1988; Valli, 1997). Experts determine what good teaching is and then teachers reflect about whether their teaching meets those expectations. Reflection is limited to the retrospective comparison of the effectiveness of pre-specified instructional strategies. Wellington and Austin (1996) explain that this level of reflection focuses on the development of instructional methodologies that maximize efficient and effective delivery of prescribed educational ends. In the same vein, it is common for teachers reflecting on pedagogical issues to reference past experiences (Taggert \& Wilson, 1998). For example, a teacher might recall an effective classroom management technique used in past situations and then choose to implement it. 
Cruickshank is the forerunner of reflective teacher education programs focusing on technical (pedagogical) reflection. His procedure, started at The Ohio State University in 1985, provides student-teachers with repeated opportunities to teach and analyze brief lessons developed by the program designers (Ross, 1990). Cruickshank's goal is to develop teachers capable of executing the technical skills of teaching. The focus of Cruickshank's reflective process is to be a method for achieving pre-specified goals, a characteristic of "technocratic rationality" (Gore, 1987). The sequence and consequence nature of this process replicates the structural foundations of Dewey's approach but does not involve the critical aspects of reflection. Several other universities have initiated teacher education programs that involved reflective practice. Implemented case study programs included the University of New Hampshire, University of Florida, University of Maryland, Michigan State University, Catholic University of America, and University of Houston and were studied by Valli (1992). According to Valli, the programs at these schools represent current thinking in the field in that they treat reflection as an important and complex process.

University of Maryland's Masters Certification Program (MCP) is a teacher education program that promotes reflection based on pedagogical skills. Specifically, the emphasis is on reflection for the purpose of understanding effective teaching and effective schools through the use of quantitative research methods (Sparks-Langer, 1992). Reflection is understood to be analogous with problem-solving, and is sought out by taking action and developing alternative actions. 
It is during the early stages of a teaching practice that pedagogical issues typically require the most attention. Several studies have reported that pedagogical reflection is the most prevalent type of reflection in beginning teachers as they attempt to master functional skills in the classroom (Goodman, 1984; Richert, 1992; Strong-Cvetich, 1995; Smith, 1999). However, teachers will continue to make numerous technical decisions concerning process and procedure throughout their teaching career. The logistics of a teaching practice allow for numerous opportunities for reflection.

\section{Curricular Reflection}

Issues of curriculum intersect with both the pedagogical and critical categories in the literature. Under this category, educators will be reflecting upon their assumptions underlying the curriculum they are implementing. "What am I teaching?" is the appropriate question for this type of reflection. Teachers may choose to use the traditional curricular paradigm either as their curricular guideline, as a resource, or as a source of resistance. At this second level of reflectivity, teachers would begin applying educational criteria to a teaching practice to make individual and independent decisions about curricular matters (Brubacher, Case, \& Reagan, 1994). However, these curricular decisions lead to a critical approach as teachers reflect on the origins, purposes, and consequences of their actions, as well as on the material and ideological constraints and encouragements found in the classroom, school, and societal contexts in which they work (Zeichner \& Liston, 1987). Pedagogical and curricular areas of reflection are therefore, intertwined with critical reflection. A teacher's awareness of the connectedness of the fluid nature of the students and the outside world, realized through a reflective practice, can result in a choral pedagogy and curriculum rooted in a critical discourse. 


\section{Personal/Professional Reflection}

Any type of reflection performed by a teacher involves consideration of the construction of that teacher on both personal and professional levels. It is impossible to extract the reflective process in a teaching practice from the teacher as a person. Within this discussion appropriately falls the effects of collaboration in the reflective process, and therefore, research that has addressed that issue will be examined here as well.

Personal characteristics such as integrity, perseverance, self-confidence, openmindedness, and risk-taking will influence the areas of reflection and the course of the reflective process (Dewey, 1933; Ross, 1990; Valli, 1997). Powers (1999) found that teachers who were knowledgeable and flexible, and who had a deep commitment to student learning were constantly reflecting about student and school issues. Power's study also revealed that a successful reflective process was practiced by those teachers who were highly verbal and imaginative. These teachers consistently assessed and created new options in their practice.

Wellington and Austin (1996) directly address the personal dimension of reflection in their delineation of the transpersonal orientation level of reflection. This orientation centers on universal personal liberation. Teachers immersed in this orientation tend to be inner-directed and focused on self-development as well as the relationship of internal to external. Questions that arise from this orientation include "how can I integrate my personal/spiritual growth with my vocation?" and "what is my personal responsibility to myself and to others?" (Wellington \& Austin, 1996). Pedagogy is typically individualized in this level of reflection. These teachers question educational content and means from a personal, inner perspective. 
The stages of a personal life as well as day-to-day personal occurrences will obviously affect a teacher's ability and/or willingness to reflect and change. Major issues such as marriage/divorce, moving, child-rearing, and illness influence the reflective process. Various moods and emotional states of mind will play a role in how and what type of reflection occurs as well. The process of reflection cannot be extrapolated from the personal affects of a teacher.

The impact of professional growth will affect the teacher's relationship with reflection. The learning that is undertaken in adulthood provides a rich vein of experience that can be used for insights into teaching practice. Graduate study and professional development workshops/conferences can be opportunities for sustained autobiographical reflection on learning. "Of all the methods available for changing how we teach, putting ourselves regularly in the role of learner has the greatest long-term effects" (Brookfield, 1995, p. 50). Continually taking on the role of learner shifts the paradigm for the teacher, thus increasing the opportunities for reflection.

The length of a teacher's professional experience has been shown to affect the type of reflection performed by the teacher (Strong-Cvetich, 1995; Smith, 1999). Smith studied two beginning and two experienced teachers who implemented reflection-inaction. The beginning teachers were more concerned with academic content while the experienced teachers were focused on broader issues facing students outside traditional subject matter. In a piece of qualitative research, Strong-Cvetich (1995) studied 11 teachers who had taught for 20 years each. The purpose of the study was to understand how these teachers sustained and renewed their commitment to the classroom. These teachers revealed the common themes of passion for teaching and learning and a 
commitment to reflective practice, personal growth, and lifelong learning. This study also revealed that opportunities to be involved with colleagues in team teaching and other collaborative work, as well as opportunities to engage in the broader context of education beyond the confines of the classroom, were critical factors in sustaining and renewing the teachers' commitment to the classroom.

Collaboration impacts a teacher's personal and professional life as well as the ability to reflect. Many studies (Cruickshank, 1985; Clemson, 1987; Gore, 1987; ThiesSprinthall, 1987; Pugach \& Johnson, 1990; Richardson, 1990b; Doyle, 1992; Hay, 1995; Strong-Cvetich, 1995; Stegman, 1996; Bogan, 1997; Kruse, 1997; Powers, 1999; Humphreys \& Suzak, 2000; Neelly, 2000; McDonald, 2001) revealed positive results when collaboration was used. The strengths of collaboration in reflective practice have been discovered specifically in the studies of Kruse (1997) and Humphreys and Suzak (2000). Kruse found that communal reflection starts with creating an individual reflective habit leading to an ongoing focused reflective conversation with peers. Collaboration was a catalyst for reflection by providing an interpersonal relationship that encouraged feedback and created personal inquiry (Humphreys \& Suzak, 2000). Collaboration performed in a relationship specifically designated as teacher and facilitator has been addressed in the literature (Pugach \& Johnson, 1990; Baird, 1992). Facilitators must guide the process of reflection by stimulating their teacher-partners to ask themselves questions about general areas of their practice. In a "focused professional dialogue" (Rudduck, 1987, p. 129), two teachers would reflect on a specific pedagogical problem or issue of importance to both of them. The pair would work closely together towards understanding and resolving the problem or issue, each teacher 
benefiting from the process. Hay's (1995) case study of a first-year science teacher resulted in dramatic changes in teacher practice due to the professional collaboration that featured continuous and supportive inquiry. By encouraging reflective teaching and negotiating understanding, an emancipatory, yet critical approach to professional development will be promoted in this study.

\section{Critical Reflection}

The notion of critical reflection begins with the "why" question, "Why am I teaching what I am teaching?" The critical arena of reflection also involves inquiry into the moral and ethical issues of teaching. Brookfield (1995) offers two purposes of critical reflection. The first is to understand how considerations of power frame and distort educational processes. The second purpose is to question hegemonic assumptions and practices that seem to make teaching lives easier but actually work against the interests of long-term practice. The discussion of critical reflection incorporates these issues of questioning, power, hegemonic assumptions, and moral/ethics into three dimensions that will be addressed in this review of literature. The ideological dimension looks at the roots of critical pedagogy by revealing the values and politics of teaching. The relational dimension is concerned with the responsibilities associated with the relationships that occur in the classroom. The dialectical dimension entails the problematic along with the exploration of multiple possibilities.

\section{Ideological Dimension}

The ideological dimension explains the actions of a critically reflective teacher to be rooted in critical theory. Critical theory has been interpreted in an educational context and reframed as critical pedagogy by writers including Giroux (1983), Shor (1987), 
McLaren (1993), and Freire (1994). Critical pedagogy analyzes education as a process through which dominant economic and social groups impose values and beliefs that legitimize their own power (Brookfield, 1995). Dominant ideologies are sets of beliefs, values, and explanations that appear to the majority to be self-evidently true and morally desirable. Because of their apparent obviousness, they are difficult to identify and hard to challenge. These ideologies legitimize certain educational practices so that those practices are accepted as representing the normal order of things. The critically reflective teacher must resist this process by creating spaces in which both the teacher and the students can become aware of this process and learn how to interact with it. Students learn to think and live in these spaces that are more democratic, harmonious, and true to their own experiences (Brookfield, 1995). Thus, democracy is a core value in critical reflection. Justice, compassion, and fairness guide teachers who are critically reflective. Their classrooms become environments where all voices can speak and be heard.

Tom (1984) was one of the first scholars to explore the moral and ethical responsibilities of a teacher. The teacher as a moral craftsman, a label created by Tom, is concerned with the normative roots of teaching. Tom believes that the status of all educational phenomena is socially constructed and therefore, reminds teachers that they are all responsible for the character of educational institutions. Tom (1985) views the spirit of inquiry as engaging in a model of inquiry that unites knowledge and action.

Henderson (2001) explores the expansive ideology in critical reflection. He proposes three overlapping components of critical inquiry: 1) visionary pragmatism;2) political awareness; and 3) ethical responsibility. The pragmatic approach encourages teachers not to believe everything they are told and not to rely just on pleasing 
appearances. Teachers must ask penetrating, unsettling questions. Critically reflective teachers tend to think in a visionary way about the possible consequences of their actions. Henderson's second component of critical inquiry, political awareness, is the focus of Freire's philosophy of schooling (1987). Freire describes the link between education and politics and theorizes that all forms of schooling are political, even if teachers are not consciously aware of this aspect of their work. Curriculum decisions, standardized testing, and decisions about who teaches are all political. Critical teachers carefully reflect upon those manifestations of power in their classrooms, schools, and communities. They also understand that schooling is situated at the intersection of knowledge and power and that too often youth are socialized to become unquestioning, conforming members of an unfair society (Henderson, 2001). Henderson's third component of critical inquiry incorporates the ideology that ethically responsible teachers feel passion for their practices and feel compassion for their students. Injustices of race, class, disability, and sexual orientation issues must be addressed. Teachers must create a safe environment for their students to flourish and experience democratic living.

Under a critical pedagogy, the educational system is never neutral. There needs to be a continual reflective examination of educational goals and alternative courses of action. Choice is essential for moral reflection and a wide range of choices further encourages this type of reflection (Liston \& Zeichner, 1987). Critical reflection demands a sense of open-mindedness and an acceptance of the reality of multiple possibilities in a teaching practice. 


\section{Relational Dimension}

The relational dimension of the critical reflective discourse is concerned with the development of caring relationships between teacher and student. A caring relationship is an essential element in a student's moral and educational growth (Liston \& Zeichner, 1987; Henderson, 2001). This ethic is rooted in the natural relation of mothering, subjective experience, and the uniqueness of human encounters (Valli, 1990). Noddings' writings (1984) serve as the basis for the relational approach to reflective practice. According to Noddings, it is important for teachers to apprehend the reality of each student and to give priority to the student's affective growth. A caring teacher would be less concerned with the scores of the students' achievement tests and more concerned with instilling attributes of respect, trust, and admiration. Relationships are more important than rationality, and empathetic understanding is more important than abstract principles (Valli, 1990). Alternative pedagogical and curricular choices are to be found in a classroom where the relational dimension is emphasized.

This focus on the affective ends and the whole person is a deliberate attempt to return the aims of schooling to the education of a moral society (Valli, 1990). Noddings (1987) regards a "relational ethic rooted in and dependent upon natural caring" (p. 6) as the best way to accomplish that end. Producing moral, caring persons demands that teachers must live with students in a caring community" (Noddings, 1986). The critically reflective teacher focusing on the relational dimension is cognizant of the position as role model of a caring member of the school community. This educator sees society as a community of individuals (Valli, 1990). A relational teacher places value in becoming involved in the reality of the other. 


\section{Dialectical Dimension}

The dialectical dimension of reflection advocates political liberation (Grimmett, Erickson, MacKinnon, \& Riecken, 1990; Wellington \& Austin, 1996). Teachers working within the dialectic mode are outer-directed and tend to focus on social and political issues. They advocate political activism. These practitioners reject the limitations of authorized organizational structures and are uncomfortable working within them. As personal responsibility and empowerment are emphasized, the pedagogy involves continual questioning, revising, and internal validating issues of education (Wellington \& Austin, 1996). Learning occurs in a dialectic exchange of mutual enquiry and may be confrontational (Freire \& Shor, 1987). To challenge existing pedagogical and curricular goals in a dialogue can result in an interchange of heated debate and uncomfortableness. However, the dialectic dimension is rooted in the need for communication, which can open doors to possibilities of multiple solutions to educational debates. The various means of communication used in the reflective practice for this study include dialogue with peers, individual interviews, and dialogue journals. These tools will enable teachers to critically analyze, negotiate, and resist - all necessary actions toward empowerment and the formation of personal and professional identity (Rose, 1997). Teachers who are willing to subject themselves to alternative possibilities from constituencies both inside and outside of the profession can then reflect independently upon issues that are relevant to their practice.

Teachers reflecting in the dialectic orientation may also consider issues of cultural replication and social repression. These teachers' goals are to create justice and equity in both educational and political arenas. Questions that may arise in the dialectic mode 
include "how can I help students to liberate themselves from cultural oppression?" and "how do institutions such as the school replicate the status quo?" Kemmis (1985) points out the need for a dialectical process in the development of reflective practice:

Reflection is an action-oriented process and a dialectical process; it looks inward at our thoughts and processes and outward at the situation in which we find ourselves. It is a social process, not a purely individual process in that ideas stem from a socially constructed world of meanings (p. 145).

The dialectic approach to reflective practice questions the prevailing discourse and accepts the possibility there are numerous solutions to problems.

\section{Benefits of Reflection}

The merits of adopting a reflective practice are at the heart of the objectives for this study. In this section, the benefits of using a reflective process will be highlighted as explained by the experts in the field. The benefits received from a teacher using a reflective process can be divided into two broad categories: 1) gaining professional and personal knowledge; and 2) changing/improving teaching practice.

\section{Gaining Professional and Personal Knowledge}

Reflection is a learned activity that informs professional knowledge (Griffiths \& Tann, 1992; Holt-Reynolds, 1992; Hunsaker \& Johnson, 1992; Emery, 1996; Valli, 1997). Teachers can identify and acknowledge the values, beliefs, attitudes, and special knowledge that are brought to an individual practice through a reflective process. Enabling teachers to be conscious of their practice has been recognized as an asset of reflection (Dewey, 1933; Cruickshank, 1980; Ross, 1989; Wildman, Niles, Magliaro, \& McLaughlin, 1990; Brubacher, Case, \& Reagan, 1994; Brookfield, 1995). Through a reflective practice, teachers are freed from impulsive, routine behavior. Then, teachers 
can learn to speak about their practices in a way that is authentic and consistent, thus helping them to find their own voices. Authentic teaching results from an educator's awareness of the different voices that have helped form the practice, and then blending those voices into an individual voice.

The professional knowledge gained through reflection can lead to greater clarity of the culture of the classroom. When teachers are encouraged to develop a habit of reflection, they are more able to conceptualize and explain their classroom practices (Schon, 1987; Yinger, 1990). If a student or a colleague questions a teacher about a curricular issue, the teacher can defend the action based upon certain assumptions, both theoretical and experiential. These assumptions can be questioned, understood, and realized through a reflective practice.

Zeichner and Liston (1987) believe that encouraging beginning teachers to develop reflective habits does not aim to correct or change their behavioral patterns but rather to help teachers become more aware of themselves and their environments in a way that changes their perceptions of what is possible. A reflective practice enables teachers to look at fundamental questions of what they want students, teachers, and schools to accomplish. Reflective teachers are then aware of the choices that they have for developing their practice. In a cyclical construct, new choices stem from new pieces of knowledge.

On an intrapersonal level, critical reflection grounds teachers emotionally. It keeps them from weighing every action as either confirming brilliance or underscoring failure. The teachers are able to view their classrooms as less chaotic as they explore the possibilities of students' behaviors and attitudes. Critically reflective teachers who 
systematically examine how their students are experiencing learning know that much student resistance is socially and politically created (Brookfield, 1995). Through reflection, teachers learn to stop blaming themselves for the hegemonic discourse and to develop a more accurate understanding of the political and cultural limits that can be placed on their practice.

The nature of the reflective process is for teachers to be always evolving on both professional and personal levels. Critically reflective teachers believe that good teaching is a continuous study of reasoning processes and pedagogic actions, as well as the origins and consequences of those actions. Reflective teachers acknowledge that they are never fully finished products professionally or personally.

\section{Changed/Improved Practice}

The benefit of changing or improving a teaching practice by employing a reflective practice is strongly supported in the literature (MacKinnon, 1987; Knoblauch \& Brannon, 1988; Rose, 1997; Valli, 1997; Wood, 2000). Reflective teachers have the opportunity to think about their teaching behaviors and the context in which they occur. Through the cycle of looking back on events, making judgments about them, and then altering their practice based on craft, research, and ethical knowledge, teachers can effectively change their practice. Teachers who engage in this process of cyclical reflection are more likely to consider new pedagogical treatments, curricular approaches and/or democratic practices. 
Improved practice can develop into a characterization of expertise. Breiter and Scardamalia (1993) define an expert teacher as someone who will approach teaching as the constant search for new ways in which teaching challenges may be addressed. They explain the development of an expert as follows:

Our conjecture is that in order to be experts, people must choose to address the problems of their fields at the upper level of the complexity they can handle, for it is through such working at the upper edge that people develop the deep knowledge that makes expert performance possible. (p. 20)

According to Bereiter and Scardamalia (1993), the expert is formed through the qualities of being open and reflective. Reflection is a purposeful, conscious act that can assist in the development of an effective teacher.

An ongoing habit of reflection will enable a teacher's practice to be more responsive to students' needs as well. Modeling intellectual inquiry and democratic processes is beneficial to all students. A critically reflective teacher activates the classroom by providing a model of passionate skepticism (Brookfield, 1995). Classrooms that incorporate critical inquiry will be challenging and stimulating for students.

\section{Barriers to Reflection}

Teachers who choose to become reflective practitioners may have some challenges along their reflective journey. The obstacles that may be encountered are divided into the following categories: cultural barriers, issues of time, personal risk, and motivation. These problematic encounters will be discussed based upon theory and practice as well as related studies. 


\section{Cultural Barriers}

Three cultural barriers to reflection exist according to Brookfield (1995). These three barriers are: the culture of silence; the culture of individualism; and the culture of secrecy. The culture of silence is portrayed when teachers infrequently discuss among themselves the meaning that teaching has in their lives and the importance it has for their students. Teaching is often understood as a secluded activity conducted in private spaces. Related to the first barrier is the barrier involving a culture of individualism. This culture exposes how time, space, and money are denied for teacher collaboration. Teachers in the United States work in isolation (Lortie, 1975; Rosenholtz, 1989). Peers rarely observe one another for the purpose of improving classroom practice. Choral music teachers are even more isolated as they are usually the single teacher in the building in that discipline. This emphasis on isolation is damaging both psychologically and pedagogically for teachers. Teachers need to use the expertise of others in their field as opposed to relying heroically on their own individual capabilities. The culture of secrecy, the third barricade of reflection, involves the reluctance of a teacher to disclose their weaknesses, uncertainties, and frustrations. To avoid this barrier a school culture would be willing to provide an atmosphere of trust to lead teachers to self-disclosure. This behavior of disclosure needs to be modeled by those in power, specifically by principals. Principals who are willing to admit that they do not have all the answers are able to generate a sense of openness among their subordinates. Their actions can thus create a culture that supports a reflective practice. 
The importance of support within the culture of the school is acknowledged in the writings of Smyth, 1992; Valli, 1992; and Humphreys and Suzak, 2000. A school community that values a teacher's reflective practice will encourage communication, dialogue, and mentoring among colleagues and will allow time and professional development opportunities for reflective growth. However, the research reveals that the hierarchical control that exists within schools discourages the risk-taking element of reflection (Wildman, Niles, Magliaro, \& McLaughlin, 1990; Russell \& Munby, 1992). A teacher's reflection on current teaching frames is likely to be based on a strategy for dealing with what that teacher sees as an institutional imperative. This implies that there needs to be changes in the institution as well. Barnes (1992) points out that until it becomes possible to find rewards for becoming a reflective practitioner within the school system, schools are unlikely to become reflective institutions.

\section{Time Barrier}

The perceived lack of time is a major constraint to reflection. Classrooms are indeed busy places with elementary teachers engaged in as many as one thousand interpersonal interchanges each day (Jackson, 1990). There is a flurry of activity based on the crowded condition of the classroom as well as the continual pressure to cover a specified curriculum. Although choral curriculums are not often specified, the pressure to perform, as well as the number of students a choral teacher encounters, impacts issues of time. It is not uncommon for a choral teacher to have large numbers of students, perhaps up to 80 or more, in a rehearsal. The time-related effects of a choral practice include 
additional rehearsals and increased opportunities for interactions with students and parents. The demands of the teaching profession make opportunities to "stop to think" challenging to find.

The dynamics of collaboration involve the issue of time with additional complications. There is the obvious challenge of two or more teachers finding a common time to engage in a collaborative process. Collaborative meeting times must be long enough to allow the teachers to think aloud, to verbally stumble, and reframe educational issues (Pugach \& Johnson, 1990). Patience is required in modeling a reflective process for a peer. Collaboration over an extended period of time is also needed for colleagues to develop a level of trust enabling them to fully explore their ideas and beliefs about teaching (Emery, 1996). Perseverance and dedication to the philosophy of a reflective practice is demanded of collaborative teachers.

\section{Personal Risk Barrier}

Another roadblock to reflection is that it involves personal risk. The questioning of a practice requires teachers to be open to an examination of beliefs, values, and feelings about which there may be great sensitivity (Peters, 1991). What if they do not like what they see? Uncomfortable feelings that a teacher may not want to arouse may occur when aspects of a practice are questioned. The experience of critical reflection can even involve a return to childlike emotional states. Teachers can become frightened when old certainties are lost (Brookfield, 1995). A teacher needs a reasonable level of maturity, mental stability, and self-esteem to be able to reflect candidly and effectively. 
Brookfield (1995) identifies four specific personal risks associated with critical reflection that can act as barriers against becoming a reflective practitioner. The first risk is the fear of being found out as a teacher who really does not know what that teacher is doing. This is called the imposter syndrome. Secondly, teachers risk exclusion from the communities that support them by being known as subversive troublemakers. The third risk involves losing innocence caused by letting go of the prospect of finding final or singular solutions. Finally, the fourth risk involves the fear of being left in a terrifying state of limbo. The reflective process can be frustrating due to its slow and incremental nature.

\section{Motivation Barrier}

What is the motivation for a teacher to develop a reflective practice? According to Lanier and Little (1986) research indicates practicing teachers have low expectations for their professional knowledge or improvement of practice:

The desire for serious and continued learning for improvement purposes is understandably low in light of growing declines in extrinsic and intrinsic rewards for the occupation of teaching itself. Further, aspirations to employ new understandings and intellectual insights while remaining in teaching are often perceived as dysfunctional because opportunities to exercise informed judgment, engage in thoughtful discourse, and participate in reflective decision making are practically nonexistent as teaching is presently defined (p. 542).

There is little incentive for a teacher to break away from habits and routines in hopes of advancing a teaching career. Changes in teaching positions are typically lateral moves. In terms of financial motivation, although there is some compensation for graduate study granted at specific levels, a teacher's salary is most closely tied to the number of years of experience rather than merit related to an improved practice. Tenure 
in the public school system can also stifle growth in a teaching practice. Very few choral teachers venture to the college level due to the higher education needed and because of competition for tenured jobs.

In conclusion, most teachers do not have the opportunity, encouragement, or resources to take the time to really think about how, what, and why they are teaching. However, the research already performed has concluded that the benefits of adopting a reflective practice are many. Any barriers that may be encountered by the choral teachers in this study will be made evident in the narrative stories in Chapter 4 and the highlighted findings in Chapter 5.

\section{Conclusion}

The idea of a reflective process as part of the discourse of teaching has become a trademark in the field of education. The "reflective practitioner" permeates the rationale and practice of over $70 \%$ of professional programs in school teacher education (Furlong, 1995). Several reasons, which are suggested by Valli (1992) and supported by this review of literature, explain the trend in nurturing a reflective practice in teacher education programs: 1) the attention given to the moral and political foundations of the educational process, along with increasing voices heard from feminists, multiculturalists, and critical theorists (Tom, 1984; Liston \& Zeichner, 1987; Valli, 1990; McLaren, 1993; O’Toole, 1994; Brookfield, 1995; Lather \& Smithies, 1997); 2) the concern about teacher empowerment and professsionalization (Zeichner, 1987; Miller, 1990; Wellington \& Austin, 1996; Rose, 1997); and 3) the increased interest in ethnography and action research (Kemmis, 1985; Wolcott, 1988; Van Manen, 1990; Gore \& Zeichner, 1991; LeCompte \& Preissle, 1993; Erickson, 1994; Smits, 1994; Dinkelman, 1997). However, 
in the world of choral music education, many practicing teachers have not been challenged to explore the possibilities of reflection and therefore, have not adopted reflective strategies to improve their practice.

The teachers in this study will learn to be reflective practitioners and will be encouraged to stay committed to monitoring and improving their own classroom practices. They will adopt various methods for accomplishing these goals. In order to be immersed in reflective practice, the following underlying assumptions need to be made (Holly, 1989): teaching is inquiry; conscious reflection and deliberation concerning students, curriculum, oneself, and the profession are inherent in professional practice; inquiry, curriculum development, analysis, and evaluation are inextricably related, ongoing, personal, professional, and collegial; supporting learning and development in others can best be done by those who are engaged in similar processes of collaboration; and continuous transformation and growth is enhanced by gaining distance from practice and exploring different dimensions of experience from different points of view.

These teachers will be developing a reflective practice as a means of professional growth. The discourses of action research, professional growth, and reflective practice are linked in Osterman and Kottkamp's "credo for reflective practice" (1993) in their statement that teachers: need professional growth opportunities; want to improve; are capable of assuming responsibility for their own professional growth and development; need and want information about their own performance; and will benefit from collaboration. These foundational assumptions related to engaging in a reflective practice serve as a philosophical framework that will guide the teachers in this study. 
This study will attempt to challenge the teacher to consider the reconstruction of day-to-day teaching practices through constructive dialogue and narrative analysis. Pedagogy, curriculum, and issues of a personal and professional nature will be areas for reflection. Critical theory is another important aspect of this reflective process. Critical inquiry examines the conditions of life in the classroom in order to see how beliefs, goals, and practices are changed and affected by the influences of ideology, institutional structures, and political constraints. In this study, teachers will be encouraged to use a reflective process so that they can become aware of the similarities and disparities between their own values and beliefs and the dominant social and institutional norms that govern their practice. A goal for this study is that a reflective process will bring new professional and personal understandings to each of these choral educators.

The abundance of writings and research performed on reflection in the educational discourse indicates that it is considered an important dimension of a teacher's practice. Reflection in and on practice has been used to mold individual practice as well as direct and revise programs of teacher education. The research has revealed that the facilitation and conditions of reflection as well as a teacher's attitudes and feelings influence the content and process of reflection. Through the implementation of various reflective methodologies, reflection has been shown to increase understanding of self, practice, and related educational issues. This study will offer the participants the opportunity to increase such understandings through various reflective vehicles as well. 


\section{CHAPTER 3}

\section{METHODOLOGY}

\section{Theoretical Framework}

\section{Qualitative Inquiry}

The focus of the research question determined the type of inquiry utilized in this study. Qualitative inquiry is the umbrella concept under which multiple approaches, methodologies, and interpretive practices can be applied for the purposes of capturing the human point of view, the constraints of every-day life, and the meaning in the lives of individuals. According to Denzin and Lincoln (1994), qualitative research is involved in an interpretive, naturalistic approach to its subject matter. Qualitative researchers are attempting to understand a phenomenon in a natural setting. The thrust of this study was to understand what the teacher experiences in the choral classroom as related to the effects of a reflective practice and therefore, calls for the use of qualitative inquiry. Interpretive Paradigm

The interpretive paradigm is a specific philosophical delineation under the qualitative discourse that served as the foundation of this study of the reflective processes of five choral teachers. The ontology of the qualitative branch reveals that individuals who are interacting with their social worlds construct their reality. The interpretive researcher is interested in understanding the meaning that people have constructed. Meaning is embedded in peoples' experiences and this meaning is mediated through the 
researcher's own perceptions (Merriam, 1998). The interpretive paradigm involves the description of a phenomenon and includes the exploration of "the meaning-perspectives of the particular actors in the particular events" (Erickson, 1986, p. 21). Interpretive research requires a multi-focused, rigorous, and systematic approach to field experiences in order to understand the phenomenon studied. However, it is important for the design to remain sufficiently open and flexible to permit exploration of whatever the phenomenon under study offers for inquiry. Qualitative designs continue to be emergent even after the collection of data begins (Patton, 1990). Methods for the study of personal experience need to simultaneously focus inward, outward, forward, and backward (Clandinin \& Connelly, 1994). Multiplicity and flexibility in methodology are necessary components of research performed within the interpretive paradigm. The process of this study continually evolved as the teachers provided input concerning meaningful ways to reflect through dialogue and the written word.

\section{Constructivist's Perspective}

The constructivist's perspective is rooted in the philosophy that the knowledge of the world is a reflection of what is perceived as being reality. Meaning is constructed rather than discovered and knowledge is a result of active rather than passive knowing (Stegman, 1996). Constructivism is in opposition to scientific objectivity, which is defined as the accurate representation of the way the world is (Schwandt, 1997). One of the assumptions underlying qualitative research is that reality is multi-dimensional and ever-changing; it is not a single, fixed, objective phenomenon waiting to be discovered as 
in quantitative research (Merriam, 1998). The triangulation of methods over time enabled the researcher to observe and find meaning in the transient nature of the participants, their teaching practices, and their reflections.

\section{Qualitative Case Studies}

Qualitative case studies are prevalent throughout the field of education (Merriam, 1998). A case is explained as a single entity; a unit with boundaries occurring within a context. Various methods of gathering data are appropriate in case study work. Case study analysis is appropriate for intensive, in-depth examination of one or a few aspects of a given phenomenon (LeCompte \& Preissle, 1993). The case study can be further delineated by three features: particularistic; descriptive; and heuristic (Merriam, 1998). Particularistic refers to the focus on a particular phenomenon. In this study, each teacher represents a separate phenomenon being examined within the boundaries of the affects of a reflective practice. Descriptive implies that the end product of a case study includes a rich, thick description of the phenomenon under study. The stories of each of the participants is revealed in a detailed, contextualized presentation. The heuristic quality is the illumination brought forth through the findings of the study. The discovery of new meaning, an extension of the reader's experience, or the confirmation of what is known are the possible revelations derived from the case study under the heuristic domain.

Descriptive case studies are explained as "atheoretical" as they move in a theoretical vacuum. They are neither guided by established generalizations nor motivated by a desire to formulate general hypothesis (Lijphart, 1971). Rather, case studies assist in the comprehension of the range or variety of human experience that is essential for understanding and appreciating the human condition (Abramson, 1992). Clark and 
Lampert (1986) further assess the attributes of descriptive (interpretive) studies in the educational setting in their statement, "The analysis of descriptive case studies ground and illustrate how abstract principles of learning and instruction look and operate in context, that is, in particular situations rather than in the mythical average situation" (p. 29). This research, which serves as a multiple case study, is anchored in real-life choral settings with the purpose of understanding the process of reflection as experienced by five teachers.

\section{Phenomenology}

This study also included some of the distinctive characteristics of the interpretive work of phenomenology. Although the researcher plays a role in assisting the teachers to describe through reflection their theories about teaching, the teacher's ways of knowing are still largely constructed from multiple realities of setting, beliefs, and social conditions (Gaumer, 2000). The experiences each teacher had as a student; the educational methods, themes, philosophies, and insights from pre-service programs; interactions with colleagues; the degree to which the school culture provides support and encouragement; and the daily teaching experiences are among the external influences that formulate a teacher's habits of mind and pattern of classroom practice (Goodlad, 1984; Rosenholtz, 1987; Sergivanni, 1996). The connections and internalizations of these experiences form the educator's theory of teaching practice. Therefore, a phenomenological approach, which "emphasizes that the meaning of reality is the way

the individuals being studied perceive their experiences," (Wiersma, 1995, p. 250) was an appropriate theoretical frame for this study. 


\section{Ethnographical Approach}

Some of the data collecting methodologies were centered in an ethnographic approach. Ethnography's emphasis on firsthand field study was relevant to this research even though this study was not an ethnography. Because I chose to become immersed in the natural setting of each teacher, as well as develop a rapport and empathetic relationship with each of them, the philosophical foundations of ethnographic research were present in this study. Wolcott (1988) delineates four ethnographic research techniques that were used in my study: participant-observation; interviewing; use of written sources; and the analysis of non-written sources as important pieces of data to increase understanding of the reflective process.

\section{Research Design}

Overview

This study involved five middle/high school choral teachers who agreed to engage in a reflective process for nine weeks; the approximate time it takes to prepare a concert from beginning to end. The nine-week time period was from January 7 through March 9, 2002.

The teachers were observed by the researcher, used various written reflective tools, and engaged in constructive dialogues with the researcher and the other participants. The choral students of the participating teachers shared their perceptions of the choral experience and their individual teachers as well. All of these data-gathering techniques were employed to create stories that would illuminate the reflective journeys of each of the teachers and shed light on the research questions. 


\section{Research Questions}

This research study began with the question "How does engaging in a reflective process over time affect choral teachers?" The related sub-questions are as follows:

1. How does engaging in a reflective process affect a teacher's consideration of new pedagogical, curricular, personal/professional, and/or critical approaches?

The reflective journals and constructive dialogues were the methodologies used to illicit responses to this question.

2. How does the notion of problematizing a person's practice affect each teacher?

Both the journals and constructive dialogues assisted in constructing this information.

3. What are the unique factors that affect the reflective process in a choral classroom?

Reflective journals, constructive dialogues, and the peer collaboration meetings were used to gain insight into this question.

4. How does a teacher's life history, current phase of development, and specific teaching assignment affect the reflective process?

The autobiographical and reflective narratives, as well as the teacher's reflective journals and constructive dialogues addressed these issues.

5. How are teachers empowered to act upon their reflections?

The reflective journals and constructive dialogues were used to gather this information. The responses to these questions will be addressed in the summary of the document. 


\section{Participants}

The participants were five central Ohio choral teachers at the middle and high school levels. One other teacher participated at the beginning of the study, but later withdrew due to personal reasons. These teachers exhibited the following characteristics in order to be selected for this study: a passion for teaching and learning; interest in developing reflective habits; and commitment to lifelong learning. As all of the barriers to reflection indicated in the previous chapter, a teacher who is not willing to work diligently would likely find the rigors of this study extremely difficult. As the choral world is a small community, all of the participants were at least recognizable names to me. Two of the participants were known to me before the study: one was a former student of mine, in her first year of teaching, and the second was a colleague from graduate school with whom I have also been working in the capacity as his choral accompanist. For the three teachers I did not know personally prior to the study, I made contact with respected choral colleagues who knew the potential participants in order to verify that there was a passion for teaching and learning. Interest in developing a reflective practice was determined through my own questioning of each participant. A commitment to lifelong learning was indicated by a track record of professional development for the four experienced teachers and the willingness to participate in this research. 
The criteria for selection included the factors of convenience, access, and willingness of participants. The practicalities of choosing participants within a practical driving distance as well as those who express a desire to be in the study explains their involvement in the study. I was not looking specifically for the quality of "excellence" as this is problematic in its definition and determination.

The students of these five teachers also participated in the research by generating data via journal entries. I, as the researcher, was also a participant in the study in the sense that I critically reflected upon my interactions with these five choral teachers and my own theories of the teaching of choral music. My voice is part of the stories of these teachers as well.

\section{Solicitation of Participants/Gaining Access/Informed Consent}

I solicited the teachers' participation by first speaking to them by phone, e-mail, or personal contact using a specified script/solicitation letter (Appendix A). It was essential that the participants knew the expectations in the study. These expectations were presented both verbally and in writing. Once a teacher had indicated interest, we met in that teacher's school environment. Each participant was verbally briefed by the researcher and presented in writing the following information: 1) the purpose of the study; 2) risks involved in the study, which may include the discomfort of analyzing a teaching practice and the loss of time for other facets of life; 3) general procedures of the study; 4) demands upon participants' time in the study; 5) timeline of the study; 6) confidentiality concerning and anonymity of participants in the study, which included the use of pseudonym names (however, the five participants would know each other and would be intertwined in the reflective process via the two group meetings); 7) rights of 
participants in the study which included that the participant is acting in a voluntary role and may withdraw at any time without penalty; 8) the phone numbers of the principal investigator and the advisor; and 9) benefits of the study to the participant and the profession. Once both parties were in agreement to working together in this study, I asked each teacher to sign a permission slip/contract (Appendix B) indicating consent to be in the study. This contract was provided by the Office of Research Risks Protection, which granted permission for the study (Appendix H). The participants were told that they could withdraw at any time throughout the research process.

After each teacher agreed to be a participant, I contacted the school principal and explained the purpose and methodology of the study. I assured the principal that the teacher would be in control of the curriculum and students. The principals were given copies of the teacher solicitation letter (Appendix A) and the student solicitation letter (Appendix C). Students and parents/guardians were given solicitation letters (Appendix C) and permission slips (Appendix B) so that both parties could give consent to the possible use of a student journal in the narration of data.

\section{The Role of the Participants}

Permission by the teachers was needed to observe the rehearsals. The five choral teachers were asked to keep reflective journals, write an autobiographical narrative (Appendix D), and to complete the reflective narrative exercises (Appendix E). Following the teacher's rehearsal in which I was present, the teacher and I reflected upon what occurred, possible changes for the future, and other pertinent topics using 
constructive dialogue. Constructive dialogue is an intentional conversation to which two or more parties consent for the purpose of bringing to light any aspects of the teacher's practice.

After initiating the reflective process, each teacher was invited to select a facet of the practice that the teacher would like to explore for the purpose of improved practice. The primary goal of the study was not to assure change, but rather, to understand how the process of reflection may affect the choice of the issue and the course of change.

The teachers were required to attend one large group and one small group meeting. The large group meeting was held with all of the participants one week prior to the beginning of the data collection process. It served as the vehicle for the preparation of the teachers for the research methodology by having them become acquainted with one another, discuss the process of the study, read a reflective narrative, and be assigned the autobiographical narrative (Appendix D). I held two small group meetings in which three participants attended the first one, and two attended the second halfway through the study in order to engage the participants in constructive dialogue. These meetings also included informal mentoring among participants as well as the sharing of ideas. During these meetings the teachers gave feedback and offered suggestions as related to the study, as well as listened to each other to show collegial support. The researcher asked questions related to the research process.

The role of the students in this research was to write one journal entry (Appendix $\mathrm{H})$ at the end of the nine weeks concerning various aspects of the choral program in which they participated, information about the choral teacher, and any change they have 
noticed in the choral teacher and/or the practice. The teachers and the researcher together designed the specific questions to be asked of the students. Feedback from the students was used to stimulate reflection for the teachers about their teaching practice.

My role in this research was three-dimensional: a colleague, a researcher, and a critically reflective teacher. In the capacity of colleague, my goals were to listen, share, and guide as requested. In a personal role, I worked to build a relationship of friendship and caring as well as become critically reflective.

As the researcher, I facilitated the process of the study by observing rehearsals, collecting field notes, initiating constructive conversations, and sharing data with the participants. I closely examined the procedures of this study as well as reflected upon my interactions with my participants. My role in this study was constantly shifting between colleague and researcher as the teachers became more comfortable being involved in the study. As a critically reflective teacher, I looked at my own philosophy of what comprises excellent teaching, my strengths and weaknesses as a teacher, and what my own personal and professional needs are as a choral teacher. 


\begin{tabular}{|c|c|c|c|}
\hline WEEK & TEACHER & RESEARCHER & STUDENT \\
\hline $\begin{array}{l}\text { Before the } \\
\text { study }\end{array}$ & $\begin{array}{l}\text { Attend meeting } \\
\text { Write Autobiographical } \\
\text { Narrative }\end{array}$ & $\begin{array}{l}\text { Host meeting } \\
\text { Read Autobiographical } \\
\text { Narratives }\end{array}$ & \\
\hline Week 1 & $\begin{array}{l}\text { Write daily reflection } \\
\text { Group A is observed, } \\
\text { interviewed and given } \\
1^{\text {st }} \text { assignment -"Past } \\
\text { Choral Experiences" }\end{array}$ & $\begin{array}{l}\text { Observe and interview } \\
\text { Group A } \\
\text { Read reflective journals } \\
\text { Write field notes } \\
\text { Write journal entry }\end{array}$ & $\begin{array}{l}\text { Meet researcher and } \\
\text { learn about study } \\
\text { (Group A students) }\end{array}$ \\
\hline Week 2 & $\begin{array}{l}\text { Write daily reflection } \\
\text { Group B is observed, } \\
\text { interviewed and given } \\
1^{\text {st }} \text { assignment -"Past } \\
\text { Choral Experiences" }\end{array}$ & $\begin{array}{l}\text { Observe and interview } \\
\text { Group B } \\
\text { Read reflective journals } \\
\text { Write field notes } \\
\text { Write journal entry }\end{array}$ & $\begin{array}{l}\text { Meet researcher and } \\
\text { learn about study } \\
\text { (Group B students) }\end{array}$ \\
\hline Week 3 & $\begin{array}{l}\text { Write daily reflection } \\
\text { Group A is observed, } \\
\text { interviewed and given } \\
2^{\text {nd }} \text { assignment - } \\
\text { "Knowing Your School } \\
\text { Community" }\end{array}$ & $\begin{array}{l}\text { Observe and interview } \\
\text { Group A } \\
\text { Read reflective journals } \\
\text { Write field notes } \\
\text { Write journal entry } \\
\text { Read Group A 1st } \\
\text { assignment }\end{array}$ & \\
\hline Week 4 & $\begin{array}{l}\text { Write daily reflection } \\
\text { Group B is observed, } \\
\text { interviewed and given } \\
2^{\text {nd }} \text { assignment - } \\
\text { "Knowing Your School } \\
\text { Community" }\end{array}$ & $\begin{array}{l}\text { Observe and interview } \\
\text { Group B } \\
\text { Read reflective journals } \\
\text { Write field notes } \\
\text { Write journal entry } \\
\text { Read Group B 1st } \\
\text { assignment }\end{array}$ & \\
\hline Week 5 & $\begin{array}{l}\text { Write daily reflection } \\
\text { Attend small group } \\
\text { meeting - "Excellent } \\
\text { Teacher Attributes" } \\
\text { exercise, share ideas, } \\
\text { discuss research process }\end{array}$ & $\begin{array}{l}\text { Organize small group } \\
\text { meetings } \\
\text { Read reflective journals } \\
\text { Write field notes } \\
\text { Write journal entries } \\
\text { Read narratives written } \\
\text { at small group meetings } \\
\text { Read Groups A \& B 2 } \\
\text { assignment }\end{array}$ & \\
\hline Week 6 & $\begin{array}{l}\text { Write daily reflection } \\
\text { Group A is observed, } \\
\text { interviewed, and given } \\
3^{\text {rd }} \text { assignment } \\
\text { - "Reflective Inventory" }\end{array}$ & $\begin{array}{l}\text { Observe and interview } \\
\text { Group A } \\
\text { Read reflective journals } \\
\text { Write field notes } \\
\text { Write journal entry }\end{array}$ & \\
\hline
\end{tabular}

Table continued 
Table 1 continued

\begin{tabular}{|c|c|c|c|}
\hline Week 7 & $\begin{array}{l}\text { Write daily reflection } \\
\text { Group B is observed and } \\
\text { interviewed, and given } \\
3^{\text {rd }} \text { assignment - } \\
\text { "Reflective Inventory" }\end{array}$ & $\begin{array}{l}\text { Observe and interview } \\
\text { Group B } \\
\text { Read reflective journals } \\
\text { Write field notes } \\
\text { Write journal entry } \\
\text { Read student journals }\end{array}$ & \\
\hline Week 8 & $\begin{array}{l}\text { Write daily reflection } \\
\text { (include reactions to } \\
\text { student journals) } \\
\text { Group A is observed } \\
\text { and interviewed }\end{array}$ & $\begin{array}{l}\text { Observe and interview } \\
\text { Group A (summarize } \\
\text { experience) } \\
\text { Read reflective journals } \\
\text { Write field notes } \\
\text { Write journal entry } \\
\text { Read Group A } 3^{\text {rd }} \\
\text { assignment } \\
\text { Read student journals }\end{array}$ & $\begin{array}{l}\text { Group A students write } \\
\text { journal entry }\end{array}$ \\
\hline Week 9 & $\begin{array}{l}\text { Write daily reflection } \\
\text { (include reactions to } \\
\text { student journals) } \\
\text { Group B is observed and } \\
\text { interviewed }\end{array}$ & $\begin{array}{l}\text { Observe and interview } \\
\text { Group B (summarize } \\
\text { experience) } \\
\text { Read reflective journals } \\
\text { Write field notes } \\
\text { Write journal entry } \\
\text { Read student journals } \\
\text { Read Group B } 3^{\text {rd }} \\
\text { assignment }\end{array}$ & $\begin{array}{l}\text { Group B students write } \\
\text { journal entry }\end{array}$ \\
\hline
\end{tabular}

Table 1: Data Gathering Schedule

\section{Data Gathering Techniques}

Data collection techniques can be divided into three major categories:

experiencing, enquiring, and examining (Wolcott, 1992). Experiencing includes the observation of activities, people, and physical aspects of a situation, and the engagement in activities that provide useful information. Enquiring occurs when the researcher or peer mentor poses some form of a question. Examining refers to the use of data that is written: journals and narratives. Each of these categories was included in the process of 
data gathering. By triangulating the methodology, teachers were able to think about and discuss the full spectrum of issues in their reflections. Triangulation was also achieved through the three voices that were heard in the study; the participants, the students, and the researcher. Each voice gives a unique story that creates a multitude of realities in the narrations.

\section{Observation}

I observed one rehearsal of each teacher bi-monthly for nine weeks (four observations per teacher). The content of the rehearsal, teacher behaviors, and specific areas requested by the teacher comprised the focus of the observation. Notes were then transferred into field notes based upon my observations. Those field notes were made available to the teachers via E-mail. The teachers were then given the opportunity to expand, change, deny or confirm the field observations. The field notes also became an object of reflection for each teacher.

\section{Constructive Dialogues -- Interviews and Peer Collaboration Meetings}

In this study, the researcher and the teachers worked together during constructive dialogues, which can be understood as conversations with intent. The purpose of these constructive dialogues was to encourage the teacher to reflect deeply and openly about teaching theories and classroom practices, to challenge assumptions that support those theories, and to construct new ones. Two types of constructive dialogues were employed in this study; a semi-structured interview between the teacher and the researcher, and a semi-structured group interview/peer collaboration meeting between the teachers and the researcher. 
The first type was a semi-structured interview between the individual teacher and researcher that took place immediately following each of the four observed rehearsals. In the semi-structured interview, a balance was established between the researcher and the teacher, therefore providing room for negotiation, discussion, and expansion of responses (Stewart \& Cash, 1982; Hitchcock \& Hughes, 1989). It was important in the interview process that an atmosphere of comfort and support for the teacher, and the gathering of information pertinent to the research question were created (Seidman, 1991; Fontanya \& Frey, 1994). The semi-structured interview following the rehearsals included questions based on the successes and challenges of the rehearsal as well as emergent questions on specific aspects of the rehearsal, the process of the study, or pertinent issues of the individual teacher. There was an additional follow-up interview at the end of the nine weeks that was not preceded by an observation. The focus of that last interview was on the teacher's reactions to the student journals, a summary of the reflective process and the study, and individual issues. How the teacher's practice was affected by the reflective process as understood by the participant and then revealed to the researcher in these interviews became a valuable part of the data. These constructive dialogues were audiorecorded in most cases. If they were not recorded, then notes were made during and following the dialogue. Transcriptions of the audiotapes were made usually within a week of the interview by a professional transcriber and then given to the participants for member checks.

The second type of constructive dialogue was a semi-structured group interview/ peer collaboration meeting between the teachers and the researcher. Three of these constructive dialogues were held with each participant taking part in the entire research 
team meeting held at the beginning of the study and one of two small group meetings. Notes were taken during and after the interview/peer collaboration meetings. During these constructive dialogues, the participants examined the progression of the study and conversed about emergent issues related to their teaching.

Teacher Written Reflective Journals

In this study, the teachers had the following formats of written reflective journals from which to choose: the Critical Incident Questionnaire; Smyth's critical questions; an unformatted reflective journal; and the dialogue journal. The suggested format for the teachers' reflective journals during weeks one and two was to focus on specific incidents that occurred during rehearsals. The vehicle used was the Critical Incident Questionnaire (Brookfield, 1995, p. 115). Critical incidents are vivid happenings that people remember as being significant (Tripp, 1993). Teachers were asked to describe the following three critical moments: 1) the most engaging (best teaching moment); 2) most disappointing (worst teaching moment); and 3) the most puzzling moment. Answers to these three questions might provide the teachers specific incidents to reflect upon and could open the door to conversation with their peers or me. It gave the teachers the opportunity to focus on elements of their practice that they feel were successful and those elements that may need improvement.

Questions designed by Smyth (1992) were the suggested focus for the journal writing during weeks three through nine. These questions are embedded in a critical pedagogy. Teachers were asked to concentrate on those aspects of their teaching that 
perplex, confuse, or frustrate them. I asked them to answer the following questions:

1) describe -- what do I do? 2) confront -- how did I come to be like this? and 3)

reconstruct -- how might I do things differently?

These two formats, the Critical Incident Questionnaire and Smyth's three key questions, were suggested to the teachers in order to give them a prescribed and sequential approach to organize reflections concerning their practice. The teachers were told that they could overlap the methodologies or deviate from the exact format in their journal writing. The weekly format was to provide them with a guideline that might move them from a simple to a more complex, in-depth form of reflection.

The participants had the option of writing in a personal journal about any aspect of their teaching or of this study. The content of the personal journals to be shared with the researcher was left up to the discrepancy of the individual. The remarks in these journals could be emotional responses to daily rehearsals, therefore serving as a cathartic outlet, a summary of events and their effectiveness, or a more analytical, philosophical description of the present and future states of the teacher's practice. The latter form of reflective thought is a movement toward the realm of critical reflection. The form and usefulness of reflective journaling would be an emergent process. The unique path of each teacher's reflection process is an important part of the story to be revealed. These journal entries were to be given to the researcher at various junctures during the data collection period at the discrepancy of each teacher.

The teachers could also choose to take part in dialogue journal writing that would occur via the E-mail. In dialogue journaling, the teacher and I would write back and forth to one another about whatever issues emerged in our individual or collective inquiries. 
This provided a communication tool for the time period in between visits to the school and the meetings. Further, dialogue journal writing contributes to the emancipatory constructs of teacher-as-researcher. The teachers could also choose to use dialogue journal writing with each other.

All of these types of journal writing were provided as options for reflection. Although each teacher was encouraged to try them all at some point during the study, it was important to provide choices so that they could find the vehicle which best suited each one of them.

\section{Student Written Reflective Journals}

The students were asked to journal at the end of the nine weeks to discuss several aspects of the choral program, the choral teacher, and any noticeable changes in the choral rehearsal and/or the choral teacher. In order for the student journals to be meaningful for this study, three conditions were met as suggested by Brookfield (1995): 1) guidelines were given; 2) the students were convinced of the importance of the journals; and 3) the students' efforts were acknowledged. The teachers and I designed the journal format that was to be used by all of the students.

\section{Researcher Written Reflective Journal}

My own personal journal contains my reflections concerning the participants involved as well as the process. Entries were made at least three times weekly on the days that I met with the teachers. It was important for me to reflect on: the progress of the study; my communication with the teachers; the reactions of the teachers to the study; my observations of the congruencies in what I see in their teaching versus their reflections in the interviews; and what new thoughts were emerging concerning my value 
system of choral education. I shared some of my reflections with the teachers when they were beneficial to the study or if they were helpful to the individual teacher. As this was a personal journal, I did not make the entire document available to the participants as I wanted to be able to express all of my thoughts and observations freely.

My own reflections are included in the analysis and narration as they had an effect on my interactions with the teachers and the progress of the study. Throughout the writing process I became aware of what my biases and interests are. Those biases would play a part in the stories of these teachers.

\section{Autobiographical and Reflective Narratives}

These narratives were written by the teachers to provide background information and to reveal their theories of practice. The documents were gathered from the teachers in one of three ways: in a written format; as part of the interview following a rehearsal; or verbally during an interview/peer collaboration meeting. The process of reflection needed to commence with an autobiographical analysis. The most significant and most deeply embedded influences that operate on teachers are the images, models, and conceptions of teaching derived from their experiences as learners (Brookfield, 1995). The autobiographical narrative (Appendix D) focused on an understanding of the personal and educational history of the participant. Another purpose of the autobiographical narrative was to contextualize the teacher within the teaching practice. This narrative also asked philosophical questions concerning the teacher's practice. The areas of retrospection and prospection in relation to the reflective process were incorporated in this narrative. The choral experiences narrative (Appendix E) was a descriptive narrative of the participant's past choral experiences. Teachers summarized both their past choral teachers' persona 
and the rehearsal and performance experiences. The contextualization of the school narrative (Appendix E) asked the teachers to define the historical, social, economic, and political contexts of the school at which they work. Brookfield's (1995, p. 146) reflective inventory (Appendix E) incorporated questions focusing on specific moments or general reflections about the teacher's practice.

\section{Data Analysis}

Analysis of the data in this study was an ongoing process that occurred both during and after the multiple pieces of data were collected. Because this is a multiple case study, there were two stages of analysis that were performed -- within-case analysis and cross-case analysis. For the within-case analysis, each case was treated as a comprehensive entity by itself. Each qualitative case was analyzed individually before the cross-case analysis began. In the cross-case analysis, abstractions were built across cases. The researcher attempted to see processes and outcomes that occurred across the five cases to develop more sophisticated descriptions and more powerful explanations (Miles \& Huberman, 1994). However, the analysis process of both singular cases and cross-cases were performed in the same manner. Common themes and variations based upon the phenomenon of the reflective process were addressed within and cross the cases of the teachers. Therefore, the techniques of the analysis were employed at both levels. As the purpose of this study was to understand how a reflective process affects teaching in the classroom, the format, frequency of entries, and description of the content of the reflective journals were crucial elements in revealing how the teachers and their practices evolved throughout the study. The teachers were able to identify the significance of the various reflection vehicles and discuss the impact concerning how 
these vehicles contributed to the reflective process. I looked for congruency, or lack thereof, between the various journals, field observation notes, constructive dialogues, reflective narratives to understand which reflective vehicles were effective for each teacher's articulation and understanding of their own practice.

I focused on particular themes, issues, or patterns that emerged from the triangulation of all of the data within the framework of each teacher. The following four steps were implemented in order to understand the phenomenon (Denzin, 1989): locate within the personal experience or reflection, key phrases that speak to the phenomenon in question; interpret the meanings of these phrases as an informed reader who knows the teacher and the context of that teacher's practice; obtain the participant's interpretation of these findings; inspect these meanings for what they reveal about the recurring features of the teacher's practice; and make a speculation based on the above factors.

A two-step coding process was employed in the analysis. After reading each piece of data, key phrases were highlighted and a summary word or phrase was written in the right-hand column of the paper. Themes/issues that recurred were determined and categories were indicated above the key phrases. These categories included: pedagogy, curriculum, critical pedagogy, professional development, personal development, feelings, and reflective process.

It was particularly important for me to listen for the dissonances in the data. Points of dissonance are pinpricks in a person's consciousness; they can sting at inopportune moments when a person is most concerned with maintaining a smooth and unruffled teaching experience (Miller, 1990). The data challenged me to directly confront the sources of dissonance that disrupted a sense of balance in the choral teaching 
world. The act of listening to the teachers' frustrations, as well as the moments of excitement and discovery throughout the process, was an important part of the analysis. These moments revealed the values that the teachers held concerning their practice and directed me to look at the congruency of the areas of reflection in both the written and spoken word.

Multiple voices were heard in this study. In addition to the voices of the teachers, the students, and me, were also the voices of past teachers, families, colleagues, and other influential people in these teacher's lives. The recognition of these voices was a critical component to the reflective process of the teachers as well as my interpretations of the meanings of those words. It was necessary to analyze these multiple voices from multiple perspectives; the oral and written journals/narratives of the teacher; the issues and problems the teachers addressed; the personal themes that inform their teaching practice, and the observations and reflections that I examined through various theoretical lenses.

Through the process of critical reflection, the teachers were encouraged to speak about their practice in a way that is authentic and consistent. Teachers who are speaking authentically are alert to the voices inside that are not their own which have been deliberately implanted by outside interests rather than springing from their own experiences. It is a difficult process to decide when and to which voices to listen. The discovery of a teacher's voice amidst the others is a transformative process that lies at the root of the critically reflective process. 


\section{Narrating the Data}

The writing of the stories was undertaken as an ongoing process throughout the study. My goal was to author my own experience and understanding of others as I gathered the data and documented it. Due to the various data collecting methods used, the narration will be presented as a multi-layered representation of knowing. I used interpretive realism to present the combined interpretations. The realist tale attempts to make the participant's world visible. Specifically, in interpretive realism the objective of the narration is to describe those texts where the researcher inserts his/her own personal interpretations into the life situations of the individuals studied (Denzin, 1994). Although story telling reconstructs events in an artificial manner, the narration is as close an approximation to the researcher's understanding as possible. In this study, the narrative presents the material in a format of five short stories. Each story represents the teacher's journey in the quest to grow through reflection. Within these five stories the essence of the teachers' reflections was presented as learned through the various data gathering tools.

A model for my narration was Schoolgirls written by Peggy Orenstein (1994). Orenstein's objective was to understand how schooling affects girls' self-esteem. Orenstein was involved in the lives of each of the female participants and captured the essence of each of the girls' lives through the stories. Orentsein's account reads like a novel, putting the author's observations and the girl's conversations in a context that is visible and understandable. 
Troubling the Angels by Patti Lather and Chris Smithies (1997) also was utilized as a model for the writing of the choral teachers' narratives. The book is actually a qualitative study of women who have AIDS and is presented in a "troubling" format. The voices of the women who have this disease are printed on the top half of each page with the researchers' reflections written on the bottom half of the page. The format of the book shows the layers of reflection by all constituencies occurring in the same space and time, and figuratively represents the complicated lives of these women who have tremendous challenges. This style of presentation was chosen due to its multi-layering effect with references to reflection-in-action of unfolding the stories through the immediate thoughts of the researcher. My reflective thoughts as they occurred are interspersed within the stories of the choral teachers in a similar philosophical presentation to Lather and Smithies' work.

These stories were written to be persuasive, accessible, and finely crafted. The story in itself is an analytical caricature in which some details are sketched in and others are left out. The issue of ethics is a part of the presentation of the stories. Some of the findings revealed areas of weakness in a teacher's practice and therefore, were sensitive issues about which to write. In the quest to increase knowledge and understanding, I needed to be committed to the careful reflection of others by trying to increase benefit and minimize personal hurt. As Bresler points out (1995), researchers should want to cultivate curiosity rather than to blame, and to emphasize strengths and contextual value. The stories told in this narration have been shared with the participants. The intention was to be able to unfold their journeys in a way that provided the teachers some level of comfort. If something was revealed that was extremely hurtful to a participant it was left 
out or expressed in a more generalized manner. The written story does not completely reveal the complex nature of a dialogue or an individual's reflection. It only hopes to captivate the essence of the teacher's journey in adopting a reflective practice.

\section{Methodological Issues}

\section{Reciprocity}

Reciprocity can be defined as give and take, a mutual negotiation of meaning and power (Lather, 1986). In this study reciprocity was created between the participants and the researcher through the collaborative involvement in the development and execution of the study. Lather (1986) suggests that reciprocity takes place when research is used as praxis: for the purpose of empowering the researched by helping them to understand and change their situations. By embracing a reflective practice, teachers may experience change and improvement as the beneficial outcomes from this study. Other possible benefits of this research to the teachers are: making collegial connections; personal growth in risk-taking; and the ability to share with their students their willingness to grow.

In other forms of repayment, I informed the teachers that I would be willing to work with their students during or after the study in any capacity. I also wrote each principal explaining each teacher's cooperation, professionalism, as well as highlights of the reflective journey. Another form of repayment was a luncheon at a fine restaurant.

\section{Researcher as Data Collection Instrument/Self-Disclosure}

Due to the process of observation, field notes, and participant interviews, the researcher is the main data collection instrument in a qualitative study. The field notes should contain everything that the observer believes to be worthy of noting (Patton, 
1990). This statement has implications regarding the researcher's perspective. My own background and personal theory of teaching affected my interactions with the teachers as well as my observations and interviews. My education and experiences were influential in the conduct of this study and specifically in the analysis of the data, formulation of themes, and narration of the teacher's reflective journeys. I shared with them this information so they, too, could be informed concerning my beliefs and biases.

I played the role of an insider in this study because I have been a choral teacher who has developed strong opinions throughout the years about expectations in the choral classroom. My variety of choral teaching experiences as well as my observations of choral teaching has left me with views of a transformed choral discourse. These experiences and opinions influenced my conversations with the participants as well as my writing of their stories. I was also in the position of an outsider in that I was a stranger in their classroom with little contextualization to their teaching practices.

\section{Power Issues}

Because I am from the university, my role as an authority figure could not be discounted completely. There was an inherent power in-balance in this design but it was not my intent to dominate all of the constructive dialogues or make all of the decisions concerning the process. The disparity of power between the scholar and the practitioner will affect the kind of knowledge that can be derived from the study (Erickson, 1994). If I had made all the decisions about the research process and kept my observations to myself, the teachers would have had limited understandings, and therefore, limited power concerning their own paths to a reflective process. Collaboration helped to close the power gap and allowed various ways of knowing to emerge from this study. One of the 
strengths of this study was the collaborative nature of the process that assisted in balancing the power relations. During the peer collaborative meetings, it was presented that each teacher's practical knowledge is valued. Throughout the study, I sought input concerning the integration of the participants' reflections into the narratives. There were methods built into the study that gave the participants an opportunity to explore their reactions to their own practice in a private way. Through the teachers' personal journals, peer constructive dialogues, and dialogue journals, each participant was able to write or discuss issues off the record.

\section{Validity}

The issues of validity and trustworthiness are concerned with the question, how does the researcher know that the data collected accurately gauges what the researcher wants to know? Guba (1981) states that trustworthiness can be addressed by the following characteristics: credibility, transferability, dependability, and confirmability. Credibility was accomplished through the following means: prolonged participation at the site; persistent observation; peer debriefing; triangulation; member checks; and the collection of narratives, journals, and audiotapes received as raw data. Transferability included the collection of detailed description of data.

Dependability was demonstrated by the overlapping of methods and an audit trail. An audit trail enabled the ability to reconstruct the process by maintaining careful documentation of the conceptual development of the study, thereby leaving an adequate amount of evidence. The documentation included in the audit trail was: raw data; data reduction and analysis products; data reconstruction products; process notes, which were 
in the form of the researcher's journal; materials related to intentions, which were also found in the researcher's journal, and instrument development information (Halpern, 1983).

Confirmability refers to the neutrality of collecting the data. It is concerned with the fact that the data and interpretations of an inquiry are not merely figments of the researcher's imagination. Confirmability calls for linking assertions, findings, and interpretations to the data themselves in readily discernable ways (Schwandt, 1997. p. 164). The audit trail is also a useful procedure for establishing confirmability.

This study is exploratory rather than propositional in nature. It was emphasized to the participants that there was no right or wrong way to respond or think about the issues addressed in the study. I, as the researcher, made no predictions or assumptions about how the teachers would engage in a reflective process, and therefore, implored the teachers not to skew their journal entries and narratives to say what they think I wanted to hear.

In praxis-oriented validity (Graue \& Walsh, 1998), the question needs to be asked, "What good will this work do and for whom?" It was imperative to examine how all parts of the research endeavor came together to provide openings for new ways of knowing. The question of praxis-oriented validity was negotiated and renegotiated throughout the life of the research project. Praxis-oriented validity highlights the responsibilities of the participants and the researcher in this project. It also presents the reality that both academic and personal outcomes for each teacher can result from this research. 


\section{Summary}

This study is indicative of my interest, both as a researcher and a teacher-trainer, in understanding the discourse of teaching choral music education, and how engaging in a reflective practice affects a choral practice. The types of questions asked and the information gained were meant to enlighten and inform the reader as well as the teachers and myself. Through a combination of the teachers' and my process of reflection, I hoped to explore the thoughts and actions, including their philosophical and pedagogical foundations, of these five educators in the choral classroom. 


\title{
CHAPTER 4
}

\section{THE FIVE CHORAL TEACHERS’ REFLECTIVE JOURNEYS}

\author{
Introduction
}

The stories of each of the five choral teachers and the merger of the reflective process will be told in this chapter. Each story provides background information, the rehearsal setting, snapshots of several rehearsals with the interviews that followed, and all related reflective materials. Specifically, the particular description style creates the narrative style used in this writing. Particular description consists of participant quotes and narrative vignettes of everyday life where the sights and sounds of what was being said and done are described in the natural sequence of their occurrence in real time (Erickson, 1986). My reflections as they occur in real time are provided in smaller print, marked with an arrow. The disruptive nature of the flow of the writing represents the character of reflection whereas it can occur at any given moment and is often precipitated by a perplexing event. At other times, my reflections offer commentary on the teaching practice and how it is affecting the teacher and/or the students. My emotional reactions, which may coincide with or contradict the teacher's feelings or actions, are presented as well.

The four delineated categories of reflection used for this study, pedagogical, curricular, personal/professional, and critical, are highlighted within the researcher's personal interspersed reflections at points of emergence. Persistent and persuasive 
themes surface from the triangulation of sources, which include the field notes, constructive dialogues, written reflections, student journals, and my own moments of reflection-in-action. Each molded story depicts the intricacies, the delicacies, histories, and the philosophies of the teacher in an intimate and revealing fashion. The benefits and barriers of engaging in a reflective process come to the forefront of the stories. The chapter concludes with a summary of each of the teachers' reflective journeys. 


\section{MADELINE OWENS}

\section{Background Information}

Madeline Owens is a young choral teacher with three years of teaching experience. A confident person, she frequently smiles and displays a positive demeanor. During her short tenure she has had a variety of teaching experiences in two very dissimilar settings. As a public school music teacher, her job involved directing high school choral ensembles, as well as teaching music history and theory. Her present private school teaching duties include directing both middle and high school choirs and teaching music theory and history. There are more differences than similarities in these two teaching situations, which have enabled her to understand various teaching environments and how they influence her teaching practice, the students' learning, and her personal life.

Madeline comes from a family of teachers. It almost seemed to be a natural career choice given the positive experiences her family shared with her about teaching. There were other influential teachers in her life, too. Madeline holds pleasant memories of a wonderful high school choral teacher who guided her to pursue teaching. Madeline recalls this teacher as being a "phenomenal choral technician and pianist," although somewhat unorganized. The experiences Madeline encountered in her high school choir were those of a typical choral program: repertoire from a wide variety of musical styles; competitions; and many performance opportunities. Madeline wrote in her journal, "I didn't appreciate her enough until I was a teacher myself. She was an inspirational teacher who had an influence on my career as a whole." 
Madeline's college choral experiences were somewhat similar to her high school situation. There was varied choral repertoire that included singing several major works with orchestra. Madeline had respect for this conductor, too, although she remembers him as being somewhat disorganized as well. "I think it has to be an artistic trait," she decides. Even still, her inclination toward becoming a choral conductor was further fostered by this instructor.

Student-teaching was also a positive experience for Madeline, which reinforced her desire to become a teacher. She was given the opportunity to work with a master teacher who was an expert at mentoring student-teachers. Madeline retains a collegial relationship with her cooperating teacher to this day and is grateful for the knowledge she gained from that person.

\section{Rehearsal Setting}

Madeline teaches at a private school with approximately 600 students (grades K12). The student population is rich in diversity based upon ethnicity, religion, and economic status. The students are college-bound, with average to above-average cognitive ability that has been determined by standardized intelligence quotient tests. The school building is approximately 30 -years old and is well maintained. Students wear uniforms, an issue that Madeline finds as a positive attribute for the students.

When you walk through the front door of the school, there is an air of casualness as you observe the students who are always visible. Students are given a fair amount of freedom within their schedule to be in various parts of the building, including the commons, library, and computer lab, throughout the day. Students can be found playing chess or having a snack as they sit on the floor talking with one another. Faculty 
members are also visible, as they are frequently found in the commons area talking with students or walking through the halls conversing with colleagues. You get the feeling that this is a friendly place as people acknowledge even strangers with greetings of hello and smiles.

The choir room is located near the front of the building adjacent to the commons. It is a square-shaped room with movable, sliding doors. The floor is terraced to accommodate visibility for the choral students. The room is also used for handbell rehearsals and general music classes, which account for the extra tables and materials in the room. There are jazz and classical composer posters on the wall. It is a space that serves several purposes that lends itself to appearing somewhat disorganized.

A non-select high school choir made up of 19 boys and girls is the choral group involved in this study. Choir is not required and meets during the last period of the day.

\section{$\underline{\text { First Rehearsal }}$}

The students casually walk into the room a few at a time with a couple of the boys rough housing with each other and two girls carrying on a discussion about some social event. I am seated in the back of the room and a couple of the students look up at me, but most of the students are unaware that I am even in the room. They are in their own worlds and are not concerned that a stranger is in their space.

Madeline begins the rehearsal with, "OK, you guys let's get started" and the students start to quiet down. She had mentioned to me before class started that several students would be missing, eight out of nineteen, and that this was not uncommon. She then simply introduces me to the class and I give them information about the study. 
There is a wide range of interest levels based on their facial expressions, with most of them looking more annoyed than curious.

$>$ Many students missing, most students seem disinterested in the study - teenage disengagement?

Madeline then continues with the rehearsal by making some announcements. Physical stretches and vocal warm-up exercises are then employed. The vocal sound is thin based on the small size of the choir coupled with the lack of proper breath support. There are also a couple of students who are not matching pitch. Madeline moves quickly from one exercise to another and accompanies the exercises on the piano.

I'm Gonna Rise Up is the first piece that the students rehearse. Madeline does not use a music stand and moves among the students while holding her music. Madeline is fortunate to have a qualified accompanist for her rehearsals. Madeline frequently sings with the students to help them with their parts. Her vocal modeling is excellent as she has a beautiful tone color that is clear and vibrant. She has an energetic teaching personality to which the students seem to respond well. It is interesting to note that the choir sound in this piece is fuller than in the warm-ups. The students may be more connected to an actual piece of music rather than the vocal warm-ups and are therefore, putting forth more effort.

$>$ Faces of the students look engaged; her voice is magnetic; their sound becomes stronger as they try to imitate her vocal quality

Madeline speaks to the students about sacred music and its appropriate use in a school setting in relation to the performance for Martin Luther King Day. She also discusses with them her frustrations about the festival event and how one of the other choirs had dropped out of the performance. She makes it a life lesson about how it is 
important to keep a commitment even when others quit. This rehearsal is not just about learning musical notes, but about understanding non-musical issues that are related to life.

$>$ Teacher revealing feelings; discussing a life lesson; nonmusical events in a music class.

After the students prepare to sing the last piece, The Cry of the Child, Madeline discusses text painting and how it fits into this piece. Specifically, she has them demonstrate how to sing like an angel versus singing as a king. The students respond appropriately by attempting to adjust dynamics and tone color to fit the characterization as the rehearsal ends.

Effective use of metaphor; no lesson plan had been made, reflection-in-action being demonstrated.

\section{Interview following First Rehearsal}

I ask Madeline how she felt the rehearsal went and if there were any high or low points. Madeline is positive about the rehearsal remarking that there were really no low points except that there were some strong singers absent. She does not seem to be frustrated with that situation and, in fact, seems to be resolved that this occasionally happens. She is particularly pleased with their understanding of text painting as demonstrated through their singing.

Madeline states that her vocal warm-up exercises emphasized articulation, blend, and space in the vowels. Her goal for the rest of the rehearsal was for the students to sing each piece with more energy and confidence. Madeline believes that building confidence is the largest hurdle her students have to face, which she addresses by setting up a comfortable, encouraging atmosphere. She believes that the students were focused and were giving a strong effort in today's rehearsal. 
Her vocal modeling and teacher personality are energetic; she helps build confidence by singing with the students; her teacher behaviors assist in meeting goals.

I ask Madeline if she thinks that the students had fun in the rehearsal and if that was important to her. She replies that she does believe that the students enjoyed the rehearsal and that she tries "to add humor to lighten up the mood." She recalls a past choral situation where she had a very serious director with no personality and how it made singing "a chore."

$>$ Past experience molding teaching practice.

Madeline remarks that my presence made the students better behaved and more focused because they wanted to impress me.

Boys were chatty; most of the students used incorrect singing posture; students never looked at me during or after the rehearsal -- I got the impression they could have cared less that I was in the room .

$\underline{\text { Second Rehearsal }}$

Six students are absent today. The initial phase of the rehearsal consists of physical exercises, two vocalises focusing on vowel formation, and breathing exercises. Madeline is very animated as well as confident in her vocal delivery. Announcements are made following the warm-up period. She tells them to check on the website about information concerning rehearsals and then discusses with them the upcoming unit on guitar.

Technology for communication in choir; a unit on guitar in choir; non-traditional -- she integrates various modes of learning in her classroom; advantage of small class and academic freedom -they do not have the pressure of large group contest; addressing students' interests.

The first piece the students rehearse is Lead Me On. A few of the boys are chatty and she addresses their talking by telling them to stop. The boys need the most help on this piece, as they do not know their parts and two of them are not matching pitch. Their 
sound is unsupported and they use incorrect posture. Madeline then addresses the girls' parts. After they have sung through a section, she gives them positive feedback, "nice job."

Twice during the rehearsal students ask questions related to musical terminology and Madeline turns the questions back over to the students to answer.

$>$ Student-centered, discovery learning.

Several other times Madeline uses musical terminology. Concepts including major/minor chords, syncopation, and triplets were addressed. There is no talking down to the students. Madeline respects their intelligence and wants to meet their needs for challenges.

The rehearsal continues with work on two selections from a Gershwin medley. Madeline continues to use vocal modeling to teach and inspire. Her attitude remains positive and encouraging. Learning pitches is the main focus of the rehearsal with rote teaching as the pedagogical vehicle. The rehearsal ends with the students taking a rhythmic dictation quiz. $\underline{\text { Interview following Second Rehearsal }}$

I ask Madeline to rate today's rehearsal on a scale of $1-10$ (10 being the highest) and she rated it a 5/6. She concludes that the students were chatty and not focused. She believes that the fact that is Friday was somewhat the culprit. Madeline expresses some frustration in the amount of learning that took place. "Sometimes I think I need to buckle down and really be on them. But I am like, wait, if I do that it almost feeds them."

Trying to balance how hard to push -- but her gut reaction was that the rehearsal needed to be more productive. 
Madeline speaks to the problem of the boys in the class having behavior issues. One of the boys with Attention Deficit Hyperactivity Disorder (ADHD) has been particularly challenging to the choir at times. However, Madeline feels comfortable handling the situation. She understands the challenges associated with this condition because her mother, who was a teacher of learning disabled children, had often discussed this condition with her.

$>$ Familial mentorship influenced knowledge and action in the classroom.

Madeline is sympathetic to this student's situation so she justifies his talking as a defense mechanism that covers up his frustration concerning the difficulty of learning the music and singing in general. She also believes that the other boys are using that same defense mechanism at times as well. Madeline attended to this problem earlier in the year by having a male singer from a local university work with the boys. The male teacher addressed the changing voice and reassured them that the challenges they were facing were common and normal. Madeline believes that this coaching session was helpful, but the boys need more frequent individualized attention on a continuing basis.

I ask Madeline if she thinks the girls are frustrated with the behavior and musical abilities of the boys. She tells me that at the beginning of the year they were particularly frustrated. Madeline shares that one of her solutions to this challenge is to give the girls the opportunity to work on a piece for solo and ensemble contest. Madeline also occasionally spends time with the girls working on parts while the accompanist works with the boys. This helps the girls feel like they are getting special attention as well. Madeline comments, “The girls are smart enough kids that they know they really can't do 
anything about it [referring to the boys' progress]." The girls are well aware that the boys need more attention.

Gender discrepancies -- how to meet both their needs; Madeline is aware and finds solutions. The issue of the rhythmic dictation is addressed in this interview. Madeline prefaced this process by telling them that when they begin to play the guitar, they will need to know some strumming rhythms.

$>$ Explained to them why they were learning a particular concept; motivated learning.

Madeline talks about how the more individual knowledge that is learned, the more the entire choir will benefit. In Madeline's teaching philosophy, it is important for the students to learn the theory behind the music.

$>$ Comprehensive musicianship approach to the choral program.

Madeline shares with me the luxury she has in participating in a college choir every day right before she begins her teaching. She acknowledges the benefits of bringing in new vocal exercises and being rejuvenated as a choral singer.

$>$ Taking on the role of learner; understanding the challenges of being a choral singer by being one. Continual learning is refreshing and a priority for Madeline. "I would hate to be stuck in a full-time teaching position and not take classes. I did that for two years and I was falling in the same path, doing the same thing."

Avoiding routine teaching; constantly being restimulated.

I turn to a discussion of the advantages of the private school situation. Madeline points out the flexibility and academic freedom that she is allowed. Because her program is without the pressures of large group contest, she has decided to let the students study two musical topics when they take a break from repertoire learning. She gave them five 
choices and the choir selected the topics of guitar and ska/reggae/world music. Madeline is excited about being able to break away from the paradigm of just learning repertoire. Although she is not an expert on guitar, she feels comfortable learning along with the students.

$>$ Innovative, breaks with the choral program canon; student interest, lifelong learning; lack of expertise not deterring her from expanding her curriculum.

Some of this innovation in curriculum comes from Madeline's teaching philosophy of individual development. She spends some time predicting the challenges of the guitar unit,

There are going to be different skill levels on the guitar. Some of them play string instruments so they are very flexible with their fingers and the fingering will be easy for them. For some of them it is going to be like they have paralyzed hands. I am going to have to deal with that and know what to do to help them out. I will introduce the chord with the right fingerings but it will be up to them to practice at home. I am going to have other people come in and learn about different styles such as Celtic guitar and bluegrass. We will listen to examples of guitar playing. I will include the history of the guitar, too. The students will have a final project where they can compose their own piece and play it or have a more proficient player perform it or they can pick a topic and write about it.

$>$ Meeting individual needs; creative curriculum.

\section{$\underline{\text { Third Rehearsal }}$}

A third of the students are missing from this rehearsal because of a ski trip.

$>$ Definite trend in students missing from rehearsals -- I wonder how frustrated Madeline must feel. Madeline asks them to set up the chairs. They go about the task half-heartedly. She then tells them the plan for today's rehearsal. A brief warm-up period follows with the focus on vowels in the vocalises. The students are operating at a low energy level. 
The first piece rehearsed is Lonesome Road. The boys have not learned this part yet, so she has them hum along as the accompanist plays their parts. The boys sit in their chairs in a slouched position.

$>$ Correct posture is noticeably absent.

Madeline then has the girls sing their part on "oo" so she can hear them and reminds all of them to sit up straight.

$>$ Acts on posture issue.

She coaches over their singing, telling them to sing louder, breathe, and articulate. She tells the boys to stop talking. Madeline continues by working with the altos, coaching over them as well. All three parts are put together after given the reminder to think about the consonants. She asks the choir what the first consonant is and one student replies, "this is making me tired."

$>$ Student is obviously bored; the comment is dismissed.

During Elijah Rock Madeline sings various parts as the choir rehearses with the accompaniment. She then has the boys stand to work on their part and some of them start to complain. She ignores their complaints and carries on with an enthusiastic air. The boys continue to grumble, so Madeline stops the rehearsal and allows them to work on their guitar project while she works with the girls on a different piece of music.

$>$ Is she just giving in or does she believe that they are unable to focus today?

A discussion begins, following the departure of the boys, concerning body piercings. One of the girls shares that she just got her belly-button pierced, and other girls tell similar piercing stories. Madeline listens to their discussion, and intermittently adds her own comments about her feelings on the subject. 
Building rapport and meeting the girls' social needs.

Madeline works on Shop Around with the girls and asks them to discuss the dynamics. One girl answered correctly.

$>$ Another girl is doodling on paper throughout the entire rehearsal, even when she is singing -Madeline ignores the behavior.

One of the boys comes back into the room to tell her there is no place to practice the guitar. She dismisses him to the computer lab. The girls then continue to learn the piece by rote as she vocally models phrase by phrase. She addresses areas that need correction by telling them to fix mistakes the second time. The class ends with Madeline asking the girls a question about an interval and then the bell rings.

$>$ Rote learning is the pedagogical norm.

Interview Following the Third Rehearsal

I begin this interview by asking her how she thought the rehearsal went.

Madeline concludes that it went pretty well considering key people were missing. She says she had to be flexible in adjusting what she wanted to accomplish knowing that some goals would not be accomplished.

We then discuss once again some of the differences between public and private schools. The fact that she can just have the boys leave the rehearsal room and trust that they will go work in another part of the building is not part of a public school procedure. Students are trusted here and usually can handle the responsibility. When students have a period with no class, they do not report to a study hall but are free to be in various parts of the building. They know that they are accountable for their actions.

$>$ Small numbers can change curriculum and expectations. 
Assessment is another issue for discussion. I ask Madeline what assessment tools are being used for her choir. Madeline explains that rehearsal and concert attendance are part of the students' grades, but there are written tests and projects, too. The rhythmic dictation and the guitar project are examples of the alternative assessment tools. Madeline feels that it is important for students to take choir seriously and treat it like any other class. Any opposition to making music as accountable as Physics or English is a challenge she is willing to face and wants to overcome. She has had no conflicts with students, parents, or administration in her assessment methodology.

$>$ Assessment involving more than attendance and participation is not always a part of a choral program.

We then discuss how a choral program fits into the whole academic curriculum and how both fellow educators and the general public value it. Madeline concludes that there is a long way to go in terms of educating the public about the intrinsic value of music. However, that does not discourage her as she maintains a strong philosophy that music is a lifelong pursuit that enriches the mind, body, and spirit.

\section{$\underline{\text { Rehearsal Four }}$}

This is more of an "odds and end" class rather than a rehearsal. There are seven students missing today. She and I have the students fill out the journals for the study for the first portion of the period. Then one student performs his original composition on the guitar. For the remainder of the class time the students watch the conclusion of the musical, Into the Woods.

$>$ Again, not a typical choral rehearsal. 


\section{Interview Following the Fourth Rehearsal}

I begin by asking Madeline to talk about her preparation to be a choral teacher in her undergraduate training. I wanted to know how well prepared she felt she was and if there were any surprises once she started teaching. Madeline feels very prepared to teach based upon the strong mentors she had along the way. These mentors included her parents and past choral teachers. She called upon those people during her first year of teaching for advice, which demonstrated her sense of security in the respected relationships she had established. The politics of the public school was an area she was not prepared to handle. Madeline was also surprised by the amount of time and energy that is expected of a teacher to give. She found it to be "overwhelming and tiring." That combined with an hour driving time each way made her day very long and added to her exhaustion during her first year of teaching.

School politics, huge amount of time expended, and exhaustion are all first-year teacher dilemmas; she had a strong support system to give her advice and encouragement.

Specifically, she wishes that her piano skills were stronger. Madeline tells me that because she has to concentrate so hard on playing the piano, she cannot hear the choir well and is less able to deal with discipline problems. She agrees that it is a luxury to have an accompanist and is hopeful to always have one.

$>$ Undergraduate curriculum faces challenges in preparing future teachers due to the many demands of the teacher education program.

Madeline has learned that one of her greatest assets is her ability to adapt. Adapting to different situations, different classes, and different students is not a problem for her and she recognizes and appreciates the importance of that skill.

\footnotetext{
$>$ The ability to adapt is part of one's personality -- this parallels her easy-going personality.
} 
I ask Madeline to talk about professional development and her plans for the future. Staying active in musical performances is very important to Madeline and she will not compromise her need for using her talents outside of the classroom. Even when she is extremely tired at the end of the day, she always works in practicing for the band in which she plays and sings. The band adds vitality and quality to her life. If something is of value to her, she will find the energy to do it no matter how demanding her schedule is.

$>$ Her ability to maintain the life of a student, teacher and performer is commendable; youth and determination are on her side.

Madeline sees the possibility of working on a doctorate as the idea of teaching college is of interest to her. However, she has other dreams as well. "I might be interested in opening up my own complex of performing arts center where I can do music and art and dance and the whole nine yards." She shares that it would be particularly exciting to have a center in an inner city neighborhood where young people might not have those opportunities.

$>$ Talented, motivated, and visionary.

Staying fresh is important to Madeline. She wants to change positions every five years or so much to her parents chagrin. She does not want to be the same teacher every year because she feels it is boring for the students but mainly it would be boring for her.

She seeks new challenges and professional growth.

\section{Last Follow-Up Interview}

Madeline is candid and thoughtful in her discussion of several issues during this last interview. I first have her look over the field notes from the third rehearsal (the fourth time I observed her was not a rehearsal). She tells me that it accurately reflects her recollections of that rehearsal. There was not anything that surprised her but it did bring 
back to light that she had spent some time with the girls discussing body piercings. She chuckles at the thought of the topic and then reflects about the appropriateness of that subject taking up rehearsal time. She shares with me how she believes that it makes her more of a real person to talk to her students about non-musical issues as long as it is not done often. Madeline remarks that the field notes in general "bring out the events of the rehearsal when it is in writing." She feels that they can serve a helpful purpose.

Madeline never referred to any of the field notes during any written reflections.

After discussing her reactions to the student journals and the process of the study we tackle important components of her professional and personal life. She speaks with confidence that her current position is the right place for her to be at this time in her life. Her colleagues and administrators have been both supportive and communicative, and have given her positive reinforcement concerning her teaching. That feels good to her and it keeps her enthusiasm high. She enjoys the independence and freedom she is given in her curriculum as she reaches outside of the choral music education discourse to meet her students' educational and personal needs. The pressures of contest and the shallowness of the show choir mentality, a phrase Madeline used, are two components of a choral program that she does not miss. Madeline talked about how she sees the public school arena as a place more likely to foster teacher burnout based on scheduling issues and a lack of collegial relationships. She seems content in both her career and personal life that she is at the right place and can make a difference in her students' lives. 


\section{Types of Reflection Tools Used/Issues of Reflection}

\section{Autobiography}

Madeline wrote a detailed autobiography that covered her family background, her recollections of past choral teachers, and her philosophy of teaching. She was open and descriptive, using many adjectives in her tale. She remembers both "wonderful teachers and horrible teachers" from her past. "Positive" is the word she used to describe her mentors, student-teaching experience, and profession. The autobiography told a positive, happy story with occasional glimpses at the negative side of teaching or her teacher personality.

$>$ Candid reflections; descriptive writing.

Her level of confidence is expressed as she describes herself as an educator who is fair, knowledgeable, easy to work with, and fun. Her traits of adaptability and flexibility can be inferred from her statement, "I am constantly striving to vary my technique to accommodate everyone. There are times I get into a rut and force myself to break free and try something new."

$>$ Efficacy is in effect; she wants change to be a part of her practice.

The autobiography is marked with optimism and idealism as expressed in this quote,

I hope my students learn something about music and the production of it that they will take with them forever. Even if they do not enjoy music as much as me, they will learn to appreciate it and the musicians who create it. In ten years I hope to be in a job educating the masses about the importance of music, whether it is in a college setting, public school, private, or corporate world.

Positive, idealistic look into the future. 


\section{Reflective Journal Entries}

Madeline wrote seven journal entries during the first four weeks of the study. Journal entry \#1 discussed the specifics of an upcoming performance and the positives and challenges of the process. She reflected about her struggle with a situation where another choir was not doing its part and how she needed to stay positive for her students. She made a positive comment saying that she was proud of the leadership role her choir had taken. However, she expressed her looking forward to the performance being over and how relieved she would feel. The realities of performances and the feelings that accompany those realities were the main course of this reflection.

$>$ Her writing reflects emotions as related to her practice.

Reflection \#2 was written immediately following the performance discussed in reflection \#1. She was proud and pleased with the performance. Along with a sense of satisfaction she felt great relief that it was over. She then talked about getting ready for Solo and Ensemble contest. She stated that there is always something for which to prepare. Emotions and program issues were the topics of the reflection.

$>$ She is discussing the product nature of a choral program.

Reflection \#3 was concerned with curriculum issues. Once contest is over, there is some time to teach some new topics, she remarked. She expressed her excitement about the possibility of letting the students choose topics that really interested them.

$>$ Making curriculum more student driven is important to her; enthusiasm is heard in her writing.

Reflection \#4 started out with "Success!" She was pleased that the students were excited about the topics presented to them for the next unit in choir. Madeline acknowledged the fact that she had to do some research on the topic of reggae/ska and 
guitar. This reflection dealt with the aftermath of contest. She felt it went well even though she had hoped for some better ratings. Then she reflected quite a bit about the strange and snobbish attitude of the other choral directors at contest. Madeline was quite specific in her description of the actions and appearances of those other directors, "as if every director in that room was trying to 'one up' the others." It was obviously bothersome to her as she felt that the aura of contest wasn't really about letting the students have the opportunity to grow musically, but rather it was more about giving the teachers an opportunity to try to impress each other.

$>$ Issues of contest with which she wrestles; as a young teacher, she is forming opinions as to how contest fits within her practice.

Reflection \#5 began with thoughts about the reflective process. She is finding the journal format to be time consuming. "I am too tired to compose my thoughts down to paper." She has found the computer to be a helpful tool when she does write, however. Madeline remarks that verbal conversations between the two of us are turning into the most useful reflective tool.

$>$ Writing is setting up possible roadblocks to reflection.

This reflection also looked at her advantaged situation of being in a choral group with the rehearsal occurring right before she teaches. The opportunity to experience both worlds at the same time has been a unique and positive experience. She writes, "I gain so much by taking classes and being in the student chair, then within the same day, teaching students. I am better able to know where they are coming from and adjust my teaching accordingly."

$>$ Her professional development has an immediate affect on her teaching practice. 
Reflection \#6 addressed once again curriculum issues and her reactions to the related successes. The different curriculum has brought about a new excitement to the students and the change of pace has been rejuvenating. Madeline refers to her learning along with the students. She reflects about the various levels of guitar performance ability in the class and decides to create two options for the project. She also relays her excitement about bringing in other teachers to perform for the students to give them the opportunity to see their teachers in another light.

$>$ Building a sense of community within the school through music.

Tension between colleagues was the focus of reflection \#7. There were personality issues that were not directly affecting her but brought back unpleasant memories from her former job. Her accompanist from that past position was very pleasant and helpful to her face but was poisoning Madeline's reputation behind her back. This sort of unprofessional behavior was very upsetting to Madeline. Because of her normally positive disposition, this reflection was particularly revealing as to the importance of colleagues treating each other respectfully in Madeline's eyes.

$>$ It is important to Madeline that people learn to work out solutions and then move beyond their differences.

\section{Student Journal Entries}

There were 12 students who were present the day of the student writing. Ten of those students had agreed to participate in the study. The students were quiet and on task during this exercise. They took anywhere from 5-20 minutes to complete the journaling exercise. The first question asked them to discuss what they enjoyed about choir. Several students referred to their love of singing as the most enjoyable aspect of being in choir. Variety of repertoire, relaxed atmosphere, vocal pedagogy, teacher personality, 
family feeling, and variety in curriculum were also highlighted as positive elements of choir. The students used various adjectives to describe Madeline's teacher personality, which fit into three main categories: 1) inspirational/motivating; 2) outgoing/energetic/bubbly/fun/cheerful/perky; and 3) knowledgeable/smart/experienced/bright. One student commented that she was "too forgiving by allowing herself to be used too much."

$>$ Atmosphere of rehearsal (and school culture) is laid back and less structured than the norm; discipline was not a major issue in her rehearsals -- she ignored most of the misbehavior, which composed mostly of talking, lack of participation, and poor posture.

The students had inconsistent comments referring to any changes they noticed in Madeline since the beginning of the study, which lead to some curious conclusions. Some students noticed no change while others commented that there was a change. Others perhaps were just trying to answer the question by commenting on some aspect of Madeline's personality.

The challenges of the choir were mostly related to the small size of the choir. "So little people, tough to make a loud noise" was a comment written by one student. Another student said, "Some sections are louder than others because they don't have stronger singers in them." Some of the students were brutally honest with two making references to the male sections of the choir. "Being able to perform with a bass section of two and a group of tenors who can't really sing" was stated by a student as one of the challenges of the choir. Another student indicated the challenge of the choir as "blending with the other voices, especially since most of the guys aren't such good singers."

Numbers can affect the success of a choral program; students are aware of the challenges of the group; weaknesses in the male singers can be attributed to the male changing voice and maturity level. 
The students listed a variety of personal challenges for them as choir members. Most of them were pedagogically based including breath control, increasing vocal range, and sight-reading.

\section{Madeline's Reactions to the Student Journals}

Madeline felt that her students were very honest and insightful in their journal entries. She thought that they were "right on" in their assessment of the challenges of the choir. She agrees that the size of the group presents some problems. "If there were more strong singers then it would cover the weaker singers." Recruitment is a high priority for her next year.

Seeing in writing that the students also recognize the challenges of a small choir reinforced her goal of increasing the size of the choir to afford the students a better choral experience.

The responses she was most interested in were the adjectives to describe her teacher personality. She found it interesting that the "perky" category came up so often. “I wouldn't describe my real personality as perky. I guess I act that way because I want them to be motivated."

She became aware of her two personalities -- teacher and non-teacher; she reflected about the manifestations of the teacher personality and acknowledged how it can get the job done.

One student wrote that the choir is a family. Madeline was pleased to read that statement, as this is important to her.

If the choir grew too large, that feeling of family might be harder to achieve; the small size has its' advantages, too.

Madeline felt that the journals were a productive vehicle to hear the students' voices.

She found their comments to be a source for reflection and wanted to use journal writing again in the future.

This was a new vehicle for her to use with her students. She found it beneficial and will use it as a medium for change and reflection in her practice. 


\section{JACOB HAMILTON}

\section{Background Information}

Jacob Hamilton is a young choral teacher with eight years of teaching experience. Jacob possesses qualities important for effective choral teaching; he is confident, organized, and musically competent. His skills as a pianist and as a singer are strong, which enable him to effectively model and convey musical ideas. His body language displays self-assurance as observable by his proper posture and proud walk. He is mindful of his physical appearance as shown by his professional dress and fit physique. Although Jacob's demeanor is often viewed as serious, he has a wonderful sense of humor. Jacob takes great pride in his profession as a choral and general music teacher and works hard to give his students the best musical experience possible.

Jacob has held two teaching positions in his tenure as a music educator. His began his career as a high school choral director in a small town. He fondly remembers that position and feels that he built a strong program of which he was proud. Graduate school came next in his career, where he also gained teaching experience by being a graduate teaching assistant. Jacob felt very comfortable teaching his college classes and was highly respected by his students and professors. His role as a graduate student was challenging, as he would occasionally become stressed over the constant pressures that are a part of graduate school. Jacob was definitely ready to re-enter the public teaching arena at the end of the degree program. 
Jacob's second and current position is at the middle school level where he is in his second year. He teaches two middle school choirs, class piano, and general music. Through the experiences of teaching both high school and middle school students, Jacob has gained the knowledge of the positive and negative sides of both age levels.

Jacob grew up as an only child in a small town. He recalls his interest in becoming a teacher as "always there" but he officially decided in 11th grade as a result of his participation as a singer in the All-State Choir with an influential and inspiring conductor. Jacob remembers his parents voicing some concerns about entering the profession because of the low salary and the shrinking number of teaching positions available at that time. However, they were always supportive, for which Jacob is thankful.

Jacob's musical history started early with piano lessons beginning in the second grade. He participated in choir at the middle school level as both a singer and accompanist. As a high school student, he was heavily involved in the music program by participating in concert choir, show choir, madrigals, and musical theater productions. Jacob also took on leadership roles as choir president and the choir manager. Jacob's musical involvement continued at his church, where he was a cantor and taught the music classes at vacation bible school. Both his public school music education and church experiences were positive and therefore, influential in his decision to become a music educator.

Jacob recalls several teachers who had positive effects on him personally and professionally. He fondly remembers his senior year English teacher in this writing, "She made us write a huge term paper in the style of the typical college paper. Everyone that 
went to college remembers her quite thankfully!” Jacob gratefully remembers his physical education teacher, "I was pretty athletically challenged in his class, but I tried. He never condemned or embarrassed me, and was supportive of my musical interests and abilities, which isn't stereotypical of football coaches." Jacob speaks highly of his high school choral director; "She gave me an outstanding foundation for undergraduate study, as well as philosophies that still influence me today. I'm still amazed at how much I learned from her." Jacob recalls her attributes as having a positive personality, being an excellent conductor, and implementing good programming.

Jacob attended a mid-sized college that had a reputable music education department. There he was able to gain valuable choral performance experiences while at the same time, enjoy a strong music education program. His two college choral directors were highly regarded within the profession and served as positive influences in Jacob's life.

\section{$\underline{\text { Rehearsal Setting }}$}

Jacob currently teaches in a large public school system located outside of a major metropolitan city. The middle school has approximately 800 students, of which 250 are involved in some facet of the music program. The school community is lower-middle class, mostly Caucasian, and predominantly Christian. The two-storied building is approximately 30 -years old and is well maintained.

The school community is a friendly one, where parents and administration are supportive of teachers, and teachers work hard to communicate openly and often. 
Attendance at concerts is high, due to a strong sense of community spirit to support one another. The students respect authority and are generally pleasant and well mannered as observed through my interactions with them.

The physical setting for the choral rehearsals is the stage of the auditorium. Risers are set up facing the back wall of the stage, away from the audience seating. A piano, folder cabinet, and table are also located on the stage. A chalkboard, which is frequently used for announcements, is on the back wall. When the students are on the stage, the area seems a bit congested as there is little unused space left. The temperature in the room tends to be somewhat warm, occasionally requiring an outside door to be open, which then lets in the noise of the outside playground. Jacob wishes he had a separate choral rehearsal room with terraced floors and room for movement, but has resigned himself to the current physical situation and makes the most of it.

The choir used for this study is an auditioned, although not highly selective, mixed choir of 96 students composed of mostly eighth graders and a few seventh grade students. They meet every day from 12:30-1:15 throughout the year.

\section{$\underline{\text { First Rehearsal }}$}

There are four back doors that lead students into the auditorium. The students enter the room with a general sense of commotion. Girls are chatting and screaming while a group of boys run down the aisle and leap onto the stage. Jacob is on the stage speaking to a couple of students about the upcoming solo and ensemble contest and is ignoring the noisy entrance. Students continue to make their presence known as they move onto the stage after leaving their backpacks in the audience seats. A few of them acknowledge my presence as they remember me when I have served as their 
accompanist. They seem excited to see me and ask me why I am there. After giving them a brief explanation I tell them to quickly get to their places on the risers. The bell rings and Jacob tells them they are to be in their places.

As Jacob begins the warm-up exercises, some students are not in their places or are still talking. Jacob has a stern look on his face and you sense his frustration with not having everyone focused, but he chooses to move ahead in his rehearsal.

$>$ It seems that there is an internal dialogue going on -- what should be ignored and at what price; the expression on his face shows internal conflict.

The pace of the warm-up exercises is quick. Jacob is clear and deliberate in his explanation and modeling of the exercises. The choir's execution of the vocalise is breathy so Jacob calls on a student for a possible explanation. The student replies with a comment that perhaps they are not breathing deeply enough. Jacob agrees and commends the student for her good thinking.

$>$ Displays skills of master teaching -- appropriate pacing, presents material clearly, poses problems for students to solve, and gives positive reinforcement.

A few members of the bass section continue to chatter during the vocal exercises. In a firm voice, Jacob addresses them concerning the inappropriateness of being noisy. The boys settle down. Resonance is the focus of the next few vocalises followed by a discussion of the term. Through the use of metaphors Jacob is able to clearly explain how to achieve more resonance in their voices and the sound of the group improved. During this part of the rehearsal about $90 \%$ of the students are focused with the remainder continuing to talk among themselves. 
The warm-up period continues with descending scale work assisted by Jacob's uses of visual cues to increase the sound. As there are some students not participating, Jacob threats to lower their grades. You can hear tension building in Jacob's voice.

$>$ Tries another technique to change student behavior.

Jacob then uses solfège hand signals as the students sing a scale. The solfège syllables are written on the board. Jacob points to the syllables and has the students sing them. The students are having moderate success with this exercise.

Using sight-reading techniques for student learning.

Sing Dem Herrn is the first piece of music rehearsed. Jacob's goal is to have the students feel the beat. He uses a metronome as the students tap and walk the beat.

$>$ Effective methodologies employed for student learning.

As the choir transitions from the first piece to the second, Kyrie, many students are talking. Jacob clearly is not pleased with the noise level and says he will add seconds of time to the rehearsal owed to him because of rehearsal time lost.

Pocus on discipline in rehearsal; uses another behavior modification technique.

The choir sings through the beginning section of the piece. Jacob gives the alto section positive reinforcement after they sing their part. Some of the boys, however, continue to chat, and Jacob assigns a detention to one of them. Jacob is matter-of-fact in his demeanor but it is clear from his facial expressions and voice quality that he is not pleased.

Jacob employs rote learning during the rehearsal of the repertoire. Jacob plays the parts on the piano and the students learn them as they hear the music repeatedly. Jacob's piano skills are very effective, giving him a valuable tool in the rehearsal. Ticket to the 
Kingdom is the next piece rehearsed. The students sing the piece energetically. By the looks on their faces and the energy level, it is apparent that many students enjoy this piece. Jacob shares how impressed he is with their performance and the bell rings.

An exciting and positive experience for many of the students.

\section{Interview Following the First Rehearsal}

I first want to focus on the pedagogical and curricular aspects of the rehearsal. I ask Jacob if he had a particular focus for the warm-up exercises. Jacob shares that the focus has been on resonance all week. He says he has noticed some change in the choir's sound but the change is probably too small for the students to notice. Jacob points out that sight-reading is a new part of the curriculum for the year. He looks back at how he did not include sight-reading during his first teaching year at the middle school level as he was learning about how to deal with young adolescents.

$>$ Prioritizing curricular goals based on his own professional skills.

I ask Jacob to continue with his goals for the rehearsal. He replies that learning the pitches is really his main curricular objective right now. I ask him how long he thought it will take them to learn the music and he admits he is not sure. In the fall, he had selected some holiday repertoire that was too difficult for them and is therefore, not confident in his ability to predict how quickly they will learn the music.

$>\mathrm{He}$ is aware of the changing nature of the adolescent, and that this is still new territory for him. I ask him to talk about the selection of repertoire. Jacob states that a few of the pieces he has performed as a choral singer and some are from the contest list. Jacob tells me that serious music has worked well with this choir. "I am a big believer that quality always wins," he states. He also feels that it is important to include foreign language 
pieces as it offers a challenge to the students. One of the pieces the choir is singing is in German. He remarks, "This is a very popular piece that choirs perform."

$>$ Has a philosophy concerning repertoire selection; prior personal choral experiences have defined some of the rules.

I then want to address the classroom management aspect of the rehearsal. I share with him that from my viewpoint; it seemed to dominate the rehearsal. Jacob states that, "about $40 \%$ of what I did today was behaviorally focused."

$>$ He knows what is happening in the rehearsal in terms of both teacher and student behaviors.

Jacob explains that the chattiness is partially because the students are frustrated within the rehearsal as well as their self-centered behavior. He acknowledges he was "really nasty" in today's rehearsal. I ask him if this is normal for him. He replies that he was more negative than usual. Part of the reason was that he was very tired and did not feel very well.

Physical state possibly affects teacher behavior.

He also shares his thoughts during the interview,

You know you are being a little bit too hard core here, so lighten up a bit. I started to shift and find the things that were good rather than focusing on these negative things. I physically [sic] remember thinking okay; we need to turn this around. It was a conscious decision.

$>\mathrm{He}$ is aware of reflection-in-action.

Jacob then explains how it is difficult to determine how far to let the chattiness go. He comments about how they are basically good kids and that it is his responsibility to teach them how to behave.

$>$ Takes responsibility for his students' behaviors.

Jacob shares that he has not completely found his style of discipline yet and knows he is inconsistent with the students. He admits that he has to be stricter because the minute he 
cracks a joke, the students think it is time to joke around. We talk about how part of the discipline problems stem from the large number of students in a very small space.

I ask him what the focus of next week's rehearsals will be and he shares with me that he is somewhat spontaneous in his lesson plans. He explains, "I am more reactionary. I tend to keep things open where we work on whatever we need to at that time. I have been pleasantly surprised that year after year it has been working for me."

$>$ He knows how he operates in the classroom and feels confident that he is effective in that mode.

\section{$\underline{\text { Second Rehearsal }}$}

The students enter the auditorium with the same energy as the first rehearsal I observed. Jacob starts the rehearsal even though many of them are not calmed down. His demeanor is positive, energetic, and determined. He proceeds through the warm-up exercises and calls out individual people who are not on task. Most of the students finally are focused and he continues with the rehearsal. He gives positive reinforcement concerning the sound of the choir. One boy is talking and Jacob stops the rehearsal, moves from behind the piano, and asks him, "Did you have the right to talk?' Jacob then continues the rehearsal. Jacob is unruffled by the few interruptions.

The choir sings My Country Tis of Thee with beautifully shaped long phrases. They then work on some sight-reading with solfège and have moderate success. Another boy is being disruptful and Jacob gives him a detention. Jacob quickly moves on to another activity.

$>\mathrm{He}$ is controlled in his reactions to the student behaviors, and recovers quickly.

The choir rehearses Sing Alleluia next. Jacob has them sing a cappella so he can walk among them. At one point the students become chatty and Jacob simply says, 
"Three-two-one silence" and they quiet down. During Kyrie, Jacob gives reassuring comments about their good progress. Lastly, the students sing Ticket to the Kingdom with enthusiasm and focus.

\section{$\underline{\text { Interview Following Second Rehearsal }}$}

The interview begins with me asking Jacob how he felt about the rehearsal. He replies, "In comparison to what you saw last time, it was much better. However, I was again displeased with behavior issues. We put a new plan into motion. From now on if they even look like they are talking it's an instant detention. Every detention I give from now on, I call home the same day."

$>$ Frustration has led to making a new, strict policy.

I comment that I noticed he was more relaxed than the last time I observed him. He says he has been relaxed all week although today he felt a little tenser because I was there. He says he also was not feeling that well.

$>$ He has made references to not feeling well both days; what effects does the physical state have on teaching?

Jacob continues to talk about discipline issues during the interview. He relates a story about the difficulty of getting no support from home when a student is a behavior problem in the classroom. He sees the importance of getting the family involved but knows that sometimes it complicates matters.

$>$ Family involvement is related to teaching with a critical consciousness.

When I ask Jacob if discipline is an issue that he wants to concentrate on in his reflections, he says that he wants classroom management to be an important focus during the study. 
Jacob speaks of how he wants to change his behavior of standing behind the piano all the time, which I observed during the first rehearsal. He says that he was consciously making an effort to move among the students. He also is aware of how much he was teaching by rote through my observations and notes that he was trying to use that technique less as the rehearsal was progressing.

$>$ Reflection-in-action.

We discuss vocal balance issues, which leads into a discussion of commonly used metaphors. Jacob says he dislikes telling boys to sound "manly" just like telling girls to sound "girlie" is inappropriate and can send messages of gender discrimination.

$>$ Issues of critical pedagogy.

\section{Third Rehearsal}

The students enter the auditorium; some are chatting with one another and others are running down the aisle and jumping on the stage. Jacob is collecting money for contest before the bell rings. As soon as it rings, he plays four chords on the piano, signifying the start of the rehearsal. The choir begins singing their first warm-up vocalise and Jacob compliments them for getting settled so quickly.

Positive reinforcement of improvement in student behavior.

Jacob continues to encourage them during the vocal exercises. His voice is energetic, eyes are bright, and a pleasant smile is on his face. Before starting the next exercise, a few boys are chatty and Jacob waits until they were quiet. He then reminds them about ensemble skills, "Don't talk in between exercises."

$>$ Has he discarded his new discipline policy from two weeks ago? 
Another exercise is started and once again, a few of the students are talking. Jacob shows them a time-out hand sign and tells them they did not do well with their ensemble skills. He continues on with warm-ups and a few more students are chatting. He calls them up to the piano and tells them, "I will not talk over you." When they return to their seats, the students get quiet and Jacob thanks them for that. During the singing of the first piece, Jacob stops about halfway through and tells them, "Good job." He continues to praise their effort and good singing throughout the rehearsal. "The quality you are singing with is very nice and delicate. I am very pleased with it.” The rehearsal ends with that positive comment.

$>$ Reinforcing good behavior and proper singing.

Interview Following the Third Rehearsal

Right after the rehearsal Jacob says to me, "This has been the day from hell. When I realized you were coming I thought, ‘oh, no!’”

$>$ He seems to be in a negative frame of mind but was very positive during rehearsal. Jacob begins to talk about all the details for which he is responsible as a choral director. Last term he had a teacher to help him with taking attendance, collecting money, and dealing with student questions that were unrelated to the rehearsal. Jacob feels somewhat burnt out as he relates that he is spread too thin based on the number of students he has and the amount of class preparations. He admits that he has not written a valid rehearsal plan in two weeks. He cancelled a concert because the students were not ready to perform. Jacob feels good about that decision.

$>$ Feels overworked; physical and mental stress is evident. 
Jacob confesses to me that he does not feel he is contributing enough to this research study. He then goes on to say that the brunt of his frustrations are the behavior issues and the non-musical parts of his job. Jacob continues,

I can't teach music because I have to be a policeman in there and that is what's going to keep me on the job market. I think a lot of it is the age because I don't know what else to try.

Serious tone; he is not sure this particular position is the right one for him.

I relay to Jacob that my perception of the rehearsal was very positive. I tell him that he certainly reacted appropriately when the students were out of line but it was not a negative rehearsal. Jacob responds with, “I just don't feel well.” He goes on to say that he has too much on his mind today to even really care.

$>$ Another reference to physical ailment; negative attitude; is there something else going on?

I want to change the focus of the conversation. As we are talking about the school culture, I ask him if the non-diverse community affects his repertoire selection. He tells me that most of the multicultural music available does not fit the typical middle school voice. "I haven't jumped on the multicultural bandwagon yet but I do try to have variety in my programming."

$>$ Has reasons for not including more multicultural music.

I ask him how he found the two multicultural pieces. He heard one performed and the other was discovered at a reading session. We then discuss the holiday program performed every year at the school. Jacob responds,

Sometimes I wonder if we do a little bit too much holiday music, but again, I went for what fits the group vocally. I try not to make it a complete Christian concert either. I try to stick to the $50 \%$ rule -- half sacred, half secular. 
His first concern when selecting music, however, is that the choir is capable of singing it based on the level of difficulty and vocal range. The issue of quality repertoire arises once again. "I tend to stay away from things that are cheesy."

The last topic for discussion is about recruitment for our profession and how there are fewer and fewer people wanting to be music educators. Jacob cynically adds,

This is a great day for me to list the reasons. I went into this career thinking that I was going to be in it forever but there have been several times this year when I have stormed out of the building.

$>$ Questioning his professional livelihood and commitment.

Fourth Rehearsal

Before the bell rings, the students enter the room with their usual state of flurry. Jacob begins the rehearsal playing four chords on the piano to get the students quiet after they completed filling out the student journals. After they do not settle down, he sternly tells them to cease talking. "I can only be polite for so long." He employs a variety of vocalises and gives the students positive reinforcement. There are two boys not participating, which Jacob addresses. After starting The River Sleeps, Jacob once again has to tell a boy to stop chatting. The boy admits it was his fault and Jacob thanks him for admitting it. The next piece sung is a difficult madrigal and is performed in Italian. I compliment the students on doing a great job and they clap proudly. The class ends with Jacob playing them a recording of one of their repertoire pieces.

$>$ Rehearsal ends positively.

\section{Interview Following the Fourth Observation}

Jacob is unable to meet after this rehearsal so I email him some topics on which to reflect: how the rehearsal went; how is undergraduate education prepared him; and 
thoughts on the use of a reflective practice. Jacob feels that the rehearsal went well overall. The challenge for the rehearsal came at the beginning when the students were not focused. As far as the musical aspects of the rehearsal, Jacob is pleased with how well they have retained what they have learned in the music. "I was wondering if we'd even be able to pull the a cappella piece off for the spring concert, and now I might actually consider it for contest."

$>$ He is excited about their musical success; positive reflection.

Jacob writes positively about his undergraduate preparation, and talks specifically about how well prepared he was in terms of rehearsal techniques and literature selection. Jacob also recalls his positive student-teaching experience. As he reflects upon his personal journey as a musician, he notes that his aural skills have vastly improved since his undergraduate days. In the present, Jacob has found that using audio and videotapes during his rehearsals has helped him to focus on his listening skills, which has made the most significant difference in his aural development.

$>$ Self-improvement enacted.

Jacob addresses the issue of reflection in an honest and forthright manner. He states that he has learned to be careful when he is reflecting a great deal. He admits that it causes him to be highly self-critical, which can be disconcerting to him. "Either I become too picky or expect too much when I put my work under the microscope. Reflecting too much only leads to anxiety for me.”

$>$ Personal risk barrier -- what if he does not like what he sees?

Jacob continues in his written response that he reflects about his job all the time and that the process of thinking about his practice is ultimately what makes things work. 
Uses reflection to affect practice.

However, journal writing is not needed to accomplish musical growth, according to

Jacob. He admits that journal writing could be beneficial at another point in his career, especially at a time when he is feeling "stagnant or in a rut."

Conflicting messages -- sometimes he admits he is stuck in his career and at other times he says he is not; even though he negates the value of journal writing, they are in-depth and revealing as seen later.

\section{$\underline{\text { Last Follow-Up Interview }}$}

First of all, I ask Jacob to look over the observation field notes from the rehearsal and then ask him if they accurately reflect what happened in the rehearsal. Jacob tells me that the notes reflect what he recalls from the rehearsal and that there were not any surprises. We then go on to discuss his journey in using a reflective process. He is honest in his remarks. Jacob says that reflecting on various aspects of his professional life has been difficult because he is unsettled in his position as a middle school teacher. He uses the metaphor that reflection is like putting "salt into a wound" as it makes it more evident that he is unhappy in his position.

$>$ Personal risk barrier admitted.

Jacob shares that he is disappointed that he has not been able to focus on pedagogical issues involving music during this study because discipline was the area that needed to be addressed. He shares that he has discovered a major insight through thought reflection that the students want to be in choir because of the social aspects. That in turn, has caused Jacob to look at how to balance social and musical experiences. 
Jacob states he has had some physical wellness issues, which have caused him to be moody and irritable. He admits that he has not been eating right nor has he been exercising. He says that this study has influenced him to take better care of himself.

Physical health affects a teaching practice; reflection has brought this to light.

Jacob ends the conversation by saying that he has always been and will continue to be reflective. He is aware of reflective thoughts throughout each day, whether they occur in the car or in bed. He believes that it is part of his personality.

$>$ He has been open and honest with himself through his reflections.

\section{Types of Reflection Tools Used/Issues of Reflection}

\section{Autobiography}

This was a difficult document for Jacob to complete. He handed in an "autobiographical outline" several weeks into the survey, even though it was assigned at the beginning. Jacob's resistance to finishing the document was explained in his comment, "It is difficult for me to write about huge issues such as the joys and challenges of teaching." We completed the autobiography via an interview near the end of the study. He told me that it was easier to talk about these issues after entrenching himself in this reflective process.

$>$ The process of reflection takes time; the ability to speak freely, clearly, and honestly occurred once the reflective process became more natural.

Jacob's autobiography reveals the value of striving for excellence for himself and his students. He refers to this three times within the document. A positive self-image was revealed in his listing of his strengths as an educator. These characteristics, which numbered eleven, included caring, kind, understanding, organized, respectful of differences among people, and competent as a musician and educator. Jacob wrote that 
internal impatience in terms of his present job and occasional difficulty articulating ideas are some of his weaknesses. He refers to the search for finding the correct age level match to meet his job satisfaction twice in his autobiography. When asked the question, "What might you be doing ten years from now?' he answers, "teaching high school."

> He knows his own strengths and weaknesses; frustration with teaching at the middle school level has been evident in several pieces of data.

\section{Reflective Journal Entries}

Jacob made seven extensive journal entries. Jacob typed five entries and two were transcribed from his tape recorder. These entries occurred during the first five weeks of the study. Jacob based his first reflection on the Critical Incident Questionnaire as I had suggested. It begins with a positive evaluation of his rehearsal. He was excited that the students were interested in this research study, which therefore, revealed his own dedication to the project. He shares that he was pleased with his teaching of a Latin text because the students picked it up quickly. Jacob found the most disappointing/puzzling moment to be focused on discipline issues.

$>$ A recurring theme based upon the observations and interviews.

However, his positive attitude is revealed in his comment that "the class overall was more focused that in Friday's rehearsal." Jacob then goes on to discuss his disciplinary action approach where he will send home a letter to or call the parents of students who are talking repeatedly. The student's grade will be lowered as well. Jacob expresses his concern with the effectiveness of the plan, "We'll see if it actually works or not."

$>$ Trying different strategies.

Reflection \#2 also employs the Critical Incident Questionnaire. Jacob first expresses how excited he is that so many students want to take part in solo and ensemble 
contest. However, he feels badly that not everyone will be able to sing in the contest because not all of the students have the appropriate level of responsibility. He relates that he will try to place everyone in an ensemble so that they will all have the contest experience. Jacob states that there were not any disappointing musical moments in the rehearsal.

$>$ Positive once again about the rehearsal; during the interviews, Jacob tended to be more negative.

The third reflection begins with a discussion of the purpose of sight-reading. He lists four important reasons for including it in his curriculum. Jacob also addresses the use of the specific sight-reading text but reveals that he is using it as an experiment as he has only used it with a high school choir.

Reflections on why he is using a specific curricular methodology; uses what he knows.

Jacob writes that he believes much of his teaching is based on experimentation. He enjoys trying new things and is cognizant that what works for one group of students will not necessarily work for another.

$>$ Does not want to practice reflexive teaching; he knows that there is always something to learn.

Jacob then expounds on his difficulties with discipline issues, chattiness in particular, during the rehearsal. "I still find myself scrambling for just the right technique that will help with this issue." He tells me that he has 16 parent calls to make because of his new plan on top of planning for solo and ensemble contest. Frustration sets in as revealed in his comment,

When the time spent disciplining starts to take away both prep and personal time, I start to consider just putting up with the disorder that exists. I don't like it, but I'm not going to drive myself insane playing the eternal policeman when there are more important things in life that matter. 
Struggles with trying to deal with this discipline issue, and being able to balance his energy among various facets of his professional and personal life.

Jacob begins his fourth reflection attending to the previous reflection, "I chuckled as I read the last few sentences of yesterday's reflection. Those sentences were written in frustration on a day which I did not feel good."

$>\mathrm{He}$ is spending time reading his reflections to find new understandings and to weigh their content; physical illness again; regains a positive attitude.

Jacob goes on to say that he was hopeful that this rehearsal would be successful but the behavior was so obnoxious in the first few minutes that he lost his patience. He writes that he firmly declared, "Instant detention for even looking like you're talking." Jacob says that he was tested five times within the following six minutes. He then added to the punishment by telling the students there would be a call home as well. Jacob recalls that the atmosphere suddenly became peaceful and quiet.

$>$ Tries another technique.

Jacob admits that it is a shame that this type of atmosphere needs to be created. However, he feels that it is justified based on the immaturity of the students. He acknowledges his struggle to find the solution, but feels his chances are good with this last approach if he follows through.

Jacob ends this journal entry on a positive note. He did some sectional work with the students and feels that it is an effective way to teach pitches. It also allows him to be more relaxed and friendly with the students.

Smaller numbers of this age group enable Jacob to have a positive teaching experience.

The fifth reflection starts out with a reference to his classroom management approach as the "Nazi discipline." Jacob finds that it is going well and remarks, "Some 
moments were even awkward in a way because I'm not used to them being that quiet!"

$>$ Must be pleased; humor is added.

Sectionals were a part of this rehearsal and seemed to be effective. Jacob even refers to the rehearsals as being "fun."

Lighter, positive attitude.

The rehearsal ended with a run-through of the pieces with the entire choir. Jacob was pleased with the results.

Jacob turns to the issues of classroom management once again. He reminds himself that students need "solid control and obvious no-nonsense consequences." Jacob has been worried in the past that using a controlling technique may create a "sour, vengeful" atmosphere in the classroom.

Seems confident that he has found the answer; much energy has been devoted to this issue.

He is hopeful that since this issue is resolved, he will be able to reflect on other pedagogical and curricular issues in this study.

Reflection \#6 begins very positively with Jacob's comment that the rehearsal "went a lot better" than the last rehearsal. He discusses how he had felt guilty about canceling the winter concert but then realized that it was the right decision based on the fact that the students were unprepared, partially due to circumstances beyond their control. Jacob shares,

I tried to make it as clear as I could that it was not their fault, even though in reality the part that I didn't tell them was that one of the big reasons for canceling is because their preparation has not been as good.

De wants to promote a positive atmosphere and help them build confidence in meeting their goals. 
Jacob writes about the music conference he had just attended and how it has refocused his teaching practice. One of the sessions was centered on the strengths and weaknesses of a product-oriented choral program. Jacob realizes that his focus on "pounding out notes" takes away from the comprehensive musical approach.

$>$ A clinician at a state convention looks at the challenges of the traditional choral discourse; he becomes aware of the choices he has made in his practice and their consequences.

The last journal entry begins with a positive comment about the week as he writes, "It has been a really good week as far as teaching and directing these ensembles is concerned." He refers once again to how the state music conference had an upbeat effect on him in terms of being rejuvenated.

$>$ Professional development and talking with colleagues produced constructive and affirming results. Jacob also feels a sense of relief about canceling the concert and is able to have a fresh start with new repertoire. This unloading of performance pressure has lightened the mood, which has therefore, improved the behavior of the students. Jacob writes,

I am trying to take more of a relaxed feel and have more fun with them. The ruling with an iron first didn't seem to be working with this group. It was burning them out and it was definitely burning me out.

$>$ He has reflected on all of the ramifications of the classroom management issue, has reached some conclusions, and has changed his behavior.

Jacob concludes that he is feeling better about the students and the rehearsal itself and he believes the students are too.

The evening following parent-teacher conferences, Jacob spent some time speaking with colleagues many of whom have 20 or more years of experience. He then is able to console himself in terms of the discipline issue. Jacob shares that although it has 
been "a little embarrassing" for the reflection process to focus on behavior so much he knows that experienced teachers have similar situations as well.

$>$ Talking with colleagues can bring perspective to a teaching practice.

Jacob writes that teachers are even trained to blame themselves because they are taught that a student's behavior is directly connected to what the teacher is or is not doing. Jacob acknowledges that teachers cannot control nor affect a student's behavior all of the time. He ends his journal writing stating his desire to stay in a positive mode.

\section{Reflective Narrative Exercise}

Listed below are Jacob's responses to questions specifically asked in an optional reflective exercise entitled, "Reflective Inventory."

"What are you proudest of in your work as a teacher?" Jacob is most proud of his students in a performance situation. He is thrilled to "see them realize the fruits of their labor." Jacob is particularly proud on Solo and Ensemble performance days as this is when "the confidence develops within the students."

Contest, part of the choral tradition, is an important part of his curriculum.

"What would you like your students to say about you when you are out of the room?" Jacob hopes that the students would say that he cares about their learning and their musical progress as well as seeing him as hard working and dedicated to their educational and personal development.

$>$ Teaching with a critical approach - being a part of the students' personal development is important to Jacob.

Jacob wants them to know that he "accepts nothing less than the best," which may require him to be strict and demanding in the classroom. 
"What do you most need to learn about in your work as a teacher?" Jacob states that he needs a better balance of strict versus understanding in terms of handling student behaviors. He wants to learn how to implement consistent management techniques for middle school behavior. "I find myself becoming increasingly impatient with this age [of students]."

$>$ Personality characteristics affect practice.

"What do you worry most about in your work?" Handling discipline problems is the answer Jacob gives.

$>$ Discipline issue reiterated once more.

He also discusses his multitude of responsibilities, which leave him with inadequate preparation time. The combination of being a choral director and general music teacher is challenging in terms of giving both priority. Jacob believes that these two responsibilities should be separate jobs. Related to this issue is the ability to have a quality life outside of the classroom. Jacob says he now refuses to let his professional life take over his personal life.

$>$ Professional life affects personal life -- difficult to balance.

"When do you know you have done good work?" Informal student assessment is Jacob's response. "Those moments when you are working with students and you see or hear them retain a technique, word, or concept that has been practiced, then you know they have learned something." Jacob refers to concerts and contests once again as being an evaluative tool. He writes that he knows that performances should not be the tell all, but they have been a major part of his self-evaluation as a teacher. Jacob especially 
values feedback from other people in the field, such as adjudicators. He balances out the perspective by stating that opinions from parents and his own relatives matter, too.

Contest is used as a measurement of competency; he recognizes that there are other constituencies that are important, too.

"What is the mistake that you have made that you have learned the most from?"

Jacob states that there are many.

$>\mathrm{He}$ is aware of his imperfections -- realistic and honest.

He shares one specific incident where he cared too much what a certain student thought and was misled to believe that many other students felt the same way. When Jacob confronted this student, the student made him believe that he had become "this terrible person whom everyone was beginning to despise.” After a few weeks of careful observation and input from other students he realized that this was not the case. "Not trusting myself and judging my actions too quickly because of what one person or small group of people think is always a big mistake to make."

$>$ Spent some time and energy assessing the problem -- reflection-on-action.

\section{Student Journal Entries}

Seventy-six students were present to fill out the student journals. Of those students, 40 had consented to be in the research study. Most of the students were quiet and on task while answering the questions. There were a few students who were talking and two students crumbled up their papers and were slightly disruptive. The students took anywhere from 4-22 minutes to write. The first question asked them what they enjoyed about choir. The following responses were given multiple times: singing, strengthening the voice, the repertoire, being able to express themselves, learning new things, being with friends, and performing. 
The second question asked the students to list three words to describe Jacob's personality. The following adjectives were listed the most often, in order of most frequent to least frequent: nice, determined, strict, mean, encouraging, and patient.

$>$ Both ends of the spectrum are revealed; issues of discipline can be read within descriptors. The students used a total of 59 different adjectives. Some students used adjectives that were the opposite of each other. One student listed both nice and cold-hearted to describe Jacob; another said both nice and mean.

$>$ Students see many different facets of his personality.

When asked if and how Jacob has changed since the beginning of the research study more students noticed a change than not. Of the students who noticed a change, the majority found Jacob to have become stricter.

$>$ Students are aware that Jacob was dealing with discipline issues.

Other students noticed that he was either nicer, more stressed, or was trying to improve how he taught.

The challenges of the choir as seen by the students are as follows: not talking, paying attention, learning the right notes, and vowel formation.

$>$ Many students are aware of their behavior problems.

Other areas concerning challenges that were mentioned were: posture, intonation, sightreading, dynamics, memorization, and singing expressively.

$>$ Some students were able to critique musical skills.

The personal challenges matched the choir challenges. Many students stated that they needed to pay attention and/or stop talking. Other students wanted to work on improving their voice or learning the music. One student said his challenge was to "ignore those who are not on task." 
Many students are aware of their personal challenges -- able to self-critique.

When the students were asked if they would encourage a new student to join choir, most students emphatically said yes. Some of the reasons why included: "It is a fun learning experience," "Even though it's challenging at times, it's all worth it in the end," "It's a chance of a lifetime," "We are a good choir," "It's a relaxing break from the normal school day," and "It's a good opportunity to meet friends."

Students are able to see the benefits of participating in choir; there is a sense of pride coming from many of the students.

\section{Jacob's Reaction to the Student Journals}

The number of positive and constructive comments pleasantly surprise Jacob. "Students are saying things that are insightful and thought-provoking. I am surprised how many say they really like the class, because as a group they don't always act like it! This is making me re-evaluate my own perception of what has been going on."

$>$ Revealed information from students is valued by Jacob, which causes more reflection. Jacob notices the inconsistencies in the students' comments. He states that it shows the different maturity levels that are in the choir.

$>$ He understands the variations possible among different adolescents.

Jacob comments that he is pleased that the students make friends in choir. He shares his belief that this is very important in musical ensembles. "The trick is finding a balance between work and social activity in ensembles of this nature. With this age any hint of social freedom in a group of 96 usually ends up in chaos."

Large number of students creates the possibility for more discipline problems; Jacob is looking for ways to allow for social interaction without losing control. 
Jacob discusses the one student who described him with some very hateful

comments. He thinks he knows who the student is and says that he feels sorry for her.

Jacob is pleased that the strong majority of "my toughest group of critics [the students]" responded positively.

Journals were affirming, and also provided new areas for reflection. 


\section{JACQUELINE O'KEEFE}

\section{Background Information}

Jacqueline is a middle-aged woman of Polish descent, with 24 years experience as a music educator. Her tall stature lends itself to a strong air of authority. A warm smile and a big hug greet all those who know her, which encompasses many people from all walks of life. Jacqueline's reputation throughout the community is marked with high regard for her musical competency and her positive rapport with adolescents. As she has no children of her own, her students truly are her family. The bond between the three hundred and forty students she teaches every day is strong and genuine.

Jacqueline grew up in a suburb of a large metropolitan city. The youngest of four, all of her siblings are involved in the educational process: one sister is a math teacher at a community college; another sister just retired after 30 years of teaching at the elementary level; and her brother serves as the assistant treasurer of a board of education. Jacqueline's husband is also an educator. After teaching for 17 years, he now serves as the information center coordinator for a large school system. The world of education and Jacqueline's marital and familial lives are strongly intertwined.

Jacqueline's journey into music began at the age of four when she observed her mother giving the three siblings piano lessons. Jacqueline writes, "I just hung around and learned with them. Supposedly, it got to the point that I was not allowed to be in the room when my siblings practiced because I would go over to the piano and out play them." During the second grade, Jacqueline was given lessons from the stereotypical piano teacher who was the "little old lady up the street." Jacqueline remembers two 
significant skills she learned from those lessons -- sight-reading and learning to not stop in the music when you make a mistake. It was during this time that Jacqueline discovered that she had absolute pitch, which she says has been both a blessing and a curse.

Jacqueline's elementary school musical career was filled with playing in the orchestra, accompanying the choir, and singing in the all-city choir. She continued accompanying choirs during her junior high school years, much to the dismay of her new piano teacher. This teacher felt it took too much time away from solo practicing, even though Jacqueline did not want to be a solo performer. Jacqueline recalls having the opportunity to take private theory lessons during this same time period where she learned how to transpose. There were three "glorious years" with her theory teacher.

When Jacqueline started high school, she took piano lessons from a music professor at a local university. This teacher was both challenging and encouraging, and exposed Jacqueline to contemporary music. Also, during the high school years, Jacqueline served as the main accompanist for five different choirs and became the choir teacher's assistant. From these experiences she learned how to read open scores.

Jacqueline shares that there are two other significant forces on her musical history; her family and her dance lessons. Her uncle was a very prominent high school choir director. Most of her aunts and uncles were teachers. On her mother's side of the family, there were sixteen grandchildren, and all of them played musical instruments. Jacqueline recalls that on every Christmas Eve the family orchestra played for each other, which her uncle conducted. 
Throughout her 13 years of dance, which included tap, ballet, and jazz, Jacqueline was exposed to the production of big shows. Her mom sewed the costumes and her dad typed the programs. Jacqueline was introduced to a variety of Broadway show tunes, as well as the art of improvisation. Because of these experiences, Jacqueline felt comfortable playing for dance lessons during her high school career and received free lessons in return.

When Jacqueline entered college at a large state university, she started as a double major in math and music. By the end of her freshman year, she was really bored with math, so she changed to a double major of music education and piano performance. She became one of the main accompanists for the voice students as well as the accompanist and assistant director of the university chorus. Jacqueline took advantage of the opportunities opened to her and remains grateful for the variety of mentors that have surrounded her throughout her life.

Jacqueline has held the same teaching position since graduation and is proud to be a part of a strong school system. During her seventh year of teaching, she also pursued her masters' degree in music education at the same university as her undergraduate training. The system in which she works is one of the largest in the state. The parents of the student population are considered middle class, with Caucasian being the dominant ethnicity. Approximately $10-15 \%$ of the student body is African-American. There is a sizeable Somalian population, as well as a large Mormon group of students. The school itself is 28 years old but was renovated 12 years ago.

The choral space is a large room with a tiered floor and is only used by the choral department. A grand piano sits on the lowest level in the middle of the floor. A 
chalkboard and bulletin board are located in the front of the room. Offices are directly connected to the front of this choral space. Music folder cabinets are located on the left side of the room and a music storage room is off to the left of the tiered floors. The entire complex represents a well-designed use of space, adequate to fill the needs of the six choirs involving 340 students that inhabit the area throughout the school day.

The choir that took part for this study is the freshmen girls' group with 90 members. They meet from 1:05-2:00 p.m. every day throughout the year. This is a nonselect group, many of whom are in this class to fulfill the arts requirement.

\section{$\underline{\text { First Rehearsal }}$}

Ninety adolescent girls entering the same space at the same time present a cacophony of sound. Jacqueline pounds on the piano to get their attention. She has them repeat; "I will be in my seat, with my folder, without gum" several times until most of them are seated. Her tone reminds me of a mother telling her children to behave, in a manner in which you know that she really cares. She addresses two students by name to see if they are ready to begin the rehearsal. Jacqueline then quickly moves into some physical exercises including shoulder rolls. The students sing a vocalise with Jacqueline constantly coaching over them and giving them positive comments throughout the exercise. During the scale exercise, Jacqueline becomes very excited about how well they are performing and yells "yahoo," and then tells them to pat themselves on the back.

$>$ The feeling in the air is one of excitement; her enthusiasm is real as she expresses pride in their singing.

Jacqueline continues with the vocal exercises, addressing individual students who are not focused, but does not let it slow down the pace of the lesson. One girl is combing her hair and Jacqueline comments, "Don't worry about your hair - there are no boys in here." 
Addressing the social needs of girls; she has a playful air in her vocal delivery of the message. Jacqueline then hands back a sight-reading quiz to the students by laying them on the floor.

$>$ Authentic assessment is a part of this choral program.

She continues with sight-reading exercises. The students use numbers as they sing through an exercise. Jacqueline moves around the room, snapping her fingers to the beat to help the students keep a steady tempo. She occasionally makes a funny or sarcastic comment. After the girls complete the exercise successfully, she tells them once again to pat themselves on the back.

$>$ There is a feeling of genuine caring as well as an atmosphere of fun.

The first piece sung is A Joyful Alleluia in six parts.

$>$ Challenging music.

Jacqueline uses her hands as a visual cue to help the students find their individual part lines. As Jacqueline rehearses the piece, she asks the students to solve problems, rather than telling them the answers.

Uses higher level thinking strategies; challenges them to think for themselves.

When a pitch problem occurs in the singing of one of the parts, Jacqueline goes to the board and shows them the difference between an A flat and an A natural.

$>$ Incorporates music theory.

Throughout the rehearsal, individual girls leave the room one at a time with a toilet seat in their hand.

I assume this is a hall pass to go to the restroom.

Jacqueline does not seem to be bothered by the constant movement in the room.

I am distracted every time a girl leaves the room; she is trying to be fair in allowing anyone who needs to use the restroom the opportunity to do so. 
The students continue to work on select portions of the piece, singing the song a cappella.

Even though she is a keyboard person, she does not allow the students to rely on the piano to get their parts -- she is training their ears.

Jacqueline notices that the balance is off, with the outer parts singing more strongly than the middle voices, so she uses a sandwich metaphor to explain the importance of those middle parts in relation to balance.

Making musical issues understandable to the students.

Several students have questions about various aspects of the piece and Jacqueline addresses each of the girls in a positive manner.

$>$ She promotes a feeling of not being afraid to be wrong or ask questions.

The students do a run-through of the piece and Jacqueline performs a multitude of tasks during their singing, which include playing the piano, singing with the students, coaching over them, and conducting.

$>$ She is prepared and can reflect-in-action as to what needs assistance.

The rehearsal closes with the singing of Oh Dear, What Can the Matter Be? It is obvious that the girls are engaged and enjoying themselves as can be seen through the smiles on their faces and their exhibited energy level. The girls leave the room with a flurry of energy.

A fast-paced, energetic, productive rehearsal.

Interview Following the First Rehearsal

I begin the interview by asking Jacqueline if this is a typical rehearsal. She answers emphatically, "No, they were on better behavior because you were here. They 
were showing off a little bit, but that is okay." In terms of their singing, she tells me that this was a typical rehearsal. She explains that they are "pretty talented."

$>$ There is pride in her voice.

The focus of the rehearsal is the next topic of conversation. Sight-reading in preparation for A Joyful Alleluia was one of Jacqueline's main goals for the rehearsal. I ask her why she uses numbers rather than solfège in the sight-reading. Jacqueline believes that students relate better to numbers. It is a practical issue-when the pitch goes up, then a higher number is used, as opposed to the abstract solfège syllables. She has found more success with the number system

$>$ Has tried both sight-reading systems and employs the one with which the students find more success.

Jacqueline continues the conversation outlining other goals for the rehearsal. We then move to the importance of the rehearsal being enjoyable for the girls. Jacqueline states that it is very important for the girls to have fun in choir. She can tell when the girls are having a good time just by a feeling in the air. She believes that they were enjoying themselves today. Jacqueline finds that the students receive pleasure from choir when they are successful in their performance. Specifically addressing contest, Jacqueline has told the group that she feels they could earn a superior rating and challenged them to be their best.

$>$ Uses part of the traditional discourse, contest, to motivate students to be successful.

We then turn to the subject of bathroom privileges. Jacqueline shares that it is driving her up a wall and she is trying to find a new solution.

$>$ It didn't affect her teaching but she is obviously bothered by the distraction and the choices some of the girls are making. 
It is usually the same 15 girls who leave everyday. She explains that because the classroom is at one end of the large school building, students legitimately do not have time to use the restroom in between classes. Because these 15 girls have an early lunch, they probably legitimately have to go to the bathroom. However, Jacqueline acknowledges that there are a few students who are abusing the privilege, therefore presenting her with a real dilemma.

I ask Jacqueline to comment on her remark about the girl needing to stop combing her hair because there were no boys around in terms of noticing a difference in her own behavior when she is teaching girls only. Jacqueline replies that she definitely behaves differently. "I am willing to use words that I might not use if there are boys in the room. Like, does anybody have a tampon so-and-so could use? One day, there was a male substitute for the assistant choral director who was really cute and we discussed the next day how cute he was."

$>$ Is aware of gender differences and relates to the girls based on situational gender issues; critical pedagogy enacted.

Jacqueline tells me that she enjoys teaching boys a little more than working with the girls, even though the boys can be exasperating because of their immaturity. She enjoys the male sound and their spunk. She comments that girls get whiny, not an attribute she particularly likes.

$>$ Open and honest about her preferences based on personal characteristics -- in rehearsal, however, it was apparent that she enjoys working with girls, too.

She humbly admits that one of the major reasons for the success of her choral program is her ability to build a relationship with her students.

$>$ Relational pedagogy. 
The process for selecting music is the next topic of the interview. Jacqueline states that some of the repertoire comes from the contest list. She wants the music to be challenging and yet incorporate some lighter pieces as well. I ask her if she does all her programming for her concerts in the summer and she shares her typical summer scenario. "I do three things in the summer, I sleep, I play tennis, and mow the lawn. I am so exhausted and worn out from the school year."

$>$ Personal life is affected by demands of profession; works to achieve balance in the summer.

\section{$\underline{\text { Second Rehearsal }}$}

As the girls enter the room, Jacqueline tells them there will be no hall passes and they must throw away their gum.

$>$ Change of policy (hall passes) due to reflection.

Once the girls are seated, I give them a quick update on the study. Then the girls are assigned new folder numbers. Jacqueline explains the procedure for picking up their new folders.

$>$ She speaks in a confident, direct tone.

She then makes a few more announcements and compliments them on their ability to learn the festival pieces quickly. She pats a couple of students on the back.

$>$ Caring, nurturing atmosphere.

Physical exercises begin the warm-up period. Throughout the a cappella vocalises, Jacqueline reminds them to check for posture. A challenging chord-building and resolution exercise is performed correctly, and Jacqueline literally jumps up and down to show her excitement about their success in resolving the chord.

$>$ Genuine enthusiasm shown to the choir. 
St. Louis Blues is the first piece of repertoire to be rehearsed. Jacqueline gives some background information about the story of the piece.

$>$ Contextualizing and building interest.

She explains to the students that the goal is to sight-read the piece and find the places where there are major changes.

$>$ Gives them clear goals.

She tells them that it is a "really, really neat piece."

$>$ Builds enthusiasm through sharing her opinion.

Jacqueline gives clear instructions as to where each part is and then has the students begin singing. She plays the piano and sings with them for the first three phrases. She then highlights the 12-measure blues progression.

$>$ Music theory, comprehensive musicianship.

As the students continue to sight-read the piece, it becomes more challenging when it breaks into three parts, and the students struggle. Jacqueline tells them that when they do their sight-reading at contest, they have to keep going; they cannot stop when they make a mistake. She reminds them that they should be pointing at the notes and helping their neighbor if someone gets lost.

The last few minutes of the rehearsal are spent on A Joyful Alleluia. Jacqueline adjusts the balance among the parts through coaching as the girls sing through the piece.

$>$ Her aural skills are well developed.

She makes a few quick adjustments on various pitch and rhythm problems and gives positive reinforcement at the same time. The bell rings.

$>$ Reflects-in-action; can critique them positively. 


\section{Interview Following the Second Rehearsal}

Jacqueline begins the interview by telling me that the reflective journaling is getting to her. She explains that she would rather talk into a tape recorder. I tell her that I think it is a great idea and I will have the information decoded by my transcriber. We then go on to the topic of discipline. She shares that she and her assistant director are having tremendous discipline problems with two of her other classes and it has totally consumed her. Jacqueline has spent countless hours talking to the parents of the students who are causing problems. I reassure her that it is fine to focus on this part of her practice even though the problems are not within the freshmen girls' choir that I am observing.

I ask her how she felt today's rehearsal went. Jacqueline replies that it went pretty well and felt that the students were acting more normal than the last time I was here. "There was still a lot of immature stuff but that's them."

$>$ She says this in a matter-of-fact manner; she understands the adolescent.

I ask her if the issues with student behavior are the same as they were ten years ago. Jacqueline discusses several issues that have affected student behavior or are relevant matters on students' minds, including the increase in number of divorces, the Columbine tragedy, and September $11^{\text {th }}$. I ask her if she spent time during her rehearsal to deal with those two tragic events. She replies that she did take a lot of class time discussing the issues associated with Columbine. In terms of the events of September $11^{\text {th }}$, a patriotic concert was added.

Finding ways to related to the global community; critical pedagogy in action. 
She says she has not emotionally dealt with that tragedy with the students "because I don't know how to deal with it, I am still having a hard time with it and so for me to initiate a conversation I am really gun shy, I don't know that I'd say."

$>$ A very difficult emotional issue that she is not sure how to handle with the students.

We move on to how has Jacqueline's teaching practice has changed throughout the years. She believes it is in the way she tries to understand the students. "I try to remember that they are people, that choir is not necessarily their number one love in their life."

$>$ Not about musical issues, it is about the person; critical pedagogy.

Jacqueline sees her belief that each student is a person first and a choral singer second is the major change in her teaching philosophy. "I think that comes with experience and maturity and feeling comfortable enough to do that, or confident, maybe I should say.” As far as musical skills are concerned, she believes that her listening skills have improved. "I think that I am not as afraid to tackle the [aural-related] problem, which you avoid when you are younger."

$>$ Confidence builds with experience. Jacqueline discusses her decision to stop the usage of the bathroom passes. "I just didn't feel like it today. I am thinking we should just have no passes. I think the no pass thing worked but that was a spur of the moment decision."

$>$ She reached the point she had had enough; frustration influenced practice. I conclude the interview by asking her about the reflective process. It has made her think about various aspects of her life more. "I am thinking a lot about my training." She says that it is making her more conscientious but it is a lot of work and is somewhat 
time-consuming. "It's like one more thing to do."

D Time barrier is evident; seems to be reflecting because she is being told to, rather than because she wants to.

She is optimistic, however, about taping her reflections on her long drive to and from work. She shares that it was enjoyable to write about her high school and college events. "This was a nice reminiscing."

A pleasurable aspect of reflection.

\section{Third Rehearsal}

The rehearsal began with 34 students being tardy. Jacqueline waits until everyone got quiet and then explains to them that their tardies are inexcusable. She states she will start to give detentions for this behavior. She tells them to "put your brains on" and begins the rehearsal.

Exercises including breathing, sirens, blowing bubbles, and scale on numbers are employed next. Jacqueline points at a chart with numbers to assist with interval training. Some of the intervals are performed incorrectly.

$>$ She grimaces at their mistakes -- perhaps the incident with the tardies has added to her noticeable frustration.

Sight-reading is next, and Jacqueline tells them once again to "put your brain on." During the singing of these exercises, Jacqueline gives them positive reinforcement and tells the students to "give your neighbor a high five."

$>$ Trying to build a positive atmosphere; her facial and body gestures changed almost immediately. A Joyful Alleluia is the first piece of repertoire rehearsed. The goals are to find the coda and then be able to sing the transition to the coda. Jacqueline relates the intervals to the sight-reading exercises. She uses metaphors and gives well-known tune clues to help the 
students sing the correct intervals.

$>$ Employs practical means for students to be successful.

Throughout this portion of the rehearsal she has to remind the students several times not to talk. Jacqueline moves around the room and assists the various parts. The piece is sung in its entirety with success.

The students sing through From Sea to Shining Sea next. Jacqueline follows the performance with an overview of the piece. Again, the sight-reading exercises from the beginning of the rehearsal are related to the specific intervals in this piece. One student is addressed six times for talking. The rehearsal ends abruptly.

$>$ She is aware of almost everything going on in the classroom and holds the students accountable for their behaviors through reprimands.

Interview Following the Third Rehearsal

Jacqueline begins by sharing her views of how using the tape recorder for her reflections is working. She feels that it is an effective way to record her thoughts although she says at times it feels like she is just rambling. "It is good to verbalize, sometimes like just talking to a friend, if you can hear yourself saying the words you are like hum, do I really mean that?"

She has found an effective way to record her reflections; is feeling a little less stressed about this process.

We turn to the events of the rehearsal. She exclaims, "They were so wild, didn't you think?" I share with her that I saw her frustration and that there were several justifiable reasons for that feeling. I ask her if the tardiness issue is common. Jacqueline replies, "This was unusual. I give them a little bit of lax. But when I went out there they weren't even walking with purpose, they were sauntering down the hallway and I am like, I don't think so.” 
Jacqueline's frustration over the sight-reading chart is addressed. She admits that they have not used the chart much. She was just hoping that they would have been able to sing the intervals better.

$>$ She is aware of her frustration.

The conversation turns to the student population of the school district. The school has had its population drawn from various subdivisions throughout the years based on the growth of the area. Jacqueline recalls teaching the "rich kids" where students were turning sixteen and being given a new car from their parents. "What in the world is this all about? I was appalled. When I first started teaching these kids, they were way too rich for me. I grew up in a blue-collar family though so that didn't help."

$>$ Family upbringing affects perspective and opinions of students.

Jacqueline continues to talk about her experiences with the rich students. She recalls a specific incident during her first year of teaching, which involved a girl who was a choir officer. At the end of the year, this girl said to Jacqueline, "You are the first person I have met who wears really pathetic clothing but I actually like you." Jacqueline looked at her and said, "Do you know how that just came out?" The girl replied, "Really badly." Jacqueline replied, "I think you are giving me a compliment." The girl stated, "Yes, I am. I am always focused on clothes and you are the first one I met who is not focused on clothes." Jacqueline told her, “Okay, let's just keep it as a compliment and we'll go on from here."

She has a very clear memory of this event -- this was a moment of revelation for both Jacqueline and the student.

Jacqueline points out that she cannot generalize as to whether it is easier or more difficult to deal with wealthy students and their families. The advantage the students 
from wealth have is that often their parents may have more time to be more supportive in terms of attending concerts and volunteering at the high school because the moms do not work as much. However, Jacqueline sees a huge decrease in the amount of commitment in supporting the teachers by following through at home on the parents' part. This is regardless of the family's financial status.

Issues of diversity are addressed next. Jacqueline has found this school community to be very tolerant. In terms of repertoire selection, she does not let the religious background of her students strongly affect her programming. She does make a conscious effort to cover a wide variety of music.

She addresses issues involving a critical pedagogy by encompassing many styles and cultures in the repertoire; she is not specifically focusing on or avoiding a specific style of music.

Lastly, we discuss issues of a professional nature. As choral programs go within this state, Jacqueline feels hers is above average. She knows of many good teachers throughout the state but also is aware of many lousy teachers where music is considered to be a joke. "If you have a senior choir of 21 kids of which one is a boy, something is wrong, you are not doing it right."

$>$ Is confident in her ability to build a quality choral program.

As far as trying to raise the number of students entering the choral education profession, Jacqueline has some thoughts. "I don't really encourage anyone to go into it, but I don't discourage them either. You have to really want to do this."

$>$ She believes that there must be commitment to enter this field.

In regards to being active in professional organizations, Jacqueline has both chosen and been forced to make some decisions. She chooses not to be heavily involved 
in attending summer conferences because of her tennis league, and is not permitted per her school district to go to more than one conference during the school year.

$>$ Staying active on a professional level has obstacles; she has resolved these issues in her mind.

Fourth Rehearsal

The students write in their reflective journals during first part of the rehearsal. After the completion of that activity, Jacqueline tells the girls to stop talking and be seated. She returns their audition tapes and tells them to take the tapes home. Jacqueline pounds on the piano to get them quiet. The students are then told to get their new folders. She plays the funeral march, the Alfred Hitchcock theme, while they are moving back to their seats. There are several reminders to get quiet.

$>$ The girls are having a difficult time settling down -- a change in the normal rehearsal routine, student journaling, and the moving around was enough to wind them up.

Warm-up exercises are the next part of the rehearsal agenda. Jacqueline uses metaphors to achieve a warm, round "oo" sound. The vocalises are sung a cappella. Jacqueline addresses several of the girls who are not focused before moving on to From Sea to Shining Sea. Jacqueline pounds on the piano three times to get their attention.

> Jolting behavior modification technique.

After telling them once again to be quiet, she explains where there are challenging spots in the music. The girls stand and run through the piece, stopping several places to fix problem areas. Jacqueline coaches over the music and sings with different sections when there are problem spots.

Trying to give them immediate success; she is multi-tasking by singing, playing, and coaching. 
A Joyful Alleluia is the last piece to be rehearsed. To assist them in focusing on their parts, she tells them, "If you are choir one, put your hand on your head. Choir two put your hand on your nose."

$>$ She is able to assess their understanding using creative means.

While singing this piece, several students leave at various times to work with the assistant director. There are several interruptions from people coming into the classroom to deliver messages. Three students are told to throw away their gum.

$>$ Rehearsal feels scattered and unglued.

Jacqueline continues to work on isolated sections of the piece. She uses a "sandwich" metaphor to help the second sopranos understand their relationship to the harmony. She encourages them while they are singing by standing near them and singing with them. The students sing the piece again with more success as the class comes to a close.

She wants them to reach success with their parts.

Interview Following Fourth Rehearsal

I ask Jacqueline if this was a normal day. Jacqueline replies, "Oh my goodness, no it wasn't. We had audition results posted, we handed back audition tapes, you came on a different day, plus it was the Monday after the musical. It was just an exciting day." I ask her if it frustrated her and she said she knew it would be crazy.

Dxperience has helped her to understand why students behave the way they do.

We then spend some time discussing a colleague who has added a stressful dimension to her teaching practice. Jacqueline is honest in her comments and relays the various emotions she is having based on her interactions with this person. However, it is important that she not treat this person unprofessionally or hurt this person's feelings. 
$>$ Being able to stay professional and be a caring person is important to Jacqueline.

Jacqueline shares that she has been able to talk about this situation in her tape-recorded reflections and that has been helpful. Jacqueline agrees that in general, she sees the reflective process as being a wonderful way for teachers to become self-disciplined and learn about their practice even if you can reflect only periodically.

$>$ Sees benefits for reflective process, although is still concerned about time issues.

\section{Last Follow-Up Interview}

We briefly meet one last time to tie up some issues. After I show her my field observation notes, she tells me that they accurately reflect the events of the rehearsal. There was nothing there that surprised her. I ask her if the field notes can help her in any way and she replies, "It is a helpful vehicle to look at what happened and summarize the rehearsal."

$>$ She seems matter-of-fact in her assessment of the field notes and their benefits -- yes, they are helpful but not life changing.

\section{Types of Reflection Tools Used/Issues of Reflection}

\section{Autobiography}

Jacqueline writes openly about many facets of her background and those people who have been important influences in her life. She reveals who she is as a teacher and openly assesses her strengths, challenges, and goals. In her discussion of why she continues to be an educator she talks about how she enjoys being around teenagers. She explains, "I like to think that I am making a small impact on their lives." Some of her professional goals are for her students to learn to sing, appreciate all styles of music, develop self-discipline, and acquire a sense of responsibility and commitment.

> She is working within a critical pedagogy. 
Jacqueline recognizes her musical strengths as: having a good ear; being a good sight-reader; being a good conductor; and understanding most styles of music. She sees her non-musical attributes as: being organized; being able to connect with students; and respecting the students' many other interests. Jacqueline believes her challenges to be: feeling angry at those students who do not seem to care; becoming frustrated with those parents who enable their lazy kids; losing patience with other colleagues who are constantly complaining; learning all of the names of the students quickly; and having enough stamina as she gets older.

> The first three challenges could also be understood as strengths in terms of goals.

Her musical goal for the future is to develop a more consistent tone quality, therefore spending much more time with vowel unification. She recognizes the challenge of this goal because there are many students who are taking choir to fulfill the arts requirement. Jacqueline also wants to solidify her teaching of sight-reading. She acknowledges, “Because I have perfect pitch, I don't always realize the struggles that the kids are having."

She is aware of she needs to stay mindful of the students' abilities versus her own.

Jacqueline also states that she wants to separate her professional life from her personal life. "I need to teach smarter rather than harder, and I need to give the kids more of the responsibility of learning."

Balancing work and home is something that is challenging but she knows how important it is to try and achieve.

This paragraph summarizes her life story,

As you can see, I had a lot of wonderful opportunities. I was lucky to have parents who made music education a priority; I was lucky to have teachers who believed in me; I am lucky to have a family who is very supportive of my 
profession. I am very glad that I have become a teacher, specifically vocal music, and am thankful for being a teacher in a very strong school system. This is my $24^{\text {th }}$ year at this school, and I intend on teaching there, God willing, through my $30^{\text {th }}$ year.

$>$ An inspiring recognition of the forces that have helped to form her as a teacher.

\section{Reflective Journal Entries}

Jacqueline shared 18 reflective journals over the first eight weeks of the study, four of which were hand written, and fourteen were transcribed from a tape recorder. Reflection \#1 uses the Critical Incident Questionnaire. Her best teaching moment on that day involved her show choir. She talks about how she moved around combinations of singers and once she found the ideal formation, there was a huge improvement in the choir's sound.

$>$ Experimentation leads to a successful teaching moment.

Jacqueline's most disappointing teaching moment was with the freshmen boys. She was trying to teach a musical symbol concept and the boys were very disruptive and talkative.

$>$ Discipline problems still evolve with experienced teachers.

The most puzzling moment, which she mentions was also the most frustrating, was during the musical rehearsal when many of the students came late with inappropriate excuses. She writes, "Where's their commitment?"

$>$ A value she continually works to address.

The second reflection is also based on the Critical Incident Questionnaire.

Jacqueline's best moment was during the freshmen girls' rehearsal when she put them in a circle so they could hear each other in the double choir piece.

$>$ Effective positioning of students improves the girls' ability to hear each other. 
The most frustrating moment was based on the hall pass situation. "It is getting ridiculous. The same kids always go. The same commotion. The same distractions."

$>$ Another discipline issue causing the most frustration.

The most puzzling moment was trying to comprehend how a large majority of the students understand how to sight-read and a small percentage have no clue as to what to do.

Searching for how to reach these students who are lost.

The Critical Incident Questionnaire is the format used for the third reflection as well. The best moment was the level of excitement in the freshmen girls' rehearsal, which she partially attributed to my presence as the girls were "showing off a little."

$>$ There was a catalyst for a motivated rehearsal.

The most frustrating situation was centered on the hall pass. She feels the situation is getting worse.

$>$ Same issue involving discipline; provoked her to stop using the hall passes.

The most puzzling moment involved the "schizophrenic" behavior of the freshmen boys' choir. Jacqueline asks herself the following questions to try and understand the problem,

Is it their age and maturity levels; is it my teaching style; is it my assistant director's teaching style; is it the literature; is it the time of day; is it the size of the class; or is it the fact that there are only boys in the class?

$>$ She reflects about all the possibilities in order to seek solutions to the problem.

Reflection \#4 uses the Critical Incident Questionnaire once again. The best moment was when 20 of the boys tried out for a solo (even though she strongly encouraged all of them to audition). Jacqueline writes how she cannot wait to hear the tape!

Excitement about students being willing to take personal risks. 
The most frustrating moment occurred during the review of the semester exam. Some of their questions made her want to scream. She writes, "I need to keep reminding myself that this is their first set of high school exams"

$>$ She is trying to match her expectations with their situation.

Her most puzzling moment was found in the question, "Why do some of the bass/baritones in concert choir insist on acting stupid? We're recording today and they purposefully sing off-key. WHY?"

$>$ The mysteries of the adolescent.

The fifth reflection, which is the first of the transcribed reflections, does not use any specific format. Jacqueline begins with an apology to me, as it has been a week since she has done a formal reflection. She explains that she has been listening to audition tapes while driving to and from school, rather than doing her reflections into the tape recorder.

$>$ She feels guilty that she is not producing enough data for the study -- however, that is simply not the case.

Jacqueline discusses the challenges of the musical, mainly the positioning of the pit orchestra and having control over the ensemble. In terms of the choirs, the biggest stumbling block is the sight-reading in the boys' choir. She shares that even though they sound like a train wreck, the good news is that they are not stopping during the exercises.

$>$ She acknowledges small doses of progress.

Other areas of writing include her student accompanist, choreographers, and the progress of contest music. She comments on all the absences in her groups, which has slowed down the musical progress of each of the choirs. "The flu bug needs to go away!"

\footnotetext{
She is aware that some things are out of her control but is somewhat impatient.
} 
Reflection \#6 starts out with a positive note about the first dress rehearsal for the musical. She then runs down the events of the day. The boys' choir continues to frustrate her because they have so much potential and yet they lack concentration. However, Jacqueline recognizes that there are several boys who are working very hard. She remembers a list of things that need to get done, including making calls and designing new seating formations, but then realizes she has little time to do them. Another frustration with a colleague and an upsetting conference with a parent of a student having a discipline problem are also discussed.

$>$ So many facets of the job, many of which are stressful.

The seventh reflection begins with the declaration that the week has continued to improve. Jacqueline analyzes the spots in the choirs that need work.

She is constantly analyzing problem areas in all of her choirs' repertoire; she seeks solutions and is willing to try a variety of methods for improvement.

She notes how much she enjoys the show choir. "They are getting along, they know how to work but they know how to have fun. They help each other; they don't get offended if there is a suggestion made by me or another kid. It is quite a treat."

$>$ She can find the joys in her practice, amidst the stresses.

Jacqueline starts reflection \#8 by expressing her tiredness after the musical rehearsal. She was very pleased with the boys' choir when I came in to work with them. They were well behaved and responsive. She appreciated my suggestions as well. Jacqueline lists some more activities for the day and then expresses how tired she is once again.

$>\quad$ Physically worn out based upon long days and many responsibilities. 
Reflection \#9, which is being done as she is driving to state orchestra contest, focuses on various aspects of the previous day's events.

$>$ What is this, another thing to do? Why is she involved in orchestra contest?

The musical opened last night and she is pleased with how well it is going. She comments that the students in the pit orchestra, who are presently on their way to orchestra contest, are "walking zombies." She explains that she is going to contest to support the orchestra students.

$>$ She is so caring, and supportive -- perhaps at the risk of her mental and physical health. Jacqueline runs down other events of yesterday's choral rehearsals with notes on problem areas. She confides that she has an unbelievable amount of work to do.

$>$ Constant pressure of many responsibilities.

Jacqueline begins the tenth reflection very positively by sharing some "neat things" that happened that day. They had a brownies and milk party as a reward for a section of singers who all had remembered to bring in tapes. She shares how the students were so thrilled. Jacqueline says that this group of girls is "the nicest people in the world."

$>$ It is apparent she really enjoys her students.

There was another incident with the hall pass where one girl insisted on going to the bathroom. However, the other girls got the point that Jacqueline was only going to allow people to leave under extreme circumstances.

$>$ She feels this issue is reaching some resolution, finally.

Jacqueline finishes the entry discussing her concerns about the boys changing their schedules to drop choir for next semester and how she hopes this does not snowball. "Getting boys in choir is rough as it is, it just kind of worries me." 
$>$ Common problem within the choral discourse.

Jacqueline's reflective \#11, which stemmed from the situation of some of the students dropping choir, poses one huge philosophical question concerning who should music education serve? She wishes that her answer would be that it is for everyone but she is not sure she believes that anymore.

$>$ An experienced teacher questioning her philosophy of music education.

The twelfth reflection continues with the subject of students who dropped out of choir. Even though ten have dropped, the remaining group "had a fantastic week" and seem to be enjoying themselves.

She is relieved and excited that this smaller group is having a positive experience and she is ready to move on.

As far as the concert choir is concerned, there were six students that dropped. Jacqueline analyzes each student's situation to try to resolve in her mind why it was okay that they quit. She is able to justify why all but one of the students (out of 14 total) dropped choir. That one particular boy is really bothering her. She writes,

That's what this dissertation is all about, it's good to think, reflection is a good thing, so I need to think how I am individually treating the kids, how I am individually getting to know them, how I should not lump them as so-and-so's buddy, take each kid as they come.

$>$ This is a powerful reflection -- she has found the merit in the act of reflection and is concerned with the issue of efficacy.

Her writing continues with a discussion of her situation with the colleague that she has made reference to in the past. She talks about how the reconfiguration of positions will be stressful for her in terms of dealing with this person for the rest of the year.

$>$ Professional relationships are causing tension. 
Reflection \#13 reveals how she had an argument with the colleague previously discussed. She outlines several other nuts and bolts that she had to deal with today.

$>$ This job is multi-faceted and extremely busy.

A positive comment begins reflection \#14. "Freshmen boys -- the atmosphere is so much better." Jacqueline highlights both positive and negative moments that occurred during the day. Pedagogical issues, including Robert Shaw's count-singing technique, which was successful, and a worksheet for sight-reading, which was unsuccessful, are addressed. She mentions some discipline issues centered around a specific boy and the boys in general.

$>$ Pedagogical issues of reflection; analyzing their effectiveness.

Then Jacqueline moves on to her problems with the colleague. She is very annoyed with this person but admits that this person does try really hard to be effective in the classroom.

$>$ Professional relationship adding stress to her life.

The reflection ends with a discussion of a meeting with the guidance counselor concerning scheduling issues.

$>$ So many non-musical issues with which to deal.

Reflection \#15 is a laundry list of what occurred during the rehearsal, including musical experiences and a reference to a meeting that will be held concerning the reconfiguration of positions in the district.

$>$ Both practical matters and revelations of more frustration in this entry. Jacqueline shares in reflection \#16 all of the day's activities. There is some assessment of some of the choir's status. She also summarizes a meeting concerning the repositioning of some teachers. "It's going to be a very stressful spring for some people. 
It's on my mind a lot. Looking forward to tomorrow as it is the last day of the week.

Yeah!”

The issue involving her colleagues is weighing heavily on her mind; she is dealing with many various levels of people, pedagogical issues, and performance expectations.

The seventeenth reflection is extremely long, as it has been a few days since she has talked into the tape recorder. Preparation for contest, a Wytnon Marsalis field trip, and discipline issues with two students, one of who felt was being compromised based on ethnicity, which also involved the colleague with whom Jacqueline has had some problems.

$>$ She reflects in a detailed, frank manner as she relates the course of events, and how she is feeling in relation to those events.

An analysis of some of the boys' choir pieces based upon the assistance from an expert in the choral field are also discussed.

$>$ She often makes use of experts in the field to gain new insight into her choral program; always wants to improve and continually seeks growth.

Jacqueline shares the wonderful experience of hearing Wynton Marsalis live and watching him play a duet with a colleague in her last reflection entry, \#18.

$>$ A highlight of her week.

There were more reflections about the troubles with the colleague. "I just am at a loss to how to deal with this. I didn't want to talk to my husband and I went to bed by $7: 30 . "$

Professional life affecting personal life.

Reflective Narrative Exercises

Jacqueline wrote on two of the suggested exercises: Exercise \#1, which deals with her past choral experience, and Exercise \#2, which is a description of the school community. The information from the second exercise has already been disseminated within the narration. 
Jacqueline's high school experiences are aligned with the traditional choral discourse: using a variety of styles of repertoire; district and state contests; and rehearsals which consisted of warm-ups and then the singing of the literature.

> Traditional choral program.

Jacqueline shares two special high school memories: one involving the participation in a choral festival associated with a large university; and the other was the performance of Beethoven's Ninth Symphony with 30 high school choirs and a world renown professional orchestra. "I was very proud of our participation." Jacqueline's college choral experiences were true to the choral music education discourse as well. The literature included Renaissance motets, Baroque cantatas, spirituals, and contemporary song cycles. Warm-up exercises and singing the literature made up the rehearsal format. The director was described as an "enigma." Although considered to be a brilliant conductor, this person could be "very derogatory." Jacqueline concludes that this person must have been having some personal problems. However, when this conductor was "on," she writes, "it was the most exciting thing that I have ever been involved in."

The power of the podium.

\section{Student Journal Entries}

Eighty girls filled out the student journal entries of which 74 had turned in a consent form to be a part of the study. The students were very quiet and on task during the 15 minute time block. Most students took ten minutes to answer the questions. The first question asked what they enjoy about choir. The response given the most was 
singing, followed by being with friends, learning new songs, having fun, improving your voice, and being part of a group.

The second question had the students list three words to describe Jacqueline's teacher personality. Thirty-five different adjectives were given, with the following descriptors given the most (in the order of largest response to smallest): funny, enthusiastic, strict, nice, understanding, talented, and loud. Other words given infrequently included patient, unique, happy, strong-willed, serious, and bad sense of humor. One student said Jacqueline was serious, humorous, and weird.

> The variety of adjectives show the students' varying perceptions of her.

Question \#3 asks the students if they have seen any change in Jacqueline since the beginning of the study. Over half of the students have not seen any change in her behavior. Six students felt that she knew the choir members better individually.

$>$ This is a logical occurrence over time.

Interestingly, six students felt she had become stricter, and ten other students believed she was not as strict as she had been before. Other single comments included she was more serious, more confident, quieter, and had become a better teacher.

The challenges of the choir were discussed in the fourth questions. The four biggest challenges according to the girls were: to stopping the chattiness/staying focused, learning their parts, improving blend/balance, and putting forth more effort/enthusiasm. One student so eloquently wrote, "We could learn a lot more if we didn't talk between every song. But I guess that comes with a class of freshmen girls."

These girls are extremely aware of their problems with talking during rehearsal but may feel it is just the nature of the beast; Jacqueline's desire to help them develop self-discipline is warranted. 
Sight-reading, posture, breath support, and memorization were also mentioned more than once. The fifth question overlapped with question \#4 in that the student's saw their individual challenges many times the same as the choir's challenges.

These responses included: learning their parts, supporting the breath, paying attention/not talking, and sight-reading the music.

Important observations, they are taking responsibility for areas that will lead to a stronger choir.

The last question asked the students if they would encourage a new student to join choir. Almost everyone said they would for the following reasons: choir is fun; it is a great way to meet people/be with friends; and you can learn how to sing. Several students were quite descriptive in their response to this potential "new" member as seen by these responses: "The people in choir are very nice and welcoming," "Choir is a great opportunity whether or not you are going to pursue music in your life," "You don't have to sing that well," "Choir is not very hard because you don't have to worry about homework," "I would describe our choir as being productive," "Choir is a lot of hard work," "Learning to read music is a great life skill! It is fun to a part of the choir community, " and "Choir creates memories."

$>$ Student responses reflect a positive attitude about choir.

Jacqueline's Reaction to the Student Journals

Jacqueline first comments that she thought most of the girls took the journal writing seriously. She shares that she uses a survey, which covers some of these questions every spring.

$>$ Student feedback is important to her; she values the students' feelings and takes most of their comments seriously.

The negative comments were hurtful, Jacqueline admits. 
Again, she takes their comments to heart.

The negative words that surprised her are: impatient, loud, and harsh. Jacqueline likes the word, trustworthy, which a couple of students used to describe her.

$>$ That is an important value to Jacqueline.

She found it interesting that some of the students felt that she had become stricter since the study began. It was also revealing, according to Jacqueline, that one third of the students would encourage a new person to join choir only if that person likes to sing.

$>$ This implies that choir is not perceived as all fun and games, a perception that she is glad to see among the students. 


\section{KATE TYLER}

\section{Background Information}

Kate Tyler, a first-year choral teacher, exudes warmth and positive energy when you meet her. She is an affectionate person, welcoming old and new acquaintances with wide-open arms. People are instantly aware of her graciousness and sincerity within moments of speaking to her. I have known Kate for two years and have always found her to be a conscientious, hard-working student and teacher as well as an honest and caring person. Integrity and high morals are important values in her life; she sees the profession of teaching as an important way to make a difference in the world.

Kate grew up in a small rural community where "everyone knows everyone." Her spirituality, family, and friends are very important facets of her life. She speaks lovingly of her parents and her only sibling, a brother, and comments about how they are all extremely different people but continually love and support each other. She knows that they are proud of all her accomplishments. Kate calls her fiancé, Nick, "God's gift to my life," and eagerly anticipates their wedding this summer. Nick has been with her through the most significant changes of her life. Kate shares that Nick's family is "a super definition of true love." Nick's father, who is a high school biology teacher, has served as a mentor to Kate. He has assisted in her growth as a teacher, with suggestions for classroom management, budgeting, and professional development. Kate also speaks lovingly of Nick's mother who, although is on disability with a rare kidney disease, is a spunky, faith-bearing person. Nick's sister is one of Kate's closest friends. 
Kate remembers her love of singing from a very early age. Children's songs still remain very near and dear to her. She loved her elementary music teacher who just happened to also be her aunt. Kate began her formal musical training as a piano student in the third grade. She played the French horn in band beginning in the fifth grade and joined choir in the eighth grade. She was fortunate to have the opportunity to take piano, voice, and horn lessons at a nearby liberal arts college during her high school years. Other high school musical experiences included taking music theory, singing in show choir, participating in musical productions, being a member of the marching band, and singing in the county children's choir. The high school band director was a person Kate truly admires and respects. She remembers that "he had very high expectations, not only in performance, but also in moral action from his students. He was loud, to the point, and full of knowledge that he was eager to share." Band was definitely more influential than choir in her decision to enter music as Kate recalls her high school choral experience as being only mediocre. She remembers an incident where she corrected the director after class, "I was probably the most annoying student, thinking back, because chances are I just thought I knew it all.”

English was also a favorite subject of Kate's. Many English teachers left a positive impact on her life. Kate's senior year English teacher was a quiet woman who insisted on the highest quality in students' work and made everything in class interesting. Kate strongly considered becoming an English teacher. In general, however, Kate's high school career was uninspired as she admits that she made the choices that were the easiest way out. Instead of taking advanced math and science classes she opted for art and more music classes. "I simply didn't try." 
One summer, Kate was able to study with a premier vocal coach from a large university, where she remembers it being a "very challenging environment. It was the first time in my life that I was not top of the totem in music." Music camps were also an important and cherished part of her music education. She attributes one of those camp experiences specifically as the turning point in deciding to enter the field of music education.

Kate chose a large university with an outstanding reputation in the field of music education. The opportunities that can be afforded with a big city were attractive to Kate. Diversity within the student body was an important attribute as well. "Living here has opened my mind to change and difference. I feel I'm more tolerant, and yet stronger in who I am and what I believe.”

Kate believes she received a solid education at this university. In particular, she remembers her music methods courses as being significant educational experiences. From a musical perspective, Kate had a variety of ensemble experiences by participating in marching band, university band, gospel choir, women's glee club, and mixed choir. It was also important to her to feed her spiritual life and she accomplished this through her involvement in two on-campus Christian groups. Kate also expanded her horizons by participating in a summer project where she tutored international students. She writes,

That summer truly opened my eyes to so many things -- I had let too many people walk over me in the past, and made too many choices based on what I thought others would want instead of searching inside to find what I wanted. I call that my summer of freedom because I was freed from so many things. 


\section{$\underline{\text { Rehearsal Setting }}$}

The school community is located in a small, rural area located 25 miles outside a large metropolitan city. The residents are low to middle income and mostly blue-collar workers. It is a tight-knit community, with Christianity being the predominant religion. Wednesday evening is church night, which means there are not to be any rehearsals or concerts on that day of the week.

I found both the staff and the students to be friendly and accommodating. The school community is proud of their students and teachers as was heard in the conversations I had with several staff members. There is a strong sense of school spirit as can be seen with the paraphernalia decorating the hallways. The present high school was built as an addition to the middle school, with the two schools being connected by a long hallway. This addition was constructed approximately ten years ago and is filled with spacious classrooms and common areas. The choir room, which is also used as the band room, is a large space with extremely tall ceilings and has mirrors on one of the walls. An office, storage room, and lockers are within this performing arts space, therefore providing an adequate facility for various musical experiences. The room itself is not aesthetic in its appearance as there is nothing on the walls and no color besides beige to be found anywhere. Folding chairs used by the band are stacked on the sides, and two long tables, a choir folder cabinet, and a piano are in the room as well. Risers for the choral students are in the back portion of the room. 
The choir used in this study is a select group of 24 students who are mostly juniors and seniors. This class meets for 50 minutes every day during the last period.

\section{First Rehearsal}

The students enter the classroom in small groups chatting excitedly about a variety of subjects. It is obvious they know the procedure as they put down their backpacks and pick up their choir folders. Kate confidently announces, "Let's get started" and the rehearsal begins. A variety of vocal exercises take up the first third of the rehearsal. Kate incorporates her own vocal modeling to demonstrate the sound she wants from the group.

Dxcellent voice to model -- clear, supported, and pleasant.

She uses lots of energy in her teaching delivery and maintains a quick pace.

$>$ Students are focused and energized by her.

Pedagogically, Kate employs metaphors to help students to understand the vocal concepts she is presenting. She asks the students several times to critique the choir in order to work on improving the sound of the group. Several students are able to make valid assessments of what they had heard and what should be done to correct problematic vocal production.

$>$ Uses higher level thinking strategies; recognizes the cognitive abilities of the students.

Sight-reading is the next activity in the lesson. Kate has them sing with numbers rather than solfège.

$>$ Why are numbers being used?

A Hungarian piece is rehearsed following the sight-reading. Kate has the choir repeatedly sing sections, each time giving them a problem to solve. The choir's sound improves with each repetition. 
$>$ Pedagogically, she is giving them effective strategies for learning the music.

Occasionally, Kate coaches over their singing, which keeps the pace and energy of the rehearsal moving forward. The students continue to be very focused, especially the boys, and seem to be enjoying this choral experience.

$>$ A very positive atmosphere -- students enjoying the challenging work; exciting to observe.

The next piece rehearsed includes a text about an old woman. Kate uses several opportunities to teach theory, including areas such as dissonance, dynamics, tempo and accents during this portion of the rehearsal.

$>$ Comprehensive musical approach.

The students confidently sing the piece using the number system. Kate gives them positive reinforcement following the run-through. She also includes more vocal demonstrating, which the students effectively transfer to their own voices. In the next piece, Seeds, Kate continues to use a variety of pedagogical techniques to assist in the learning process. Several comments about breathing have been interspersed throughout the rehearsal but the students do not seem to be making that transfer. At one point, Kate blows raspberries in frustration at the students not being able to carry out the correct breathing technique.

Student posture is not always correct -- this issue has not been addressed; raspberries show human side of her.

The rehearsal ends with a discussion about the research study. The students seem to be very excited about being a part of it. They leave the room with positive energy and appear to be pleased with their performance in rehearsal.

It was so much fun to see students enjoying the process of making music; I was inspired. 


\section{Interview Following the First Rehearsal}

I begin the interview by asking Kate how she thought the rehearsal went. She replies, "I think it went okay."

That was not what I expected based on what I observed -- I was much more impressed than she was.

She goes on to say that it made a difference with me being there. Kate believes that the students were more focused and responsive.

I then ask her what the goals for the rehearsal were. She explains that rhythm was the focus of the Hungarian piece, as well as making sure they had all the correct notes. She tells me that she is trying to be very particular about the rhythm and the pitches, which is something on which she wants to continue to work.

I ask her about the choice to use numbers rather than solfège in the sight-reading. Kate explains that a number system was used by the teacher before her, and therefore, is what the students are able to use successfully. She has previously tried using solfège with the students but found it was difficult for the students to make the switch.

$>$ Understands where the students are and accommodates their prior knowledge.

Kate explains that beyond the basics, she is trying to help the students feel the appropriate mood and style of this piece. She shares how she likes to throw in a funny analogy every now and then to help them relate to the music.

$>$ Puts humor into the rehearsal; wants to make the music meaningful to the students.

Kate discusses her relationship with the students,

I have so much fun with this group. I give them a little more leeway when they have had a rough day or have had a lot of tests. I think my rapport with this group is pretty good. I think they trust me and I trust them. I can tell them when I am having a bad day. 
$>$ Her relationship with students is important to her -- relational pedagogy.

I ask Kate if she thinks the students find choir enjoyable. She responds that she tries to vary things so the rehearsal does not get boring. Most of the students truly want to be there. She discusses, however, that there are three students who she has a difficult time motivating. One of the girls has some mental problems as well as Attention Deficit Disorder. I ask Kate how the other students treat her. Kate responds that the students know the way she is and just go about their own business. The student does have a couple of close friends in the choir.

$>$ Knows the non-musical aspects of her students.

Kate continues with more discussion about pedagogical issues involving blend and diction. She is also aware of their general lack of breath support. "I think I do a really poor job of incorporating breath support issues into what I am teaching."

$>$ She is aware of a weakness in the choir and knows she needs to find a solution.

I want to turn to the topic of text in the literature. I ask Kate if she discussed with the students the meaning behind the Hungarian piece. She tells me that they talked about Hungarian folk songs in general and then had one of the students write a dramatic interpretation of it.

$>$ Creative text analysis encouraged.

Kate ends the interview saying that she thought the rehearsal went well and she actually had fun.

She was more excited and pleased with rehearsal at the end of the interview versus the beginning; interview served as a reflective vehicle. 


\section{$\underline{\text { Second Rehearsal }}$}

This rehearsal is mostly a sectional for the boys. The girls are told that they can work on homework until later in the rehearsal. Kate begins with a few vocalises and coaches over them. In a confident voice she tells them, "Put breath behind it when changing from chest to head voice." The sound changes into a more supported tone.

$>$ She works on an area on which she wanted to focus.

As they work on the piece, Seeds, it is apparent that the boys are having some intonation problems. She assesses the situation and asks them to raise their eyebrows.

$>$ Reflection-in-action.

The boys sing another section and are still flat. Kate has them sing a chromatic exercise, emphasizing smaller half steps. She also asks them to point up while singing a descending line.

$>$ Continues to find new techniques to help them become successful -- she is persistent.

Kate continues by modeling for them. Her strategy is to be very fastidious and not to quit until the correct sound is produced. Along the way Kate encourages them through positive reinforcement. The boys do not seem to be discouraged.

The second piece, John Brown, has similar pitch problems and Kate reminds them about breath support, keeping the eyebrows up, and dropping the jaw. She also tries having them sing the piece on the syllable, 'pim.' The intonation improves only slightly so she employs visual cues to help them get on top of the pitch. Kate shares with them that part of the problem is the range of the piece.

$>$ Correct assessment; selection of usable repertoire is challenging. At the end of the rehearsal the girls join in and sing The Old Woman. 
$>$ Five girls were chewing gum. Kate either doesn't see it or chooses to ignore it.

The choir sings John Brown and then the bell rings.

$>$ The boy's intonation improved.

Interview Following the Second Rehearsal

I ask Kate how she felt the rehearsal went today. Her response seems a little cautious, "I think it went all right but it could always be better."

$>$ She doesn't want to be over confident.

"After having a sectional rehearsal the week before, I noticed that several of the students needed work in a smaller setting. This rehearsal was an opportunity to help individuals and assess more accurately their progress.”

$>$ Is concerned with individual progress and finds way to assist those needs.

I inquire about the challenges of the rehearsal and we agree on the issues at hand. Kate shares with me that she is not sure she knows how to fix their problems with intonation. I tell Kate that she provided several solutions and that it takes time for their bodies and ears to work together to find success. She concludes that movement is probably the best solution.

$>$ Constructive dialogue has instigated reflection.

We discuss what Kate would like to focus on during the study. She states that improving their breathing through various techniques and bringing emotion into the music are the two goals on which she would like to concentrate. I ask her if she was able to work on those during this rehearsal and she replies, "Not in today's rehearsal, it was not really my intention. I hope to get into that next week." I then point out that indeed, breathing was addressed in the rehearsal and then she says she remembers that she did make some references to it. 
Posture has been an issue she tells me she has been working on with the students.

> She made no references to it during this rehearsal and the students' posture was poor at times.

Kate has been trying to transfer the fact that correct posture will assist breathing. By using metaphors and being insistent, she is hopeful that it is becoming clearer to the students what they need to do in order to have a supported tone. We discuss the need to create behaviors of habit so breathing correctly will become more automatic. Kate admits that sometimes she just does not want to focus on it. "I get distracted sometimes; I just move one. Then I am thinking, they will never have it."

$>$ The amount of repetition that some students need is somewhat unclear or just frustrating for her. We continue the dialogue by discussing how the reflective process is working for her so far. Kate shares that sometimes she looks at what she writes and it sounds to her like she is angry. She admits that she has been thinking negatively and is just not happy.

$>$ These are strong emotional reactions coming out for the first time.

Kate feels annoyance and frustration because she has too much to do and too little time.

$>$ The profession is demanding and time-consuming; as a new teacher, she may not have been totally prepared for this aspect.

She shares that it is helpful to write down how she feels and to review what has occurred during the rehearsal.

$>$ Reflection has positive ramifications.

Kate tells me that she has more to say than she has time to write. As she has looked back on her negative written reflections, she says, "Maybe I am failing, maybe I am not a good teacher, but I was just like, I don't care. For me this is too much, it may be fine for someone else, it's just too much for me."

$>$ Very honest and forthcoming. 
I remind her that she is a first-year teacher and the feelings of inadequacy and being overwhelmed are quite common. Her teaching load is quite heavy in this position. Kate goes on to say that there is a lot of dissatisfaction in her life everyday as far as her job is concerned.

$>$ Questioning her career choice, which causes her to be shaken in her confidence.

\section{Third Rehearsal}

The students seem wound up today as they come into the choir room. Kate gets them going quickly with some vocalises and breathing exercises. She uses a particularly interesting exercise, which focuses on vowel formation combined with body gestures. It is very effective and the students are very intent in doing it well. Kate moves right into the first piece, Seeds, with the sopranos singing a very expressive opening line. The tenors have some intonation problems when they sing their first phrase. Kate asks them what they think the problem is.

$>$ Asking them to critique and problem solve.

A couple of the students are able to assess the problem correctly, pointing out that some of the students' mouths are not open adequately and some people are not breathing early enough.

$>$ Students are aware of the challenges.

As the students continue to sing, Kate moves away from the piano so she can listen more closely. The intonation problems are still present, so when they finish singing she has them stand in a mixed position. The intonation improves significantly.

Reflection-in-action; trying new strategies. 
Kate has the students sit in chairs in a circle to sing Old Joe Clark. She tells them that they are going to work on improvisation. She first sings the piece for them and they repeat it a cappella. It is a little under tempo and sounds somewhat unenergetic. She asks them to sit up straight, and be livelier. The students sing it faster and with more energy. By the looks on their faces, they seem to be enjoying themselves. Kate then asks them, "What's a folk song?" One student gives a response that is almost correct and Kate clarifies. Two sets of sticks are then handed out and the students improvise rhythmically on the refrain. Almost every student has the opportunity to improvise.

$>$ Incorporating one of the National Standards that is often ignored in the choral classroom; encouraging creativity.

The next piece of music the students sing is the gospel piece, He Never Failed Me Yet. Kate immediately ties in the rhythmic improvisation to the vocal improvisation that is characteristic of this style of music. Two of the students sing improvised solos with a sense of ease.

$>$ Sets up this experience so the students could have success.

The concept of the folk song is addressed once again as the students sing the Hungarian piece. Kodály and the tradition of writing down folk songs are discussed.

$>$ Effective sequencing is a result of a well-developed lesson plan.

The students stay focused as Kate concentrates her efforts on working with the basses that are having some pitch problems. Although the time spent during the last half of the rehearsal is mainly with the boys, the girls are still energized and positive. Kate ends the rehearsal by praising their efforts and telling them that the pieces are much improved. She informs them what areas still need work and that they will focus on those areas tomorrow. 
She makes them feel good about their improvement and yet is honest with them concerning the work that still needs to be done.

Interview Following the Third Rehearsal

Once again, I ask Kate to talk about the events of the rehearsal. She expresses her concerns about the effectiveness of the rhythmic improvisation. Part of her motivation for doing this activity was to have the students "loosen up a little bit and have some fun." Kate has just returned from the state music conference and explains that she went to a session on including The National Standards for Arts Education (MENC, 1994) into the choral rehearsal. "I know I need to get all the standards in and I haven't done that at all this year."

Professional conference encouraged curricular agenda; she responds to the important reminder.

I ask Kate what other things did she take away from the music conference. Kate replies,

I think I was kind of stuck before the conference, because we have to get through this and this. Contest is an example, and then I think, who really cares? We need to cover the things that are important for them for their overall education. There are so many things the kids need to learn about and learn to appreciate.

> Conference has stirred up her views of the choral discourse and has reset her priorities.

I turn to issues of balance between her professional and personal lives, as this was an important item of discussion during the last interview. She shares her thoughts on the subject,

I was complaining to a colleague this morning because I was actually working until 9:30 last night on my lesson plans for this unit I am doing in the middle school. If I had more time I would probably use it for planning my ensembles because they get put on the back burner all the time. Oh, it's just the chorus rehearsal; I can wing it (said sarcastically). Honestly, that is something I do -come in the next day and we just pick up where we left off. I don't put the time into planning these things that are important. 
Candid reflection; there is great frustration in her voice; the issue of time is affecting her ability to teach effectively in her eyes.

I inquire about her feelings of not having the time to do effective lesson planning consistently. She expresses her feelings of guilt, "It's never good enough."

I then ask her what she wishes she could be spending more time on in her personal life. "I'd love to work out but I never get it done because I am so exhausted."

$>$ Physical ramifications from too many pressures.

She shares how she feels guilty about this as well. Fortunately, her fiancé, Nick, is able to give her some perspective on her life. "He will tell me to just put things away and forget about it."

$>$ Her personal relationship is important to balancing life's demands.

I change gears to discuss the school culture and how it affects Kate's teaching practice and specifically, her choice of repertoire. The Christmas concert is a tradition that Kate feels obligated to continue. Because there are so many extra concerts at church services as well, the repertoire is largely sacred Christian music. Kate admits that the community definitely drives the curriculum to some degree. The fall concert was programmed with a few multicultural pieces that the students seemed to enjoy but the parents were not as responsive.

Seems torn between teaching with a critical pedagogy and fulfilling community expectations.

The last topic of constructive dialogue focuses on Kate's role as a teacher in terms of the non-musical areas of her job. Kate responds, "Being so young, I know that the students will naturally want to come to me to talk about issues. I am thankful that I can impact them morally."

$>$ She is aware of and gladly accepts her role as a mentor. 


\section{$\underline{\text { Fourth Rehearsal }}$}

Vocalises promptly begin after the bell rings. Kate gives the students positive feedback concerning their vocal production and sound. As she focuses on having them tune within a harmonic structure, the students sing in a mixed formation to hear the inner parts. After the warm-up period, I have the students fill in the reflective journals.

Kate then makes a few announcements and has them sing a short vocalise to get them musically focused once again. Correct posture is addressed and then the students sing the Hungarian folk songs. Seeds is the next song rehearsed with supported breathing and posture being encouraged.

$>$ Attends to her areas of focus.

The students sing I Will Sing Every Day, a gospel piece, with great energy. One of the tenors performs an improvised solo during the piece. Kate enthusiastically calls out at the end, "That was great." She gives them a little talk about taking creative risks and then asks several other students to try some improvisation. A few of the students then improvise with moderate success.

$>$ She has set up a safe atmosphere where students are willing to take musical risks.

The choreography for Steppin' Out is the last activity for today's rehearsal. Kate plays the piece on the piano and coaches their movements over the music. At one point she makes an obvious mistake on the piano and says, "Am I bad?" and the students laugh.

$>$ Admits mistakes -- shows that she's human; adds humor.

The students then sing the piece along with the choreography accompanied by a tape. The students have a great time performing and actually groan when the bell rings. 


\section{Interview Following the Fourth Rehearsal}

This was to be a shorter interview as Kate has some make-up voice lessons to teach. I ask her how she feels about the rehearsal and she shares that she has been really thrilled with their progress all week. "I am so pleased with their focus level and how they challenge themselves everyday when they come in here. It is very exciting, but I am alittle nervous, too." I ask her why she is nervous. Kate talks about taking the students to contest. There are high expectations and lots of pressure to perform well, Kate explains.

$>$ A first-year teacher going to contest is quite an undertaking; she is aware of the pros and cons of that part of the choral discourse.

We discuss her varied job responsibilities as the middle school general music teacher, middle school choir director, and high school choir director. Once again, she expresses frustration about the many sides to her job, which leads little time to be effective in all areas. She believes that breaking the job into two parts - general music teacher and choral director makes much more sense. The job has gone through several music teachers in the past few years and Kate attributes this to the unrealistic demands of the position.

$>$ She is questioning herself if this is the right position for her.

I finish the interview with a question about how the reflective process is working for her. She maintains a very positive attitude about he process, "It has really, really helped me. I process more when I write things."

$>$ Her motivation and enthusiasm as far as the reflective process is concerned has remained relatively constant.

She ends the interview a little abruptly, realizing that she has more teaching to do. 
One more responsibility.

\section{$\underline{\text { Last Follow-Up Interview }}$}

We spend the last interview discussing the student journals and the reflective process. Kate has found the constructive dialogue to be the most helpful reflective tool. She shares that it gives her immediate feedback and frequently starts a chain of reflections where one thought leads to another. Kate remarks that she has kept mental notes of our conversations and has used much of the information in writing her lesson plans.

Reflection has helped Kate realize that she has been pushing her choral students and herself too hard for performances, especially contest. Since the beginning of the study, however, Kate has tried to gradually loosen up her expectations for both constituencies. She has vowed to not work so hard. "This study has helped me personally put things in perspective and be able to see things honestly and realistically."

Powerful, life-changing outcome.

\section{Types of Reflection Tools Used/Issues of Reflection}

\section{Autobiography}

Kate reveals many different facets of her personality in her honest account of who she is and who she hopes to become. As a teacher, Kate uses the following phrases to describe herself: "confused but trying my best," "overwhelmed and frustrated," and "happy to make a difference."

$>$ Reveals humility of spirit and challenges of being a new teacher. 
Kate believes that others see her as hard-working, upbeat, caring with the students, musically talented, a good communicator, and someone who has brought success to a failing program.

$>$ Interesting that she see others as perceiving her in a much more positive frame than she sees herself.

Kate wants her students to enjoy their music classes and hopes that her teaching encourages them to stay involved in music throughout their lives. It is her desire to help them become independent learners as well.

$>$ Important and admirable goals.

In discussing her joys and challenges with the job, Kate writes that she feels great when the students seem to enjoy a rehearsal. She is pleased when she is on top of things from a planning perspective, although she notes that this rarely happens. There are many other challenges that Kate addresses in this writing. As teaching is very new and different for her, she acknowledges that accepting and adjusting to change always causes some stress. Kate writes,

I think the greatest challenge I face right now are the significant changes and questions in my life right now, and how my career, whether it be teaching or not, will be affected by those changes. That's the big picture. In the little picture the every day challenges of disrespectful or irresponsible kids, too many things to do in too little time, busy paper work, and little personal time that's free from thinking about these things become frustrating.

$>$ She is aware that her personal life and professional life have a strong effect on one another; everything is in question; reiterating recurring themes.

As Kate reflects on why she became a teacher, she says it is the only thing she could see herself doing.

$>$ Not terribly convincing. 
She goes on to say, "I made that choice before most of the personal growth occurred in my life, and now I wonder if it was the right one."

Personal doubt.

She continues,

I enjoy it, but I'm not sure it's truly what I want to do. I keep telling myself to have courage to try something else. I just don't want to get in a rut, or get so busy and caught up with things that I shut myself out of new opportunities. I'm young! I know I'm successful, but not as successful as I could be. My life as a wife and eventually a mother will come first for sure. I'm taking my present job day by day and trying to do the best I can.

$>$ She is confident that new roles as wife and mother will take priority.

In the same vein, one of the questions in the autobiography asks, "Would you become a teacher again?" Kate responds,

I feel as if I am in a career holding zone. I'm certainly not completely happy with my current job. Sometimes I wish I had a job I could just leave entirely every evening. But then again there are many rewards to teaching that would not come from a job like those. I'm still deciding. I'm afraid of not being able to 'have my cake and eat it too' yet I don't dare not chance to dream big.

$>$ Kate is very baffled about her career.

In response to where she will be ten years from now, she sees herself settled in a community and beginning a family of her own. Kate shares in her writing,

I want to stay home with my kids when they are young. I want to be a devoted wife and mother first of all. I have a feeling I'm probably going to be one of those people who never quite knows what I want to be when I grow up.

Having her own family is important to her; life is an uncertainty for Kate.

\section{Reflective Journal Entries}

Kate wrote nine reflective journal entries during the first half of the study. The first two entries were produced on the computer and sent to me via E-mail. In the first Email, Kate had several items to share with me, and starts the email with a positive 
reflection, "The time you were here has already been helpful. I was even thinking today during chorus about breathing." Kate then uses the email to vent some frustrations about a variety of topics,

I'm going nutso! I have so many little things to take care of and I feel terrible because I can't keep track of everything. Thank God for my music booster treasurer. I don't know what I'd do without her. Sometimes I wish this school was more 'student-led.' The teaching styles here are very traditional, and even though we've talked about change in staff meetings, nothing ever comes of it. I'm feeling like 'mom' because half of my job is teaching them responsibility issues.

$>$ Strong feelingful reactions; is comfortable sharing frustrations; honest and understandable comments.

Kate's second E-mail journal was written in response to my field notes. Kate remarks that she did not realize she blew raspberries and how ridiculous and unprofessional that must be. She expresses her desire to stop that behavior. Areas on which Kate would like to focus during this study include implementing breathing techniques within the context of the music and helping the students to put more emotion into their singing.

She was grateful for the observation of something she didn't know she was doing -- she was also able to put it into perspective.

Kate's next seven entries were written in her personal journal. Her first journal entry began with a religious-based reflection. Kate then expressed how she is grateful to God for all of the support she has received from her school staff. She writes down some common sense advice that one of her administrators gave her. "Hey, I think I can handle that," is Kate's reaction.

$>$ Looking for assistance tackling a new job; building her confidence.

At the end of this day's reflection, scripture that relates to seeking wisdom is quoted. 
$>$ Her faith is an important source of strength.

Kate gives a detailed account of her rehearsal and her emotional reactions to it in the next reflection. She writes,

Today I was in pretty much a 'get it done' mode. The rehearsal was tedious as we're still in the note-learning phase of our contest music. The kids worked hard but I could feel the rehearsal took a lot of exhausting concentration. I'm worried that we won't get enough rehearsal time before contest.

$>$ Certain parts of a teaching practice are not enjoyable -- she recognizes this from both the students' and her own perspective; pressures of contest.

She continues, "I need to do a creative activity to get them into the mood of the piece." I desire for them to see this as fun as well as educational."

$>$ Needs to vary pedagogy for affect; her philosophical goal of having choir be pleasurable is noted.

Kate's third reflection is a short entry focusing on her positive attitude the past

few days. She has been giving singing exams to her students, and although some of them did not sing all the correct notes, she realizes that an exam of this nature is not always the best measure.

$>$ Maybe positive attitude is based on change of pace (exam period rather than regular rehearsals); reflecting on assessment options.

Exam period is still operating during Kate's fourth reflective writing. She shares

how the students are 'mad' because they had to come in for their choir exam during their free time. This was due to the fact that there were scheduling issues because of her teaching at the middle school. Kate expresses her frustration because she understands the students' point of view.

$>$ A negative side effect of teaching two levels -- more frustration.

The fifth journal writing is a hodge-podge of various aspects of Kate's practice.

She starts out with saying that she has gotten some things accomplished. She writes, 
I've definitely been harder on posture and having them being prepared with pencils. I've tried to address breath issues more specifically but I'm beginning to see something is missing. I think some of it is just plain laziness on some parts, yet I wonder what I could do differently.

She takes ownership on trying to solve the problem but feels she is out of solutions -- feelings of inadequacy.

Kate expressed her concerns about the overload of responsibility in this position. The music booster parents want her to address and stuff eighty envelopes, while she is also trying to plan next week's general music unit, and prepare for the middle school choirs. She exclaims, "I'm ready for a long weekend!"

$>$ Too many responsibilities, too little time -- she is feeling overloaded.

The sixth writing begins with Kate admonishing the fact that she is still at school at 5:00 with several things still to be done.

$>$ Repeated sentiments.

Kate also writes about how rumors are flying about if she will still be in her same teaching position as everyone knows she is engaged and could be leaving. When the students asked her directly about the situation she tells them that she has to be honest and cannot make any promises concerning where she will be next year.

$>$ Honest and integrity are important standards for her; is unsure where she wants to be next year.

Frustration is revealed in her writing concerning the laziness of some of the girls in regards to bringing a pencil and staying focused. However, she remarks that she is pleased with the accomplishment of the sopranos in terms of breath support, intonation, and vitality of sound. But she goes on to say, "I'm running out of ways to get from them what I need. Sometimes they just have to do it. I think I need to go home and blow off some steam.” 
Although she is able to find some positive aspects of the rehearsal, she is more focused on her lack of pedagogical tools and her feelings of irritation and dissatisfaction.

The last reflective journal writing is a more positive entry. "Things are in a little better perspective today. Chorus rehearsals went very well in both sectionals. Middle school unit off to a good start."

$>$ She is able to see the labors of her good work.

Kate ends the entry expressing her concerns about taking the eighth-grade girls to contest.

As do other choir directors...

She wishes the eighth-grade group were smaller but recognizes that they do try hard.

\section{Student Journal Entries}

Twenty-two out of the 24 members of the choir filled out the journals. Of those 22 students, 20 had given consent to be a part of the study. The students were very quiet and spent 12-23 minutes answering the questions. The responses to what the students enjoyed about choir were as follows: "when we sound good," "I can express my emotions," "I enjoy music," “we sing fun songs," "I enjoy using my voice," "I like seeing my friends," "choir makes my day a little brighter," "I like the dancing," and "it's a chance to take a break from the requirements of high school."

The most common words used to describe Kate were as follows: fun, helpful, positive, enthusiastic, and caring. The only negative word used once was stubborn.

$>$ The students see her in a very positive vein.

Several students have noticed that since the beginning of the study, Kate has become stricter in terms of student behavior and her musical demands. About half of the students did not notice any change. 
The challenges of the choir as noted by the students are as follows: using correct posture, paying attention, using properly shaped vowels, talking less, breathing correctly, projecting the sound, working as a team, having too many absences, singing in tune, blending, singing more expressively, and dancing.

> Most of the students were able to articulate several specific musical skills that needed improvement.

The students' personal challenges closely matched the challenges of the choir. Many students listed "learning my part."

$>$ They have personal ownership in the choir.

Once again, the students were specific in their description of vocal techniques upon which they wanted to improve.

The students emphatically supported the encouragement of others joining choir. They reasons listed closely matched why they personally enjoyed choir (from question \#1). One student wrote, "I would encourage someone to join, but I would be honest. It's not a play period; it is a time to work. It can be fun but only if all the members do their fair share.”

A perceptive student.

\section{Kate's Reaction to the Student Journals}

Kate's first general remarks about the student journals focuses on the ideas that many of the comments were sometimes not specific enough to give her clear information for growth or change. However, she admits it brings to light some important issues. Kate finds the writings to be very optimistic and encouraging. She also believes that the students were honest in their responses based upon the time they took to answer the questions and the amount of detail and effort that went into their writing. 
The main result of the journal is that it instigated the use of the suggestion envelope where students can have a format to discuss any facet of choir with Kate. Of course, Kate also welcomes the students to come talk to her face-to-face as well. Kate says that the student journals have changed her practice as she realizes the importance of giving students a voice.

$>$ Dramatic outcome of a vehicle designed for this study. 


\begin{abstract}
ASHLEY BROOKS
Background Information

Ashley Brooks, a choral teacher with 20 years of experience, exudes the energy level of a young child. Always in constant motion, this petite woman with short, light brown hair thrives on finding new challenges and pushing herself and her students to reach musical excellence. Filled with an intensity in spirit and a curiosity about the art of teaching, a stranger upon first meeting her would immediately know that teaching music is her life and that she loves to discuss any related topic to her craft.

Ashley's birthplace is located in a middle-class suburb of a large New England
\end{abstract} city. Her parents and two sisters, along with three nieces and a nephew, still call this area of the county their home. Ashley ended up in the Midwest when her husband received a transfer thirteen years ago. Ashley and her husband have a twenty-year-old daughter and reside in the school district where she teaches.

Ashley's formal musical career started during her senior year in high school, even though she was constantly exposed to music as a young child. Ashley's father was a percussionist, until he encountered a war injury in World War II, resulting in the loss of his left arm. Fortunately, he continued his involvement in music by serving as the Drum Major for the world champion Sacred Heart Drum and Bugle Corps, and later became their marching and maneuvering instructor. Ashley fondly recalls going to these rehearsals with her father and believes this is where her interest in music was sparked. She specifically remembers the camaraderie, high expectations, and competitions as highlights of this experience. Ashley continually asked her father to take music lessons 
but the response was always no. "As I look back, I often wonder if the lack of support from my father was due to the fear that the memories he harbored would be too much to cope with had he watched me do something that he once loved and could never do again.”

Through middle and high school, Ashley participated in the school's choral and drama programs. There were two music teachers who solidified her desire to pursue music as a career. "It sounds corny, but I idolized these two women and wanted to be just like them," Ashley writes. These two teachers were talented, caring, funny, and devoted professionals who built relationships with their students both inside and outside of the classroom. When Ashley informed her parents that she wanted to major in music during her last year in high school, they purchased a piano so she could begin taking lessons. She worked diligently and was able to audition for college that spring. Ashley's real dream was to become a concert pianist, but quickly learned that no matter how hard she worked, a concert pianist does not begin training at the age of eighteen. Therefore, she decided to become a teacher.

Ashley recalls that during her middle school years, she thought about becoming a nurse. "Something always led me back to music," she writes. There is no other profession in which she can imagine herself being involved. "I love what I do and enjoy watching the spark that I have for music igniting and developing in my students. I only wish I could ignite this fire in everyone I meet." You can hear her passion for music in her writing. 
Ashley's music teaching career began as a high school choir director, elementary remedial reading teacher, and elementary math instructor all in the same position. After five years in that job, Ashley spent 12 years teaching elementary general music. Her current position of four years has her instructing over 300 middle school students divided among six choir classes. Ashley also teaches a drama extension class, directs the school's annual musical, and is the advisor for the music honor society. Outside of school, Ashley maintains a piano studio with 25 private students and directs a highly respected auditioned community children's choir. Her professional life is extremely busy.

\section{$\underline{\text { Rehearsal Setting }}$}

The middle school where Ashley works is in an upper-class suburb of a large metropolitan city. The parent community is white collar professional, with high expectations for the school system. This system is known for their strong support for athletics, a feature that has frequently been an area of conflict for the music department.

The building was constructed 12 years ago and is attractive in appearance. Approximately 600 hundred students attend this middle school. The choir room is a medium sized rectangular room with high ceilings and carpeting. The space is barely adequate for the number of students in several of the ensembles (up to 70). However, it is efficiently and attractively conceived, with chalkboards and bulletin boards hung in the front of the room. An upright piano and a large music folder cabinet are also located in the front of the room. Ashley's desk is on the left side of the room, and there are two computer desks located in the back of the room. Various posters are on the walls, which 
represent some type of musical teaching concept. There is an office situated next to the choral room, with two large rehearsal spaces and two practice rooms located within this performing arts wing.

The choir participating in this study consists of 70 seventh-grade students, both boys and girls. This is a non-auditioned ensemble; students are required to take choir, band, or orchestra to fill the music requirement. The choir is divided into two sections with each section rehearsing every other day for 40 minutes.

\section{$\underline{\text { First Rehearsal }}$}

Due to a last minute scheduling change, I discover that there are only ten minutes left in the rehearsal when I arrive. The rehearsal is in full swing with the students fully engaged in their singing. The students are practicing one of their pieces on solfège in parts with much success.

$>$ Students' music reading ability is very high.

Ashley's teacher personality shines through during this brief encounter. She exhibits high energy, which can be found in her facial expressions and tempo of her vocal delivery. Therefore, the pacing is fast, leaving the middle school students with no time to chat or become off task.

Driven, vigorous display of teacher personality; this looks like serious business.

\section{$\underline{\text { Interview Following First Rehearsal }}$}

I begin by asking Ashley to discuss today's rehearsal plans. She tells me about her warm-up exercises first. She uses non-melodic vocalises first to get the students using their voices especially in the higher register. The next exercise involves tuning chords with continual reminders concerning breath support. Specifically today there was 
a focus on dynamics and how to produce crescendos and decrescendos. Ashley wants to then apply this technique to a piece of literature. She explains how the students used their hands to demonstrate the creation of a faster flow of air through the body for crescendos and a slow circular motion being used for decrescendos.

$>$ Uses kinesthetic cues to help students understand musical concepts.

Ashley continues to talk about the pedagogy of vocal production and explains the various metaphors that she used with the students to help them understand how to produce the sound.

She understands vocal pedagogy and finds ways to make content comprehensible; master teaching techniques.

Ashley explains how she has the students mark their music for places to breathe, but usually after they have been rehearsing the piece several times. She then comments, "We probably should do it in the beginning so that we are reinforcing it right straight through."

She is reflecting as she speaks, realizing that she knows that there is a better way; reflection-inaction occurring during constructive dialogue (interview).

I ask Ashley how important it is for the students to enjoy the rehearsal. Ashley believes that they do enjoy choir and tries to infuse humor periodically during the rehearsal. She recognizes that because this class is required, not everyone will love it, although she wishes all her students would. Ashley remarks,

I can tell the students who love it because they are the people who are sitting on the edge of their chairs the whole time. I don't have to say, sit up or stop talking. Those are the people that I know are with me and are clinging on to every word.

$>$ Recognizes the focused, motivated student.

"Was there a particular high point or low point in this rehearsal?" I ask Ashley next. She feels the rehearsal went well, with the students being very attentive. Her only 
frustration was not getting through her entire agenda. We then move on to talk about her typical rehearsal plan. The warm-up exercises are a very important part of the rehearsal and she admits that sometimes she spends too much time on them in relationship to the rest of the class time.

$>$ Training the vocal apparatus is a high priority in her curriculum.

Ashley then explains that she rehearses the piece that needs the most focus immediately following the warm-up exercises. By the end of the rehearsal, she finds her students are often burned-out as there is no down time.

$>$ Fast pacing is an important characteristic of her rehearsal strategy.

Repertoire selection is the next topic of conversation. Ashley likes to do demanding literature, typically in three parts, because she believes the students are up to the challenge. Much of the literature is a cappella to help the students develop aural skills.

$>$ High expectations.

Ashley shares that she found the piece that I heard them rehearsing at a conference. Repertoire that is found to be successful often will be used every year.

Ashley tells me this is the first year she did not prepare a holiday concert for the seventh graders. "I have so many Jehovah Witness families, I just didn’t want to deal with it."

> Outside influences alter curriculum.

“Did you get any backlash?” I ask her. Ashley replies, “Only one father of a student was angry. When the parents were told at the beginning of the year that there would be no holiday concert, some of them looked relieved because the holidays are so busy." The 
amount of time to prepare for a concert is also a factor in the decision to not scheduling a performance during the holiday season. The students are frequently pulled out of class for various reasons. Ashley shares,

I am really stressed in wondering whether we can achieve what we need to achieve in order to do a concert. I am not product oriented. My feeling is that if we get up there and do three songs to the best of our ability then we have done well.

$>$ She does not want the outside pressure to perform guide her agenda; process-based program falls outside the canon.

The last question I ask Ashley is if this interview, or constructive dialogue, has instigated any other thoughts. She returns to her realization that she should have the students mark in the breath marks when they first begin working on a piece, rather than having her just verbally tell them when to breathe as the piece is being sung. She states that she wants the students to learn the pitches and rhythm first, and then add the correct breathing places, dynamics, and vowel shapes later.

$>$ Music literacy is the top goal.

Ashley ends the discussion with her philosophy of reading music. "I don't teach by rote, I won't teach by rote, and the fact that they have to work to figure out what they are doing just takes away my discipline problems."

$>$ Making students accountable and keeping them on task are two of Ashley's objectives; music reading aids the achievement of these objectives.

$\underline{\text { Second Rehearsal }}$

I arrive at the school a few minutes before the rehearsal is to begin. Ashley comes up to me with a frustrated look on her face and tells me how the students are not ready for their concert next week. The boys, in particular, are not motivated and are 
affecting the morale and musicality of the entire group. The bell rings and the students begin to pour in the classroom.

The rehearsal begins with a preview of the sequence of today's rehearsal. Ashley's delivery is serious and her face looks stern, implying she means business.

$>$ Intense atmosphere.

The vocalises involve various ways to utilize the head voice. As she walks among the students, she has them echo certain intervals and reminds them about their posture.

Ashley prefaces every instruction with "without talking."

$>$ No smiles today -- the mood of the rehearsal is intentional based on her conversation before class began; her concern for the students not being ready for the concert has determined her approach.

After several more warm-up exercises, Ashley asks six students to individually sing minor thirds. She changes the starting pitch for each student based on that particular child's tessitura.

$>$ Individualizing teaching strategy to maximize chance of success.

The students are very supportive of each other as they applaud for each of their peers.

$>$ Students are relatively comfortable being put on the spot -- this is a delicate approach that both the students and Ashley handle well.

As the choir begins rehearsing one of their pieces, Hine Ma Tov, Ashley asks them to critically listen for several musical concepts.

$>$ Challenging, student-centered pedagogy.

Singing at appropriate dynamic levels and articulating ending consonants are two of the goals for this piece today. Ashley uses the teaching strategy of demonstrating the wrong way and then the correct way to help the students understand what they should be doing.

$>$ Effective pedagogy. 
Ashley works on very small sections of the piece and employs much repetition to achieve her goals.

$>$ A very driven, relentless rehearsal; again, making sure the students are prepared for the concert is at the heart of her pedagogical strategies today.

At the end of this portion of the rehearsal, Ashley has the students review the important concepts of this piece.

$>$ Students are accountable and have ownership.

The last piece rehearsed is Dreamer. Ashley prepares this musical selection by addressing the difference in style from the last piece. Again, Ashley works on small sections and uses repetition until the piece comes together musically. The bell interrupts the student singing.

$>$ Continuation of intensity, seriousness, and accomplishment; a very productive rehearsal.

Interview Following the Second Rehearsal

I ask Ashley if she accomplished what she set to do. She answers that she worked on what she wanted to accomplish. She shares that often she sets out to address one problem, but after listening to the choir sing, she will hear different things and then want to fix them. "I don't really stay on the task that is at hand."

$>$ She wants to correct it all and try to reach perfection.

"Was there a particular high point of today's rehearsal?" I ask Ashley. She replies when the students individually sang the minor thirds. She intentionally did not select the best students because she wants to make sure every student can do it.

$>$ Efficacy in action; no student is left behind.

I comment how exciting it was to see the students be so supportive of each other when they are being put on the spot. Ashley says, "That is something I have worked really 
hard to accomplish, especially with this age level. They don't want to do it, I do a lot to encourage them."

She is aware of the adolescent state of mind and tries to be sensitive by setting up a positive, safe atmosphere; critical pedagogy in action.

We turn our discussion to the importance of the focus and discipline of the group. "I am a real firm believer in that there is a time to be disciplined." Ashley believes that their good behavior is what will enable them to pull off the concert.

$>$ She has high expectations in terms of behavior during the rehearsal; it is a high priority for her to have students who are driven and focused.

Ashley talks about the challenge of working with a choir where not everyone is equally motivated or talented. "My own personal opinion is that anybody can take a good group and make them sound good, but it is a master teacher that can take a group of just anyone and mold them into something that is halfway decent."

Takes great pride in the challenge of working with students with all levels of ability and motivation.

I ask Ashley if there is any particular area on which she would like to focus in her reflections during this study. She mentions assessment as that has been an area that has been evolving. She wants to find quicker ways to assess a multitude of concepts, one of which she used today by having individual students sing minor thirds.

Authentic assessment takes time, but it is a value of her teaching practice.

We turn to a discussion about making music expressive. Ashley confesses, "We hardly even get to it with the seventh grade group. I just think that mere numbers are part of my problem because I have to control 70 kids." I comment that it must be difficult to enter the realm of emotional singing when you as the teacher have to be dictatorial in 
your instruction. She replies, “I don't know if you noticed that but I feel like I am very dictatorial in seventh grade.”

Because this discussion has been solely focused on what she wants to improve, I turn to the topic of her perfectionism. Ashley describes the circular nature of how she stays away from total frustration based upon her strong drive to have the students do their best in her comments,

I find myself when I get frustrated and start thinking about what I can do next to make this better, then the next time we come around and I have the kids again and it always is better. For example, yesterday I thought, these kids are singing in three parts and are not sounding too bad and so then I get charged up again. That is kind of what keeps me going.

$>$ Her job satisfaction comes from seeing the fruits of her labor.

Ashley shares that she has some insecurities concerning vocal pedagogy. "I am not a voice person so I always have this question in the back of my mind, am I doing this right, am I giving them good vocal pedagogy or am I killing their voices?"

$>$ The sound of her choir is free, healthy, and centered; she spends a significant amount of time on vocal production during her rehearsals, and uses appropriate techniques to achieve this high quality sound.

Ashley proudly states that one of her professional goals is to elevate the level of what people think about music. It is also important for her to give her students many opportunities to share their music. The students will be going to contest as well as participating in an adjudicated event at an amusement park. She knows that this event is a real motivator for the students and can serve as a reward for their hard work. Her choirs also perform at the elementary schools, nursing homes, and various community events.

It is hard work planning all of these opportunities; she wants to give her students the best musical experiences. 
I comment that she certainly has many irons in the fire. Ashley replies, "I think that maybe it [all the extra performances] adds to my frustration because I think I am very energetic but like today I could sit down and cry because I am just tired."

She does not want to admit that all of this will pay a price on your physical and mental health; has somewhat unrealistic expectations about how much a person can do in a day.

My last question is in reference to how the reflective process is working for her at this point in the study. Ashley replies,

I think I am thinking a lot more about what I am doing. I thought that I thought a lot about what I was doing before, but maybe in a different way, maybe in a more critical way. In a way that reflects on me but doesn't reflect on the kids, does that make sense? Before I would put a lot of thought into my lesson plans and how I was going to go from one thing to another and what I was going to do, but then that would be it. So now I think more, okay, did I do what I perceived, what I wanted to happen, did it happen?

$>$ The reflective process has taken Ashley from thinking about what and how she should be teaching, to assessing if it really happened; she is able to think about her practice on a new level.

\section{Third Rehearsal}

Due to a communication mix-up, I am able to observe only the last third of the rehearsal. It is not a "normal" rehearsal as the students are watching the video of their concert from the previous evening. The students are filling out a worksheet with their comments about the performance. The students are very attentive to watching the video and most students are writing on their papers. I read some of the student comments and found them to be both descriptive and insightful. It was obvious that the students are taking this seriously.

An important form of assessment using critical thinking skills. 


\section{Interview Following the Third Rehearsal}

We spend time looking over the student comment forms. Some of the students shared that their parents enjoyed the program but did not like the songs in foreign languages because they could not understand them. Ashley admits that she should have put in the translations in the program. I ask her if she ever talks at the concert in between the pieces. She replies, "No, and I should, I really should to give them a little bit of background about what the words mean."

$>$ The comment forms and our discussion have brought about awareness of improving the listener's experience.

Ashley continues to read more of the comments from the parents.

$>$ Feedback is important to Ashley and she is proud when the comments are complimentary.

I tell her that there are definitely consistent messages from the parents and studentsthere is appreciation for the beauty of the sound and the difficulty level, and frustration over the foreign language pieces. I ask Ashley if she was satisfied with the performances. She was very pleased with the sixth grade choir, as they were "incredibly musical." Ashley felt that the seventh choir gave a decent performance as found in her comment, "Overall I don't think the sound was too bad, I think it was pretty darn good." After hearing the tape she is going to move some of the guys to other parts. This turns our discussion to how she determines part placement. She places students singing harmony based on their ear, not their range. She tells me how she read some research that pointed out that students are either harmony singers or melody singers.

\footnotetext{
$>$ Takes the time to learn through scholarly reading and therefore, be able to advance her practice.
} 
Ashley has found that the harmony singers are stronger so it is a challenge to balance parts. Often the harmony singers have to be placed on the melody part in order to lend some strength and leadership on that part.

$>$ She stays open and flexible to find the best sound.

Ashley discusses the challenges with the male unchanged voice. She wants to keep working on their head voice while at the same time stretching their total range. She refuses to let the boys just drop the octave because it is easier for them to do. If the song is not scored to have the boys sing lower, the sound, according to Ashley is "like garbage, it really sounds horrible, it's an ugly sound."

We turn back to the concert and how there is so much behind the scene work that has to take place besides the performances. She tells me that she had no one to help watch the seventh grade choir and at the same time, she had to run around to deal with the accompanist, the flutist, organizing her music, and controlling the students. Ashley compares this experience to her community children's choir where there are people to assist with all of the odds and ends. When she steps on the stage for those performances, she is relaxed because she is only there to conduct. She vows to try to get parents to sign up at curriculum night next year to help with concerts at the school.

Finding ways to lessen the stress; working smarter, not harder.

When Ashley stood on the podium at the concert last evening, she was amazed at how the students were completely quiet and everyone was in the right spot. "It was incredibly impressive; I mean it was just like a robot."

$>$ The students know what Ashley's expectations are; they respect her and they respect the choral program. 
She admits that she tells the students that if they do not cooperate that she will pull them out, tell them to go home, and give them an F. "It's a threat that nobody has ever challenged me on."

$>$ Makes firm rules and the students know she is serious.

We talk a little about singing in the gymnasium and I ask her if she has ever had a concert in the high school auditorium. Ashley has given it some thought but has not taken the time to plan for it because it is so complicated. "I am not a good manager of time. By the time I think, wouldn't it be nice, all the dates are filled up."

$>$ She freely admits a shortcoming.

I conclude the constructive dialogue with discussion about the reflective process. Ashley has written two reflections so far, so I ask her how she felt after writing them. She answers,

I felt guilt-ridden. I think I told you the last time I think a lot but to have the time to sit down and do it is the hard part. When I get home at 9:30 at night, I just don't have the energy.

Why is she consistently getting home at 9:30 at night?; does she have a choice concerning the hours she is spending at work?; journaling is time and energy consuming.

She shares with me that her husband is frustrated with her not having time and energy to spend with him.

$>$ Professional life negatively affecting personal life.

However, Ashley remembers one day when she did a written reflection at home on a day she came home much earlier and how good it felt because "I had these thoughts and it kind of helped me think them through and then just perpetuated more thought."

$>$ Profound statement; reflection helped clarify thoughts and ideas, and stimulated more thought. 
She ends with, "I am also a person who does not like to write down what I feel because I think it is too revealing."

$>$ Personal risk involved with reflection.

Because she is frustrated that she cannot write as much as she would like, she asks if I would be willing to come in an extra time to observe and converse. She comments that she really enjoys the constructive dialogue and feels it is a helpful form of reflection. I tell her that I would more than happy to come in one extra time.

\section{Fourth Rehearsal}

I arrive a few minutes before class is to begin. Ashley greets me with, "things are not going to be good."

$>$ She seems frazzled and not particularly pleased that I am there.

Besides having to teach her normal classes, she has been preparing for a workshop and is in the midst of the musical. I search for a way to help lighten the load and volunteer to work with the students today. She looks relieved as she says that she would love if I would teach the students at the end of the period.

The rehearsal begins with some head voice exercises. Ashley gives a clear explanation of breath control and draws a picture of the diaphragmatic region to help explain further.

She seems focused and not stressed; her energy level is high.

The next portion of the rehearsal is spent on reading rhythms. Each student has a set of flash cards and as Ashley speaks a rhythm, the students have to find that rhythm card and hold it up.

This is an activity that involves each student assessing knowledge instantly; this is a result of her wanting to focus on new assessment strategies; uses positive reinforcement with the students. 
To continue the work on rhythmic reading, Ashley has written on the board measures of rhythmic patterns that contain mistakes. The students have to find the mistake and fix it.

Using different techniques to teach concepts; music literacy is the goal.

Ashley includes some humor as she talks in a funny accent to get them ready to focus.

She is smiling; seems to be completely in a different mood than when I first saw her today.

Next, the students are asked to form a pentatonic scale and then sing it. Ashley gives them a more difficult challenge of singing a pentatonic scale ascending and a minor scale descending. The students perform the scale successfully.

$>$ She is giving the students challenges in a positive atmosphere.

Ashley then points to various solfège syllables and has the students sing them. The last activity involves the sight-reading of a difficult rhythmic passage. The students once again are successful as the rehearsal comes to a close.

$>$ Very impressive music reading; this entire lesson was well conceived and executed; students demonstrated a clear understanding of and ability to sight-read.

Interview Following the Fourth Rehearsal

Ashley seems calm and content when we begin our conversation. It was obviously a successful rehearsal that enabled her to feel positive once again about her teaching practice. I want to hear her talk about various aspects of her career. We first talk about the musical since that is what she is working on at this time. It has had its challenges related to scheduling and co-directing. The principal has been supportive and let the students be pulled from class three days a week for two hours to assist with the scheduling problems.

$>$ Administrative support affects teaching practice, in this case, very positively. 
The other director is very different from Ashley in terms of personality and leadership style. Ashley shares these observations of her colleague, "She sees the glass half full and I see it half empty. She is more free spirited and is less directive with the students than I am."

Knowing her perfectionist qualities, it must be a challenge to collaborate with any colleague unless that person portrays that same perfectionist characteristic.

We discuss the school culture next. Ashley says that this upper-class school district contains lots of divorced families and many stay at home moms. It is not a very diverse community but the school district embraces the concept of diversity. There is a very active multicultural committee of which Ashley has not taken advantage, as they would pay for some of her music. This leads to a discussion of multicultural music. Inclusion of music from other cultures is an important aspect of her curriculum but one that is not supported by some of the parents, as they want to hear pieces in English at concerts.

$>$ Critical pedagogy present; she does not allow the community to influence her curricular decisions; she is interested in what is best for the student.

Ashley shares more of her philosophy of teaching multicultural music, "I try to set up being respectful of the languages; be tolerant. I try to give a little background on each song, translate the words, but I know I should do more."

$>$ She is aware of the enormous responsibility of teaching with a multicultural approach and yet feels she is not extending the full range of applications and understandings to the students.

The discussion of working with a wealthy clientele reveals the advantages and disadvantages of socio-economical situations. Ashley has taught both rich and poor children and says that she does not treat them any differently. "You set high standards with all students and they will rise to the occasion." 
Setting challenging expectations for students is part of her philosophy; she knows it works based on the successes of her practice.

Ashley shares that it is more enjoyable to work with parents from a lower socio-economic background, as they are typically more appreciative.

I ask Ashley how choral music education is viewed in today's society. Ashley shares her definite views on the subject,

Most people view it as fluff, playtime, especially at the middle school level. It is very difficult to teach these students because they are unique. We don't give them enough credit to read music. Rote teaching lends itself to discipline problems because they have no ownership.

$>$ This statement reinforces her strong belief concerning the importance of music literacy.

She continues, "Teacher personality is key to teaching middle school music. You must be creative, think fast on your feet, energetic, be one step ahead of them, have high expectations, and have a lot of drive."

$>$ She has just described herself.

We turn to a brief discussion of how professional organizations have helped Ashley in her teaching practice. The Organization of American Kodály Educators has been the organization that has served Ashley the best. They hold three local workshops a year in which she takes part. She also serves as the secretary of that organization.

$>$ She chooses to grow professionally and give of her service as well. After recognizing all of her commitments along with her driven personality, I ask Ashley if she ever has time to relax. She replies,

No, never, I have no time. It is difficult. My husband is frustrated. I would like to finish my Kodály certification and apply some of that towards my Masters. But I really feel like I know what I need to do to effectively teach the Kodály method, so why should I do it. Who really cares? 
There is some frustration in her voice as she recognizes that her professional life is already too full, and yet there are other things that she could be doing to grow; she has to make some difficult choices about both her professional and personal life.

\section{$\underline{\text { Fifth Observation }}$}

The rehearsal begins with the students filling out the journals for the study. After the completion of that activity, Ashley quickly moves into a brief warm-up period. Sightreading is the next focus of the rehearsal. There are three lines of rhythm and solfège written on the board. Different parts read different lies successfully. Ashley asks the students to recognize the similarities and differences between the lines and the students once again answer correctly.

$>$ Challenging music reading.

The rehearsal continues with more music reading. As the students sing through the musical exercises, Ashley plays a piano accompaniment. The students get a little chatty and she comments that all the students need to support each other. The students refocus and read the music successfully as the bell rings.

$>$ A rehearsal filled with challenging musical problems posed to the students. Their abilities are quite extraordinary.

\section{Interview Following the Fifth Observation}

Ashley begins the conversation with a story that has obviously really upset her concerning a parent confrontation where the parent was totally out of line and was very angry with her. She tells me that she will never do a musical again at this school based on this situation.

She is very sensitive, she works so hard and it hurts that much more when people do not know how much heart and soul she puts into things. 
We then discuss today's rehearsal. Ashley shares that she felt that she was not prepared because a colleague had called her during her prep period and then she was rushed in getting ready for this rehearsal.

$>$ I think she feels she has to justify why the rehearsal was not perfect (in her eyes) -- on the contrary, I was quite impressed with how much learning took place; she is too hard on herself. perfectionism showing.

She goes on to confess that she made numerous mistakes during the rehearsal. Her musical opens tonight she is physically and emotionally drained. I share with her that my perception of the rehearsal today was of a teacher who was working hard and teaching important skills. I ask her if she felt like she was acting during that rehearsal and she answers yes.

$>$ She is able to transcend beyond her own feelings to teach the students well.

We discuss the parent confrontation a little more and then I change the focus to the reflection process. I ask her if this study has been a catalyst for change. Ashley replies that it has generated a lot of thought.

$>$ Generative results.

Her parting words after realizing that she has come across as very stressed are, "I do what I do because I love to do what I do, I mean I love teaching, I love my kids.”

$>$ A positive way to end the conversation.

\section{Last Follow-Up Interview}

This brief conversation begins with a discussion about the professional conference she just attended in Chicago. She was somewhat disappointed in the sessions but did get a couple of helpful teaching ideas. As we are talking she gets up and starts moving around the room looking for papers. It is obvious that she has lots to do and little time for 
the interview. I ask her to comment on the field notes from my observation and what purpose they serve for her. Ashley believes that they reinforce the events of the day and highlights important teaching moments. However, she believes that an improvement from her perspective would be the inclusion of the critiquing aspect, where I would give her my opinion. She states that not having my opinion is a flaw in the study because to her, a valuable part of the reflective process would be to receive feedback about her teaching.

$>$ That was not my purpose in the study to critique her; however, in this portion of the study, my reflections can be used to offer direction.

\section{Types of Reflection Tools Used/Issues of Reflection}

\section{Autobiography}

Ashley shares many facets of her personality and philosophy of music education in this document. She articulates her thoughts well on paper and is able to be honest and open concerning her strengths and weaknesses. In terms of her teaching philosophy, Ashley reveals that the most meaningful part of her education was realized when she moved to her present location and began training in the Kodály philosophy. She writes,

The training stretched and challenged me as a musician more than any other undergraduate or graduate training that I received. It was this training that molded me into the educator that I am today. I feel more confident as a musician and more knowledgeable as an educator.

$>$ Kodály methodology drives her pedagogy; she is a firm believer in its usefulness in creating young musicians.

Ashley is motivated though her own pride and personal satisfaction that she draws from knowing that she strives for excellence and works hard to accomplish all that she does. Her students' enthusiasm to learn also motivates Ashley. Ashley also writes about how she cares about how others view her and her work. "I hope that people describe me 
in the same way that I would describe myself, as energetic, devoted, dedicated, caring, giving, humble, knowledgeable, patient, and encouraging."

$>$ I, too, have found her have all of those characteristics.

Ashley believes that her greatest strength lies in her ability to encourage her students to work to their fullest potential. She sees herself as process oriented and is competent at analyzing and breaking down music so as to insure the success of her students. Ashley states,

I am very creative and able to devise many different ways to review the same information so that my students get ample practice time without becoming bored. I have the ability to control large groups and keep them engaged for extended periods of time in the learning process. I do a good job of building a positive and supportive environment in my classroom so that my students feel comfortable taking risks and performing by themselves. I think I do a good job of building efficacy in my classroom. Finally, I am very devoted and dedicated to my students, and their musical growth.

Through this autobiography she has had the opportunity to focus on all the positive attributes she possesses to strengthen the music education of her students.

Ashley feels that her biggest weakness is her inability to say no. She admits that she is always working, therefore, providing little time for herself. This quality explains her lack of patience for the students who sit in class and do nothing.

Ashley ends her autobiography with a summary of her hopes for her students, which reads,

I hope that my students leave my class with a love for music, a desire to be involved in some aspect of music as an adult, the knowledge to be intelligent consumers of music, and a tolerance for people with varying abilities and talents.

An admirable philosophy with a critical agenda as well. 


\section{Reflective Journals}

Ashley turned in five written reflections over the course of the study. The first three reflections were in the form of E-mail. The last two were typed reflections that contained both general thoughts concerning her choirs and specific incidents that had recently occurred in rehearsals.

The first E-mail journal begins with a thank you to me for listening to her talk (sometimes venting) about a wide assortment of topics after my last observation. She states that she was tired.

Physical ramification from stress.

She then shares that she wants to focus on two pedagogical ideas as part of this study. The first idea involves assessment. She actually put together three assessment rubrics: one for assessing the repertoire, one for general behavior, and one for rehearsal expectations. She writes, "I don't know if I will use all of these but I want to begin organizing a notebook of different assessment ideas so I have a resource at my fingertips." Ashley also wants the students to develop their own assessment rubric to use for evaluating their concert performance. Along that same line, she would like to write some reflective questions that the students could answer after listening to the tape of the concert. "This could give me a lot of insight into what my students perceive to be important. I also want them to do some type of self assessment as I need to put the ball in their court and make them responsible for their learning."

\footnotetext{
She has given some thought as to the number of assessment possibilities and how they will assist
} the students' learning in the most meaningful way. 
Ashley would also like to develop a tool for communication for important information for the students. She notes that keeping 300 students and parents informed is an overwhelming task.

$>$ A pedagogical issue that is based on her values of organization and communication.

Ashley then discusses three recent rehearsals. Her rehearsal with the sixth-graders the previous day was an "awesome" rehearsal as the students were attentive and much progress was made. She writes, "I was so proud of them, and I think they feel really good about their upcoming performance." A combined sixth grade rehearsal the following day went extremely well, too. During the seventh grade rehearsal, Ashley used competition with the sixth graders to motivate them to work hard. She told the students that it would not look very good if the sixth grade choir performed better than they did. It was an effective motivator as they had a productive rehearsal.

The second journal writing includes a synopsis of her recent choir rehearsals. She includes many emotional reactions as she writes. One section of her eighth grade choir is really worrying her as she is concerned they will not be able to learn the music for contest.

This is January and contest is in May; she causes herself stress by worrying so early in the game. The other section of eighth graders had an opposite experience. Ashley writes,

They really wowed me today! This group of kids is amazing and fun to work with. We are able to relax, have fun, and get the job done. That's the way it should be!!! Oh, to have all my classes be this way.

$>$ She thrives when her students are working at a high level.

Ashley writes that her sixth grade choir is on target for in the process of learning their repertoire. The flute player came today, which gave the students the opportunity to 
hear another layer of the music. Ashley is very excited that the accompanist is coming tomorrow, as Ashley will then be able to conduct. Ashley has a mixed review of her seventh grade choir. One of the pieces is in good shape. However, when she added the boys in on another piece of repertoire, Ashley says in her writing, "Ughhhhhhh! I had to spend time working on notes again."

$>$ Is impatient with their lack of ability to retain their parts.

After rehearsing parts once again, she believes that finally, they all should be able to sing their part. She writes, "They all know the part, they just choose to let someone else sing it. How do I build accountability in everyone when there are seventy kids in a class?"

$>$ Her assessment tools can come into play for this problem.

Her last comment is very revealing, "I have been thinking more and more about moving to high school. I think I am getting tired of being beaten down on a daily basis.”

$>$ Considering professional career change -- maybe she is just tired.

Ashley's third reflection starts out positively. "The best idea I had was to do the concert evaluation forms."

$>$ A result from the reflective process invoking a positive change in her practice.

Ashley is pleased that the students have internalized her "words of wisdom" she has been sharing throughout the year. She plans on continuing to use this type of evaluation.

Ashley also writes that she finished her announcement bulletin board.

$>$ Another successful product from the reflective process.

She is very pleased that she has found a vehicle to distribute choir information. It also puts the responsibility to obtain the information on the students.

$>$ This supports her philosophy of making students responsible. 
Ashley admits that she had a lot of help with this project from her student teacher. She wishes that she had this kind of help all the time.

$>$ Where else can she get assistance - from students, parents?

Ashley reflects on her eighth grade choir. There is a group of girls who are not participating and therefore affecting the other students in a negative way. Ashley is not quite sure what to do about this situation. She poses a philosophical dilemma, "Do I give them an ultimatum - shape up or you are not going? Am I taking them to contest for the rating or the experience? Ughhhhhh.”

$>$ Questioning her own ideals concerning contest.

The fourth reflection is a discussion of the seventh grade choir. Ashley begins with a general statement of how this group has been improving throughout the year. The students just took a rhythm test and 59 out of 65 scored perfect papers.

$>$ She is very proud of their accomplishments.

Ashley writes that this group "is doing sooooooooo much better singing in three parts."

$>$ Her style of writing indicates her feelings related to the progress of the choir.

She explains how she has reassigned parts and it has made such a positive difference in the product.

Ashley talks about working with a small group who is preparing for solo and ensemble contest. The students' reading ability was remarkable. "I was blown away by them!" Ashley exclaims.

$>$ The development of her students' musical progress is what keeps her motivated. In the fifth reflective journal, Ashley writes about the sixth grade choir. She raves about their incredible progress and how proud she is of these students. Ashley is 
impressed with the fact that there are students who are feeling comfortable and knowledgeable enough to put themselves on the hot seat and sight read new music. She writes, "The best part is they are singing with few to no mistakes!!!!!!"

The exclamation marks say it all.

Ashley shares a story about how a boy humiliated another boy who sang in front of the class. She spent some time with the class explaining why this was wrong, as she warned the students that she would not support that kind of behavior. When another boy was individually singing later in the rehearsal, it almost happened again but Ashley saw a boy catching himself from laughing at this student. She feels that they understand the concepts of respecting and supporting each other.

$>$ Teaching more than just music; critical pedagogy enacted.

Ashley concludes this writing by revealing that she has changed her pedagogy in one way. She now is putting a form of their pieces on the board to help with transfer to the actual octavo. She is pleased with the success of adding this step. She writes, "How stupid I was to leave out that step. I should have figured this out a long time ago!”

A master teacher who continues to find better ways to teach.

\section{Student Journals}

Sixty-three students were present to fill out the student journals. Of those students, 44 had consented to be in the research study. The students were quiet and on task while answering the questions. They spent anywhere from 6-14 minutes to complete the questions. The first question asked the students to indicate what they enjoyed about choir. The most frequent responses were learning new songs and singing. Other students wrote that they enjoyed performing, having a nice teacher, and being with friends. A few 
students indicated that they did not enjoy choir at all. One student responded, "I enjoy doing rhythms. I like them because we get to throw around a beach ball."

$>$ It is interesting what makes an impression with students.

The second question asked the students to list three words to describe Ashley's personality. The most common word was strict, followed by expects the best, is a good teacher, and is nice. Other adjectives included were fun, energetic, outgoing, and helpful. One student said that she was both hyper and relaxed. Two students wrote that Ashley was stressed.

$>$ Observant assessment with which Ashley would concur.

The third question asked students if Ashley has changed throughout the last nine weeks. A little more than half indicated that they saw no change in her where other students said that she seemed to have even higher expectations.

$>$ Students are aware of her desire to challenge students to be the best they can be.

Other students found her to be stricter, a few stated she was more relaxed and some were aware of different teaching strategies. One student commented, "She has enhanced her teaching strategies." Another student commented, "She doesn't threaten us with detentions 24/7."

$>$ Different perceptions of the same teacher.

The challenges of the choir were the focus of the fourth question. Singing the correct notes and not talking were the two most common responses. Other students noted singing in tune, correct breathing, and singing with enough volume as other challenges. One student wrote, "Our teacher makes it very challenging. She gets on our case for everything." Still another student comments, "Meeting her expectations is a challenge." 
Some of the students are aware of her high level of expectations for each student in the choir.

The challenges of the individual singer are discussed in question number five. Correct breathing, intonation, and overcoming the fear of singing alone are the most common responses. Other students mentioned not talking, singing the correct parts, and singing high notes as individual challenges. One student wrote, "Meeting the high goals she sets for us" was a challenge.

$>$ One more reference to her high level of expectations.

Whether to recommend choir to a new student or not is the last question posed in the journaling exercise. A few students said they would not recommend choir to someone new. A student wrote, "No, it is hard and you have to be good."

$>$ She would agree with that comment.

The two reasons written most often to encourage students to join choir was that it is fun and the teacher will make you work hard to achieve your best.

$>$ Another clear indication that students are aware of her goals.

Other comments made more than once included: they have a great teacher," "you learn a lot," and "it is better than band." One student wrote, "It is hard but we are the best school choir in our district."

$>$ Pride in a demanding program.

\section{Ashley's Reactions to the Student Journals}

The discussion of Ashley's reaction to the student journals occurred on the day that she seemed rushed. Her only comment was that nothing surprised her except that there were lots of positive comments. She was trying to figure out which student said what but was unable to do so.

She seemed pleased with the comments but she needed more time to digest the information. 


\section{A SUMMARY OF EACH TEACHER'S JOURNEY}

This chapter concludes with a synopsis of each choral educator's reflective journey as understood through the reflections of that teacher, his/her students, and the researcher. Areas of reflection, depth of reflection, and methodologies of reflection will be presented to form an encapsulated view.

\section{Madeline Owens}

Madeline's issues of reflection were derived from all four of the categories used in this study. Pedagogically, Madeline reflected on discipline issues concerning student chattiness, as that was the only discipline problem that typically arose in her classroom. Madeline usually did not seem frustrated when students were talking, as she attributed it to factors including: it is Friday; a student has Attention Deficit Hyperactive Disorder and that is just the way it is; and boys disrupt the rehearsal due to a defense mechanism covering up their insecurities about singing. She has addressed the boys' insecurity issues by bringing in a male singer to assist their changing voice and confidence problems. In general, she seems to ignore the talking behavior and not let it bother her. One specific example that demonstrates her casualness concerning classroom management was during the first interview, where I had observed some chattiness, Madeline had remarked that my presence made the students actually better behaved because they wanted to impress me. This may be an acceptable level of noise for Madeline. Following the second rehearsal, she acknowledged some frustration with the talking, but commented that if she becomes harsh with them it almost works in reverse and they talk more. She is not 
interested at this point to address this issue. The relaxed atmosphere was noted by some of the students in their journaling. One student intimated that Madeline was too laid back, therefore allowing more chattiness in the classroom.

Madeline spent some time reflecting on issues of curriculum. Madeline incorporates a comprehensive musicianship approach in her choral program. Music theory is taught and assessed, and other musical topics are introduced, including guitar, ska, reggae, musical theater, composition, bluegrass, and world music. Madeline wrote that having the students take part in determining the curriculum is important to her. The variety within the curriculum was noted by some of the students in their journals as an enjoyable aspect of being in choir.

Contest is a part of the curriculum with which she has some concerns. She was candid in her reflection concerning the arrogance and strong competitive spirit that can be found among the directors, which Madeline believes does not lend itself to making the experience be student-focused. She does take a small group to solo and ensemble contest but has not yet taken a group from this school to large group contest.

Issues that fall within a critical pedagogy are found periodically throughout Madeline's reflections. Madeline's discussion during a rehearsal of sticking to a commitment represents one of life's lessons she feels is important for her choir students to hear. Her awareness of the various vocal and behavioral challenges of the boys in her choir and the effect that it plays on the girls is evident in her verbal reflections. She addresses this in several ways by giving the girls other opportunities to be challenged and focusing attention toward them in order to balance the attention and energy that the boys frequently receive. Madeline knows there are gender discrepancies and works hard to 
find the balance that will make all the students feel they are having their needs met within her classroom. Madeline's discussion with the girls about body piercings also represents a critical pedagogy from the view that she is building a relationship with the students, which is very important to her. Both Madeline and at least one of the choir members, as revealed in the student journals, value the feeling of family that exists within the choir. The combination of the close-knit school community and the rapport that Madeline has established with her students allows for the feeling of family to occur.

The area of her professional life was an important facet of reflection. At this point in her life, she is able to be both a teacher and a student, which she feels strengthens herself as an educator. The concept of professional development is exciting to Madeline. She wants to avoid routine teaching, as that would be boring for her and her students. As far as her professional life outside of the classroom, she revealed that it is important for her to stay active as a singer. She also talked about eventually earning a doctorate. The creation of a fine arts center is also of interest to her. She has many professional dreams.

Also within the professional domain, Madeline reflected about a colleague from her previous teaching position that was very unprofessional, which was upsetting to Madeline. Madeline made another reference in a reflective writing concerning her frustration with the politics at her first school and how that was stressful for her. Madeline's current teaching position exists within a community environment that is supported by both colleagues and administrators. The philosophy of Madeline's school embraces innovative curriculum, which is important to her. Based upon Madeline's curricular philosophy, she knows she is teaching at the right school. 
From a holistic personal perspective, Madeline appears to be content with her life as she is mostly positive in her reflections, and thrives on her outside responsibilities of being a student and a performer. I sensed no stress when I spoke with Madeline or read her writing concerning any aspect of her life.

Madeline's reflective journey began in an understated fashion concerning the depth of her reflections. Her initial enthusiasm for being a participant in the study produced seven reflective writings occurring within the first four weeks of the study. These reflections were short journal entries involving the logistics of her practice along with references to emotional connections to those perfunctory portions of her job. She did not choose to follow either of the suggested reflective formats nor did she fill out any of the three suggested reflective exercises. She did write her autobiography. There was not a clear focus of something that Madeline wanted to address during the study, rather, she just wanted to become more aware of her teaching practice.

Madeline's interview responses grew from short, surface level remarks to paragraphs of thought-provoking analysis of who she was as a teacher, her hopes and dreams, and the realities of her personality. Madeline said that the interviews were the most stimulating means for reflection as "talking leads to other things." Although Madeline was comfortable talking with me from the very beginning, she tackled more intimate issues as the study progressed. Her lack of writing during the second half of the study was an issue of the time factor and her changed belief that the verbal mode was more effective. 
Madeline's present stage of life is filled with being a student, a teacher, a performer, and a girlfriend. She has lots going on in her life but does not seem particularly stressed. Her easy-going personality enables her to stay busy without causing her life to seem chaotic. She was not going to let this study add any complexity to her life. Her youthful confidence and positive outlook on life may have been a hindrance to problematizing her own practice.

$\underline{\text { Jacob Hamilton }}$

Jacob's reflections touched upon all four categories of the study but were focused mainly on the pedagogical issue of discipline. From the first rehearsal I observed, Jacob's role as a disciplinarian was characterized by using various methods based upon trial and error, which caused him to encounter frustration at numerous times. While the reality of his situation was that he was teaching 96 middle school students, which was preceded by teaching high school and college students, Jacob was hard on himself in his quest to find a balance of what is appropriate behavior for these children and what can he personally tolerate. During rehearsals, I observed gestures and behaviors that demonstrated a clear frustration for Jacob in his dealings with students. These ranged from a stern look on his face to giving detentions. Calls were also made home to parents of these disruptive students. Jacob talked and wrote openly about his frustrations and his various attempts to remedy the classroom management situations. Following reflection, Jacob would come back with a positive approach with the students, only to find that for a few of them, that was not going to work either. He acknowledged in the interviews that it is difficult to determine how far to let the chattiness go. Jacob also said that he knows he is inconsistent with the students as he searches for his style of discipline. Classroom 
management was the topic he chose to focus on during this study, and it was clearly the area most addressed in both the verbal and written forms. The students were aware of his need to manage student behavior as could be found in their selection of adjectives which included strict and mean to describe him. Interestingly, several students noticed a change in Jacob's behavior during the timeline of the study, saying that he had become stricter. They also acknowledged that the largest challenge of the choir was not talking and paying attention. The problem was evident by both constituencies.

The issue of discipline is fused with the professional category. On more than one occasion, Jacob questioned his desire to teach at the middle school level. He reflected about moving to the high school level, and even thought about changing professions completely. Discipline is also intertwined within the arena of his personal life. He said on three occasions that he was not feeling physically well. The question to be considered is whether the stress from dealing with these discipline issues is adding to Jacob's lower state of physical health, or if his physical health is attributed to his frustration in finding some solutions to deal with these children in a way that he would be satisfied. His personality enters into the picture as well, as he looks for a fit in developing a rapport with this age of students.

There were two smaller, additional pedagogical issues that Jacob changed as a result of the field notes: standing behind the piano during the entire rehearsal, and rotelearning. During the second rehearsal, he said that he made a conscientious effort to move among the students and implement some sight-reading. He did indeed get out from behind the piano and began the implementation of sight-reading exercises. However, 
during the next rehearsals I observed, he was back behind the piano most of the time. The sight-reading was used periodically. Small changes in both of those areas of pedagogy were made as a result of his reflection of my observations.

Within the professional realm, Jacob also wrote about the positive outcomes of attending a professional conference, which made him aware of the challenges of the traditional choral discourse. He shared that he would like to gear his curriculum to a more comprehensive musical approach. Collegial relationships were also a subject of reflection, as he spent time speaking with them and conversing about student behavior problems. After his conversation with them, he felt better knowing that they, too, have discipline problems in their classroom.

From a curricular standpoint, contest was addressed in Jacob's reflective writing. He sees several strengths of having this tradition within the discourse be a part of his curricular program. He believes contest can build confidence in the singers and is an opportunity for the students to "see the fruits of their labor." Jacob also uses contest to serve as an assessment tool for the students and his own teaching.

Jacob addressed several issues of a critical nature in his reflections. Jacob discussed gender-related metaphors that he finds to be inappropriate and will not use. In relation to the discipline issue, Jacob felt that it was important to involve the family, so he began to make phone calls to home to inform the parents and build a community structure to facilitate improved classroom management. In one of his written reflections, Jacob also briefly touched upon his desire to have fun with the students, thereby creating a rapport, but found that because of the discipline issues, he was unable to do this most of the time. 
The critical subject of teaching multicultural music, which overlaps with the curricular paradigm, is not an issue on which Jacob has developed a strong philosophy. He believes in selecting quality literature but does not practice teaching from a multicultural perspective. He says he likes variety, which leads to the selection of an occasional piece of literature from another culture, but feels that most of the multicultural music is not fit for the middle school voice.

Jacob addressed how the process of reflection has affected him personally. He tends to be highly self-critical, which can lead to anxiety. His nature to strive toward perfectionism causes stress and perhaps physical consequences. He mentioned this striving toward excellence in his autobiography. In addition, the multitude of responsibilities in his position is very time-consuming, which also affects his personal life. Jacob finds frustration in trying to be an effective teacher and yet have a balance between his professional and personal life.

Jacob's reflective journey commenced as an enthusiastic adventure, followed shortly by feelings of nervousness concerning being observed. Frustration due to his belief that he was inadequately participating took place in the middle of the research study. However, Jacob ended the study with a sense of comfortability involving the reflective process. Although Jacob felt he was not contributing enough data, the opposite was found to be true. Jacob wrote five extensive reflections and dictated two more. His first two written reflections were based on the Critical Incident Questionnaire, and the last five reflections were in a free form. Jacob did write an autobiography and filled out reflective exercise \#3. The constructive dialogues Jacob and I entered into were honest 
and in-depth. He tended to be more negative in our constructive dialogues than in his written reflections. Although the issue of discipline dominated his reflective journey, many issues came to light as a result of his reflections. The intensity of his spirit led to descriptive reflections in all forms that sometimes revealed information Jacob, himself, did not want to know.

\section{$\underline{\text { Jacqueline O'Keefe }}$}

Jacqueline's reflections centered on issues from all four of the categories used in the study. Student behavior problems accounted for most of the pedagogical domain reflections. Those students who were misusing bathroom privileges, tardy for class, and talking were discussed in Jacqueline's written and verbal reflections. Jacqueline did change her policy on the bathroom pass during the course of the study after reaching a high level of frustration. Tardiness was dealt with through the assignment of detentions, and talking during rehearsals was addressed on a daily basis through individual accountability. Even though classroom management issues will always be part of a teaching practice, Jacqueline understands why most of them occur, and seldom allows them to affect her in a negative way. Several students wrote in their journal entries that talking during rehearsal was one of the choir's challenges, which demonstrated an awareness of the problem on their part as well.

Jacqueline's pedagogical reflections touched on a variety of topics, which included count-singing, sight-reading worksheets, and creating alterative choir formations. Jacqueline was open and up-front about the successes and failures of various techniques. However, she confidently attends to issues of pedagogy due to her years of experience and her level of musicianship. 
Repertoire selection and adjudicated events comprised the curricular areas of reflections. Based on Jacqueline's experience and philosophy of choral music education, choosing choral literature is done with confidence, incorporating challenging repertoire of various styles. Jacqueline supports the concept of contest and regularly prepares her choirs to perform at them.

Jacqueline reflected on several issues in the personal/professional domain. Numerous journal entries and constructive dialogues included a discussion of a colleague who was performing inadequately in the classroom. This was a source of great frustration to Jacqueline, who has a clear vision as to the pedagogy of an effective rehearsal, how the students should behave, and what the musical outcomes should be. Although Jacqueline has worked hard to assist this colleague in developing that teacher's practice, the quality of the choral program has been affected negatively to a certain degree. Jacqueline's strive for perfection and her years of experience as a master teacher have made it difficult to work with this particular colleague. However, Jacqueline frequently employs outside master teachers in rehearsal as part of her practice, as she welcomes new perspectives for her own personal teaching knowledge and her students' benefit. Over the course of the study, three experts came in to work with the students, thereby providing input for improving the choirs.

On several occasions, Jacqueline did speak to her frustration level concerning the multitude of responsibilities in her teaching practice that are time-consuming and consequently, exhausting. The professional domain once again is connected to the personal domain in that one affects the other. Jacqueline discussed how the hectic 
schedule puts a strain at home as she does not have as much time or energy to spend with her husband. Jacqueline wrote about the importance of seeking balance, which can be found in her statement, "I need to teach smarter rather than harder." She also shared how her summers are spent being involved with activities, such as tennis, that are not related to her teaching life.

Issues that fall within the critical arena dominated Jacqueline's reflections. Her critical pedagogy, as articulated in her written and verbal reflections, includes teaching students to be self-disciplined and responsible. Jacqueline addressed the effects of tragic events such as the Columbine tragedy and September $11^{\text {th, }}$ and how she found ways to relate to the students to assist them with their fears and anxieties. Jacqueline is realistic in her understanding that for many of her students, choir is only a class; it is not a high priority in their lives. This point was reiterated in two of the student journals, "Choir is a great opportunity whether or not you are going to pursue music in your life," and "You don't have to sing that well." However, her love of teenagers drives her pedagogy to be socially engaging as well as musically meaningful for all of her students. Efficacy is enacted as she strives to reach all students.

There are numerous examples of relational pedagogy found in Jacqueline's reflections that fall within the critical domain as well. Jacqueline writes about how proud she is of her students, her enjoyment of being with them, and her example of how she supports them by attending orchestra contest, even though she had no professional reason to be there. Her recognition of gender differences was acknowledged in one of our constructive dialogues, with a reference to how she relates to each gender in a dissimilar manner. Her actual preference of teaching males was shared in a verbal reflection 
although she works hard at not revealing that bias. Jacqueline's reflections have the ability to highlight issues of importance, as well as the strengths and challenges of her practice of which she welcomes a greater understanding.

Jacqueline did not set out to change any one specific aspect of her practice as a result of this study. However, she stated on more than one occasion that she wanted to have a better understanding of her practice and herself. Jacqueline's quantity of reflections resulted in many opportunities for her to achieve those goals. Jacqueline wrote/recorded 18 reflections, most of which were quite lengthy. The Critical Incident Questionnaire was used for the first four entries. The last 14 entries did not use a specific format; rather, a free form was employed. These reflections included a laundry list of the day's events, emotional reactions to the rehearsals and issues of the professional/personal domain. They were presented in a conversational style that was open and direct. Jacqueline wrote an autobiography and completed the first two Reflection Exercises. Jacqueline was honest in her comments concerning the barriers to reflection. She found that handwriting the reflections was time-consuming and therefore, caused some stress. However, she enjoyed the new format of tape-recording her reflections, as it was efficient because it could be done during her long drive to work. I sensed some resistance to the reflection process about half way through as Jacqueline became even busier in her professional life and was therefore, finding the reflective process to be somewhat of an annoyance. Nonetheless, Jacqueline continued to reflect, partially because she had made the commitment to be a participant in the study and perhaps 
somewhat because she was finding some benefit to the process. Jacqueline also shared that she did enjoy writing the second Reflection Exercise, as it was pleasurable to reminisce about her past choral experiences as a singer.

$\underline{\text { Kate Tyler }}$

Pedagogical and personal/professional issues dominated Kate's written and verbal reflections. As a new teacher it would seem logical that the development of her craft in terms of strengthening her pedagogical skills would take precedence in her thought processes. Professionally, Kate questioned her choice in taking this particular position, as there were multiple responsibilities that, at times seemed overwhelming. Her demanding professional life was affecting her personal life as well.

Pedagogically, Kate decided that incorporating effective breathing techniques and focusing on the emotional aspects of the piece were the two goals she wanted to undertake during the course of this study. Kate did implement consistently a variety of breath control exercises that the students executed. In one of her journal entries, she wrote that she had spent some time thinking about the breathing mechanism and applicable exercises. Through our constructive dialogue and her reflective writing, she was able to process a strategy to improve her students' breath control management. Some of the students wrote in their journals that learning how to breathe correctly was an area that needed improvement.

The discomfort Kate was experiencing in terms of her professional life was highlighted in her journal writings and our constructive dialogues. First of all, her wavering confidence level can be heard in her comments regarding the rehearsals that she perceived were not going very well, when in fact, they were very productive. Her 
tremendous level of frustration presented itself in the interview following the second rehearsal in her statement, "Maybe I am failing, maybe I am not a good teacher, but I was just like, I don't care. For me this is too much, it may be fine for someone else, it's just too much for me." This lack of confidence and the huge amount of responsibility have led her to question her choice in jobs. During the next constructive dialogue, Kate shared how she does not have enough planning time to teach as effectively as she would like. This desire to be the best, a perfectionist quality, has caused internal conflict. Kate once again spoke to the unrealistic demands of this position in our fourth discussion. She acknowledged that this research study has enabled her to see things honestly and realistically, and that through this more clear vision, she really wants to "loosen up" her expectations in her professional life.

In Kate's autobiography, there are more references to the questioning of her career choice and where she might want to be several years from now. Kate is eagerly anticipating taking on the role of wife and mother in the future. Her reflective journals also contain various references to job decision issues.

The effect of Kate's professional life on her personal life is connected to the relationship with her fiancé. She reflects that she needs to make him the priority and struggles with finding a way to have a balance between her professional and personal life. Inversely, an element of her personal life that affects her professional life is her spirituality. Kate draws great strength from her relationship with God and reflects about this several times in her journal writing. 
Curricular issues that arose in Kate's reflection included the implementation of one of The National Standards for Arts Education (MENC, 1994). After Kate attended a professional conference, she was motivated to find ways of incorporating the standards in to rehearsals. The students were able to experience improvisation as a result of Kate's decision to introduce this standard. Kate also struggled with issues surrounding contest. While she acknowledges the positive reasons for giving the students the opportunity to participate, she also recognizes the time it takes to prepare them for it and that other parts of the curriculum may have to be put aside.

One of our constructive dialogues tackled the issue of repertoire, which enters into both the curricular and critical frameworks. The school community expects there to be a traditional Christmas program, which Kate knows is conceptually resistant to a critical pedagogy. She has found that when she programmed some multicultural pieces the students seem to enjoy them but some of the parents did not have an appreciation for their educational worth.

Within the critical arena, Kate often spoke of her role as a model for students. In her reflections, she shared her goals of raising students who are independent and responsible. Kate would outwardly admit her mistakes to her students, thereby, showing them the human side of their teacher. Integrity can be found in her honest replies to the students in regard to her returning to the job next year. The qualities of being helpful and caring that the students used to describe Kate are ones that Kate highly values.

Kate's reflective journey was honest, filled with emotions, and revealing. Both the writing and the constructive dialogues were effective vehicles for reflection, according to Kate. Her responses to questions and journal entries were not long in 
length, but addressed a variety of issues that were of relevance to her. All of her written reflections were produced during the first half of the study. The lack of written reflections during the last four weeks of the research time-line was probably attributed to Kate's increasing performance demands. She did not follow either of the suggested formats, but rather, always wrote in a free form. Kate did write an autobiography, but did not fill out any of the reflective exercises. As Kate struggled with the normal issues of a first-year teacher, coupled with an overloaded teaching schedule, she found the reflective process to be helpful in sorting out her challenges as well as her feelings.

\section{$\underline{\text { Ashley Brooks }}$}

Ashley's areas of reflections were rooted in all four of the categories delineated in this research. She was very specific and forthcoming on the areas of change she wanted to seek out during this study. Both focal points were pedagogical and easy to assess in terms of their completion. The first included developing a communication tool for students, which would therefore be used for parents as well. A bulletin board to post important information was designed about two-thirds of the way through the period of this study, with the assistance of the student-teacher. Ashley was satisfied and relieved to have this communication vehicle in place. Developing meaningful, yet easy to use assessment tools was Ashley's other pedagogical goal. That goal was met as she implemented a form for the students to use following the viewing of their concert video. Ashley was pleased with the results of that assessment instrument. Ashley also implemented a form of authentic assessment by having students sing individually during 
the rehearsal so she could evaluate their ability to develop certain musical skills. In addition, Ashley enthusiastically contributed to the design of the student reflective journals used for this study.

In our constructive dialogues, Ashley attended to other pedagogical skills she uses in her rehearsals. She reflected on vocal techniques, including breathing techniques and the use of head voice, and classroom management. Her concern for correctly teaching vocal pedagogy is evident based upon the amount of times she reflected upon it. On more than one occasion Ashley implied that she felt inadequate teaching about the voice, where in fact, this was a strength in her teaching practice. Classroom management was an area that was discussed from the standpoint of its emphasis rather than problems Ashley encountered. Maintaining control in the classroom is a high priority for Ashley and she is confident in her ability to manage it in most cases.

Ashley's curricular approach is based on music literacy. She has found a system that works for her students to achieve the goal of becoming musically literate. The Kodály approach drives her program and results in students who are challenged, held individually accountable, and focused during rehearsals. Ashley stated her satisfaction with this methodology throughout her verbal reflections.

Outsiders affected the curriculum from the aspect that Ashley did not prepare a holiday concert for one of the grade levels due to the various religious sectors within the school community. In terms of repertoire selection, Ashley seeks out music that is demanding, typically in three parts, and a cappella music to help develop the student's aural skills. Multicultural music is taught, but sometimes criticized by parents because they do not understand it. Ashley has become more aware of the importance of the 
translations as a result of our constructive dialogue and the students assessment tool of the concert. The students indicated that what they enjoy most in choir is the learning of new songs, thereby supporting the variety in the curriculum Ashley has selected.

Several personal/professional topics arose as a result of this study. Ashley has entrenched herself as a music teacher both inside and outside of school. She thrives on being busy, even though she is aware of the impact that it is having on her personally. In her reflections, Ashley talked about being physically worn out and referred to her husband's jealousy of her time away from him. She wrote that she has no time to do anything for herself, which she admits is a problem. Ashley clearly acknowledged in her autobiography that her biggest weakness is her inability to say no.

Ashley does avail herself to professional development opportunities through the local chapter of The American Organization of Kodály Educators, as evidenced in her written and verbal reflections. Scholarly readings are also part of Ashley's search to reach a high level of competence and therefore, Ashley acknowledges her readings as a form of professional development.

Issues of a critical nature were a part of Ashley's reflections. Ashley holds the goal of developing self-discipline for her students as a high priority. She sets up an atmosphere that encourages individual responsibility and risk-taking.

Ashley's reflective journey closely resembled her teaching life. Sometimes it caused her great frustration and other times it served as a satisfying, reaffirming reminder as to why she became a music educator. From the beginning of the study it was evident that Ashley's plate was already full and the only way to enable Ashley to engage in a reflective process would be via her most comfortable and convenient form of 
communication, which was constructive dialogue. Her intensity of spirit could also be found in her reflections. She frequently shared her strong convictions and beliefs as well as her frustrations and insecurities, which drive her to seek continual improvement. Perfectionism is one of her characteristics that often would lead to disappointment when students were not able to meet the challenges she set for them. Often times, however, the students would rise to the occasion, giving Ashley the ultimate satisfaction in her teaching life. Many students recognized Ashley's high expectations by writing that she "expects the best" in their descriptions of her teacher personality.

Ashley wrote five reflections and an autobiography during the time period of the study. These relatively short, written summaries were commentary on the positive and negative aspects of the rehearsals presented in a free style format. Ashley was very expressive in her descriptions of the reactions to what had occurred as found in her frequent use of exclamation marks. Ashley shared that there were two barriers to writing reflections, the time barrier and the personal risk barrier. Although at times, she felt guilty that she was not able to write more, it was clear that this study was not a high priority and her participation was evidence of her inability to say no. However, Ashley's drive for self-improvement and her comfortability with verbal communication enabled her to reflect through constructive dialogue. Our conversations were always lengthy and filled with a range of topics and emotions. Ashley shared that this study generated a variety of reflections, and allowed her to think about her practice at a new level. She began asking herself if her rehearsals truly accomplished what she wanted to happen. It was a form of accountability assessment, which connected to the goal for change in her practice. 


\section{CHAPTER 5}

\section{FINDINGS}

The purpose of this study was to increase understanding of the phenomenon of five choral teachers' engagement in a reflective process. As proposed in Chapter 1, the following elements were examined: how choral teachers use the reflection process to understand and shape their practice; the ways that they reflect; and when they reflect. The new constructs of how teachers engage and use a reflective process composed the descriptive dimension of the study as explored through the various methodologies utilized by the teacher, the students, and the researcher. Within the generative dimension, this research produced a field of knowledge concerning issues that arise in defining a teaching practice, new ideas for pedagogy and curriculum, and innovative approaches to reflection.

This chapter begins with a cross-case analysis of the five participants within the contexts of the four delineated categories and the research questions. What follows is the presentation of The Cyclical Model of Reflection, a theoretical extension of the concepts developed by Schon (1983). This model introduces a third dimension of reflection, reflection-fore-action, which synthesizes Schon's framework of reflection. Found in this new model are six methodologies occurring within three positioned modes, which serve as options for reflection. A summary of the study is presented with the inclusion of noteworthy findings, a discussion of the value of engaging in a reflective process, and a 
recapitulation of the usefulness of the qualitative paradigm. Implications for music teacher education and professional development that resulted from this study and recommendations for future research conclude this chapter.

\section{Cross-Case Analysis}

\section{Four Categories of Reflection}

The four categories delineated for the purpose of this study include pedagogical, curricular, personal/professional, and critical. These domains will be analyzed through the identification of specific issues that instigated reflection, a comparison of the topics of reflection within the categories among the teachers, and a summation of the relative points related to the participants' reflections.

\section{Pedagogical Reflections}

All of the teachers reflected on pedagogical issues, with classroom management being the consistent topic for reflection in this area. Since each of the five educators taught in unique situations, which is based on the school community and the population of the choir, various classroom management scenarios occurred. Jacob focused the most intently on the area of discipline, followed by Jacqueline. These two teachers had the largest choirs of the five teachers as well.

The teacher personality comes into play in analyzing the various approaches to and effects of student behavior problems. Jacob's desire to be in control, along with his perfectionist personality often conflicted with the challenges of the adolescent psyche. Jacqueline's persistent, almost relentless drive to incur efficacy in the choral classroom is congruent with her striving for perfection for both her students and herself. Ashley's firm control in the classroom, stemming from her no-tolerance rule for misbehavior, 
amounted to occasional frustration with the typical adolescent way of being in the world. Madeline's easy-going personality kept her from becoming agitated or motivated to control the students' every indiscretion. Although Kate did not encounter many behavioral issues, her conscientiousness and drive to continually improve kept her attuned to each classroom management situation. Teacher personality and the persona of the choir were the determining factors concerning how problems were approached and how the teachers reacted to those behavioral problems.

Various other pedagogical issues were addressed throughout the study. These topics included vocal pedagogy, the development of a new assessment tool, the implementation of a communication device for parents and students, the inclusion of sight-reading within the rehearsal, the creation of new choir formations, and an analysis of the effectiveness of count-singing accounted for other areas of pedagogical reflection. The pedagogical topics highlighted in this study are homogeneous to the choral discourse.

\section{Curricular Reflections}

Madeline and Ashley reflected on issues of curriculum more than the other three teachers. The incorporation of a comprehensive musicianship approach and nontraditional curricular elements in Madeline's teaching practice were facilitated by a school philosophy of academic freedom and individualized teaching. This atmosphere was congruent with Madeline's creative spirit and enthusiastic nature. However, the implementation of this non-traditional curriculum was balanced with the inclusion of many attributes found in a traditional choral program. Music literacy, based upon the 
Kodály methodology, was a focus of Ashley's curricular reflections. Her strong belief that this curricular approach is a viable means to teach choral singing was evident in her writings and constructive dialogues.

Other curricular topics of reflection surfaced as a result of this study. These included the preparation of challenging repertoire discussed by Ashley and Jacqueline, the programming of a variety of styles of music addressed by Jacqueline, the implementation of The National Standards for Arts Education (1994) reflected on by Kate, and the strengths and challenges of adjudicated events noted by Jacob and Jacqueline. Curricular issues highlighted in this study displayed no discrepancies based on years of teaching experience. Reflections on this domain represented the least amount of emotional impact or sense of urgency.

\section{Personal/Professional Reflections}

Issues that focused on the personal/professional domain revealed the most emotional and emphatic reflections. The topics addressed within this domain held the potential for the most life-changing effects. All five of the participants reflected on topics that fell within this category, with four of the five teachers clearly emphasizing this category over the other three. For these four teachers, this was the domain with the most negativity and intense responses. Only Madeline approached this category with a positive perspective, once again reflecting her easy-going personality and contentment with her personal/professional life.

The interconnectedness of a teacher's professional situation and personal life is evident through the reflections from this domain. Both Jacob and Kate questioned their specific job placement as well as their choice of a career in music education. Ashley also 
addressed the possibility of a level change in one of her constructive dialogues. Jacob discussed the physical effects of job stress most often, but Kate and Jacqueline also shared frustrations associated with this topic. Fatigue was the physical complaint given by those three teachers. Kate, Jacqueline, Ashley, and Jacob all reflected on the negative effects that their teaching practice has had on their personal relationships, which is connected to the issue of exhaustion. The demands of the choral teaching profession come at a price for these four teachers.

Other topics that were addressed as part of the personal/professional category included the effects of professional conferences on growth, belonging to professional organizations, and seeking further development through scholarly readings. Jacob wrote that as a result of attending a conference, he wanted to transform his curriculum into a more comprehensive musical approach. Kate had a similar reflection, where she shared that a professional conference motivated her to implement the National Standards into her curriculum. Ashley made specific mention of her participation in the local chapter of The American Organization of Kodály Educators as well as trying to find relevant research to her practice.

Collegial relationships, which fall within the professional domain, were objects of reflection for four of the teachers. Jacqueline reflected about her relationship with a colleague that was causing enormous stress, affecting both her professional and personal life. In discussing this situation, she used both verbal and written reflections as a cathartic tool. Similarly, Madeline wrote a reflection that was centered on the frustration that she felt when a colleague in a previous position had betrayed her. Ashley shared the challenges of working with a colleague in one of her reflections. On the reverse side, 
Jacob reflected on an incident where a conversation with several experienced colleagues had been reaffirming to him, as they all shared stories of students' behavioral problems. Jacqueline also had a positive story to impart in terms of her bringing in colleagues from outside of the school system to work with her students for the purpose of improving their choral singing.

Written and verbal reflections within this domain were highly, emotionally charged and emphatically expressed by all the teachers except Madeline. Interestingly, the negative effects of collaboration, in terms of team teaching, surfaced in some of the reflections, contradicting much of the past research (Cruickshank, 1985; Clemson, 1987; Gore, 1987; Thies-Sprinthall, 1987; Pugach \& Johnson, 1990; Richardson, 1990b; Doyle, 1992; Hay, 1995; Strong-Cvetich, 1995; Stegman, 1996; Bogan, 1997; Kruse, 1997;

Powers, 1999; Humphreys \& Suzak, 2000; Neelly, 2000; McDonald, 2001). It is possible that the teachers' quality of perfectionism, combined with the situation of isolation unique to the choral discourse hindered the facilitation of collaboration in certain situations. Similar personal and professional challenges crossed age and years of experience boundaries.

\section{Critical Reflections}

Issues of a critical nature, as well as topics of pedagogy, curriculum, and personal/professional experiences that were viewed through a critical lens served as points of reflection by all five teachers. Five common themes arose in the reflections: the importance of student citizenship; building a relational practice; issues of multicultural education; gender issues; and creating a sense of community. 
Four of the teachers addressed the theme of the importance of student citizenship. Madeline identified raising responsible students as a priority in her discussion of people learning the value of keeping commitments. Jacqueline reflected on the importance of teaching students to be self-disciplined and responsible. Kate often spoke about being a role model for her students, emphasizing the need for them to be independent and responsible. Ashley shared those sentiments in her reflections as she talked about the goal of her students developing self-discipline.

The second theme, which focuses on the relational aspect within a critical pedagogy, was addressed by four of the teachers. Madeline's conversation with the girls about body piercings was one example of her desire to relate to the students so that a safe and caring environment can be built. Jacob expressed his desire to have fun with the students in order to build rapport, even though he believed it could not be done. Jacqueline's numerous examples of caring about her students found in the written reflections demonstrated the importance of the relational component to her practice. Her discussion with the students following the Columbine tragedy, also exemplified her concern for their feelings and anxieties. Kate's students identified caring as one of the adjectives to describe her, thereby, providing evidence that this quality is observable in the classroom.

The value of multicultural music education, which is the third critical theme, was discussed by three of the participants. Jacob has not developed a strong philosophy concerning the inclusion of multicultural music based on his professional opinion that most of the literature does not fit the middle school voice. Kate has wanted to build a program that provides opportunities for her students to sing music from other cultures, 
but has met some resistance within her community. Her own philosophy of music education has been somewhat compromised by this outside force. Ashley, too, has encountered resistance concerning the parents' acceptance of multicultural pieces of music, but has decided that she could educate the parents by including the translations of the literature in other languages as a means to build support. The concept of teaching with a multicultural approach is not a part of any of the participants' practices.

For three of the choral teachers gender issues, the topic of the fourth theme, initiated points of reflection. Madeline discussed the importance of meeting the needs of both sexes because of the skills involved in singing and the varying levels of maturity between boys and girls. Jacob discussed his sensitivity to stereotyped metaphors that he will not use in his class out of respect to each sex. Jacqueline acknowledged her different treatment of the two sexes and her own bias toward the males.

The value of creating a sense of community, the fifth theme within the critical domain, could be found in the reflections of Madeline. Madeline expressed how pleased she was that there was a sense of family felt in the choir. Although the other four teachers did not openly discuss this arena of critical pedagogy, the feeling of community could be sensed by my observations in the classrooms of Jacqueline and Kate as well.

The critical reflections presented in this research shed light on the personal philosophies held by each of the participants. These teachers' value systems and life strategies are intertwined with their teaching practices. Realism, intensity of spirit, and deliberate frame of mind molded the reflections found in this domain. 


\section{Research Questions}

The overarching research question for this study asked, "How does engaging in a reflective process over time affect choral teachers?" The five research sub-questions posed in Chapter 3 serve as the focus of the cross-case analysis in this portion of the findings and address the main research question.

1. How does engaging in a reflective process affect a teacher's consideration of new pedagogical, curricular, personal/professional, and/or critical approaches?

All five teachers considered new approaches in the pedagogical, curricular, personal/professional, and/or critical categories as a result of the reflective process. Jacob, Jacqueline, Kate, and Ashley considered new ways to approach their rehearsals from a pedagogical standpoint. Specifically, Jacob and Jacqueline focused on classroom management issues, while Ashley and Kate examined issues of vocal training. Individually, Jacob initiated a sight-reading program and the physical monitoring of his students, and Ashley developed a new assessment tool as well as a vehicle for communication. Jacqueline changed her bathroom pass policy as a result of pedagogical reflection.

Within the curricular domain, Madeline's implentation of non-traditional curricular topics, which were initiated by the students, received internal support as she reflected about their purpose toward developing a comprehensive musicianship choral program. Through the reflective process, Jacob and Jacqueline reaffirmed his positive beliefs toward contest. Kate contemplated the pros and cons concerning contest in her writings, ultimately deciding to participate, but with some reservations. Kate also executed the implementation of one of The National Standards of Arts Education (1994), 
which was first considered following the attendance at a professional conference, after some reflection. Ashley reflected extensively about her strong belief in the value of teaching music literacy, identifying it as a prominent goal of her teaching practice.

Reflections centered on the personal/professional domain revealed that Madeline confirmed her philosophy of keeping her practice fresh by continuing to take classes and maintaining performance skills by playing in a band. Jacob reflected about his career options, writing about the possibility of interviewing for high school positions. As Jacqueline dealt with the conflict between her colleague and herself, she used the reflective process as a therapeutic tool to handle her own stress and consider the various options of how to resolve the situation. Jacqueline was also determined to seek balance in her life by "working smarter, not harder." Kate, too, was resolute to pursue a better sense of equality between her professional and personal life as related in her reflections. Ashley's acknowledgement of the stress brought about by her overscheduled professional life was made in her written and verbal reflections.

As part of the critical domain, a result of inviting the students to take part in the reflective process through the implementation of the student journals was the multitude of possible uses for the teachers to contemplate. These potential benefits included student empowerment, a means of assessment, and new teaching and learning ideas. All of the teachers found the student journals to be a valuable tool in increasing the level of understanding of their practice

Other critical issues that surfaced in the teachers' reflections included the confirmation that a relational pedagogy is an important part of a practice, which was discussed by Madeline. Jacob's sensitivity to gender stereotypes was highlighted within 
his reflections. Jacqueline articulated her goal to teach students to be self-disciplined and responsible. Jacqueline frequently wrote about her love for her students, which was supported in her daily encounters with them. Ashley and Kate both reflected on the importance of guiding students to be independent and responsible, which they practiced on a daily basis.

Change was enacted as a result of the reflective process. Educational philosophies were justified through reflective writings and constructive dialogues. The reflective process facilitated the external confirmation of the pedagogical, curricular, personal/pedagogical, and critical issues that each individual teacher faced.

2. How does the notion of problematizing a person's practice affect each teacher? Madeline simply did not engage in the act of problematizing her practice. Rather, she used the study to examine the pedagogical aspects of each rehearsal, discuss in written and verbal forms her history and philosophy of music education, and enter into some collegial discussion about related choral music education topics. Madeline's confident personality, combined with her relaxed outlook on teaching and her life in general, prevented her from addressing areas in her practice that could have been problematized, and therefore, changed.

Jacob was hard on himself as he consistently reflected on the negative areas of his practice, which often added to his physical and emotional stress. His lack of confidence, along with his search for the correct job fit, set Jacob up to be highly self-critical throughout the nine weeks of this study. The realization that there were challenges in his practice, which were brought to the surface through his reflections, caused internal 
conflict with his perfectionist qualities. Jacob's written reflections and his verbal discussions with me were filled with an outpouring of emotions, therefore allowing the honesty to turn to pain. The act of problematizing his practice was both mentally and physically draining, and often resulted in an increase of negativity and lack of confidence.

Kate's process of problematizing her practice was more similar to Jacob's in that she, too, was struggling to find her strengths as a teacher, therefore indicating a lack of confidence. Her search for an answer in deciding if this was the right job for her, via the reflection process, was a painful journey but one that she wanted to make. The reflective process was also used as a problem-solving device as well as a tool to bring to light the negative effects the stress from this job was having on her personal life, therefore, making the process painful at times.

Although Jacqueline openly discussed and wrote about a multitude of aspects of her teaching life, she remained confident in and positive about her teaching. Problematizing her practice enabled Jacqueline to assess a situation and then attend to possible solutions without causing her additional stress. Jacqueline is secure enough in her teaching that she did not feel that bringing the challenges of her practice out in the open was a sign of weakness. Even thought Jacqueline shared many emotional responses in both her written and verbal reflections, she was able to keep her thoughts and actions in perspective. Jacqueline used the reflective process as both a tool for highlighting positive and weak components of her practice as well as for problem-solving. Reflection was a practical means to an end. 
Ashley used the reflective process to both highlight the strengths of her teaching and release the frustrations concerning various aspects of her practice. Ashley is confident in her philosophy of teaching choral music; she knows what works for her students and she stays true to that methodology. Ashley's challenges were in the area of finding balance in her life, which she acknowledged in her reflections but was not able to change. The fact that she selected two concrete projects to complete as part of this study as opposed to the issue that was causing the most stress in her life, overworking, indicates a resistance to the reflective process. Ashley recognized the problem but chose to take on a simpler project much easier to complete as part of this study.

A two-step process is necessary to initiate change in a teaching practice. First, the teacher must identify and assess a problem area, and then needs to find possible strategies to solve the problem. Four of the teachers were able to complete step one. However, the teachers encountered varying degrees of success in step two. The structure of this study served as a motivational vehicle for the possibility of change, of which three of teachers responded and two of the teachers demonstrated resistance.

3. What are the unique factors that affect the reflective process in a choral classroom?

The pedagogy of choral teaching is engulfed in the art of problem-solving, which lends itself to reflection-in-action as it involves the act of hearing a musical problem, choosing a method to correct the problem, and applying that particular method. For example, if the educator hears that the bass section is unable to sing a particular interval, the teacher must strategize in that moment of the rehearsal a plan to solve the problem, and then apply that strategy or find another until the problem area is corrected. While all 
areas of teaching utilize reflection-in-action, performance-based fields, which involve active-learning as well as a potentially large number of students, increase the opportunities for reflection-in-action to occur.

Commonly found in choral positions is an overload of responsibilities. All of the teachers except for Madeline reflected often about this stressful situation that is typical of a choral teaching position. The pressures that stem from concerts, contest, musicals, and the numbers of students affect the amount of time and energy a teacher has to invest in a reflective process. Choral teachers also encounter many constituencies who influence the program based on traditions and expectations, as music programs are often considered a public relations tool for the school. The many facets of varied job responsibilities and relationships with people who play a part in the program allow for many opportunities to reflect, but the time barrier can be a strong deterrent in a teacher's engagement in a reflective process. The issue of limited time was found to be a barrier to reflection by all five of the teachers to some degree, but was diffused in varying amounts by the teachers' desire to fulfill their commitment as well as the two external motivational devices -- the choices of tools for reflection and the researcher.

As the choral teacher is often without choral colleagues in the same building, the process of written reflection can be a useful tool for assessment and problem-solving as an individual activity. However, although constructive dialogues with other colleagues can be a rich opportunity for both affirmation and growth, time and energy need to be allotted to work together, which are often difficult to find. The challenges of working with a colleague were also previously noted. 
Every field in education has exclusive qualities that will affect the reflective process. Choral teaching is rooted in reflection-in-action, but often requires increased internal and/or external motivation to achieve a deeper reflective state. The teachers in this study were externally motivated, at least initially, to engage in a reflective process and then followed individual paths of reflection.

4. How does a teacher's life history, current phase of development, and specific teaching assignment affect the reflective process?

Each teacher's reflective journey develops as a result of many factors, including the past experiences and present teaching situation. The richness of life's experiences, the support or lack thereof from influential people, and the individual personality contribute to a teacher's desire and ability to reflect. In this case, all five teachers had histories filled with positive musical experiences and mentors. It is interesting to note that Madeline and Jacqueline were the least affected by problematizing their practice and had the most support to become a teacher while they were growing up. Their confidence levels appeared to be the highest of the five teachers as well.

Although all of the teachers reflected on all four of the categories delineated in this study, the developmental phase of the teacher could have partially served as a determining factor in consideration of categories of reflection and motivation on which to reflect. Kate and Jacob were both new in their positions and spent a substantial amount of time reflecting on the appropriateness of their present jobs. In general, they were both very motivated to engage in a reflective process, despite the obvious time barrier that the reflection process presents. On the opposite end, Jacqueline's and Ashley's master level of teaching, combined with the multitude of responsibilities that are partially a result of 
their level of expertise, left them somewhat resistant to the reflective process. Interestingly, Jacqueline was the most active reflective teacher of the five, and Ashley engaged in more constructive dialogues than the other participants. Conversely, even though Madeline was a relatively new teacher, she was not as motivated to engage in the reflective process because her present position was not offering any challenges in her eyes. Because she was presently involved in furthering her education, she may have believed that professional development through a reflective process was not necessary.

In terms of specific teaching assignments influencing the reflective process, each of the positions was unique in many aspects and therefore, produced a variety of topics for reflection. The interrelated components of the teacher's life history, current phase of development, and specific teaching assignment created the individualized, distinctive journeys each participant took.

5. How are teachers empowered to act upon their reflections?

It is first necessary for teachers to problematize their practice in order to enact change as a result of reflection. Madeline's resistance to finding challenges in her practice was evident by the reaffirming nature of her reflections, therefore inhibiting actions or changes in practice to occur. However, because the reflective process served as a vehicle to confirm Madeline's confident beliefs in her pedagogy and curriculum, the reflective process reinforced her motivation to seek non-traditional curricular goals.

Jacob's reflections were deeply rooted in a quest for finding solutions; he chose to take steps to solve the problems at hand. In terms of classroom management, he did seek solutions because he had become so frustrated with disciplining students who were not focused. The reflective process had made the problem more apparent, and therefore 
called him into action. Jacob's frustration in the job created a need for him to consider other job possibilities, which he chose to explore as a result of reflection. Reflections also served as an affirmation of feelings for Jacob.

Jacqueline's reflections worked as a game plan to attend to issues that she would have addressed anyway. However, the reflections gave clarity and direction to solve specific solutions, but were not used as emotional triggers that instigated change as with Jacob.

Kate's reflections confirmed issues associated with self-confrontation, particularly in her questioning of career choice. However, through the timeline of this study, she was not able to make any firm decisions as there were other determining factors that would be part of that decision making process. Perhaps Kate's confidence level attributed to the lack of forward movement on significant issues that were problematic for her. For example, Kate saw no possible solution to the overload in her schedule, in that even though the reflective process outlined a strong resistance with reasonable justification, Kate made no specific moves to alter her situation.

Ashley used the reflective process to validate her realization that she is too busy, but did not choose to alter her behavior. She attributed it to her personality, and did not make any changes in her professional life. This reveals the possibility that Ashley is receiving some benefit or pleasure from being as busy as she is, even though she wrote and discussed her feelings of frustration. Ashley's reflections revealed a discrepancy between her reflections and her actions. 
Empowerment is a result of either internal or external forces, or a combination of

the two. Internally, the reflective process served as motivator to seek change in the cases of three of the teachers. Some of the issues that arose in the four categories found external resistance, thereby causing facilitation for change to be difficult. The time length of this study may have also been too short to enact change in some of the scenarios.

\section{The Cyclical Model of Reflection}

\section{The Three Dimensions of Reflection}

Based upon the findings of this study, a new theoretical model of reflection has been developed. As an extension of the paradigm created by Donald Schon (1983), which incorporated two types of reflection, reflection-in-action and reflection-on-action, a new dimension, reflection-fore-action, is being proposed. Reflection-fore-action incorporates all possibilities of reflection that transpire before a teaching episode occurs. An educator's lesson plan formulates the concrete, tangible product of reflection-foreaction, but other modes and methodologies serve as reflective tools in this dimension as well. The life history and educational philosophy of a teacher, which can be analyzed and delineated through various reflective methodologies, is always included in the predetermination of what is to be taught, thereby representing reflection-fore-action. Another aspect of the reflection-fore-action dimension is its role as an extension of the reflection-on-action where certain understandings have been reached concerning the previous teaching episode and how the next teaching episode will be affected. Therefore, each dimension of reflection is referenced from the dimension that occurs before it, creating a cyclical flow to the reflective process. 
Schon (1983) addressed the impact of past experiences on reflection-in-action, whereas a problematic situation is recognized, frames are imposed based upon prior knowledge, and problem-solving actions are generated. The recurring nature of the framing and reframing of a problematic situation are documented as a reflective exchange (Grimmett, 1988). The dimension of reflection-fore-action recognizes the cognizant act of perceiving those past experiences and their influential affect on the problem-solving process.

\section{The Three Modes of Reflection}

Reflection can be actualized through the use of the three modes: thinking, writing, and conversing. Within the thinking mode, there may be either a planned or unplanned stream of thought focused at any aspect of a teacher's practice. Creative ideas, problemsolving solutions, and emotional reactions are possible outcomes that may result within the thinking mode. In the writing mode of reflection, a teacher makes a conscious decision to put down on paper various aspects of a practice or a specific teaching episode. The conversing mode is the result of a conscious decision to participate in a dialogue focused on some aspect of a teaching practice.

\section{The Six Methodologies of Reflection}

Each of the three modes of reflection can be performed by using one of two different methodologies. The thinking mode utilizes either a structured or unstructured thought process. A structured thought process engages purposeful thinking such as lesson planning or creative brainstorming. When a teacher makes the conscious decision to think about some aspect of his/her practice, a structured thought process is enacted. Cogitation involving past personal and educational experiences is a type of structured 
thought process. This methodology occurs within the reflection-fore-action and reflection-on-action dimensions. An unstructured thought process includes some problem-solving or idea that develops on the spot, found within the paradigm of reflection-in-action. An unstructured thought process is a result of reflection-on-action and reflection-fore-action, which represents the cyclical reflective process, but is presented as a spontaneous, contextualized reaction to some aspect of the teaching episode.

The two methods utilized in the writing mode of reflection are structured written documentation and unstructured written documentation. Both methods represent a conscious decision to engage in the reflective process but are executed in different formats. Structured written documentation specifies some type of preconceived structure, such as the Brookfield's' Critical Incident Questionnaire (1995) or Smyth's Three Critical Questions (1992) for a teacher to reflect on specific aspects of his/her practice. An unstructured written documentation is best known as the reflective journal, where an educator writes in a free form style on any aspect of a teaching practice or specific episode.

The conversing mode of reflection can be delineated into the two methodologies of structured constructive dialogue and unstructured constructive dialogue. Both methods involve a teacher holding a purposeful conversation with someone who is capable of being a valued listener, responder, or interviewer, thereby creating a constructive dialogue. A colleague, friend, relative, administrator, parent of a student, and student are all constituencies who may enter into a constructive dialogue with a teacher engaging in a reflective process. A structured constructive dialogue is based 
upon a preconceived set of questions with exact intentions. Formal interviews are a common form of structured constructive dialogues. Unstructured constructive dialogues occur in a free-flowing fashion, with no preconceived specific intention in mind, except for the concept of discussing areas related to that teacher's practice. It must be noted that conversing with self, as actualized in this study when two of the teachers engaged in talking into a tape recorder, is to be considered an altered form, albeit verbal, of the thinking mode.

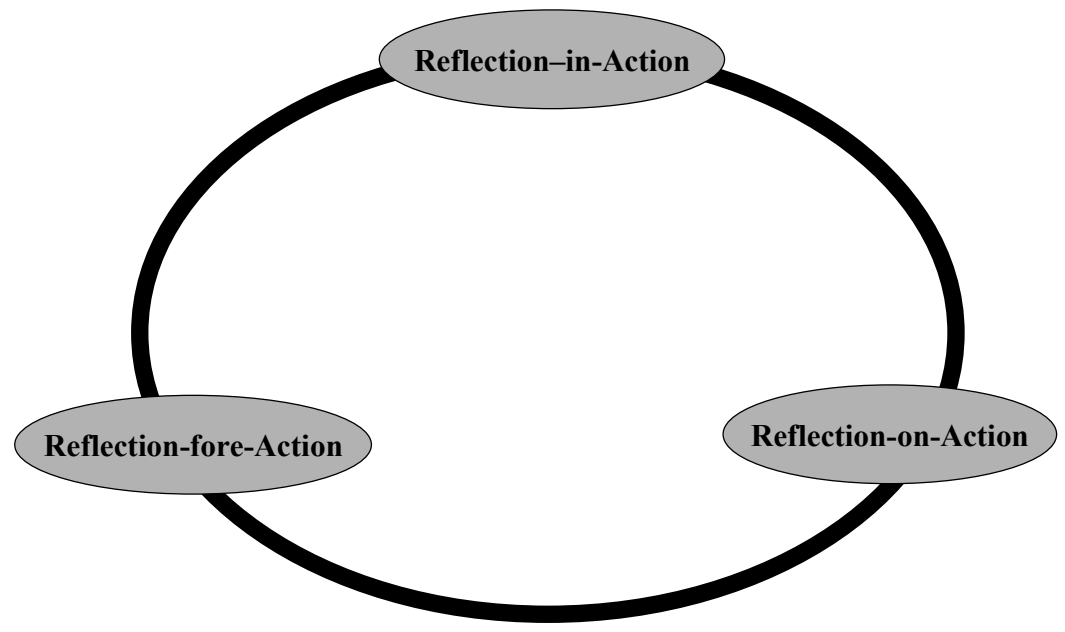

Concepts of reflection-in-action and reflection-on-action developed by Schon, 1983 Concept of reflection-fore-action proposed by Butke, 2003

Figure 1: The Cyclical Model of Reflection

This cyclical model of reflection delineates the three dimensions of reflection, which involves when reflection takes place -- before, during, or after a teaching episode; the three modes of reflection, which presents the three ways reflection can occur; and the 
six methodologies of reflection, whereby each of the modes can be executed in two different ways. There is an overlapping within the structure of two of the three dimensions of reflection, as any of the various modes/methodologies can effectively be employed in either reflection-fore-action or reflection-on-action. Within the reflectionin-action dimension, only the unstructured thought process from the thinking mode can occur because the teaching episode is happening in real time, and teachers can only reflect as events are taking place, as opposed to being able to write or talk about what is happening at that moment in time.

The cyclical nature of reflection is revealed through the interdependent dimensions, whereby when a teacher reflects after a teaching episode, the next teaching episode is influenced by those reflections-on-action, therefore influencing and channeling specific reflections before the next teaching episode. The reflections that occur during the teaching episode may be related to the reflections that have taken place before and after the lesson is taught.

The Cyclical Model of Reflection is a product of the understandings gained from this study. The designations of the proposed dimension, reflection-fore-action, the three modes, and the six methodologies have not been delineated in this inclusive format in any of the related literature. This model presents the reflective process as multi-dimensional with interrelated choices in which to engage and facilitate change in a teaching practice. 


\section{Summary}

\section{Noteworthy Findings}

As a result of this study, several issues of reflection are highlighted as noteworthy findings. Specifically, five important discoveries resulted from this study. The philosophy of qualitative research does not engage in making generalizations, therefore, these issues are presented as important points of interest, rather than as conclusions or predictions for future behavior. Phenomena worthy of emphasis create these issues of reflection.

1. The value and success of the constructive dialogues. All five of the teachers found the constructive dialogues helpful in terms of thinking about their practice. These dialogues also served as external motivation tools for reflection as also found by Stegman (1996). The isolation feature of the choral teaching situation may have been an influential factor in their positive response to the constructive dialogue methodology. Four of the five teachers connected with the researcher in a close collegial and friendly way, and those teachers produced more reflections in terms of quantity and depth. Comfortability with the other person in a constructive dialogue may allow a teacher to become more reflective. It was found that reflections resulting from the conversing mode represented more negativity in terms of reactions to the problematic areas of the teaching practice. This outpouring of points of crisis may have been due to the comfortability factor with the researcher to unload frustrations openly and freely. 
2. The influence of the attribute of perfectionism. Four of the five teachers displayed qualities of perfectionism, and those same teachers presented more pieces of reflections with increased depth than the one teacher who did not portray perfectionist characteristics. This finding supports the studies of LaBoskey (1993) and Stegman (1996) who found that reflection was enhanced or restricted by certain personality attributes.

3. The effects of time-related issues. The time barrier was addressed in some form of reflection by all of the educators, although the extent to how much each teacher reflected varied greatly. All of the teachers displayed some degree of resistance to engaging in a reflective process, particularly in the use of the structured written documentation methodology. However, this time factor barrier motivated three of the teachers to find another format, conversing with self into a tape recorder or holding more constructive dialogues, in order to stay engaged in a reflective process.

4. The feelings of pleasure and pain are associated with the reflective process. All of the teachers in this study made a reference to one or both of those feelings in their reflections. This is associated with the personal risk barrier (Brookfield, 1995) whereby teachers may or may not like what they discover about their teaching practice or who they are as people. Three of them expressed the painful effects of being open and honest, although they did choose to participate in the three modes of reflection, sharing their painful thoughts. Reflection is not neutral, nor without emotional impact. 
5. Reflection is an instrument for tangible change and the processing of personal and educational philosophies. Reflection encouraged many observable changes that occurred among four of the teachers in this study. The reflective process also enabled the teachers to understand the fluid nature of their belief system by confirming, denying, and challenging various pedagogical, curricular, personal/professional, and critical topics. The individualized development of each teacher's journey was crucial to the successful engagement in a reflective process. Effective reflection was achieved through an individualized selection of various modes and methodologies in order for change and realization of philosophy to take place.

Other significant findings included the issue of discipline. Discipline was a topic of reflection for all of the educators, therefore highlighting the always-existent challenge of approaching adolescents, regardless of the level of teacher expertise. This pedagogical issue created the need for the teachers to continually search for options that will work in controlling student behavior. This finding supports the research of Smith (1999), which revealed that pedagogical issues, such as classroom management, are common areas for reflection because of their nature of immediacy.

The impact of a choral teacher's full schedule was another finding of the study. Four of the teachers reflected about the busyness of their lives in terms of workload and the negative effect their professional lives had on their personal lives. Reflection served as a vehicle for a cathartic outlet and as a motivator to seek change. 
Another noteworthy finding involved the structured written reflection vehicle for the students, which was seen as a meaningful device by all the teachers for empowering the students to have a voice and for the teachers to understand the students' various perspectives. The five educators valued this input and four of them plan to use this device on a regular basis.

The last important point to be made is that four of the five teachers had never engaged in a reflective process before, therefore demonstrating that engaging in a reflective process can be effectively implemented at various points in a career. Although more resistance was initially found in the teachers with the most experience, the effectiveness of the reflection process was consistent across the different levels of experience.

The Value of Engaging in a Reflective Process

This study revealed important benefits as a result of engaging in a reflective process. As each choral teacher found individual advantages to reflecting on his/her teaching practice, the potential value can be understood through the examination of these particularistic benefits. Constructive dialogues enabled teachers to share feelings of frustration and joy, receive feedback, and explore new pedagogical and curricular strategies. An increased understanding and a reconstruction of a teaching practice as a result of collaborative constructive dialogues connect to the findings of Stegman (1996). Both written and verbal modes of reflection allowed teachers the opportunity to voice emotional reactions as a means of cathartic release. 
Once a teacher was able to problematize his/her practice through a reflective process, changes and improvement in practice resulted. Dewey (1933) stated that reflection occurs during the perplexing and unusual as opposed to the routine. Reflection also helped to confirm, deny, or challenge philosophies of music education within a critical pedagogy. Teachers used various modes of reflection to process important life decisions, therefore, positioning change of dramatic importance.

The findings from this study provide evidence that none of the educators were engaged in reflexive teaching. Reflection enabled the teachers to consider the events that took place within the choral classroom, and the effects of those events on the students, therefore decreasing the possibility of reflexive teaching. Teachers who reflect on their practice are made aware of the interactions, understandings, and nuances existing within a rehearsal. The consideration and implementation of change opposes routine action.

\section{The Usefulness of the Qualitative Paradigm}

This study employed interpretive fieldwork research methodology combined with a constructivist perspective, which created multiple possibilities of the construction and explication of meaning of a practice for both the participants and the researcher. Through the various data collection tools, insight into and understanding of the teachers' practice became evident. The weaving of the data and analysis into the individual narrative stories brought the researcher closer to the experience of the teachers and to the research process. The qualitative paradigm allowed for multiple layers to increase understanding of a choral teacher's practice through the presentation of various topics for reflection, the numerous ways to reflect, and the possibilities for change in practice as a result of reflection. 
Implications For Music Teacher Education and Professional Development Music Teacher Education

The implication for undergraduate music teacher education programs lies in the development of reflective habits. Previous research has indicated the benefits ascribed to the implementation of a reflective process with student-teachers (Goodman, 1984; Russell \& Munby, 1991; Doyle, 1992; Richert, 1992; Valli, 1992; Doloff, 1994; Smits, 1994; West, 1994; Galvez, 1995; Stegman, 1996; Winkleman, 1997; Hight, 1998; Snow, 1998; Bailey, 2000; and Burrack, 2001). The findings of this study support reflection as a viable means of making sense of experience, connecting theory and practice, and providing insight into the perceptual awareness of the teacher. Structured written reflections can improve the reflective capacity of new teachers as well as promote an understanding in bridging personal and formal theory. This view supports the research of Stegman (1996) who also found that reflection serves as a connection between personal practical knowledge and theoretical knowledge. Autobiographical reflection serves as another important reflection tool that can increase personal practical knowledge as well as link the relationship of the past to a future teaching practice.

Within the framework of the undergraduate preparation, the use of critical inquiry into the structure of school practices, curricular decisions, and the moral development of students may empower teachers from an early age to initiate change for the improvement of society. It is important that novice teachers are cognizant of what they believe as well as why and how they come to their beliefs (Griffiths \& Tann, 1992). Self-understanding and flexibility within a philosophical discourse is crucial to future professional growth. 
The collaborative nature of student-teaching, which involves both the cooperating teacher and the supervising teacher, lends itself to the possibility of meaningful constructive dialogues. Collaborative teaching within the framework of the preservice teacher's reflections can enhance understanding and improve practice. These dialogues can establish habits of collaboration and collegiality important to a student-teacher's maturation. If the habits of reflection can be instilled early in a teacher's career, then the possibilities of change and improvement are increased based upon the longevity of a teaching practice.

Music teacher education programs need to adopt a curriculum that cultivates a reflective process through the following means: 1) in introductory music education courses, students should engage in autobiographical devices to reflect upon their family background, educational journey, influential people, and journey of becoming a musician; and hold constructive dialogues among peers and the professor that center on pedagogical, curricular, and critical pedagogies; 2) in early field observation experiences, students should write about their observations of teaching episodes and include their personal reflections concerning the observed experience; and students should enter into constructive dialogues based on the events of the teaching episode, as well as the philosophy of the educational strategies and curriculum; 3) in method courses, students should become familiar with and begin to implement The Cyclical Model of Reflection; students should be given ample opportunities to reflect in hands-on problem-solving situations that easily transfer to classroom situations; and a cooperative learning environment with supportive teachers and peers should exist; 4) in the student-teaching 
experience, the reflection process should be incorporated on a regular basis, utilizing the various methodologies. Future teachers must be raised in an atmosphere of risk-taking, open-mindedness, and collaboration.

\section{Professional Development}

In this study, only one of the teachers had any experience with reflection during the music teacher education program. The process implemented with these choral educators serves as a model for the professional development of teachers at all levels of expertise. The steps used for engaging practicing teachers in a reflective process include: 1) introducing the teachers to the concept and philosophy of reflection, and explaining The Cyclical Model of Reflection; 2) preparing teachers for the time and personal risk barriers that they may encounter; 3) providing structured written documentation vehicles as a means for reflection; 4) giving samples of reflective writing; 5) allowing for constructive dialogue opportunities; and 6) encouraging teachers to be open, honest, and willing to challenge the choral discourse, the school structure, and themselves.

School systems that want to support the reflective discourse among their staff members need to be aware of the obstacles to engaging in a reflective process. Smith (1999) found that curricular requirements, changing classroom composition, and school schedules impeded teachers in becoming reflective practitioners. Beyond a course in the mechanics of the reflective process, a professional, supportive atmosphere of mentoring, collaboration, and time for reflection must be provided within the school setting. 


\section{Recommendations for Further Research}

As this is the first study involving the reflective process of practicing choral teachers, more research is needed to solidify understanding of how the reflective process works, and the various outcomes of engaging in a reflective process. Due to the broadly open-ended and constructivist nature of this research, there are additional questions that have been generated. The potential topics for further research related to the reflective process and choral music education include: 1) a follow-up study with these participants to understand the long-term effects of the reflective process; 2) a longitudinal study based upon the methodology of this research to understand the reflective development of teachers over time; 3) an investigation of the influence of personality characteristics on the reflective process; 4) an examination of the longitudinal effects of teachers who began the reflective process as an undergraduate; 5) a study of the various levels of expertise in terms of how they engage in a reflective process; 6) research based on the incorporation of either the writing or conversing mode of reflection over time;

7) a study that implements either structured or unstructured methods of reflection; 8) an investigation of how gender affects engaging in a reflective process; 9) a thorough examination of only one of the four categories of reflection: pedagogical, curricular, personal/professional, or critical; and 10) further replications of this study until there is a large body of literature for choral teachers to examine the reflective lives of many others.

Qualitative research is still developing towards informing the profession of music education. It has the potential to provide rich data for the purpose of gaining new knowledge concerning the human phenomenon of teaching. As demonstrated in this 
study, the engagement in a reflective process enables a choral educator to understand the individual experience of teaching with the beneficial possibilities of change and improvement. 


\section{BIBLIOGRAPHY}

Abramson, P. R. (1992). A case for case studies. Thousand Oaks, CA: SAGE Publications.

Apple, M. W. (1989). Teachers and texts: A political economy of class and gender relations in education. New York: Routledge.

Applegate, J. \& Shaklee, B. (1992). Stimulating reflection while learning to teach: The ATTEP at Kent State University. In L. Valli (Ed.), Reflective teacher education: Cases and critiques (pp. 65-81). New York: State University of New York Press.

Bailey, R. M. (2000). Visiting the music classroom through the use of the case method In the preparation of senior-level music teacher education students. A study of reflective judgment. Dissertation Abstracts International 61(107), 2639. (UMI No. 9978962)

Baird, J. R. (1992). Collaborative reflection, systematic enquiry, better teaching. In T. Russell, \& H. Munby (Eds.), Teachers and teaching: From classroom to reflection (pp. 33-48). Philadelphia: The Falmer Press.

Barnes, D. (1976). From communication to curriculum. Hammondsworth, England: Penguin.

Barnes, D. (1992). The significance of teachers' frames for teaching. In T. Russell \& H. Munby (Eds.), Teachers and teaching: From classroom to reflection (pp. 9-32). Philadelphia: The Falmer Press.

Boardman, E. (1990). Music teacher education. In W. R. Houston (Ed.). Handbook of research on teacher education (pp. 730-745). New York: MacMillan Publishing Company.

Bogan, P. (1997). Structured dialogue as staff development: A case study of one public high school's dialogue. Dissertation Abstracts International 58(07), 2605.

(UMI No. 9801849)

Breiter, C. \& Scardamalia, M. (1993). Surpassing ourselves: An inquiry into the nature and implications of expertise. Chicago: Open Court. 
Bresler, L. (1995). Ethical issues in qualitative research methodology. Bulletin of the Council for Research in Music Education, 126, 29-41.

Brinson, B. (1996). Choral music methods and materials: Developing successful choral programs (grades 5-12). New York: Schirmer.

Brookfield, S. D. (1995). Becoming a critically reflective teacher. San Francisco: Jossey-Bass Publishers.

Brubacher, J. W., Case, C. W. \& Reagan, T. G. (1994). Becoming a reflective educator: How to build a culture of inquiry in the schools. Thousand Oaks, CA: Corwin Press, Inc.

Bullough, R. V., Jr., \& Gitlin, A. D. (1991). Educative communities and the development of the reflective practitioner [revised]. In B. R. Tabachnick \& K. M. Zeichner (Eds.). Issues and practices in inquiry-oriented teacher education (pp. 35-55). London: The Falmer Press.

Burrack. F. W. (2001). Using reflection and video self-confrontation to uncover the instructional though development of student teachers in instrumental music. Dissertation Abstracts International 62(06). (UMI No. 3017031)

Calderhead, J. (1989). Reflective teaching and teacher education. Teaching and Teacher Education, 5(1), 43-51.

Carter, K. (1992). Creating cases for the development of teacher knowledge. In T. Russell and H. Munby (Eds.). Teachers and teaching (pp. 109-123). Philadelphia: The Falmer Press.

Clandinin, D. J. \& Connelly, F. M. (1994). Personal experience methods. In N. K. Denzin \& Y. S. Lincoln (Eds.). Handbook of qualitative research (pp. 413-327). Thousand Oaks, CA: SAGE Publications.

Clark, C. \& Lampert, M. (1986). The study of teacher thinking: Implications for teacher education. Journal of Teacher Education, 37(5), 27-31.

Clemson, R. L. (1987). Mentoring in teaching. Action in Teacher Education, 9, $85-90$.

Clift, R. T., Houston, W. R. \& Pugach, M C. (Eds.) (1990). Encouraging reflective practice in education: An analysis of issues and programs. New York: Teachers College Press.

Coleman, T. R. (1999). The music student teaching experience: Making connections. Dissertation Abstracts International 61(02), 540. (UMI No. 9961813) 
Collins, D. L. (1993). Teaching choral music. Englewood Cliffs, NJ: Prentice Hall.

Consortium of National Arts Education Associations. (1994). Dance, music, theatre, visual arts: what every young American should know and be able to do in the arts: National Standards for Arts Education. Reston, VA: MENC.

Cruickshank, D. R. (1980, April). Reflective teaching: A new instructional alternative for use in teacher education. Paper presented at the Annual Meeting of the American Educational Research Association, Boston, MA.

Cruickshank, D. R. (1985). Uses and benefits of reflective teaching. Phi Delta Kappan, 66(10), 704-706.

Day, C. (1999). Developing teachers: The challenges of lifelong learning. Educational Change and Development Series. (ERIC Document No. 434878).

Denzin, N. K. (1989). Interpretive interactionism. Newbury Park, CA: SAGE Publications.

Denzin, N. K. (1994). The art and politics of interpretation. In N. K. Denzin \& Y. S. Lincoln (Eds.), Handbook of qualitative research (pp. 500-515). Thousand Oaks, CA: SAGE Publications.

Denzin, N. K. \& Lincoln, Y. S. (Eds.) (1994). Handbook of qualitative research. Thousand Oaks, CA: SAGE Publications.

Deutsch, G. L. (1996). Influencing factors along the road to reflective practice: Learning styles, school improvement. Dissertation Abstracts International 57(04), 1569. (UMI No. 9626671)

Dewey, J. (1933). How we think. Chicago: Henry Regnery.

Dinkelman, T. D. (1997). Critically reflective teacher education in secondary social studies: A preservice case study. Dissertation Abstracts International 58(10), (UMI No. 9734376)

Doloff, L. A. (1994). Expertise in choral music education: Implications for musicianship. Dissertation Abstracts International, 56(07A), 2600. (UMI No. NN97179)

Doyle, M. (1992). Learning to teach: Case studies of elementary preservice teachers' reflective thinking about early field experiences. Dissertation Abstracts International 53(07), 2333. (UMI No. 9235578) 
Duling, E. B. (1992). The development of pedagogical-content knowledge: Two case studies of exemplary general music teachers. Dissertation Abstracts International 53(06), 1835. (UMI No. 9227261)

Elliott, D. J. (1995). Music matters. New York: Oxford University Press.

Emery, W. G. (1996). Reflection through expert talk. Journal of Teacher Education, 47(2), 110-119.

Erickson, F. (1986). Qualitative methods in research on teaching. In M. C. Wittrock (Ed.). Handbook of research on teaching ( ${ }^{\text {rd }}$ ed., pp. 119-161). New York: MacMillan Publishing Company.

Erickson, F. (1994). Where the action is: On collaborative action research in education. Bulletin of the Council for Research in Music Education, 123, 10-25.

Fontana, A. \& Frey, J. H. (1994). Interviewing: The art of science. In N. K. Denzin \& Y. S. Lincoln (Eds.). Handbook of qualitative research (pp. 361-376). Thousand Oaks, CA: SAGE Publications.

Freire, P. (1987). Letter to North-American teachers. In I. Shor (Ed.), Freire for the classroom. Portsmouth, NH: Boynton and Cooks.

Freire, P. (1994). Pedagogy of hope: Reliving pedagogy of the oppressed. New York: Continuum.

Freire, P. (1999). Pedagogy of hope. New York: Continuum.

Freire, P. \& Shor, I. (1987). A pedagogy for liberation. South Hadley, MA: Bergin \& Garvey.

Furlong, J. (1995). Mentoring student teachers. New York: Routledge.

Galvez, M. E. (1995). The improvement on preservice teachers' reflection through content-specific reflective teaching. Dissertation Abstracts International 56(09), (UMI No. 9544566)

Gaumer, J. E. (2000). Reflecting and reframing: Beginning teachers' use of metaphor. Unpublished dissertation, Columbia University, New York.

Giroux, H. (1983). Theories of reproduction and resistance in the new sociology of education: critical analysis, Harvard Educational Review, 53(3), 315-322.

Goodlad, J. (1984). A place called school: Prospects for the future. New York: McGraw Hill. 
Goodman, J. (1984). Reflection and teacher education: A case study and theoretical analysis. Interchange, 15(3), 9-26.

Gore, J. M. (1987). Reflecting on reflective teaching. Journal of Teacher Education, 38(2), 33-39.

Gore, J. \& Zeichner, K. M. (1991). Action research and reflective teaching in preservice teacher education: A case study from the United States. Teaching and Teacher Education, 7(2), 119-136.

Graue, M. E. \& Walsh, D. J. (1998). Studying children in context: Theories, methods and ethics. Thousand Oaks, CA: SAGE Publications.

Green, E. (1997). The modern conductor (Rev. Ed.). New York: Prentice Hall.

Greene, M. (1986). Reflection and passion in teaching. Journal of Curriculum and Development, 2(1), 68-81.

Griffiths, M. \& Tann, S. (1992). Using reflective practice to link personal and public theories. Journal of Education for Teaching, 18(1), 69-84.

Grimmett, P. P. (1988). The nature of reflection and Schon's conception in perspective. In P. P. Grimmett \& G. Erickson (Eds.), Reflection in teacher education (pp. 34-48). New York: Teachers College Press.

Grimmett, P. P., MacKinnon, A. M., Erickson, G. L. \& Riecken, T. J. (1990). Reflective practice in teacher education. In R. T. Clift, W. R. Houston, \& M. C. Pugach (Eds.), Encouraging reflective practice in education: An analysis of issues and programs (pp. 20-38). New York: Teachers College Press.

Guba, E. G. (1981). Criteria for assessing the trustworthiness of naturalistic inquiries. Educational Communications and Technology, 29(2), 75-91.

Guba, E. G. \& Lincoln, Y. S. (1994). Competing paradigms in qualitative research. In N. K. Denzin \& Y. S. Lincoln (Eds.), Handbook of qualitative research (pp. 105-117). Thousand Oaks, CA: SAGE Publications.

Halpern, E. S. (1983). Auditing naturalistic inquiries: The development and application of a model. Unpublished doctoral dissertation, Indiana University.

Hamlin, K. B. (1995). When students won't respond: A music teacher's reframing of his practice. Dissertation Abstracts International 33(05), 1376. (UMI No. MM95481) 
Hamrick, J. C. (1995). Elementary teachers' reflections on major influences impacting their decisions in reading and language arts instruction during their first two years of teaching. Dissertation Abstracts International 57(01), 87. (UMI No. 9618159)

Hay, A. A. (1995). A teacher-teacher collaborative inquiry into the teaching of elementary science. Dissertation Abstracts International 34(01), 50. (UMI No. MM99119)

Henderson, J. G. (2001). Reflective teaching: Professional artistry through inquiry. $\left(3^{\text {rd }}\right.$ ed.). Columbus, OH: Merrill Prentice-Hall.

Hight, E. J., III. (1998). Reflective inquiry as deconstruction in teacher education. Dissertation Abstracts International 60(03), 637. (UMI No. 9918048)

Hitchcock, G. \& Hughes, D. (1989). Research and the teacher: A qualitative introduction to school-based research. New York: Routledge.

Holly, M. L. (1989). Writing to grow: Keeping a personal-professional journal. Portsmouth, NH: Heinemann.

Holt-Reynolds, D. (1992). History based beliefs as relevant prior knowledge in coursework. American Educational Research Journal, 29(2), 325-349.

Houston, W. R., \& Clift, R. T. (1990). The potential for research contributions to reflective practice. In R. T. Clift, W. R. Houston, \& M. C. Pugach (Eds.), Encouraging reflective practice in education: An analysis of issues and programs (pp. 208-224). New York: Teachers College Press.

Humphreys, K. \& Suzak, Z. (2000). Learning how to fish: Issues for teachers engaging in self-evaluation and reflective enquiry in school. Research in Education, 64, 78-90.

Hunsaker, L. \& Johnson, M. (1992). Teacher under construction: A collaborative case study of teacher change. American Educational Research Journal, 29(3), 350-372.

Hylton, J. (1995). Comprehensive choral music education. Englewood Cliffs, N. J.: Prentice Hall.

Jackson, P. W. (1990). Life in classrooms. New York: Teachers College Press.

Jordan, J. (1996). Evoking sound. New York: Schirmer. 
Kemmis, S. (1985). Action research and the politics of reflection. In D. Boud, R. Keough, \& D. Walker (Eds.), Reflection: Turning experience into learning (pp. 139-163). London: Kagan Page.

Kilbourn, B. (1992). Philosophical, subject matter and classroom understandings: A case of history teaching. In T. Russell \& H. Munby (Eds.). Teachers and teaching: From classroom to reflection (pp. 71-89). Philadelphia: The Falmer Press.

Kilgore, K., Ross, D., \& Zbikowski, J. (1989). Understanding the teaching perspectives of first-year teachers. Journal of Teacher Education, 41(1), 28-38.

Knoblauch, C. H. \& Brannon, L. (1988). Knowing our knowledge: A phenomenological basis for teacher research. In L. Z. Smith (Ed.), Audits of meaning: A festschrift in honor of Ann E. Berthoff. (pp. 17-28). Portsmouth, NH: Heinemann, Boynton/Cook.

Kruse, S. D. (1997). Reflective activity in practice: Vignettes of teachers' deliberative work. Journal of Research and Development in Education, 31(1), 46-60.

Kuhn, T. (1970). The structure of scientific revolutions. Chicago: University of Chicago Press.

LaBoskey, V. K. (1993). A conceptual framework for reflection in preservice teacher education. In J. Calderhead \& P. Gates (Eds.), Conceptualizing reflection in teacher development (pp. 23-38). London: The Falmer Press.

Lanier, J. E. \& Little, J. W. (1986). Research on teacher education. In M. C. Wittrock (Ed.), Handbook of research on teaching ( $3^{\text {rd }}$ ed.) (pp. 527-569). New York: MacMillan.

Lather, P. (1986). Research as praxis. Harvard Educational Review, 56(3), 257-277.

Lather, P. \& Smithies, C. (1997). Troubling the angels. Boulder, CO: Westview Press.

LeCompte, M. D. \& Preissle, J., with Tesch, R. (1993). Ethnography and qualitative design in educational research ( $2^{\text {nd }}$ ed.). Orlando, FL: Academic Press.

Lijphart, A. (1971). A comparative politics and the comparative method. American Political Science Review, 65, 682-694.

Liston, D. P. \& Zeichner, K. M. (1987). Reflective teacher education and moral deliberation. Journal of Teacher Education, 38(6), 2-8. 
Lortie, D. (1975). Schoolteacher: A sociological study. Chicago: The University of Chicago Press.

MacKinnon, A. M. (1987). Detecting reflection in action among preservice elementary science teachers. Teaching and Teacher Education, 3(2), 135-145.

McDonald, N. L. (2001). Reflective practices: Collective case studies of selected K-8 general music teachers in peer problem-solving discipline and management workshop settings. Dissertation Abstracts International 62(03), 956. (UMI No. 3007294)

McLaren, P (1993). Schooling as ritual performance ( $2^{\text {nd }}$ ed.). New York: Routledge.

Mezirow, J. (1991). Fostering critical reflection in adulthood. San Francisco: JosseyBass Publishers.

Merriam, S. B. (1998). Qualitative research and case study applications in education. San Francisco: Jossey-Bass Publishers.

Miles, M. B. \& Huberman, A. M. (1994). Qualitative data analysis: An expanded sourcebook $\left(2^{\text {nd }}\right.$ ed. $)$. Thousand Oaks, CA: SAGE Publications.

Miller, J. L. (1990). Creating spaces and finding voices: Teachers collaborating empowerment. New York: State University of New York Press.

Munby, H. \& Russell, T. (1992). Frames of reflection: An introduction. In T. Russell $\&$ H. Munby (Eds.), Teachers and teaching: From classroom to reflections (pp. 1-8). Philadelphia: Falmer Press.

Neelly, L. P. (2000). Collaborative childhood practice: A year in the life of a pre-kindergarten music teacher. Dissertation Abstracts International 61(03), 927. (UMI No. 9965304)

Nightingale, Abell, S. E. (1993). Teacher Evaluation Practices in the elementary music classroom: study of three teachers. Dissertation Abstracts International 55(04), 900. (UMI No. 9424582)

Noddings, N. (1984). Caring: A feminine approach to ethics and moral education. Berkeley: University of California Press.

Noddings, N. (1986). Fidelity in teaching: Teacher education and research for teaching. Harvard Educational Review, 56(4), 496-510. 
Noddings, N. (1987). An ethic of caring and its implications for instructional arrangements. Paper presented at the annual meeting of the American Educational Research Association, Washington, D.C.

Olson, G. B. (1988). Music teacher education: Partnership and process (Report of the MENC Teacher Education Task Force). Reston, VA: Music Educators National Conference.

Orenstein, P. (1994). Schoolgirls. New York: Anchor Books.

Osterman, K. F., \& Kottkamp, R. B. (1993). Reflective practice for educators: Improving schooling through professional development. Newbury Park, CA: Corwin Press.

O’Toole, P. A. (1994). Re-directing the choral classroom: A feminist poststructural analysis of power relations within three choral settings. Dissertation Abstracts International 55(07A), 1864.

Parr, N. C. (1996). Toward a philosophy of music teacher education: Applications of ideas of Jerome Bruner, Maxine Greene, and Vernon A. Howard. Dissertation Abstracts International 57(09), 3867. (UMI No. 9701030)

Patton, M. Q. (1990). Qualitative evaluation and research methods. Newbury Park, CA: SAGE Publications.

Peters, J. (1991). Strategies for reflective practice. In R. Brockett, (Ed.), Professional development for educators of adults: New directions for adult and continuing education. San Francisco: Jossey-Bass.

Phillips, K. (1997). Basic techniques of conducting. New York: Oxford.

Posner, G. J. (1996). Field experience: A guide to reflective thinking $\left(4^{\text {th }}\right.$ ed.). White Plains, NY: Longman Publishers.

Powers, L. S. W. (1999). The nature, roles and interplay of the inner and outer voices of reflective teaching. Dissertation Abstracts International, 60(01), 3598. (UMI No. 99-47742)

Pugach, M. C. \& Johnson, L. J. (1990). Developing reflective practice through structured dialogue. In R. T. Clift, W. R. Houston, \& M. C. Pugach (Eds.), Encouraging reflective practice in education: An analysis of issues and programs (pp. 186-207). New York:Teachers College Press.

Purpel, D. E. (1989). The moral and spiritual crisis in education. Granby, MA: Bergin and Garvey Publishers, Inc. 
Raiber, M. A. (2001). An investigation of the relationship between teachers' engagement in reflective practice and music teaching effectiveness. Dissertation Abstracts International, 62(02), 505. (UMI No. 3004869)

Reames, R. R. (1997). Repertoire and conductors of fifty all-state choirs, 199596. Choral Journal, 38(5), 29-32.

Richardson, V. (1990a). The evolution of reflective teaching and teacher education. In R. T. Clift, W. R. Houston, \& M. C. Pugach (Eds.), Encouraging reflective practice in education: An analysis of issues and programs (pp. 3-19). New York: Teachers College Press.

Richardson, V. (1990b). Significant and worthwhile change in teaching practice. Educational Researcher, 19, 10-18.

Richardson, C. \& Whittaker, N. (1992). Critical thinking and music education. In R. Colwell (Ed.), Handbook of research on music teaching and learning (pp. 546-557). New York: Schirmer.

Richert, A. E. (1992). The context of student teachers' reflections within different structures for facilitating the reflective process. In T. Russell \& H. Munby (Eds.), Teachers and teaching: From classroom to reflection (pp. 171-191). Philadelphia: The Falmer Press.

Rose, A. M. (1997). The internship experience: A reflective and critical model. Dialogue in Instrumental Music Education, 21(2), 142-166.

Rosenholtz, S. (1987). Workplace conditions that affect teacher quality and commitment. The Elementary School Journal 89(4), 421-440.

Rosenholtz, S. (1989). Teacher's workplace. New York: Longman.

Ross, D. D. (1989). First steps in developing a reflective approach. Journal of Teacher Education, 40(2), 22-30.

Ross, D. R. (1990). Programmatic structures for the preparation of reflective teachers. In R. T. Clift, W. R. Houston, \& M. C. Pugach (Eds.), Encouraging reflective practice in education: An analysis of issues and programs (pp. 97-118). New York: Teachers College Press.

Ross, E. W. \& Hannay, L. M. (1986). Towards a critical theory of reflective inquiry. Journal of Teacher Education, 9-15. 
Rudduck, J. (1987). Partnership supervision as a basis for the professional development of new and experienced teachers. In M. F. Wideen \& L. Andrews (Eds.), Staff development for school improvement: A focus on the teacher (pp. 56-63). London: Falmer Press.

Rudduck, J. (1992). Practitioner research and programs of initial teacher education. In T. Russell \& H. Munby (Eds.), Teachers and teaching: From classroom to reflection (pp. 156-170). Philadelphia: The Falmer Press.

Rudolph, M. (1950). The grammar of conducting. New York: Schirmer.

Russell, T., Munby, H., Spafford, C., \& Johnston, P. (1988). Learning the professional knowledge of teaching: Metaphors, puzzles, and the theory-practice relationship. In P. Grimmet \& G. Erickson (Eds.), Reflection in teacher education (pp. 164187). New York: Teachers College Press.

Russell, T. \& Munby, H. (1991). Reframing: The role of experience in developing teachers' professional knowledge. In D. Schon (Ed.) The reflective turn: Case studies in old and on educational practice (pp. 67-89). New York: Teachers College Press.

Schon, D. A. (1983). The reflective practitioner: How professionals think in action. New York: Basic Books.

Schon, D. A. (1987). Educating the reflective practitioner: Toward a new design for teaching and learning in the professions. San Francisco: Jossey-Bass Publishers.

Schon, D. A. (1988). Coaching reflective teaching. In P. P. Grimmett \& G. Erickson (Eds.), Reflection in teacher education (pp. 19-29). New York: Teachers College Press.

Schulman, L. S. (1987). Knowledge and teaching: Foundations of the new reform. Harvard Educational Review, 57(1), 1-22.

Schwandt, T. A. (1997). Qualitative inquiry: A dictionary of terms. Thousand Oaks, CA: SAGE Publications.

Seidman, I. E. (1991). Interviewing as qualitative research. New York: Teachers College Press.

Sergiovanni, T. (1996). Leadership for the schoolhouse. San Francisco: Jossey-Bass Publishers.

Shor, I. (1980). Critical teaching and everyday life. Boston: South End Press. 
Shor, I. (1987). Critical teaching for everyday life. Chicago: University of Chicago Press.

Small, C. (1998). Musicking: The meanings of performing and listening. London: University Press of New England.

Smith, T. H. (1999). Teachers reflections: The content of process. Dissertation Abstracts International, 60(07), 2380. (UMI No. 9938852)

Smits, H. (1994). Interpreting reflective practice: A hermeneutically inspired action research. Dissertation Abstracts International 56(03), 895. (UMI No. NN95267)

Smyth, W. J. (1984). Teachers as collaborators in clinical supervision: Cooperative learning about teaching. Teacher Education, 24, 60-68.

Smyth, J. (1992). Teachers' work and the politics of reflection. American Educational Research Journal, 29(2), 267-300.

Snow, S. L. (1998). Rehearsing the choral context: A qualitative examination of undergraduate conductor/teacher planning processes and relationship to emergent pedagogical knowledge evidenced in teaching. Dissertation Abstracts International 60(03), 684. (UMI No. 9922376)

Soltis, J. (1989). The ethics of qualitative research. Qualitative Studies in Education, 2(2), 123-130.

Sparks-Langer, G. M. (1992). In the eye of the beholder: Cognitive, critical, and narrative approaches to teacher reflection. In L. Valli (Ed.), Reflective teacher education: Cases and critiques (pp. 147-160). New York: State University of New York Press.

Stegman, S. F. (1996). An investigation of secondary choral music student teachers' perceptions of instructional successes and problems as they reflect on their music teaching. Dissertation Abstracts International 57(03), 1070. (UMI No. 9624737)

Stewart, C. J. \& Cash, W. B. (1982). Interviewing principles and practices ( $3^{\text {rd }}$ ed.). Dubuque, IA: Wm. C. Brown Company Publishers.

Strong-Cvetich, J. R. 1995). Sustaining and renewing commitment to the classroom. Dissertation Abstracts International 56(05), 1660. (UMI No. 9530163)

Tabachnick, B. R. \& Zeichner, K. M. (1991). Introduction. In B. R. Tabachnick \& K. M. Zeichner (Eds.). Issues and practices in inquiry-oriented teacher education (pp. ix-xix). London: The Falmer Press. 
Taggart, G. C. \& Wilson, A. P. (1998). Promoting reflective thinking in teachers' action strategies. (ERIC Document No. ED 422317).

Thies-Sprinthall, L. (1987). A collaborative approach for mentor training: A working model. Journal of Teacher Education, 37(6), 13-18.

Tom, A. R. (1984). Teaching as a moral craft. New York: Longman.

Tom, A. R. (1985). Inquiring into inquiry-oriented teacher education. Journal of Teacher Education, 36(5), 35-44.

Tripp, D. (1993). Critical incidents in teaching: Developing professional judgment. New York: Routledge.

Tyler, R. W. (1950). Basic principles of curriculum and instruction. Chicago: The University of Chicago Press.

Valli, L. (1990). Moral approaches to reflective practice. In R. T. Clift, W. R. Houston, M. C. Pugach (Eds.), Encouraging reflective practice in education: An analysis of issues and programs. (pp. 39-56). New York: Teachers College Press.

Valli, L. (Ed.) (1992). Reflective teacher education: Cases and critiques. New York: State University of New York Press.

Valli, L. (1997). Listening to other voices. Peabody Journal of Education, 72(1), 67-88.

Van Manen, M. (1977). Linking ways of knowing with ways of being practical. Curriculum Inquiry, 6(3), 225-228.

Van Manen, M. (1990). Beyond assumptions: Shifting the limits of action research. Theory into Practice, 29(3), 152-157.

Verrastro, R. W. \& Leglar, M. (1992). Music teacher education. In R. Colwell (Ed.). The handbook of research on music teaching and learning (pp. 676-696). New York: MacMillan.

Vinz, R. (1996). Composing a teaching life. Portsmouth, NH: Boynton and Cook Publishers, Inc.

Wellington, B. \& Austin, P. (1996). Orientations to reflective practice. Educational Research, 38(3), 307-316. 
West, J. K. (1994). A qualitative study of student teachers' perceptions and reflective thinking during the student teaching experience. Dissertation Abstracts International 55(06), 1489. (UMI No. 9428820)

Whitaker, N. (1989). Reflective thinking as exemplified in musical decision making. Dissertation Abstracts International 50(11A), 3510. (UMI No. 9011074)

Whitaker, N. L. (1996). Illusive connections: Music integration and the elementary classroom. Bulletin for the Council of Research in Music Education, 130, 88-99.

Wiersma, W. (1995). Research methods in education: An introduction. Boston: Allyn and Bacon.

Wildman, T. M., Niles, J. A., Magliaro, S. G. \& McLaughlin, R. A. (1990). Promoting reflective practice among beginning and experienced teachers. In R. T. Clift, W. R. Houston, \& M. C. Pugach (Eds.), Encouraging reflective practice in education: An analysis of issues and programs (pp. 139-162). New York: Teachers College Press.

Williams, D. A. (1995). The nature of discourse in small group discussions during reflective teaching. Dissertation Abstracts International 56(09), 3549. (UMI No. 9544720)

Wolcott, H. F. (1988). Ethnographic research in education. In R. M. Jaeger, (Ed.), Complementary methods for research in education. Washington, D. C.: American Educational Research Association.

Wolcott, H. F. (1992). Posturing in qualitative inquiry. In M. LeCompte, W. L.Millroy, \& J. Preissle (Eds.), Handbook of qualitative research in education. (pp. 3-52). San Diego, CA: Academic Press.

Wood, D. R. (2000). Narrating professional development: Teachers' stories as texts for improving practice. Anthropology \& Education Quarterly, 31(4), 426-448.

Yinger, R. J. (1990). The conversation of practice. In R. T. Clift, W. R. Houston, \& M. C. Pugach (Eds.), Encouraging reflective practice in education: An analysis of issues and programs (pp. 73-94). New York: Teachers College Press.

Zeichner, K. M. (1983). Alternative paradigms of teacher education. Journal of Teacher Education, 34(3), 3-9.

Zeichner, K. M. (1987). Preparing reflective teachers: An overview of instructional strategies which have been employed in preservice teacher education. International Journal of Educational Research, 11(5), 565-576. 
Zeichner, K. M. (1992). Conceptions of reflective teaching in contemporary U.S. Teacher education program reforms. In L. Valli (Ed.), Reflective teacher education: Cases and critiques (pp. 161-173). New York: State University of New York Press.

Zeichner, K. M. \& Liston, D. P. (1987). Teaching student teachers to reflect. Harvard Educational Review, 57(1), 23-48.

Zeichner, K. M. \& Liston, D. P. (1996). Reflective teaching: An introduction. Mahwah, NJ: L. Erlbaum Associates.

Zimmerman-Brown, S. (1992). Teacher satisfaction: Reflections upon my life. Dissertation Abstracts International 54(01), 122. (UMI No. NN73954) 


\section{APPENDIX A \\ LETTER FOR OBTAINING PARTICIPANTS}

December 1, 2001

Dear

I am conducting a research study as partial fulfillment for my doctoral degree in music education from The Ohio State University. This letter is written to invite you to be a participant in this study. Through this study I am hoping to learn whether reflective processes lead to deeper understanding of and modifications to teaching practices. This study is also based on the premise that collaboration with peers can shed new light on your practice.

The research question is, "How does using a reflective process affect choral teachers? To answer this question, the following methodological techniques will be employed: 1) I will observe your teaching in the choral classroom one rehearsal period every two weeks, from January $7^{\text {th }}$ through March 9, 2002 (four times over the nine weeks). I will also videotape your teaching (at your request) to increase your understanding of your teaching. Following each of those rehearsals we will have an informal interview to reflect upon the experiences in the rehearsal. An audiotape of these interviews will be made to be used as data concerning how you reflect upon your practice. 2) You will be asked to keep a reflective journal and write reflective narrative exercises where you will share experiences related to your teaching. 3) You will be asked to write an autobiographical story based on a series of questions to understand your beliefs about teaching. 4) You will be asked to participate in two meetings: one large group and one small group with other teachers and me in order to reflect upon your 
teaching practice through conversations with peers and writing. This can also serve the purpose of a mentoring program where you will receive support. Audiotapes of these two meetings will also be made so that each teacher's verbal reflections can be used as data. 5) You will choose at least one element of your teaching on which to focus. This item may transform throughout the research process.

At any time during the study, you may withdraw without penalty. You are part of the study in a voluntary position.

Dr. Patricia O'Toole, Assistant Professor of Music at The Ohio State University is the Principal Investigator. If at any time you have questions about the study, you can contact her at 614-292-8956 or otoole.18@,osu.edu.

You will be a valuable part of the process and will be able to look at the data as well as the analysis and narration. It is my hope that you will see this as an exciting opportunity to reflect upon your teaching practice and feel empowered and supported.

Sincerely,

\author{
Marla A. Butke \\ The Ohio State University \\ 614-798-0737 \\ butke.3@osu.edu
}




\section{APPENDIX B \\ CONSENT FOR PARTICIPATION IN SOCIAL AND BEHAVIORAL RESEARCH}

\section{Protocol title: A STUDY OF HOW THE USE OF A REFLECTIVE PROCESS AFFECTS CHORAL TEACHERS \\ Protocol number: 01B0227 \\ Principal Investigator: Dr. Patricia O'Toole \\ I consent to my participation in (or my child's participation in) research being conducted by Dr. Patricia O'Toole and Marla A. Butke (Co-Investigator) of The Ohio State University.}

The investigator(s) has explained the purpose of the study, the procedures that will be followed, and the amount of time it will take. I understand the possible benefits, if any, of my participation (and/or my child's participation).

I know that I can (and/or my child can) choose not to participate without penalty to me (and/or my child). If I agree to participate, I can (and/or my child can) withdraw from the study at any time, and there will be no penalty.

I consent to the use of audiotapes. I understand how the tapes will be used for this study.

I have had a chance to ask questions and to obtain answers to my questions. I can contact the investigators at (614) 292-8956. If I have questions about my rights as a research participant, I can call the Office of Research Risks Protection at (614) 688-4792.

I have read this form or I have had it read to me. I sign it freely and voluntarily. A copy has been given to me.

Print the name of the participant: 
Date:

Signed:

(Principal Investigator or his/her authorized representative)

Witness:

(When required)

HS-027 (Rev. 05/01) and behavioral research.)
Signed:

(Participant)

Signed:

(Person authorized to consent for participant, if required)

(To be used only in connection with social 


\section{APPENDIX C \\ SOLICITATION LETTER FOR PARENTS/STUDENTS}

January 2, 2002

Dear Choral Student and Parent,

This letter is written to explain the research I will be conducting at your child's school to fulfill my degree requirements for a Ph.D. in music education from The Ohio State University. For my research, I will be at the school one day every two weeks investigating the question, "How does using a reflective process affect choral teachers?"

The students will be asked to write one reflective journal entry (ten minutes of class time) where they will discuss their observations concerning change in the choral teacher's practice. This will occur in early March at the end of the nine-week research process. This information will only be used to help the teacher reflect upon his/her own teaching practice. The teacher will then have another way of knowing if there has been some noticeable change in his/her practice as indicated by the students. The students will also be able to reflect upon the choral program in general in this writing assignment, therefore, providing information that may be beneficial to the teacher and the choral program in general.

What the student is observing and experiencing in the choral classroom is valued information for the choral teacher. However, it is important to note that the focus of this study is on the choral teacher, not on the choral students. The student's written reflection will not be used as an assessment tool. The student has the right to not participate. There will be no penalty for not participating or withdraw.

Dr. Patricia O'Toole, Assistant Professor of Music at The Ohio State University, serves as the Principal Investigator of this study. If you have any questions concerning this research, please contact her at (614)292-8956 or otoole.18@osu.edu.

The data gathered from this research will give valuable insights to those who are interested in the field of choral music education. Confidentiality will be maintained as none of the students' names will be used in the dissertation.

Thank you,

Marla A. Butke

Doctoral Candidate in Music Education

The Ohio State University

(614) 798-0737

butke.3@osu.edu 


\section{APPENDIX D}

\section{AUTOBIOGRAPHICAL NARRATIVE}

Write a narrative which includes answers to the following questions. Please be as detailed as possible.

- Where have you lived?

- Who is your family (parents, siblings, spouse, children)?

- Give your educational background. Include extracurricular activities.

- Give your musical history.

- Why did you become a teacher?

- When and how did you decide?

- What and who influenced you? In what ways?

- As you look back, possibly to your first years of schooling, what feelings and images remain?

- Which teachers do you remember and why do your remember them? What do you remember about them?

- Focus on one or two teachers who really influenced you. What adjectives might you use to describe them?

- What were the most meaningful aspects of your education (including teacher education) that contributed to your development as a teacher?

- If you could make the decision again to become a teacher, would you? Why or why not? Did you consider other options?

- What are other family members' attitudes toward your work? How might these influence you?

- Why do you continue to be an educator?

- How would you describe yourself as an educator?

- How might you like others to describe you as an educator?

- How would you describe your roles and responsibilities?

- What do you consider to be your strengths as an educator? Your weaknesses?

- What and who influences your work?

- What are the biggest challenges you face? the biggest frustrations? the greatest joys and satisfactions?

- What hopes do you have for the children you teach?

- What patterns can you identify in your teaching?

- What aspects of your work might benefit from more focused attention?

- What might you be doing ten years from now? 


\section{APPENDIX E \\ REFLECTIVE NARRATIVE EXERCISES}

1. Describe your high school, college, church, community and/or professional choral experiences. Summarize the types of repertoire performed, the location of performances, the personality of the directors, the typical rehearsal, and any other related information.

2. What are the social, economic, political, and historical contexts within which you teach? What do you know about the history of the community and school where you teach? How do these contexts influence your teaching practice?

3. Reflective inventory (Brookfield, 1995)

- What are you proudest of in your work as a teacher?

- What would you like your students to say about you when you are out of the room?

- What do you most need to learn about in your teaching?

- What do you worry most about in your work as a teacher?

- When do you know you have done good work?

- What is the mistake you have made that you have learned the most from? 


\section{APPENDIX F \\ VERBAL SCRIPT TO INFORM STUDENTS ABOUT STUDY}

1. The choral teacher introduces me as Marla A. Butke, doctoral student from The Ohio State University in music education.

2. I tell students my teaching background and why I am doing this study.

3. I give a brief synopsis of the study.

4. I tell the students their role in this study (one written reflection at end of study). I will let them know that their participation is valued and I will express my gratitude for their participation.

5. I explain that the focus is on the teacher, not the students. When I observe the classroom, I am not focusing on them.

6. I will encourage them to ask questions that may arise at any time during the study.

7. I will pass out the solicitation letters and consent forms. I will explain to them that it is not required that they participate. I will collect these forms from the choral teachers when I do each observation at the school 


\section{APPENDIX G \\ SUPPORT FORM - PRINCIPAL \\ “A STUDY OF HOW THE USE OF A REFLECTIVE PROCESS AFFECTS CHORAL TEACHERS"}

I understand the purpose and design of the study, "How the Use of a Reflective Process Affects Choral Teachers" (Dr. Patricia O’Toole, Principal Investigator, and Marla A. Butke, Co-Investigator) and support this research being performed at my school.

I have been given contact phone numbers and email addresses of the two investigators.

I have discussed with the participating choral teacher his/her role in this study.

I have been given copies of the solicitation letters for the choral teachers and students, as well as the consent form.

Principal's Signature

Date

School 


\section{APPENDIX H}

STUDENT JOURNAL REFLECTION QUESTIONS FOR RESEARCH STUDY

1. What do you enjoy about choir? Be specific.

2. Name three words to describe your teacher's personality.

3. How has your teacher changed (if at all) since January?

4. What are the challenges of your choir?

5. What are your personal challenges as a choir member?

6. If a new student moved on your street, would you encourage him/her to join choir? How would you describe your choir to that person? 